\title{
Are automated daylight control systems working as they should?
}

BY

James Thompson

\author{
A thesis submitted to the \\ Victoria University of Wellington \\ in fulfilment of the requirements for the degree of \\ Master of Building Science
}

Victoria University of Wellington

August 2013 



\section{Author:}

James Thompson

School of Architecture

Victoria University of Wellington

james.a.thompson@gmail.com

Mobile (+64) (0)27 6995642

\section{Research Supervisor:}

\section{Nigel Isaacs}

Senior Lecturer, School of Architecture

Victoria University of Wellington

PO Box 600, Wellington, New Zealand 6140

Nigel.Isaacs@vuw.ac.nz

VUW phone (+64) (04) 4639745

Mobile (+64) (0)274 349363 

The history of architecture is the history of the struggle for light Le Corbusier 



\section{Acknowledgements}

Many thanks go to my supervisor Nigel Isaacs, for his assistance and enthusiasm with this research.

Thank you to Michael Babylon for his help with the measuring equipment and taking the time every fortnight to help with data retrieval. Thanks to Adrian Leaman of Building Use Studies Ltd for permission to use the questionnaire and help with the survey analysis and Prof. George Baird for his help with developing the extra questions. Thanks to Peter Ramutenas for his help with calibrating and organising the equipment that was required to complete this research.

I would like to thank BRANZ Ltd and BEES (Building Energy End-Use Study) for their financial support this year including a scholarship, their staff's time to help with equipment and providing electricians to install and retrieve equipment.

I wish to thank my partner Hannah and my family for their constant support throughout my time at varsity.

Thank you to all that participated in the survey and those who helped with access to the buildings. 



\begin{abstract}
Lighting in office buildings can account for approximately $30 \%$ of electrical use. This provides an opportunity for energy efficient technologies to be implemented to reduce this load. Automated daylight control systems are part of a growing industry, based on complex electronics and careful placing of light sensors. In an economy that is accepting the need for energy reduction due to the realisation of limited fossil fuels, it is important to maintain and enhance energy efficient systems.

Research highlighted that previous studies would either use a physical measuring approach or an occupant survey to understand how well automated daylight control systems are working, but never both. This thesis combined both of these approaches to quantify how much energy automated daylight control systems are saving while ensuring that occupant satisfaction and comfort is maintained. Four office buildings within Wellington city were therefore analysed to investigate the average energy saving from automated daylight control systems. Energy savings reported from other research studies ranged from $15 \%$ to $80 \%$, with an average of $49 \%$. The savings from the four buildings researched in this thesis average $20 \%$ savings. The surveys further indicated that all occupants within each of the buildings were satisfied with both natural and artificial lighting in their working environment. Glare was however highlighted as an issue.
\end{abstract}





\section{Contents}

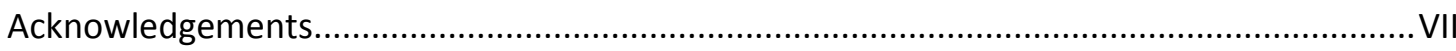

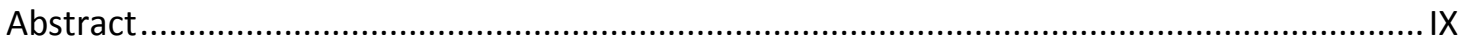

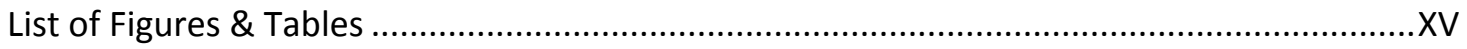

List of Abbreviations \& Definitions ...........................................................................

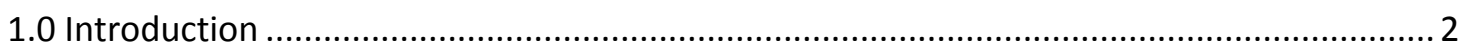

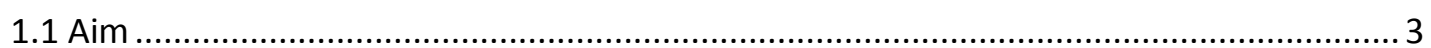

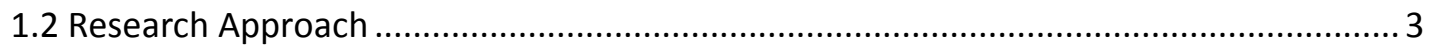

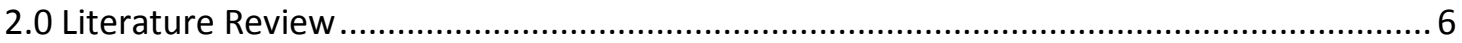

2.1 Why Automated Daylight Control Systems are Important ..................................... 6

2.1.1 Natural Light.................................................................................... 7

2.2 Automated Daylight Control Systems - Why Install This Technology? ..........................9

2.2.1 What Automated Daylight Control Systems are and how they work?.................. 10

2.3 How to measure Light; Horizontal Plane vs. Vertical Plane ....................................... 12

2.3.1 How to measure light; Close vs. Far............................................................ 13

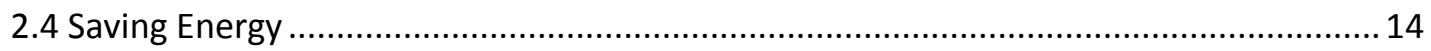

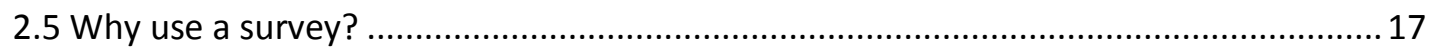

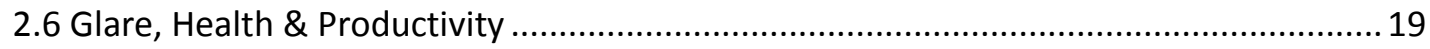

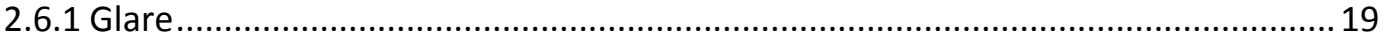

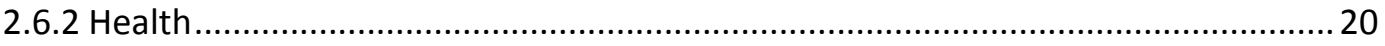

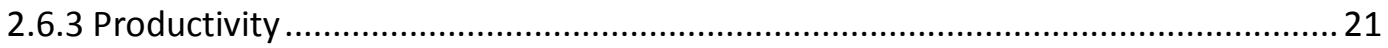

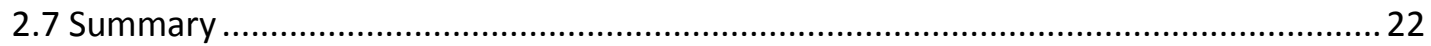

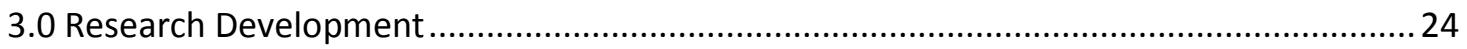

3.1 Pilot 1: Post-Graduate Room Pilot Study ........................................................... 24

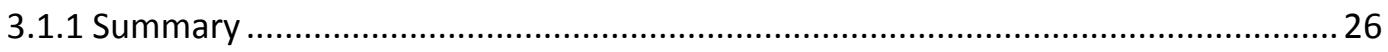

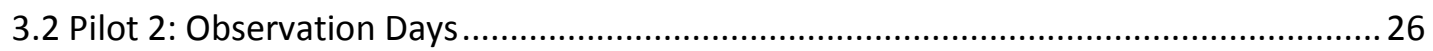

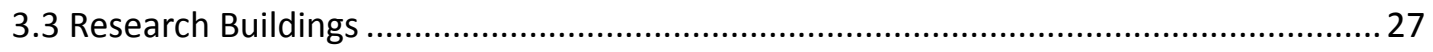

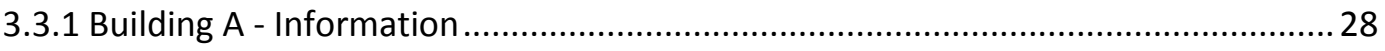

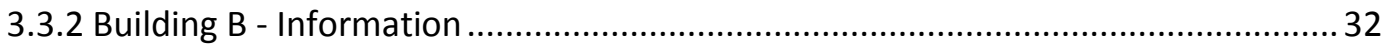

3.3.3 Building C - Information ....................................................................... 36

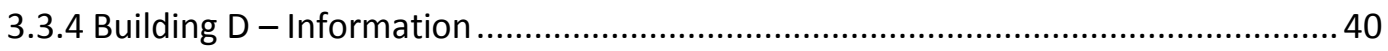

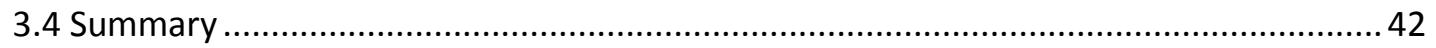

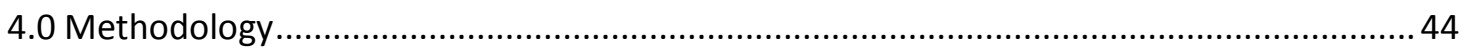

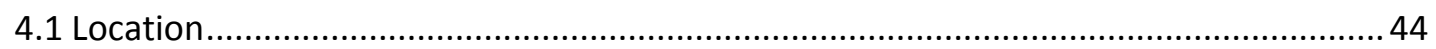




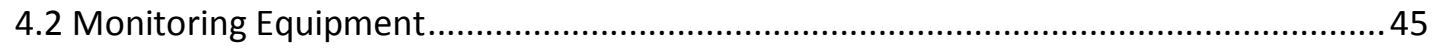

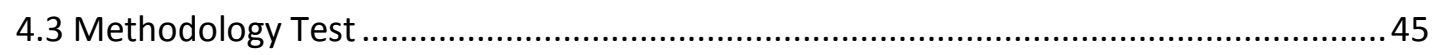

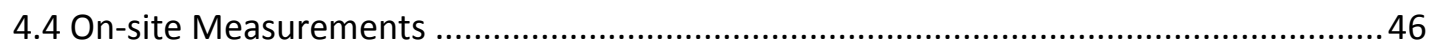

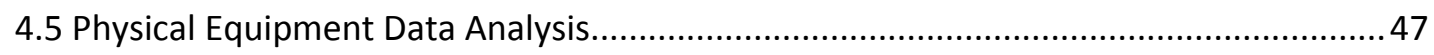

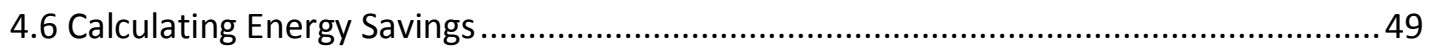

5.0 Survey

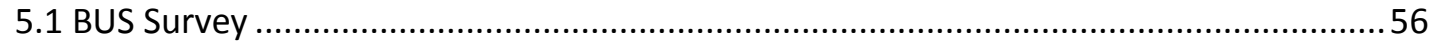

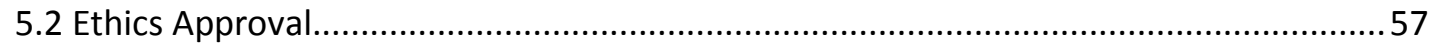

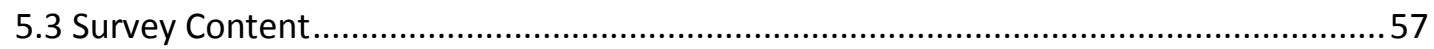

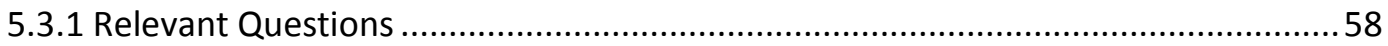

5.4 Analysis of Survey vs. Physical Measurements? ...........................................................59

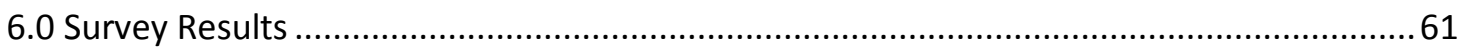

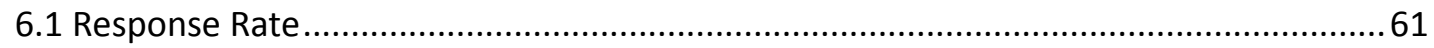

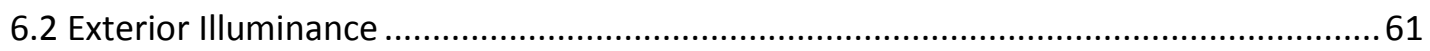

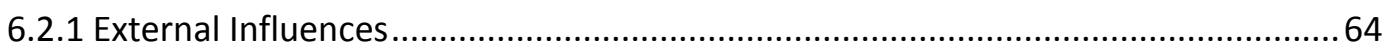

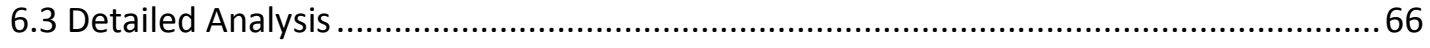

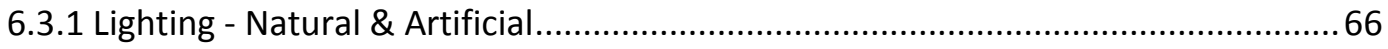

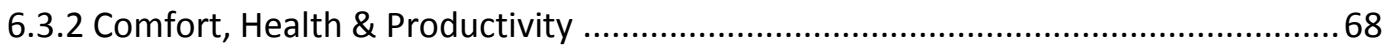

6.3.3 Automated Daylight Control System ...................................................................... 70

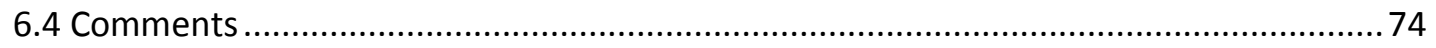

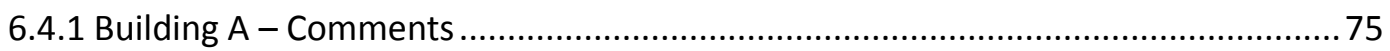

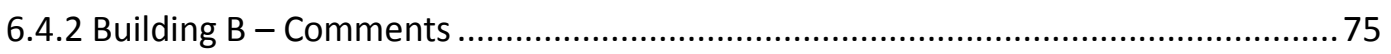

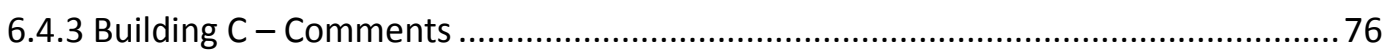

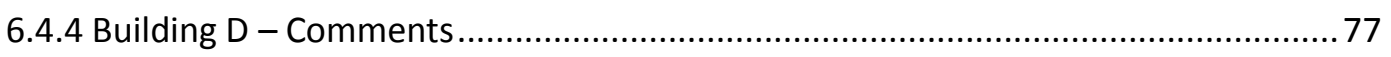

6.5 Lighting \& Automated Daylight Control System Comment Summary .............................. 78

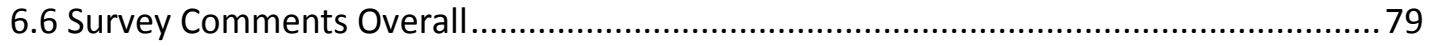

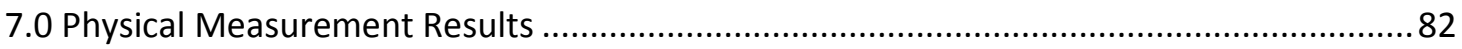

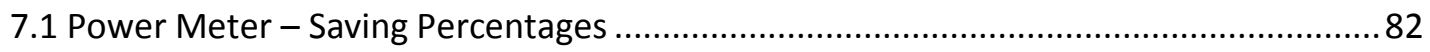

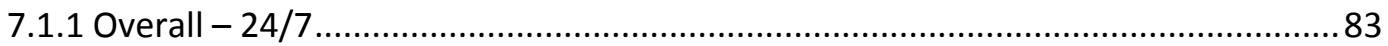

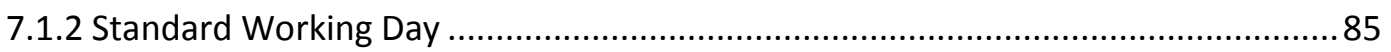

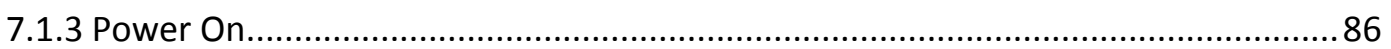

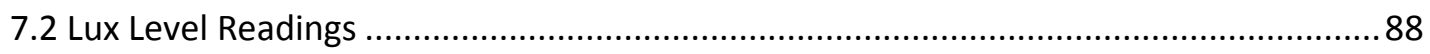

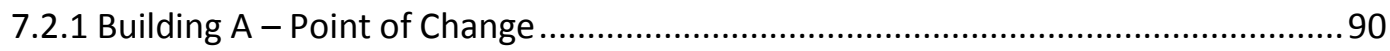

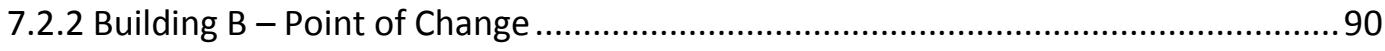




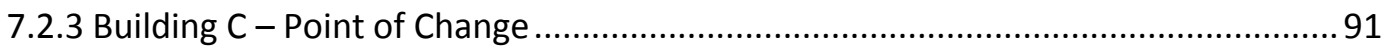

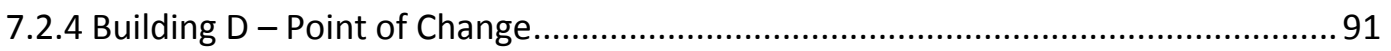

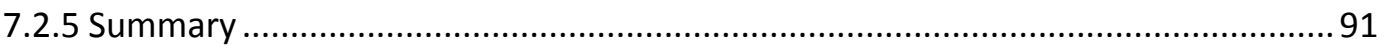

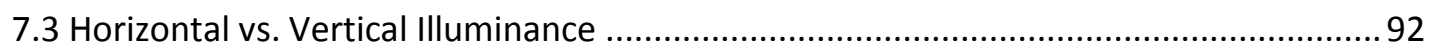

7.3.1 Comparison of Light Availability by Plane ............................................................. 92

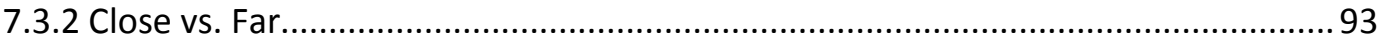

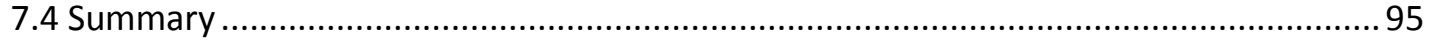

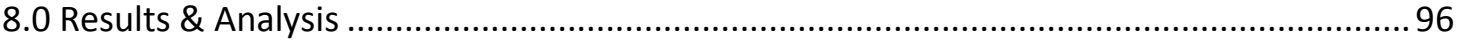

8.1 Layout vs. Automated Daylight Control System ............................................................. 96

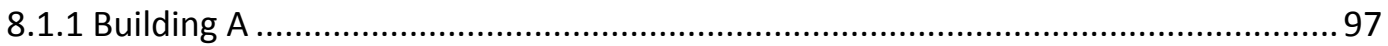

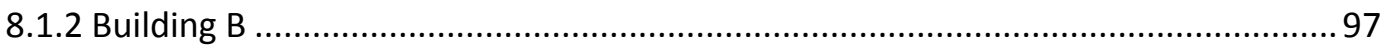

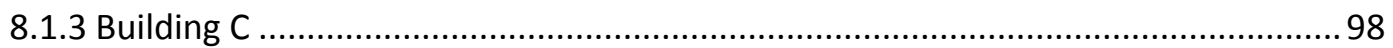

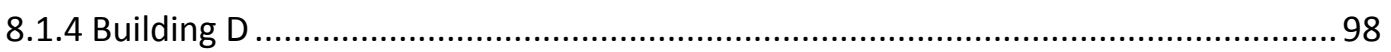

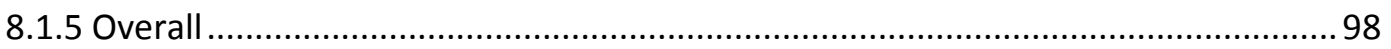

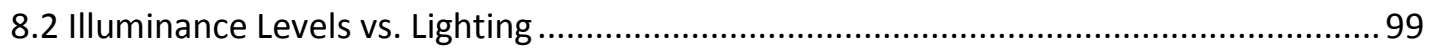

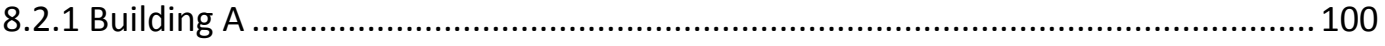

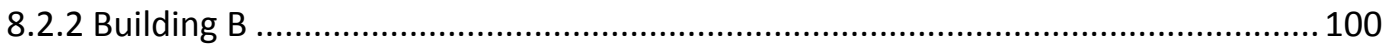

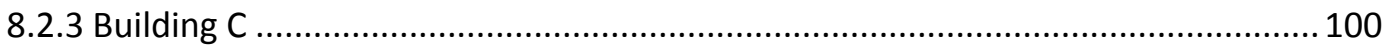

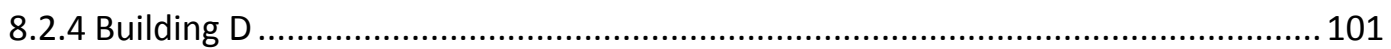

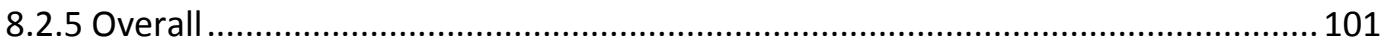

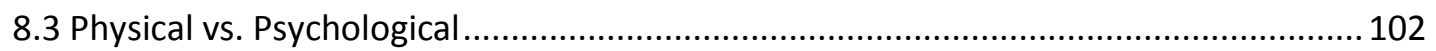

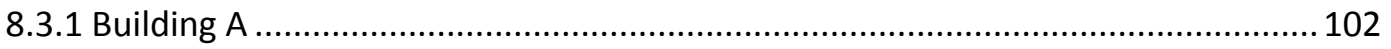

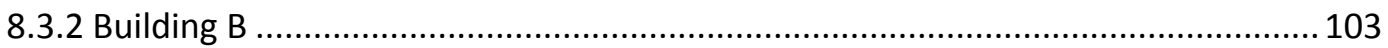

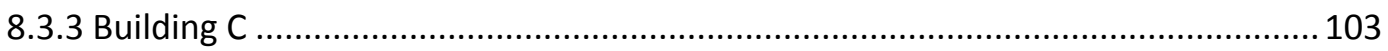

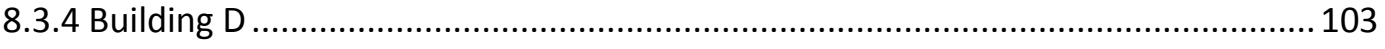

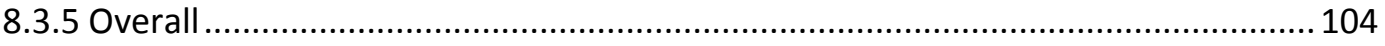

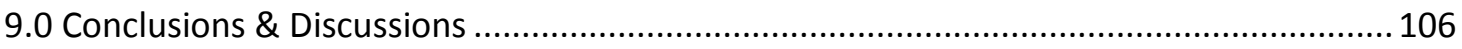

9.1 Discussion and Recommendations for Individual Buildings ........................................ 106

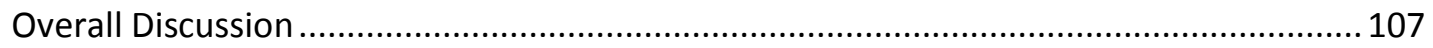

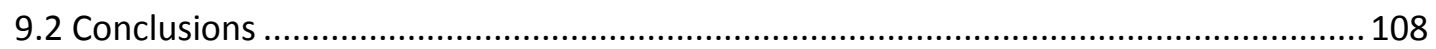

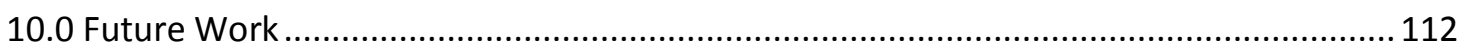

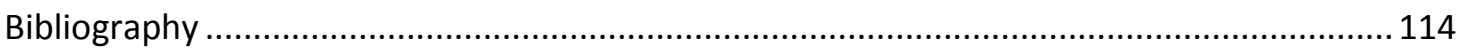

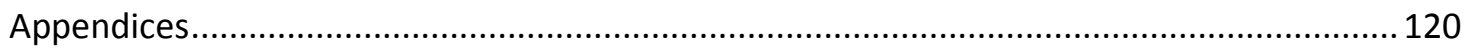





\section{List of Figures \& Tables}

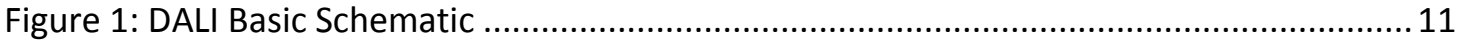

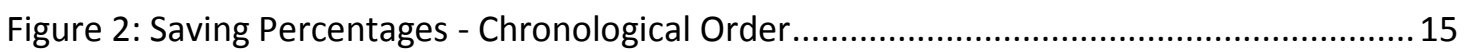

Figure 3: Saving Percentages - Highest to Lowest ................................................................. 16

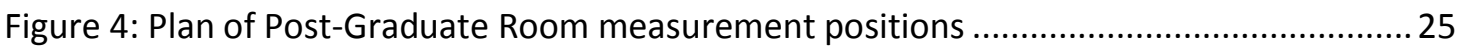

Figure 5: Elevation of Post-Graduate Room Window Elevation ................................................ 25

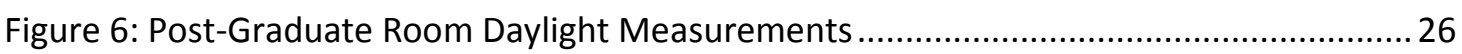

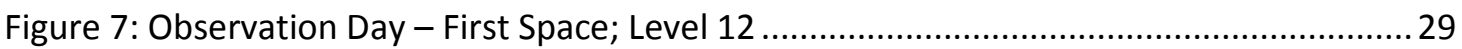

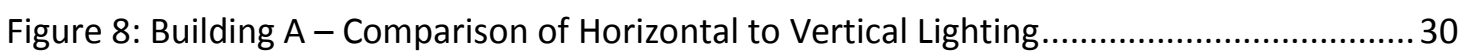

Figure 9: Observation Day - Second Space; Level 8 ............................................................ 31

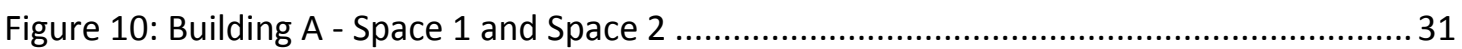

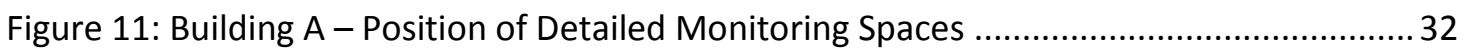

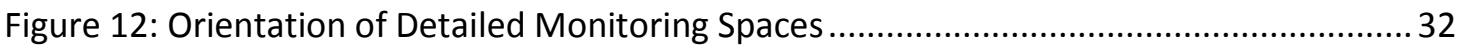

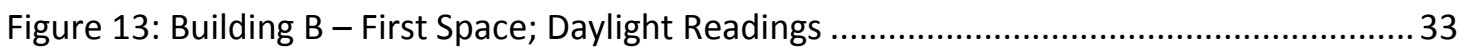

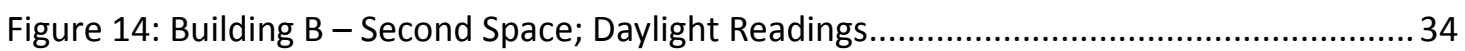

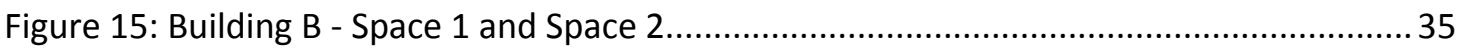

Figure 16: Building B - Position of Detailed Monitoring Spaces............................................. 35

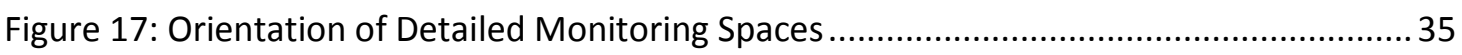

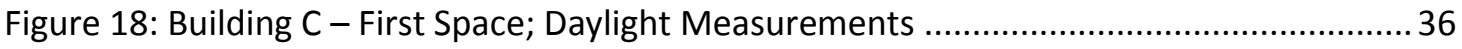

Figure 19: Building C - Second Space; Daylight Measurements........................................... 37

Figure 20: Building C - Second Space; Daylight Measurements with Window Measurements

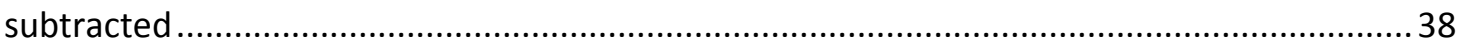

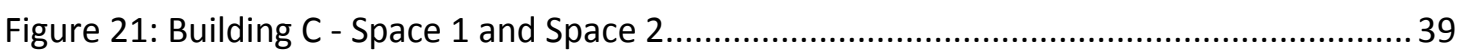

Figure 22: Building C - Positions of Detailed Monitoring Spaces ........................................... 39

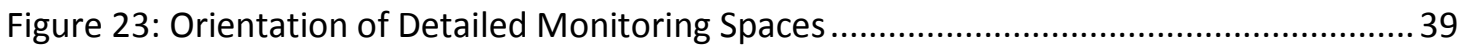

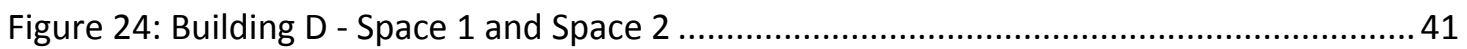

Figure 25: Building D - Position of Detailed Monitoring Spaces ........................................... 41

Figure 26: Orientation of Detailed Monitoring Spaces ......................................................... 41

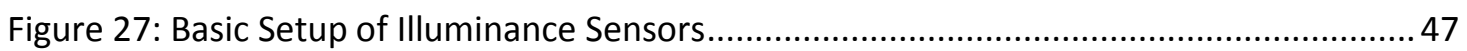

Figure 28: Example of an automated daylight control system working .................................. 48

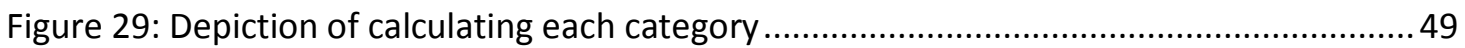

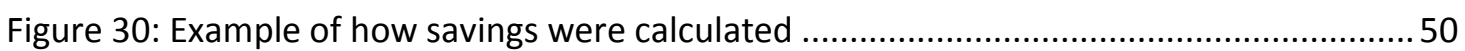

Figure 31: Example 1; Typical Day with lighting on constantly..............................................50

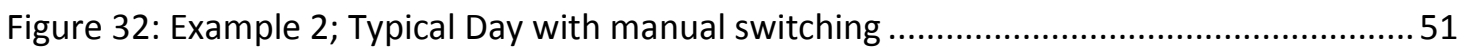

Figure 33: Example 3; Typical Day with an automated daylight control system ......................52

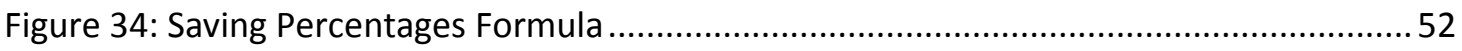

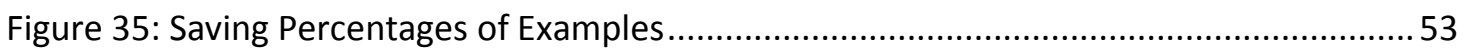

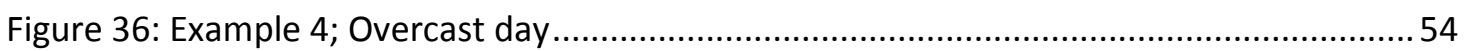

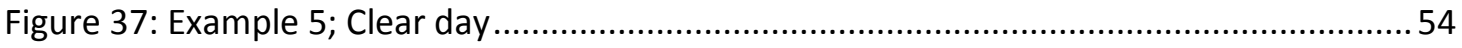

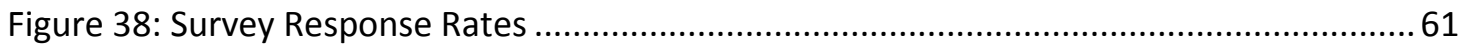

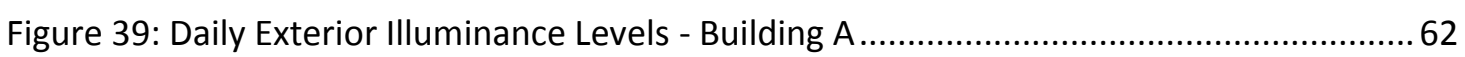

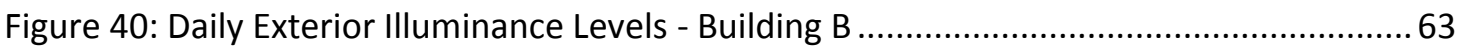

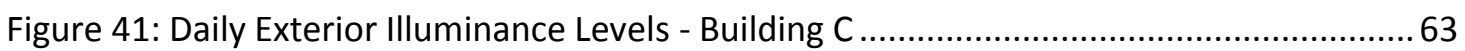

Figure 42: Daily Exterior Illuminance Levels - Building D .......................................................64 


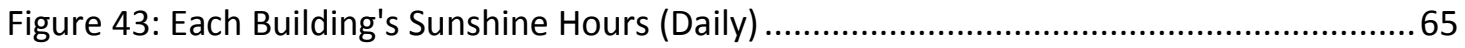

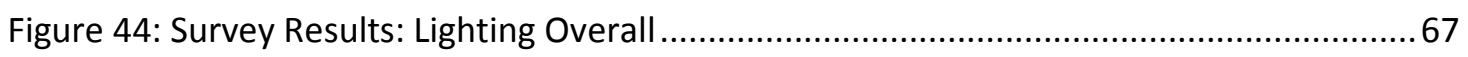

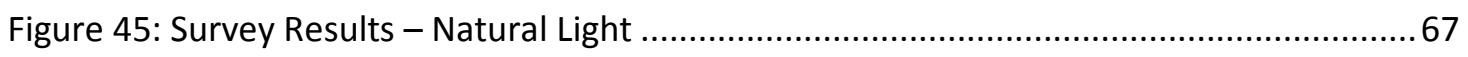

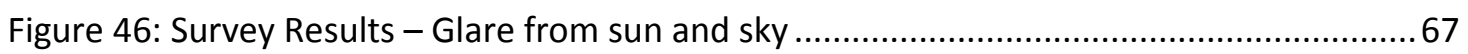

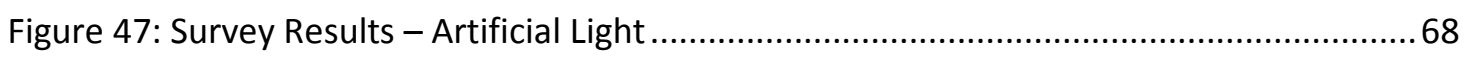

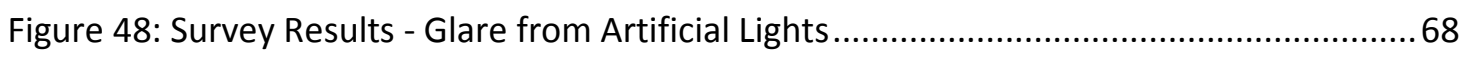

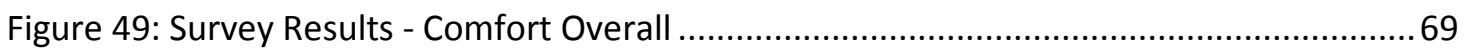

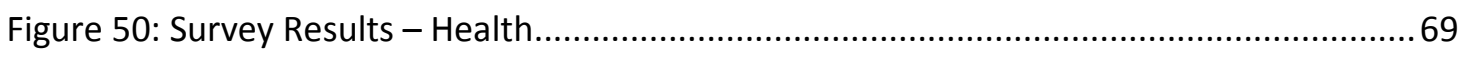

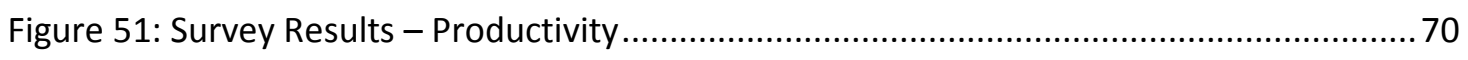

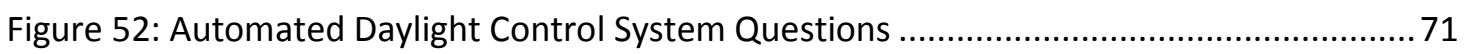

Figure 53: Building A - Occupant responses to automated daylight control system question. 71

Figure 54: Building B - Occupant responses to automated daylight control system question. 71

Figure 55: Building $C$ - Occupant responses to automated daylight control system question. 72

Figure 56: Building D - Occupant responses to automated daylight control system question 72

Figure 57: Number of Occupants who answered each question..........................................72

Figure 58: Survey Results - Amount of Light on Work Surface ................................................. 73

Figure 59: Survey Results - Difficulty to View Tasks at Desk....................................................... 74

Figure 60: Survey Results - Automated daylight control system Overall ................................. 74

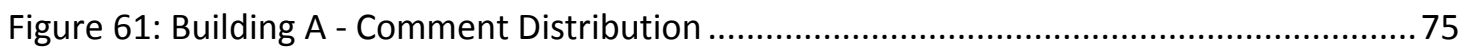

Figure 62: Building B - Comment Distribution ................................................................ 76

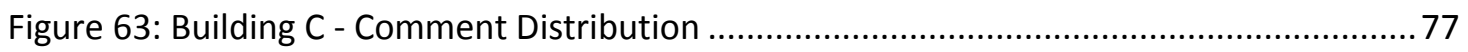

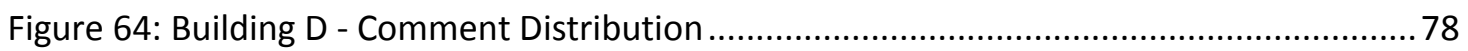

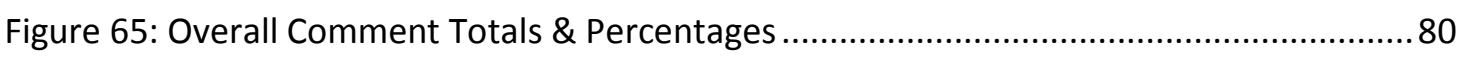

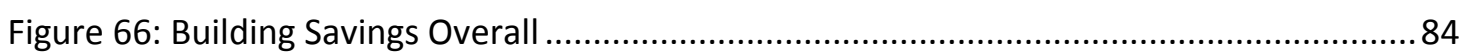

Figure 67: Average energy savings of all buildings from 9:00am to 5:00pm .......................... 85

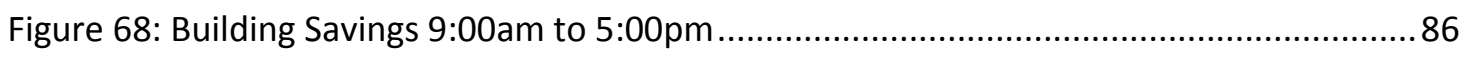

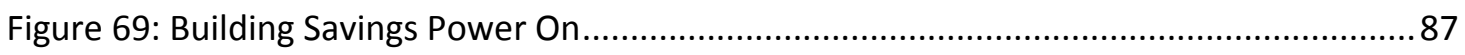

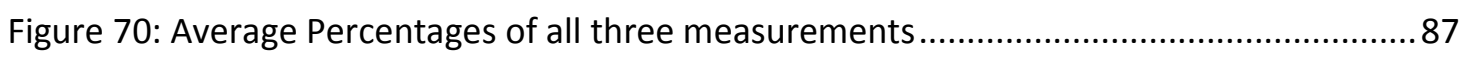

Figure 71: Image showing the automated daylight control system point of change ...............89

Figure 72: Lux Level Points of Change in automated daylight control system .........................89

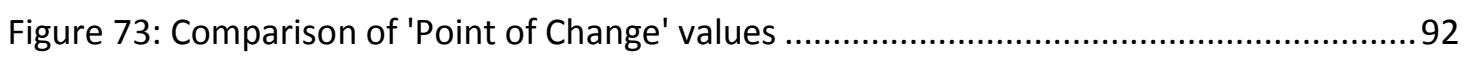

Figure 74: Horizontal vs. Vertical Far \& Close Measurements Comparison ..............................93

Figure 75: Overall Differences between Close and Far Illuminance Sensors...............................94

Figure 76: Survey Results for automated daylight control system Questions - Comments ....97

Figure 77: Survey Results for automated daylight control system Questions.........................97

Figure 78: Survey Results for Lighting Questions...................................................................99

Figure 79: Survey Results for Lighting Questions - Comments ............................................ 100

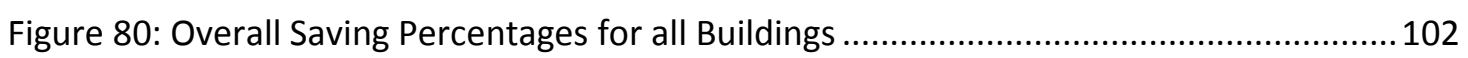

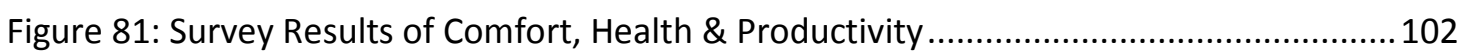




\section{List of Abbreviations \& Definitions}

ADCS - Automated Daylight Control System - This is a system that responds to the availability of sunlight or skylight detected by a sensor and dims the artificial lighting appropriately while maintaining the overall lighting levels of the space. This is also known as 'daylight harvesting'.

DALI - Digital Addressable Lighting Interface - A daylight control system/protocol.

DF - Daylight Factor - The illuminance inside a building related to the illuminance outside.

MSL - Measurements Standards Laboratory of New Zealand.

POE - Post Occupancy Evaluation- A survey undertaken of an occupied building after completion, often as a questionnaire completed by the occupants.

Daylight \& Natural Light - These are interchangeable terms used to refer to the light available from the outside sky.

Skylight - The amount of light (illuminance) that is produced from the sky, either blue sky or reflections from the clouds, with no direct sunlight.

Sunlight \& Direct Light - This refers to light (illuminance) produced by the sun.

Illuminance - This is the amount of light coming directly from a light source, such as the sun or a light bulb. This is different to luminance.

Luminance - This is the amount of light that is reflected off a surface. For example, the amount of light that is reflected off a white wall.

Illuminance Meter - An illuminance meter has the ability to read light levels and produce a reading on a visual screen built into the meter.

Illuminance Sensor - An illuminance sensor converts light levels into a form able to be used by a lighting control system, or data logger for monitoring purposes.

Standard Working Day - According to the Department of Labour - New Zealand Government - full-time work is usually 35-40 hours a week. Therefore, a standard working day used for this investigation was 9:00am to 5:00pm. 



\subsection{Introduction}

Lighting in office buildings can account for $25-40 \%$ of total electricity use (Leslie, 2003). With such a high proportion of electricity being used for lighting there is an opportunity for improved energy efficient systems to reduce energy consumption. The purpose of this research was to identify how well automated daylight control systems are operating in a selection of New Zealand office buildings and investigate whether the current systems reduce energy consumption while maintaining occupant satisfaction.

Automated daylight control systems are part of a growing construction and building industry, reliant on hi-tech electronics and precise instruments. In a society that accepts the need for energy reduction due to the realisation of limited fossil fuels and increasing energy costs, it is important to maintain and enhance energy efficient systems. As identified by John McDonagh of Lincoln University, Christchurch, in 'Electricity Use Trends in New Zealand Office Buildings':

While New Zealand generates most of its electricity from renewable hydro electric sources, there are limited opportunities to expand such generation. As a result, the NZ government has been promoting energy efficiency as a means to reduce growth in electricity demand, with the focus to date on the residential sector. Efficiency policies relating to office buildings have recently been proposed, but little prior research has been carried out on this sector in NZ. (McDonagh, 2010, p. 1) $-17^{\text {th }}$ ERES Conference, 2010

This thesis investigated automated daylight control systems, an energy efficient technology that reduces electrical demand in office buildings. Recent studies on automated daylight control systems found both positive and negative responses to their implementation. For example, a study completed in 2005 by Choi et al. on the characteristics of photosensors and electronic dimming ballasts, reported "the accuracy and reliability of daylight responsive dimming systems are the major market barriers to their more widespread use despite the energy saving potentials and a resurgence of interest in using daylight" (Choi et al., 2005, p. 48). In a similar study, the International Energy Agency (IEA) reported that "poor design, faulty installation, and lack of system commissioning will degrade the performance of automated lighting control systems, as well as contribute to user dissatisfaction" (IEA, 3-12, 3-13). Studies have reported potential savings using automated daylight control systems 
ranging from $15-80 \%$. This illustrates that while some savings can be great, some may not be cost-effective.

Studies that collected information using surveys (such as Loftness) further highlighted that there are positive and negative reactions to having an automated daylight control system installed in an office building. Loftness et al. found that occupant satisfaction can decrease when these types of systems are installed if they don't work as they are designed to. From the literature reviewed in this thesis, none combined the physical savings and the occupant's psychological satisfaction in order to evaluate automated daylight control systems overall. This is discussed further in Chapter 2.0.

The literature reviewed highlighted current discussions surrounding the positive and negative attributes of automated daylight control systems and occupant satisfaction. How well automated daylight control systems work is dependent on the way they are designed, and their performance is dependent on the position of the building, orientation, surroundings but also evaluated by the occupants within a building.

\subsection{Aim}

The aim of this thesis was to understand how well automated daylight control systems are working in a number of Wellington office buildings using two approaches. The first approach was concerned with the physical aspects of natural light and power reduction, while the second approach surveyed the occupant's psychological perceptions. The physical and psychological aspects were then combined to ascertain how well automated daylight control systems are working overall. The research was not concerned with establishing direct links between the physical and psychological aspects, except in terms of occupant self-reporting through the survey.

\subsection{Research Approach}

Chapter Two: This Chapter investigates current literature on automated daylight control systems to identify why this technology is important. An explanation of what an automated daylight control system is and how it works is followed by a discussion on whether the horizontal or vertical plane is the best way to measure light levels. This is followed by an analysis of energy savings found in other research finishing with the rationale for using a survey and the importance of occupant perception. This chapter concludes by discussing the importance of glare, health and productivity. 
Chapter Three: To understand how automated daylight control systems are working in practice, four buildings were selected for monitoring. A description is provided of two pilot studies which led to the development of a methodology. Information regarding each of the spaces in each building is presented, describing the positions of the measuring equipment, the type of automated daylighting control system that is installed and observations from site visits to each building.

Chapter Four: This Chapter sets out the methodology developed from the pilot studies outlined in Chapter Three. It highlights the selection criteria of the four buildings analysed and lists the equipment required to carry out the study. This Chapter further explains how the measuring was conducted by analysing the test methodology of the sensors and by outlining the process of the onsite measurements. This Chapter concludes with a description of how the energy savings were calculated.

Chapter Five: This Chapter explains the post-occupancy evaluation survey questions in detail.

Chapter Six: This Chapter looks at the POE survey results, examining the response rate, mean scores and comments for each aspect. It also discusses the rationale of not measuring the exterior illuminance simultaneously with the interior illuminance levels.

Chapter Seven: This Chapter outlines the process of calculating the energy savings from each automated daylight control system and how much energy each building was able to save in three measured categories. The illuminance readings were compared with the power meter data to find the 'point of change' lux levels for each building. The maximum and average illuminance levels for each measuring period are calculated. This Chapter further examines the differences between the locations of the illuminance sensors and the maximum and average readings to understand how natural light is affecting each space.

Chapter Eight: The results from the measurements and POE survey are combined to obtain an overview of each building's automated daylight control systems. This compares the overall design of each system and the comments made about it, examines the light levels recorded in each space and the scores of the lighting aspect in the survey. It then investigates the relationship between the physical and psychological aspects overall, comparing the overall energy savings to the general occupant satisfaction.

Chapter Nine: This discussion Chapter explores the results and analysis further by offering solutions and ideas that could improve each automated daylight control system. The 
conclusions outline the final results to the question, 'Are automated daylight control systems working as they should?' This final question is answered by taking the measured information and comparing it with the perceived occupant satisfaction and the overall savings of the automated daylight control system.

Chapter Ten: This final Chapter takes the lessons learnt from this research, discusses improvements for any future research and identifies further research opportunities. 


\subsection{Literature Review}

\subsection{Why Automated Daylight Control Systems are Important}

Vaidya's (2005, p. 564) research found that "automatic switching or dimming control systems do not always provide the expected energy savings. The possible reasons for an unsuccessful implementation of daylighting controls are numerous. It seems prudent to look for object lessons for success and failure from the set of early adopters". Expanding on this, Vaidya stated that "if energy efficiency through daylighting controls is to proliferate as a strategy its success rate needs to be improved. Though there are successes, our intention here is to throw light on the weak areas so that future research and development on improving the process can be more focused" (Vaidya, 2005, p. 564). Vaidya's research reinforces the need for further analysis into how to improve automated daylight control systems by understanding problems arising from their implementation. Sustainable buildings are gaining more interest and with this are energy efficient technologies. Yet such technologies are still not being implemented into buildings as standard designs. Before these technologies are widely accepted, further research is required to ensure that they are developed to a point that will minimise poor performance issues.

There is a need to reduce energy consumption globally. As a nation, New Zealand entered into the Kyoto Protocol in 2005 which would see green house emissions reduced back to 1990 levels. An excerpt from a report made one year after New Zealand signed the protocol stated that, "it was envisaged that for New Zealand this target would be able to be met through a combination of domestic emissions reductions and increases in carbon sinks. It was also anticipated that more significant emission reductions would need to be negotiated for future commitment periods" (Sinclair Knight Merz, 2006, p.13). It is this commitment to reducing energy consumption and overall efficiency that increases the need to use energy efficient technologies such as automated daylight control systems.

This research is also directly applicable to the current BEES research (Building Energy End-Use Study). BEES is investigating how energy is used in commercial buildings and identifying ways to make them more energy efficient. To place this study into context, currently electricity makes up $54 \%$ of fuel usage in the commercial sector in New Zealand, so an efficiency improvement of $10 \%$ would give $\$ 90$ million in savings (BEES, 2008).

According to a report completed by the IPENZ (Institution of Professional Engineers New Zealand), on electricity generation in New Zealand "for all sectors, lighting has been 
identified as the area where a change in technology has the highest value" (IPENZ, 2010, p. 9). This relates back to the BEES research where their goal is to "create new knowledge to support improvements in non-residential building energy efficiency as well as occupant comfort and productivity" (BEES, BUILD Magazine, 2008). These studies and research projects all support the need for further study in this area.

So what is the solution? With every building providing different constraints and demands, automated daylight control systems need to be developed independently for each building to focus on the opportunities identified at each site. It is therefore difficult to provide a set of rules or standard guidelines to ensure that an optimum system is designed. This research is aimed at exploring some of the barriers and constraints around automated daylight control systems and how they affect energy savings and occupant comfort. To do this, four buildings were selected and each measured for two weeks. To obtain a comprehensive view of how each system was working, both physical and the psychological aspects were measured using monitoring equipment and a detailed survey. The survey was considered vital within this thesis as research highlighted that maintaining occupant comfort was considered to be of prime importance. As Hopkinson et al. describes:

The aim of a good daylight design is first, to provide fully sufficient light for efficient visual performance, and second, to ensure a comfortable and pleasing environment appropriate to its purpose. The comfort aspect of a daylight design is closely related to the problem of glare. (Hopkinson et al., 1966, p. 606)

As Hopkinson et al. has described, if automated daylight control systems are able to reduce the amount of available light, they must do so in a way that does not affect occupant comfort and satisfaction.

\subsubsection{Natural Light}

A benefit of a building that is designed to allow natural light to enter is the visual quality and occupant preference of work place light. When "given a choice, people prefer to work by daylight and to enjoy a view" (AS/NZS 1680.1:2006, p. 10). Fluorescent lighting is able to produce constant high levels of light and will always be required but is no substitute for daylight. "Lighting of good colour quality aids visual discrimination, and so reduces the quantity of light required for many tasks. While artificial light sources with a spectral composition very close to daylight are available, clearly, other things being equal, daylight itself is preferable" (Energy Research Group, 1994, p. 2). 
"Daylighting is experiencing a renaissance since aspects of this approach have been shown to significantly increase human, environmental and economic performance compared to standard construction with electric lighting" (Ternoey, 2000, p. 2). This resurgence in the use of daylight design has come from understanding that occupants require good lighting in their built environment. This has led to building designs changing to adopt energy efficient technologies and smarter building techniques, which is further highlighted by the IEA:

The development of electric light enabled the design of buildings that include windowless rooms and deeper plan layouts with lower floor-to-ceiling heights which limit daylight penetration from the perimeter. Electric light may have freed building design from the constraint of needing to provide each space access to natural light, but it has also led to the routine squandering of a natural resource. (IEA, 2006, p. 158)

The popularity of artificial lighting saw a decline in the use of natural lighting and a change in the way buildings were designed. As Johnsen writes on the time of the artificial lighting boom; "electric light was scarce and expensive. However, this architectural tradition (daylight designed buildings) was to a large extent lost during the next few decades, and it seemed for many years as if everything we knew about the advantages of daylighting was forgotten" (Johnsen, 1998, p. 142). Now with a better understanding of natural light and its benefits, automated daylight control systems and other environmental technologies are becoming more common.

Green Buildings are en vogue and promoters of green building rating systems such as LEED and EPBD have experienced an unprecedented wave of interest in this design approach. In Europe, the 'European Energy Performance Building Directive' (EPBD), which includes lighting, has already triggered strong national efforts and is expected to have a significant impact on lighting and daylighting design as well as energy efficient lighting techniques. This positive trend is accompanied by a mounting demand for more rigorous performance metrics and assessment tools, as a whole industry begins to make more design decisions based on these rating systems. Since daylighting is a declared feature of most sustainable green buildings, interest in daylighting strategies is rising, thus generating renewed interest in better daylight simulation tools and performance metrics. (Reinhart \& Selkowitz, 2006, p.4)

As Reinhart \& Selkowitz have explained, there is a renewed interest in daylighting techniques coupled with emerging technologies to enhance performance and building quality. There is a 
need for more information about these types of technologies. Reinhart \& Selkowitz also note that daylighting is a declared feature of most sustainable green buildings. This thesis will add more information on the subject of how well automated daylight control systems are working and identify any issues.

\subsection{Automated Daylight Control Systems - Why Install This Technology?}

The main reason for installing an automated daylight control system into a building is to reduce energy use. This benefits operating costs by reducing the overall energy use, as described by Choi and Mistrick where "using a daylight responsive dimming system becomes an appropriate option to reduce the electric lighting energy consumption in spaces where daylight can be a useful source of illumination" (Choi \& Mistrick, 1999, p. 231). However, this does not exclude the need for artificial lighting altogether as "no matter how good the daylighting design, virtually every building needs an artificial lighting system as well - for night time use, for windowless spaces, or to supplement daylight when it falls below acceptable levels" (Energy Research Group, 1994, p. 11).

The energy saving potential of automated daylight control systems can be reduced by a lack of integration with other services during the construction phase. A study by Vaidya explained that "daylighting systems failed due to a lack of coordination between the design disciplines architectural, interior and space planning, mechanical and lighting. Designers seemed to be unaware of how the decisions they make can affect the performance of a daylighting control system. Sensors were blocked by other equipment and were located so as to be inaccessible for calibration" (Vaidya, 2005, p. 565). Poor decisions made during construction that can directly affect the way in which a system works as well as the impact it can have on the occupants:

Buildings were configured throughout architectural history to use daylight until inexpensive electricity and technological developments such as air conditioning, fluorescent lighting, steel frames, and elevators enabled the economic construction of taller, deeper buildings. Developers and owners often are not willing to offset the first cost associated with large building perimeters with potential energy savings. Current research results are leading to a realization of broader economic benefits from daylighting, a dividend that may strongly justify initial construction expenses. (Leslie, 2003, p. 381) 
As Leslie has summarised, it is the maximising of the floor area by constructing taller, deeper buildings that has disregarded the need for access to natural light. It is these types of buildings that are standing aside as 'green' buildings are becoming increasingly popular.

\subsubsection{What Automated Daylight Control Systems are and how they work?}

An automated daylight control system recognises the presence and quantity of daylight (illuminance value) using a sensor. The sensor relays this information to a controller where the illuminance value is assessed. A signal is then sent to the artificial lights which are adjusted to keep the light at a constant level. Thus through a combination of natural and artificial light the system provides a constant light level - dimming or increasing the intensity of the artificial lights to suit. Each system has a set point (point of change - a predetermined lux level), which is set to a certain illuminance level of daylight. If the daylight is higher than the set point, the controller will communicate with the lighting controls (normally electronic ballasts) and reduce the artificial light output.

Automated daylight control systems differ in design and layout from one building to the next, but all have the same fundamental principles. As Figure 1 illustrates, a simple automated daylight control system consists of five separate components; an Ethernet Network, a DALI gateway or controller, a separate power supply, electronic ballasts and dimmable lamps. In this example, daylight sensors are also occupancy sensors. These dual sensors allow relay information back to the controller about the amount of light in a space and if there is anyone present in the space (Information sourced from DALI by Design, 2011).

Ethernet Network - An Ethernet Network is a closed network that allows digital equipment to communicate. This allows the sensors, controller and ballast to communicate to each other to adjust the requirements of each lamp.

DALI Gateway/Controller - This part of the system is set up during the commissioning stage to programme how the lamps will operate and to what extent e.g. exterior daylight levels, occupancy number, interior lighting levels, set points and occupancy times.

DALI Power Supply - The DALI devices such as sensors, ballasts and controllers all require small amounts of power to run. Therefore a separate power supply is needed for each device.

Electronic Ballast - Electronic (or Digital) Ballasts are used to control lamps. Ballasts can control whether the lamp is on or off and able to dim lamps. They can also start the lamp at any desired level. 
Lamp - Most commonly used in automated daylight control systems are fluorescent lamps as they are dimmable from $1-100 \%$. Other lamps are also able to dim, however all four buildings in this study have fluorescent lamps.

Sensor - A daylight sensor, commonly used as a dual sensor as it normally includes a PIR (Passive Infrared) occupancy sensor, relays information back to the controller. Other sensor types such as an acoustic sensor can be activated by sound, such as typing on a keyboard or conversation which some buildings require when occupants are mainly sedentary.

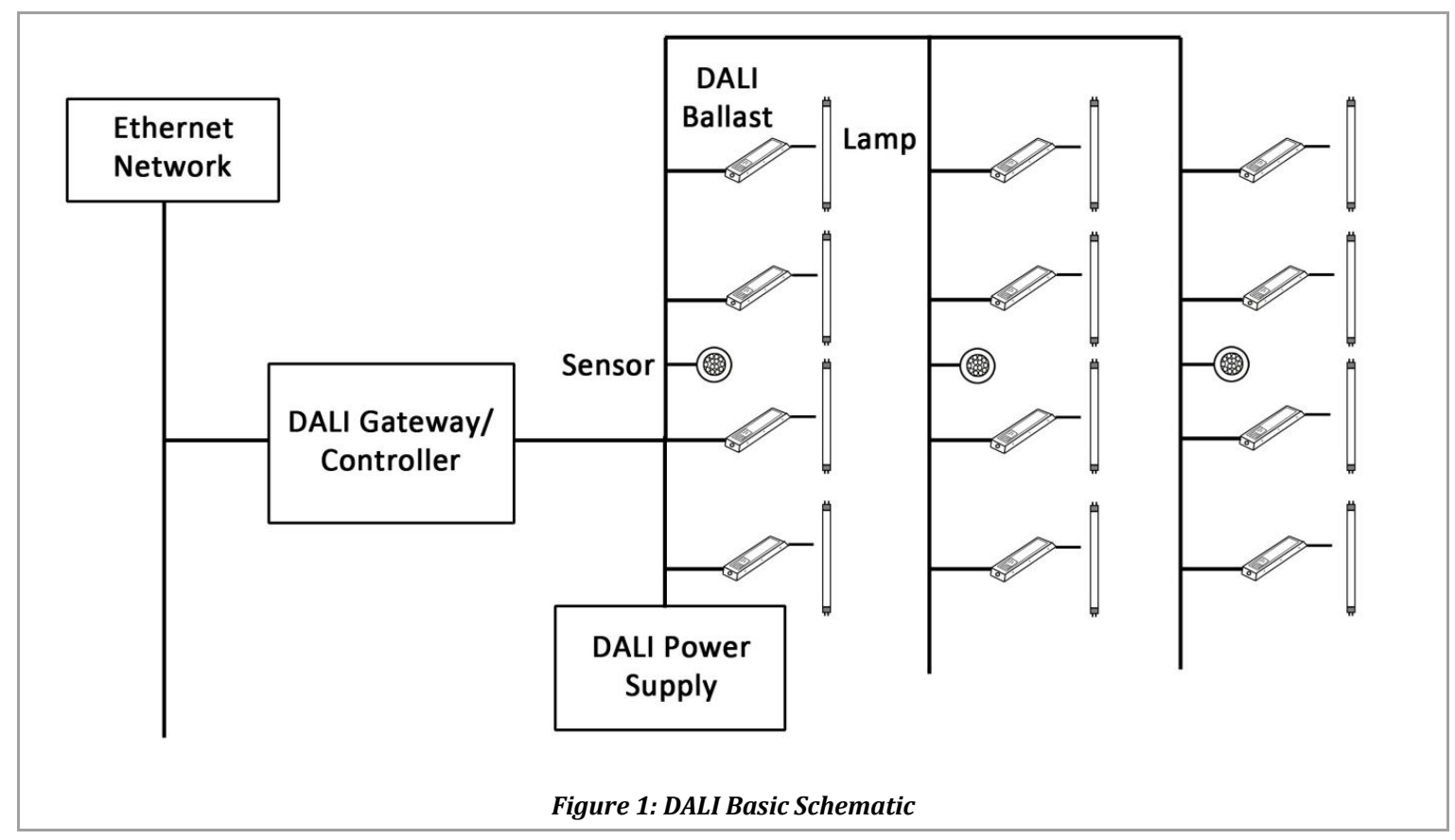

According to the Apollo Lighting company, there are many advantages to an automated daylight control system such as a DALI system. The first is that all the major ballasts manufacturers use the same protocols, allowing almost any system to work accurately with a DALI controller. Other advantages include but are not limited to;

- Simple wiring control lines (no group wiring, polarity free),

- Control of individual units (individual addressing) or groups is possible (group addressing),

- Simultaneous control of all units at any time through broadcast controls,

- No interference of data communication due to simple data structure,

- Device status, lamp fault, current level, assigned group, battery status etc is available,

- Automatic search for connected devices (commissioning). (Apollo Lighting, 2012) 
Automated daylight control systems can also help with operational and maintenance issues. The interface can tell the building manager if there is a faulty lamp and direct the building manager to it as each lamp is individually addressed. With each lamp individually addressed, it allows the building manager to alter, dim or set each lamp to a different lighting intensity. This has the potential to increase occupant satisfaction by attending to personal preferences of lighting requirements and can also save energy by having less lights on in less frequently used areas such as corridors, storerooms and filing areas.

There are various ways in which automated daylight control systems can be commissioned. In the example of Figure 1, the artificial lights can be dimmed individually or by row. By having one sensor per row there is better control and an even light distribution throughout the space. This setup allows the lamps closer to the window to dim more as they receive more daylight than those further into the building. This gives an even lighting level for the users sitting under each row of lights.

\subsection{How to measure Light; Horizontal Plane vs. Vertical Plane}

While researching the topic of lighting, it was found that there are two approaches to measuring illuminance levels. Firstly is on the horizontal plane facing up and secondly is the vertical plane. There are different reasons for measuring light in each way as explained below.

The horizontal plane is used to measure how much light is required at a desk and is the standard way to measure illuminance. The theory behind this measurement is explained by Kit Cuttle in his 2010 opinion paper; "the concept that lighting adequacy is determined by ability to read from a sheet of paper on a horizontal workplane was a legal argument devised almost one hundred years ago, and it continues to dominate all aspects of lighting practice" (Cuttle, 2010, p. 82). However Cuttle continues and suggests that the horizontal plane is an old-fashioned way of measuring illuminance and that the vertical plane is a better representation of illuminance as it represents the light that reaches the eye. Current lighting and measuring techniques (measuring the horizontal plane), are described by Cuttle, as needing to "switch from thinking about light incident on planes, to light arriving at the eye" (Cuttle, 2010, p. 82), which is measuring light on the vertical plane. Cuttle's paper is based on his personal and professional experience, and highlights an important aspect when measuring light. This is also reiterated in another recent study which states that a "simple consideration of horizontal illuminance at work plane height is a serious limitation and does not represent a complete methodology for the assessment of lighting conditions. Non- 
horizontal components of lighting need to be considered as well because these are the components perceived by the occupants" (Cantin \& Dubois, 2011, p. 292). Although these viewpoints continue to be debated, they have not been widely accepted by the lighting community.

Measurements on the horizontal plane at desk height are however used as a reference point for programming automated daylight control systems. The horizontal plane is also used as a measurement for relevant New Zealand Standards. For general office work, 400 lux is the minimum set amount of light required on the horizontal plane (AS/NZ 1680.2006 - see Appendix One). Therefore this research decided to use 400 lux as a reference point of minimum lighting requirements, but to also investigate Cuttle's challenge. To further understand the differences between the horizontal and vertical planes, it was decided that both will be measured and compared. This will provide information on how glare affects the occupants and will be recorded right next to the window and further into the building.

\subsubsection{How to measure light; Close vs. Far}

Another aspect to consider when measuring illuminance is the distance from the window that the sensors should be placed. According to a study by Choi et al., "overall, the locations of 2.4 and $3.4 \mathrm{~m}$ are the optimal spatial characteristics and related mounting location for the photosensor" (Choi et al., 2005, p. 43) to accurately represent the workplace illuminance levels. It was decided that these distances would be used as a guide when placing the illuminance sensors in each test building, or as close to the automated daylight control systems sensor as possible. The sensors were therefore placed far enough apart from each other to record different lighting scenarios (different sides of the room or orientations e.g. NE or NW) and to see how different occupants use their spaces.

The closer to a window an occupant is sitting, the greater the amount of daylight they will have on their desk and directly around them. A study on lighting by Loe found that glare was an issue as "people near the windows suffer the most discomfort and control any blinds that may be necessary, which can be an annoyance to other users" (Loe, 2009, p. 217). This statement strengthens the reasoning of Cuttle in the previous section where he describes the need to start assessing lighting from the user's point of view to be able to assess occupant comfort. While it is common practice to only measure light on the horizontal plane, in response to the comments of Cuttle and Cantin and Dubois, it was decided to measure both horizontal and vertical illuminance as there is enough concern about vertical illuminance measurements to adopt this way of measuring into the methodology. 


\subsection{Saving Energy}

The values in Figure 2and Figure 3 are produced from other automated daylight control studies. These studies reported overall energy saving percentages and techniques used i.e. researched, calculated or simulated. If $25-40 \%$ (Leslie, 2003) is the electrical demand of a commercial building's total energy use, and with the literature suggesting the possibility of saving $15-80 \%$ (Figure 2 \& Figure 3), using automated daylight control systems would seem a simple solution to the growing problem of high energy consumption. To put this in context, with a minimum saving of $15 \%$ and maximum of $80 \%$ and lighting accounts for $25-40 \%$ of a buildings energy use, then anywhere from $3.75 \%-32 \%$ of total energy use could be saved. Even with this large range, the saving potential over all buildings throughout an entire country would be a significant reduction overall.

Understanding how automated daylight control systems work once they are installed is a key aspect in changing how systems operate in the future. As described in a study by Atif et al. many energy saving calculations are based on computer simulation or scale modelling, test cells or high daylighting availability calculations. In addition, the current situation is that "daylighting field-measured data with respect to transient daylighting contribution and electrical lighting control are very limited" (Atif et al., 1997, p. 5). The presence of daylight does not necessarily imply high energy savings as there are decreases in savings due to occupant behaviour, poor commissioning and associated thermal loads. Atif et al. concluded that for "daylighting to be considered as a source of energy savings in buildings, monitoring the daylighting performance of real case studies becomes an essential procedure" (Atif et al., 1997, p. 5). Field measurements are important to this area of research as they investigate real situations in order to understand how automated daylight control systems work in practice. The post-installation use and occupant interaction of these systems cannot be simulated.

In order to promote the use of automated daylight control systems from a manufacturer's viewpoint, good data is required as to understand how much energy each system is going to save. Bodart and De Herde, concluded that "daylighting can reduce artificial lighting consumption from 50 to $80 \% "$ (Bodart \& De Herde, 2002, p. 421). Leslie suggests total building savings "from reduced lighting and cooling loads can be substantial because electric lighting can account for $25-40 \%$ of a commercial building's energy requirements" (Leslie, 2003, p. 381). These are both very large ranges which can become difficult to achieve when 
accounting for the many variables an automated daylight control system and building will have.

\begin{tabular}{|l|c|c|c|}
\hline \multicolumn{4}{|c|}{ Automated Daylight Control System's Saving Potential - Chronological list } \\
\hline Researchers & Date & Savings & Type of Research \\
\hline Szerman & 1993 & $77 \%$ & Simulation \\
\hline Energy Research Group & 1994 & $50 \%$ & Literature Review \\
\hline Opdal \& Brekke & 1995 & $30-40 \%$ & Field \& Simulation \\
\hline Floyd \& Parker & 1995 & $36 \%$ & Field Measurements \\
\hline Syomei-Gakkai & 1996 & $15-30 \%$ & Field Measurements \\
\hline Embrechts \& Van Bellegem & 1997 & $20-40 \%$ & Field Measurements \\
\hline Li \& Lam & 2001 & $50 \%$ & Field Measurements \\
\hline Bodart \& De Herde & 2002 & $50-80 \%$ & Simulation \\
\hline Leslie & 2003 & $52 \%$ & Literature Review \\
\hline Tridonic PCA EXCEL & 2003 & $25-75 \%$ & Manufacturer \\
\hline Li et al & 2006 & $33 \%$ & Field Measurements \\
\hline Lee \& Selkowitz & 2006 & $60 \%$ & Field Measurements \\
\hline International Energy Agency & 2006 & $30-41 \%$ & Literature Review \\
\hline Loftness et al & 2011 & $35 \%$ & Literature Review \\
\hline Philips OccuSwitch DALI & 2011 & $70 \%$ & Manufacturer \\
\hline ABB i-bus KNX DALI & 2011 & $28-66 \%$ & Manufacturer \\
\hline OSRAM MULTIeco & 2011 & $55 \%$ & Manufacturer \\
\hline Glamox - Luxo & 2011 & $70 \%$ & Manufacturer \\
\hline Hightech Electronic Products & 2011 & $60 \%$ & Manufacturer \\
\hline \multicolumn{2}{|l|}{ Figure 2: Saving Percentages - Chronological Order } & \\
\hline
\end{tabular}

The values in Figure 2 (chronological order) and Figure 3 (savings order) are studies that reported on information of the actual savings of automated daylight control systems. Those dated 2011 were found in other researchers' publications and manufacturers' information as named in the table above. The two tables show the differences between the overall savings percentages but also identify that as time has progressed, there have been no obvious improvements.

Only 19 studies were found on automated daylight control systems which published actual savings; however they lacked detail such as point of change and building design. This meant there was no way to analyse how well each system was working in comparison to the test buildings in this thesis. For example, a high daylight point of change would result in lower savings when compared to a low point of change. It is not sure what these studies used as a point of change value.

There are many other variables between all of the studies that are not known, such as orientation, system type and weather patterns/sky type. Each study only briefly described its process and what was being investigated making it difficult to directly compare each of the studies. These studies do however point out that it is possible to achieve high savings using 
automated daylight control systems. It is the saving percentages in these studies that will be compared to each of the test buildings.

\begin{tabular}{|l|c|c|c|}
\hline \multicolumn{4}{|c|}{ Automated Daylight Control System's Saving Potential - High to Low } \\
\hline Researchers & Date & Savings & Type of Research \\
\hline Bodart \& De Herde & 2002 & $50-80 \%$ & Simulation \\
\hline Szerman & 1993 & $77 \%$ & Simulation \\
\hline Tridonic PCA EXCEL & 2003 & $25-75 \%$ & Manufacturer \\
\hline Philips OccuSwitch DALI & 2011 & $70 \%$ & Manufacturer \\
\hline Glamox - Luxo & 2011 & $70 \%$ & Manufacturer \\
\hline ABB i-bus KNX DALI & 2011 & $28-66 \%$ & Manufacturer \\
\hline Lee \& Selkowitz & 2006 & $60 \%$ & Field Measurements \\
\hline Hightech Electronic Products & 2011 & $60 \%$ & Manufacturer \\
\hline OSRAM MULTIeco & 2011 & $55 \%$ & Manufacturer \\
\hline Leslie & 2003 & $52 \%$ & Literature Review \\
\hline Energy Research Group & 1994 & $50 \%$ & Literature Review \\
\hline Li \& Lam & 2001 & $50 \%$ & Field Measurements \\
\hline International Energy Agency & 2006 & $30-41 \%$ & Literature Review \\
\hline Opdal \& Brekke & 1995 & $30 \& 40 \%$ & Field \& Simulation \\
\hline Embrechts \& Van Bellegem & 1997 & $20-40 \%$ & Field Measurements \\
\hline Floyd \& Parker & 1995 & $36 \%$ & Field Measurements \\
\hline Loftness et al & 2011 & $35 \%$ & Literature Review \\
\hline Li et al & 2006 & $33 \%$ & Field Measurements \\
\hline Syomei-Gakkai & 1996 & $15-30 \%$ & Field Measurements \\
\hline \multicolumn{2}{|l|}{} & & \\
\hline
\end{tabular}

Of the 19 studies found; two were completed using computer simulation; four were literature review percentage ranges; six were calculated from onsite field measurements; one (Opdal \& Brekke) used both field measurements (30\%) and simulation (40\%); and the remaining six were manufacturers' information. With an average of $49 \%$ of all 19 studies with a range of $65 \%(15 \%-80 \%)$, the ability to save energy varies considerably. It is assumed that this is due to the many different variables in each study that would affect the results.

When comparing the manufacturers' saving percentages against the savings found in field measurements and other research based investigations, it was found that the difference between the two areas was averaged at $60 \%$ (Manufacturers) with a range of $25-75 \%$, compared to $43 \%$ (Research Literature) with a range of $15-80 \%$. While the ranges of savings are similar, the researchers' savings were $17 \%$ less than manufacturers' claims. Lower still is the average percentage savings for the Field Measurements, with an average of $39 \%$ - some $21 \%$ lower than the average of the manufacturers' claims and $4 \%$ less than the average of the literature reviews. This further supports the need for a standardised method of assessing the 
performance of automated daylight control systems but also identifies the difficulties in doing so.

\subsection{Why use a survey?}

The studies in Figure 2 and Figure 3 are examples of research looking specifically at the possible energy savings of automated daylight control systems. This is important information, but as "electric lighting is responsible for up to one third of an office building's electricity needs making daylight more available in office buildings can not only contribute to significant energy savings but also enhance the occupants' performance and wellbeing" (Linhart \& Scartezzini, 2010, p. 587). This is why a survey is required to assess how occupants perceive their environments.

The purpose of the survey was to understand how occupants perceive their surroundings in context to their environmental conditions. As described by Loftness et al. "the value of POE (post-occupancy evaluation) is multifaceted. It allows building occupants and managers to: take back control of building systems; identify technologies and systems that work; prove that places affect health and productivity; ensure investment where it matters; recognize the importance of behaviour in environmental gains; and catalyse innovation that can meet today's challenges" (Loftness et al., 2011, p. 267). Post-occupancy evaluations can reveal significant gaps between the design intent and the performance of buildings. POE surveys show various aspects of the building from the occupant's point of view, which can lead researchers to an understanding of how well the building is working and identify what can be improved.

Suggestions between the physical measurements and the occupants' psychological perception of their space have been made in the above studies, but none have tested them together. As highlighted in the study by Loftness, there is a need to understand how automated daylight control systems are working with regard to occupant satisfaction. Aspects such as occupant comfort, productivity and overall satisfaction are difficult to measure. Therefore a survey is used as a tool to collectively assess how well the automated daylight control system is working by allowing the occupant to assess their own surroundings.

The survey being used in this study was created and developed by Adrian Leaman and Bill Bordass of Building Use Studies (Building Use Studies (BUS), 2010) in the United Kingdom. It 
has been widely used by Prof. George Baird on a range of New Zealand buildings as well as many international buildings (Baird, 2010).

To demonstrate the importance of using a survey, the results of a post-occupancy evaluation study on 15 office buildings in the United Kingdom, by Cunill et al., found that " $80 \%$ of the daylight linking systems installed in the UK are deactivated, failing or not working properly (12 out of the 15 sample)" (Cunill et al., 2007, p. 6). There are many differences between Cunill's survey sample and the survey that was used for this research, but specifically Cunill's survey was conducted on building management staff members, rather than occupants. Furthermore, as Loftness et al. summarise, it is the occupants that need to comment on the way the building is operating:

Environmental and occupancy variations are exactly why we need control. Few automated control systems can anticipate the range of conditions that may emerge in an office..., especially as these spaces evolve and the control systems remain static. Moreover, with the right controls, occupants can not only meet their individual environmental expectations, they can save dramatic amounts of energy in the process - especially with performance feedback. (Loftness et al., 2011, p. 265)

Loftness et al. encourages the undertaking of a survey alongside physical measurements to obtain an overall view. The importance of an occupant's satisfaction in comparison to the potential savings of a system is made clear by studies such as Tsikaloudaki's research on indoor daylight conditions. Tskialoudaki found that "although the potential for reducing energy costs and environmental emissions is substantial, the most powerful impact of daylight is on the building's occupants, since it is strongly associated with human health, psychology, mood and productivity" (Tsikaloudaki, 2010, p.8).

Building owners are taking this advice and introducing energy efficient technologies into their buildings in order to retain tenants. This development is supported by findings such as Ko et al. who indicated that "in order to increase the occupants' productivity and well-being, owners and employees do not want to renew leases for office space that lack daylight, relying on artificial lighting. Therefore, from an environmental point of view, everyone concerned with an office-building project, including the owner, tenants and occupants, prefer daylight efficient buildings" (Ko et al., 2008, p. 954). If the introduction of natural light through building design can increase productivity and well-being, a building will become 
more attractive to companies as their employees will have a better work output (productivity) which is beneficial to both employer and employees.

\subsection{Glare, Health \& Productivity}

This research does not directly measure the physical impacts of glare, health or productivity of building occupants, but allows self-reporting of these aspects through the survey. The likely disadvantages of natural light entering a building are the negative effects of glare, the varying temperatures throughout the day which can affect the productivity and the overall comfort of an occupant.

\subsubsection{Glare}

Direct light can often be too strong or bright, requiring an occupant to change their surroundings to suit them, a situation known as glare. The Illuminating Engineering Society of North America (IES) defines glare as "the sensation produced by luminance (brightness) within the visual field that is sufficiently greater than the luminance to which the eyes are adapted to cause annoyance, discomfort, or loss in visual performance and visibility" (IES, 2011).

Baird, in his book 'Sustainable Building in Practice' noted "among the other issues that seemed to arise reasonably frequently was the incidence of direct glare from the sun. This was noted in buildings in every climatic zone and is somewhat surprising, given the predictability of sun angles" (Baird, 2010, p. 20). With buildings designed for daylight, there is a need to reduce glare and other unwanted occupant discomforts. An automated daylight control system should not sacrifice occupant satisfaction but still needs to capitalise on the available daylight (Park et al., 2011). Research conducted by Chauvel et al. in 1982, and then again by Osterhaus in 2001, concluded that "discomfort glare from daylight appears to be tolerated to a much higher degree than predicted by available assessment methods if there is a pleasant view from the window causing the glare" (Chauvel et al., 1982; Osterhaus, 2001). It is this desire for natural light that allows occupants to accept higher levels of glare even if it's only for a short period, "however, direct sunlight penetration can be a problem and this must be addressed if problems of glare and overheating are to be avoided" (Loe, 2009, p. 217). Loe explains that manual blinds that are altered to suit an individual's comfort next to the window may be an annoyance to other users close by. The use of blinds also reduces the saving capability of the automated daylight control system. 
Research identifying the effects of glare and light in office buildings has found that if an occupant's light source was "natural, rather than artificial, people accept a wider range of illuminance values" (Energy Research Group, 1994, p. 1). This suggests that occupants are willing to sacrifice issues of glare if they have daylight at their work space. The Energy Research Group has also found that when there are insufficient blinds, manual controls or there is a badly lit environment, that "poor lighting can cause eyestrain, fatigue, headaches and irritability" (Energy Research Group, 1994, p. 1). These are issues that begin to affect health, comfort and productivity.

\subsubsection{Health}

A healthy, comfortable environment is likely to make an occupant more productive and they are likely to have fewer days off during the year (Loe, 2009). Studies have concluded that health is an issue "that needs to be addressed and over the years it has been claimed that light exposure is essential to good health, and yet people working most of their lives indoors now have much less exposure than their forefathers" (Loe, 2009, p. 212). With a noticeable return to building with daylight orientated designs, natural light should be incorporated into more buildings. "Workplace illumination is of paramount importance in determining the employee's productivity and well-being. Moreover, light exerts non-visual effects with respect to biological rhythms" (Hoffman et al., 2008, p. 719). This is because daylight is rich with short wavelength (blue) radiation which regulates the circadian rhythm (Webb, 2006). These studies found that natural light is good for health and well-being, but also state that when there is a lack of natural light that the ramifications can be far worse. As explained by Begemann et al. (1997):

\section{Medical research has shown that a prolonged lack of 'light vitamin' can cause health problems ranging from minor sleep and performance difficulties to major depressions. This inevitably suggests that 'poor' indoor lighting is the underlying cause of many of the health and performance problems. (Begemann et al., 1997, $p$. 231)}

Once techniques and methods for controlling the amount of light entering a building have been better developed, "there arises an opportunity for the profession to move lighting from being purely a building service to a service that enhances human performance, well-being and health" (Loe, 2009, p. 210). 


\subsubsection{Productivity}

The impact of building performance on occupant productivity is very difficult to quantify. The Oxford Dictionary defines productivity as "the state or quality of being productive - the effectiveness of productive effort" (Oxford Dictionary, 2011), measured by the rate of output, per unit of input. Productive is defined as "producing or able to produce large amounts of goods, crops, or other commodities" (Oxford Dictionary, 2011). Trying to quantify the amount of work someone produces by evaluating their surroundings is difficult, but the word 'productivity' is still used regularly within post-occupancy evaluation surveys. In a study completed by Phelan, it was found that a "major benefit attributed to daylighting is the increased productivity of occupants. Reasons behind increased productivity are an improved sense of 'well-being' and reduced absenteeism related to having a direct visual connection to the outdoors and the natural solar cycles. Daylighting also creates more dynamic visual environments" (Phelan, 2002, p.2). The study by Phelan identifies the present health qualities of having an automated daylight control systems that have made these systems a more considered option.

The repercussions of low productivity can affect businesses; a common approximation of the costs of a building over its lifetime can be simplified to a ratio of 1:10:100. This is an approximated ratio of operating costs (1), to combined capital and rental costs (10), to total salary costs of the occupants (100) over the life of a building. As Baird notes, this "makes it abundantly clear where attention should be centred" (Baird, 2010, p. 1), which is focusing on the occupants.

The purpose of investigating productivity in this research was to identify if having an automated daylight control system had any effect on an occupant's productivity level. A difficulty in measuring productivity within the selected office buildings was that there were no set tasks, no monitored rate of work. This is in comparison to the Hawthorne experiment, where a rate of work could be monitored as a single task was being undertaken by each of the participants. For the Hawthorne experiment, it is argued that as the occupants were aware that they were being monitored and therefore their response was altered. The BUS study does not monitor the respondents, it only asks for their one-off, self-reported view of their productivity and health.

A recent study by Linhart and Scartezzini explores the link between daylight and energy in office buildings. They concluded that "electric lighting is responsible for up to one third of an office building's electricity needs. Making daylight more available in office buildings can not 
only contribute to significant energy savings but also enhance the occupants' performance and wellbeing" (Linhart \& Scartezzini, 2010, p. 587).

\subsection{Summary}

Overall, as long as the automated daylight control system is reducing the energy loads of the building and at the same time creating a comfortable working environment by utilising natural light then it is working correctly. However, the payback period for small energy savings can be a restriction on their implementation.

Referring back to the two approaches being investigated in this research, (physical and psychological), Hoffman et al. explain how "qualitative and quantitative aspects of workplace illumination are among the key factors determining the employee's productivity. Thus speed, quality of work, downtime, absenteeism, and accident rates are affected by the environmental lighting conditions" (Hoffman et al., 2008, p. 719).

Reinhart and Selkowitz, in a study on measuring illuminance and daylighting implications, concluded:

Nowadays, the quest to light buildings with daylight and sunlight is enjoying increasing interest from building owners and architects alike. The source of this interest often lies beyond the energy-efficiency concerns of the past decades. Instead, a 'new', emerging school of daylighting design has become more occupant-centred, concerning itself with questions such as how can one design a building that satisfies occupant needs for comfort and health, and, in a commercial setting, positively influences the productivity of the organization it hosts? Within that school of thought energy savings remain important but the real challenge is to find design solutions that simultaneously serve both goals. (Reinhart \& Selkowitz, 2006, p. 2)

This literature review found that even though both the physical and psychological aspects are recognised as being important, other research on automated daylight control systems have used only one approach at a time - no study was found that combined both approaches. For example, Cunill et al. (2007) researched the performance of automated daylight control system by using the survey approach, while researchers such as Bodart \& De Herde (2000), Lee \& Selkowitz (2006), Li (2010) and Leslie (2003), use a physical measuring approach to examine energy savings. The benefit of natural light has obvious health qualities; however it was also found that the effects of glare can be detrimental. With the implementation of 
natural light, the positive and negative factors must be accounted for and this thesis endeavours to measure these factors by recording both physical and psychological data. 


\subsection{Research Development}

This Chapter explains the development of the research methodology. To understand how the equipment would be best used and to check its correct operation, two pilot studies were conducted. Firstly a basic understanding of lighting levels and site orientation was conducted in a ground level, south facing room. As two sets of monitoring equipment were available for the research, they were both checked to see that they produced consistent results and that the equipment was working correctly. This was further tested in an east facing room in one of the four selected test buildings to trial the methodology and equipment over a five day period. This ensured that all the measuring equipment would work in unison, as well as testing how long it would take to set up the monitoring equipment and identified any changes required before the detailed measuring.

The second pilot study consisted of observation days that occurred in each of the four selected buildings (see Section 3.2). These observations documented the lighting (artificial and daylight) in different areas of the buildings, observed how the occupants used the spaces and selected two spaces in each building for the detailed measurements.

\subsection{Pilot 1: Post-Graduate Room Pilot Study}

The initial pilot study was of a south facing room at the Faculty of Architecture and Design post-graduate room (level 0, 24 - 32 Wigan Street, Wellington). This was to test the equipment and its limitations, how well it recorded data and to identify that the data was in a usable format. It was also used to understand daylight penetration, record occupant behaviour and understand the light distribution of a south facing building.

The first pilot study cross checked the light meters in a systematic way, to ensure both sets of equipment were operating correctly and producing data in a usable state.

The post-graduate office is on the ground floor of the building facing south and has a building painted white directly across the road. The measurements were taken on the $19^{\text {th }}$ of May 2011, which was a clear sunny day and it was noted that throughout the day there were no clouds present in the area of sky visible from the window. Seven points in the room were measured every half hour starting at 9:30am and finishing at 4:30pm. One measurement was taken directly against the window while the other measurements were spread evenly throughout the room at the distances shown below in Figure 4 (locations $A-F$ and W). The points of measurement were placed in the centre of the room away from both walls to ensure that they were least affected by the surroundings and/or any obstructions. The 
measurements were all taken at desk height (0.7m), following AS/NZS 1680.1, 2006 Clause 3.6 'Recommended Illuminances' which states this is the height that 'tasks' are typically completed at.

Figure 5 depicts the window in the post-graduate room. The top third of the glass is clear, while the remaining two thirds has a frosted film. The space has a manual switch that controls the fluorescent lamps which are turned 'on' by the first person to arrive and turned 'off' by the last to leave.
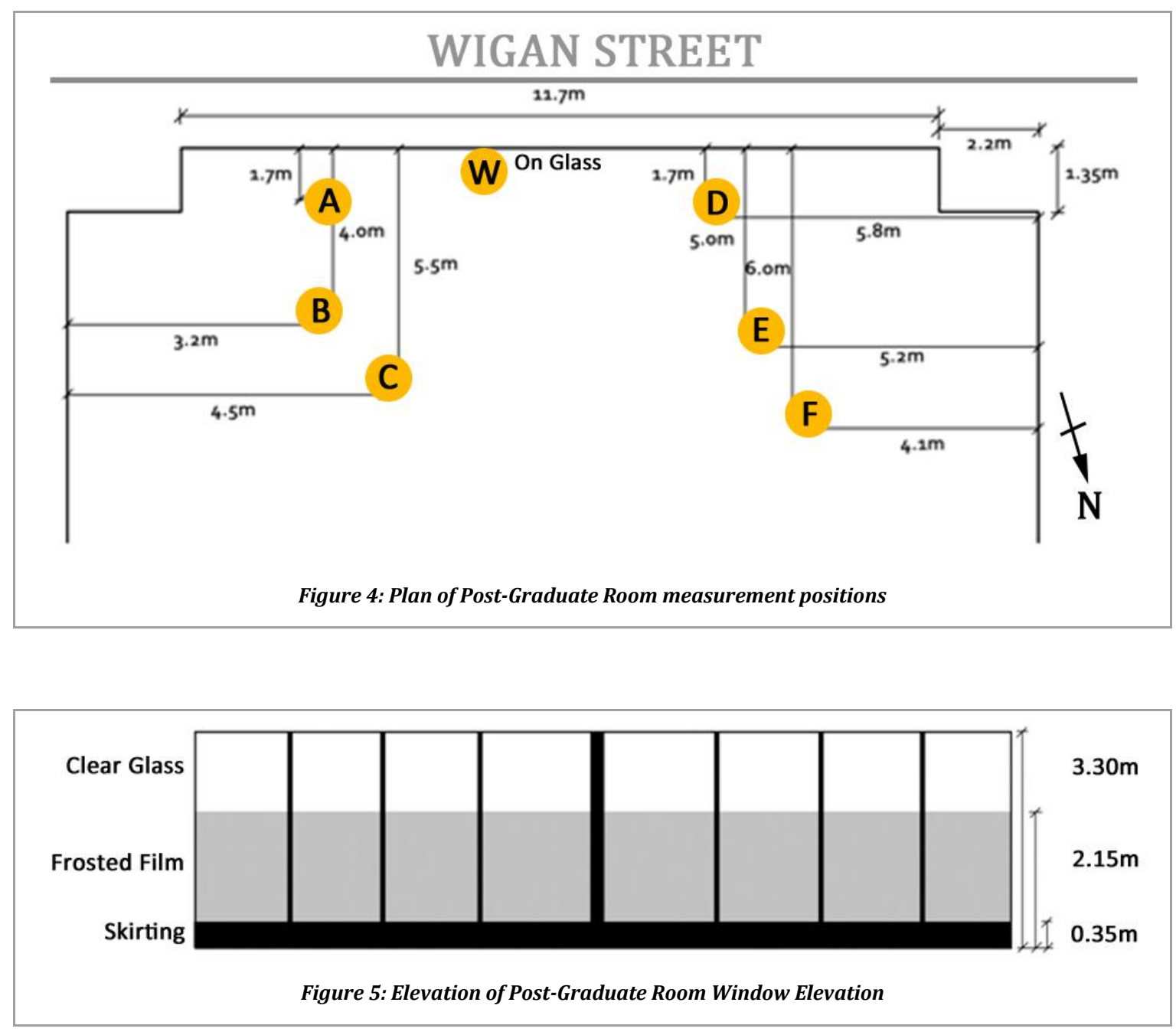

Throughout the day no illuminance levels increased higher than 400 lux deeper into the space (positions B, C, E \& F) as the daylight did not penetrate more than $4.0 \mathrm{~m}$. For the positions closer to the window ( $A, D$ and $W$ ) the illuminance levels never went above 1,000 lux. There was very little variation in the illuminance levels throughout the seven hour measurement period, as shown in Figure 6. This is as expected as there was no direct sunlight, only skylight which produces an even distribution of light when south facing in the southern hemisphere. 


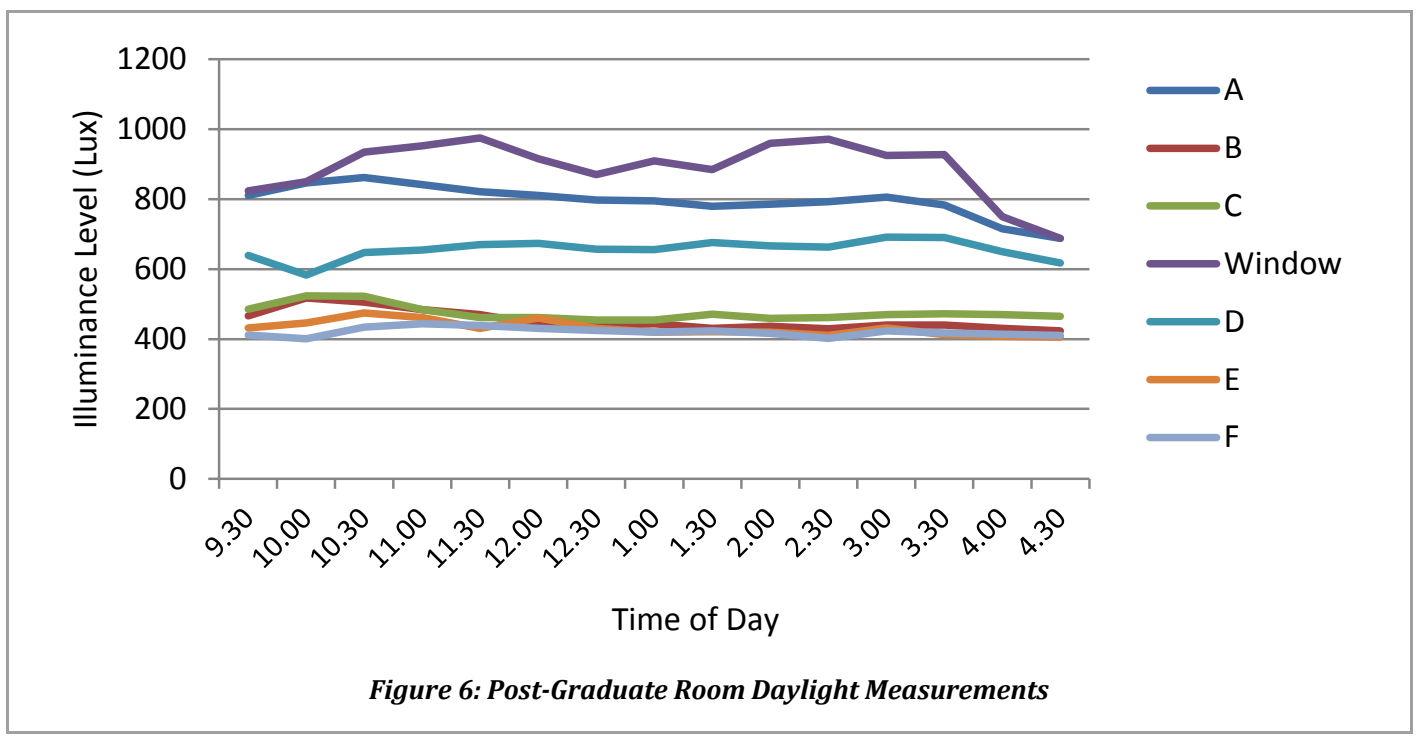

The half hourly measurements were not taken outside the room but were taken directly against the window. The measurements were taken this way because any reflective film or tint on the window would reduce the amount of light entering the space, and it is only the light within the space that is recognised by the automated daylight control system sensor.

\subsubsection{Summary}

The results from this pilot study for a south facing ground floor space found that light coming into a building from the south is evenly distributed and should be easy to manage with an automated daylight control system. The half-hourly measurements provided sufficient data to document the illuminance levels throughout the day. When measuring illuminance levels using data loggers in conjunction with power meter data loggers, more frequent measuring would be beneficial in order to document how well the automated daylight control system is working. Shorter measuring periods would also be able to detect slight or significant changes and identify how those changes in light affect the automated daylight control system.

As a result it was decided that where possible, north facing work spaces should be monitored. The dynamic north sky, with both sunlight and daylight, would better examine the difficulties surrounding automated daylight control systems, as well as identifying how the occupants react to the changes in light levels.

\subsection{Pilot 2: Observation Days}

The four building managers involved within this research requested that they and their buildings remain anonymous. The buildings within this thesis are therefore referred to as Buildings $A, B, C \& D$. 
The majority of one working day was spent in each of the four buildings to observe how the occupants interacted with their physical environment and available natural light. Manual measurements were taken in a range of locations every 10 to 15 minutes and two positions on the north facades of each building were identified for the detailed monitoring. Two positions were to be used to compare how different areas and occupants alter and adjust their spaces. The observations for all buildings were completed during winter when the angle of the sun is particularly low, $\left(27.1^{\circ}\right.$ sun angle, at solar noon on 15 July), compared to the height of summer $\left(72.2^{\circ}\right.$ at solar noon on December $22^{\text {nd }}$, (Level, 2012)).

\subsection{Research Buildings}

This Section begins with the initial observations made within each of the spaces of each building. All information, including a graph of the manual illuminance measurements, and any other information that was deemed important to the research and the development of the methodology follows. A description of how the spaces are used, the positions of the illuminance sensors (which was established after the observation days) including the distances from the windows and a summary of the automated daylight control systems was recorded for each building.

The positions listed as letters $\mathrm{A}-\mathrm{N}$ (varying for each building) were the test positions to gauge how much and deep daylight was penetrating into the building and was only used during the observation days. The positions used for the detailed measuring period are named Close Horizontal, Close Vertical, Far Horizontal, Far Vertical and Lamp, and refer to where they were placed in relation to the window and the plane they are measuring. These are documented at the end of each of the following building information sections.

In accordance with AS/NZS 1680.1:2006, the working plane is $0.7 \mathrm{~m}$ from the floor and therefore the illuminance sensors were placed as close to this height as physically possible. Two sensors; one horizontal (Close Horizontal) and one vertical (Close Vertical) were set up as close as possible to the window and two sensors; one horizontal (Far Horizontal) and one vertical (Far Vertical) were set up further into the building close to the point where the automated daylight control system sensor was positioned. The fifth sensor was placed directly under the lamp (Lamp). Often it was not possible to place sensors directly under the automated daylight control system sensor, so the illuminance sensor was placed at the same distance from the window but further along in the space. The far horizontal sensor is used for the 'point of change' measurement as this is where the automated daylight control system's sensor is focused. 
3.3.1 Building A - Information

\begin{tabular}{|l|l|}
\hline Total Storeys & 14 \\
\hline Type of System & Philips MultiDim \\
\hline Observation Day & $15 / 07 / 11$ \\
\hline Measuring Period & $18 / 10 / 11-31 / 10 / 11$ \\
\hline
\end{tabular}

On the day of observation the sky was mainly clear with minimal clouds present for the entire time. Observations occurred on two levels, level 8 and level 12 from 9:00am to 1:00pm as other levels had security restrictions on them. There are obstructions from the west from a building across the road. There are buildings close by on the south side while the north is mainly unobstructed and the east is only obstructed at the lower levels (ground floor to the level 4). Entering level 12, the space was found to be very well lit with a lot of natural lighting in an open plan area. At this height and with very little obstruction from surrounding buildings in this area, it is expected that natural light will be available all year round. Half of the occupants were seated next to, or one row of desks back from the window.

First Space; Level 12 - The first part of the day was spent on level 12 (9:00am to 12:30pm). During this time the sun was low and direct as it entered the space. It was observed that about half of the blinds were pulled down along the north side. To the human eye it appeared the lamps near the windows were dimmed slightly. Manual measurements were recorded at 1,480 lux on the horizontal plane directly under the perimeter lamps. On level 12 there were no obstructions or reflections from other buildings on the northern facade.

Handheld measurements were manually taken every 15 minutes at seven locations as shown in Figure 7. It can be seen that desktop lighting levels do not drop below 500 lux. This is most likely due to the supplementary artificial lighting. As shown on the graph below, the lighting levels increase steadily towards midday. The positions closer to the perimeter windows (A, B and F) were $1.0-2.0 \mathrm{~m}$ from the window and have the same daylight availability. The large drop in lux levels from 10:00am to 11:00am was due to the sun going behind a column which created a shadow over the sensor locations. The measurement positions deeper into the space $(3.0-4.0 \mathrm{~m})$ mostly recorded artificial light, as the daylight did not reach that far into the building. 


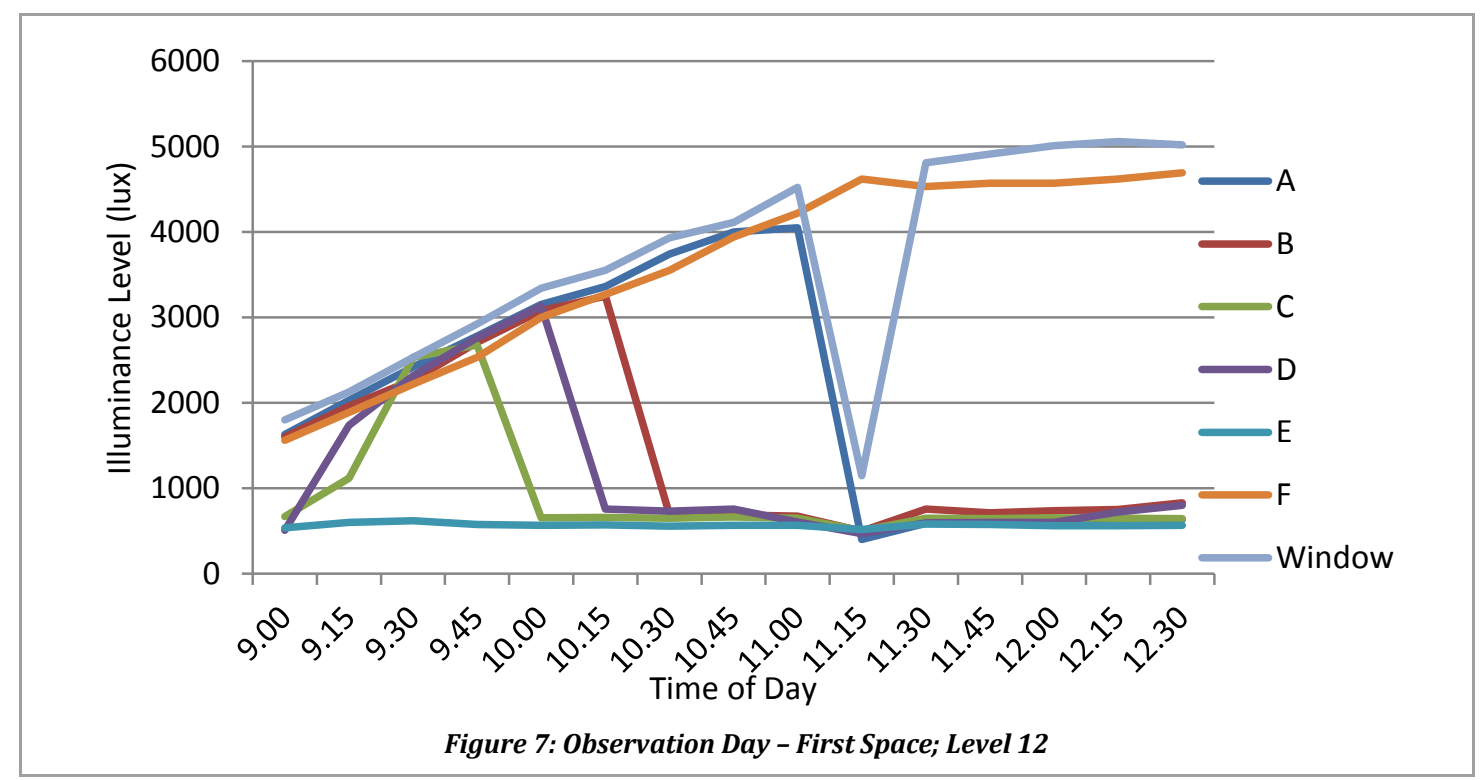

\section{Vertical or Horizontal Measurements}

Illuminance levels were firstly measured on the horizontal plane and then immediately measured on the vertical plane. This was completed to understand the difference (if any) between the amounts of light on the desk, (which would be observed by the automated daylight control system sensors) and the amount of light coming in directly from the windows (eye level).

Figure 8 shows the 3.5 hours of readings manually taken every 15 minutes at both the horizontal and vertical planes. Both the vertical and horizontal measurements closely follow each other, showing the peaks in the day as well as the large drop when there was an obstruction. The vertical readings however are more responsive to the changes in the sky and record higher lux levels compared to the horizontal which results in a more stable trend. 


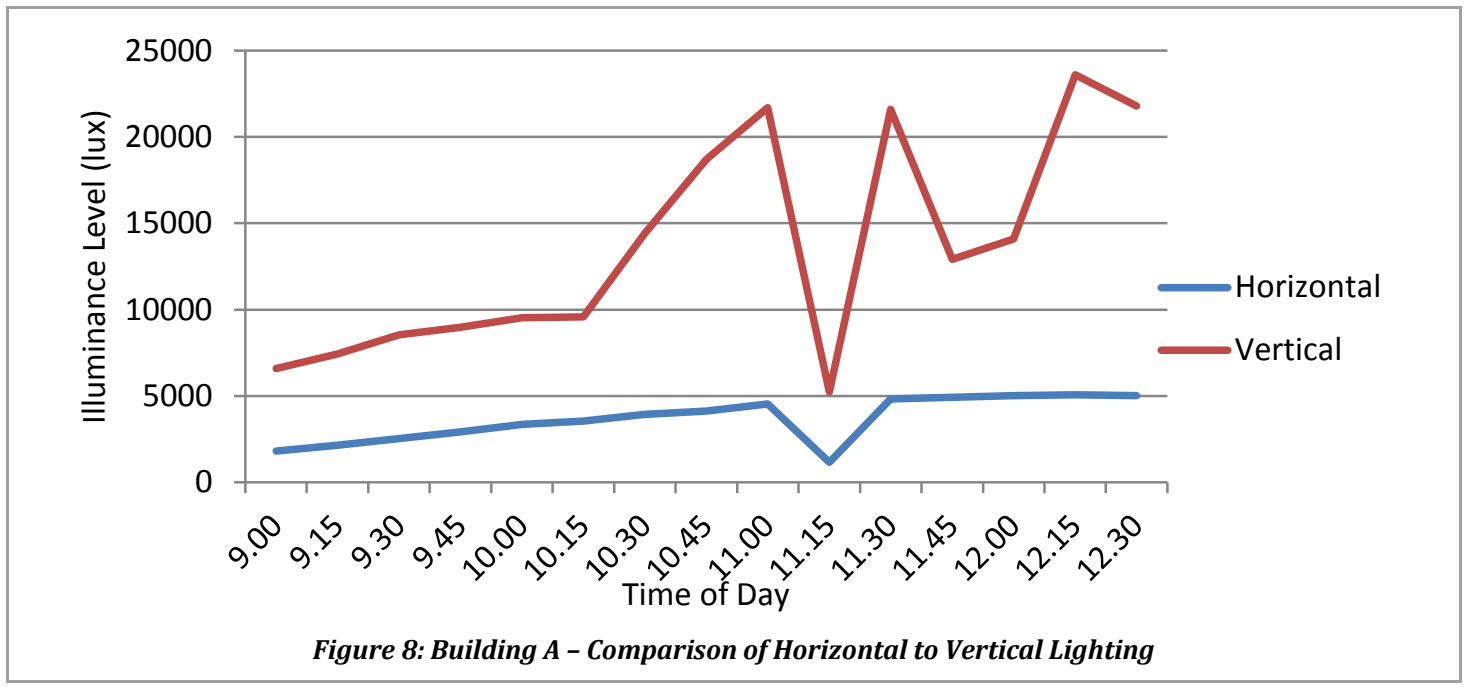

As described in Section 2.3, different researchers have investigated both horizontal and vertical planes with regard to natural light and the best way to measure lighting (e.g. Cuttle (2010), Cantin \& Dubois (2011), and Wienold \& Christoffersen (2005)). For example on average the horizontal plane (3,653 lux) recorded in Building A was only $27 \%$ of the vertical (13,645 lux) planes lux level. It was this large difference (9,992 lux) between the measurements and comments found in the literature that questioned the relevance of the standard horizontal measuring and prompted a change in the methodology to measure the light levels both horizontally and vertically in order to make a comparison. The conclusions from the researcher's work above and the observed results, have led to the decision to include in this research both vertical and horizontal measurements. This will further the analysis of the measurements against the survey responses as occupants will view light on both planes.

Second Space; Level 8 - The second position located on level 8 was investigated after 12:40pm. In contrast to level 12 , level 8 had most of the blinds closed all the way. The only apparent difference between the two floors was that on level 8 there were more occupants with their desks nearer the windows on the northern facade. It is possible that occupants on this floor were more affected by the daylight due to their seating arrangements around the perimeter which in turn has led to more blinds being drawn. Interestingly the site and exterior obstructions on level 8 and 12 were practically the same. Figure 9 shows the light levels in this space ( $\mathrm{H}$ to $\mathrm{K}$ ) were constant, as natural light was excluded by the blinds making this space artificially lit. The measurements at the window were made by placing the illuminance meter under the blind. 


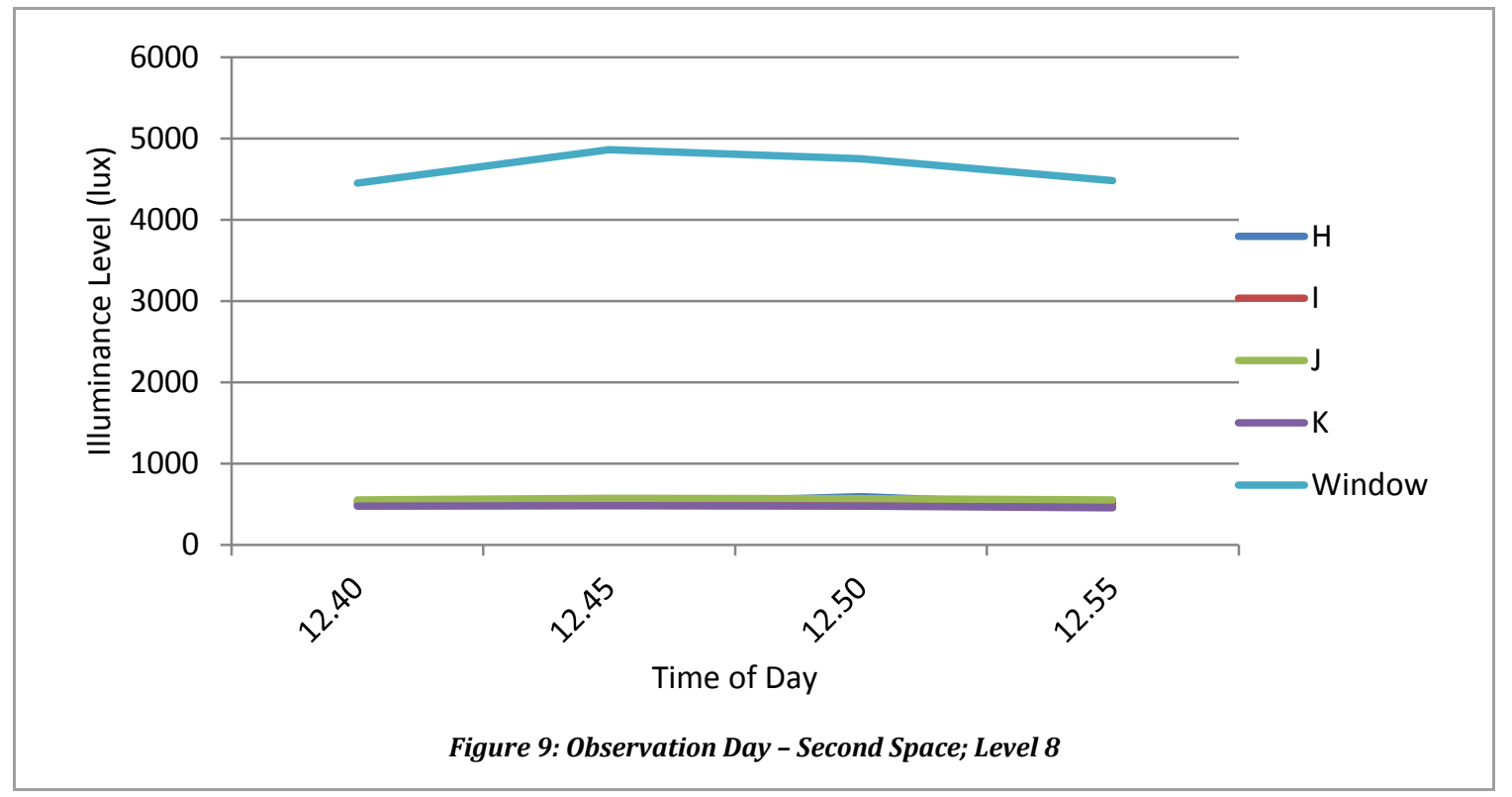

\section{Selected Spaces - Equipment in Each Space}

It was decided that two spaces on level 12 would be used for the monitoring period, as the majority of level 8 occupants had their blinds pulled down. Figure 10 shows a diagram of the spaces, while Figure 11 documents the positions of the illuminance sensors for the detailed monitoring and Figure 12 describes the orientation.

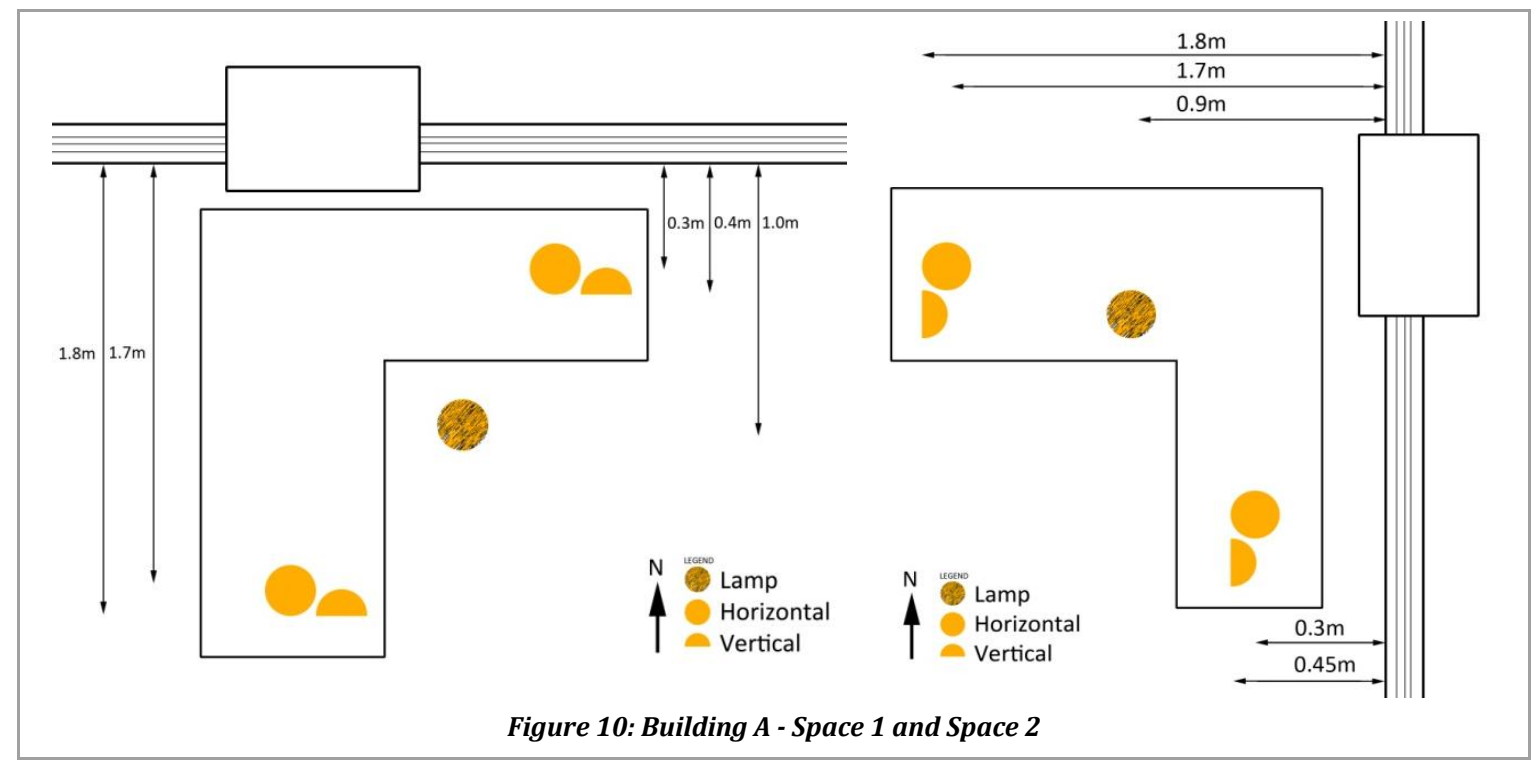




\begin{tabular}{|l|c|c|c|c|c|c|}
\hline & \multicolumn{2}{|c|}{ Distance to Window } & \multicolumn{2}{c|}{ Distance to Wall } & Height from Floor \\
\hline Illuminance Sensor & Space 1 & Space 2 & Space 1 & Space 2 & Space 1 & Space 2 \\
\hline Lamp & $1.0 \mathrm{~m}$ & $0.9 \mathrm{~m}$ & - & - & $2.6 \mathrm{~m}$ & $2.6 \mathrm{~m}$ \\
\hline Close Horizontal & $0.3 \mathrm{~m}$ & $0.3 \mathrm{~m}$ & - & - & $0.7 \mathrm{~m}$ & $0.7 \mathrm{~m}$ \\
\hline Close Vertical & $0.4 \mathrm{~m}$ & $0.45 \mathrm{~m}$ & - & - & $0.7 \mathrm{~m}$ & $0.7 \mathrm{~m}$ \\
\hline Far Horizontal & $1.7 \mathrm{~m}$ & $1.7 \mathrm{~m}$ & - & - & $0.7 \mathrm{~m}$ & $0.7 \mathrm{~m}$ \\
\hline Far Vertical & $1.8 \mathrm{~m}$ & $1.8 \mathrm{~m}$ & - & - & $0.7 \mathrm{~m}$ & $0.7 \mathrm{~m}$ \\
\hline
\end{tabular}

\begin{tabular}{|l|c|c|}
\hline & Space 1 & Space 2 \\
\hline Vertical Height & $40.0 \mathrm{~m}$ & $40.0 \mathrm{~m}$ \\
\hline Directional Facing & $0^{\circ}$ Due North & $135^{\circ}$ South East \\
\hline Surrounding Buildings & Minimal & Minimal \\
\hline \multicolumn{2}{|c|}{ Figure 12: Orientation of Detailed Monitoring Spaces } \\
\hline
\end{tabular}

Five locations were selected for the detailed monitoring. Figure 11 describes the positions of the illuminance sensors of Spaces 1 and 2 in relation to the window, wall and floor.

\section{Daylight Control System Information}

The automated daylight control system installed in Building A is a Philips MultiDim ${ }^{\circledR}$ system which can be fully integrated with DALI compatible devices. The lamps can turn on/off, be dimmed individually or in several different groups giving the ability to change an entire lighting plan to suit the occupants.

There are seven sensors on each level placed approximately $2.0 \mathrm{~m}$ from the windows. The Philips MultiDim ${ }^{\circledR}$ sensors are PIR (Passive Infrared) occupancy sensors as well as dimming sensors. This type of sensor only recognises movement not sound, so if occupants are still for too long, the system will dim to a lower default setting or turn off completely.

\subsubsection{Building B - Information}

\begin{tabular}{|l|l|}
\hline Total Storeys & 15 \\
\hline Type of System & Helvar DigiDim $^{\circledR}$ \\
\hline Observation Day & $04 / 07 / 11$ \\
\hline Measuring Period & $01 / 11 / 11-14 / 11 / 11$ \\
\hline
\end{tabular}

For the duration of the time spent observing this building (9:00am to $4: 00 \mathrm{pm})$, the sky was constantly dark with heavy rain. There were only small patches of lighter cloud during the later part of the day. Some of the blinds (six of thirty) were closed three quarters of the way down, leaving only minimal amounts of light entering through the windows. It was presumed that some of these blinds were permanently in these positions to control the low sun angles 
during this time of the year, as they were not required to be pulled on such a dull, overcast day. It was also observed that they were not altered throughout the day.

There are four daylight sensors on each floor which are positioned at each of the north, east, south and west orientations of the building, each operating four bulk sets of lamps. There are two heights of ceilings on each floor with the first height at the windows edge at $2.4 \mathrm{~m}$ high which is a bulkhead that reaches $1.5 \mathrm{~m}$ into the building, and is then raised to $2.65 \mathrm{~m}$ for the rest of the space. This limits the amount of daylight that can enter. Space 1 is east facing but daylight penetrates in from the north due to the large corner windows and deep glass core.

Building B has low occupant density with approximately twenty people in the immediate area at the time of observation. Comments from the building manager on the day of observation mentioned that there is a high level of satisfaction with the lighting system. This suggests some changes have been previously made to suit the occupants. Glare is controlled by manually operated blinds and at first appearance there is adequate natural light.

First Space; Level 14 - Even on a dark, raining day the low illuminance levels, as shown in Figure 13, provided a minimum of 400 lux which would be the result of the artificial lighting. There were few obstructions at level 14 as there are no surrounding buildings, so it is assumed that on a clear sunny day the space will be sufficiently illuminated if not over illuminated

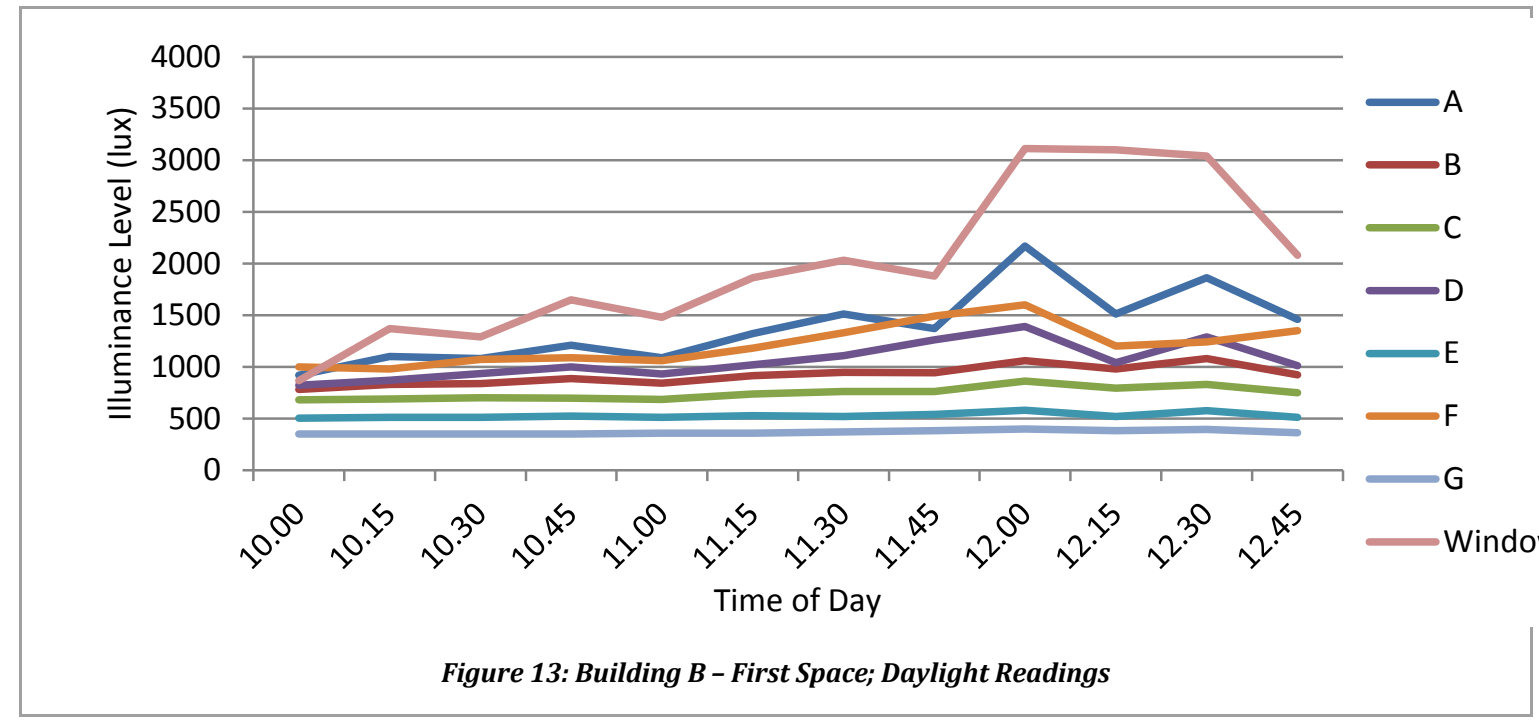

Second Space; Level 14 - This space (on the northern facade of the building) during the afternoon had slightly higher illuminance values (Figure 14) as the rain subsided. Due to the overcast sky the change in illuminance across the space was minimal. The illuminance meter 
readings further into the building suggest that daylight was not penetrating very far. As access was only available to a single floor in this building two positions were chosen at either end of the northern facade to record how different occupants and layouts can affect automated daylight control systems.

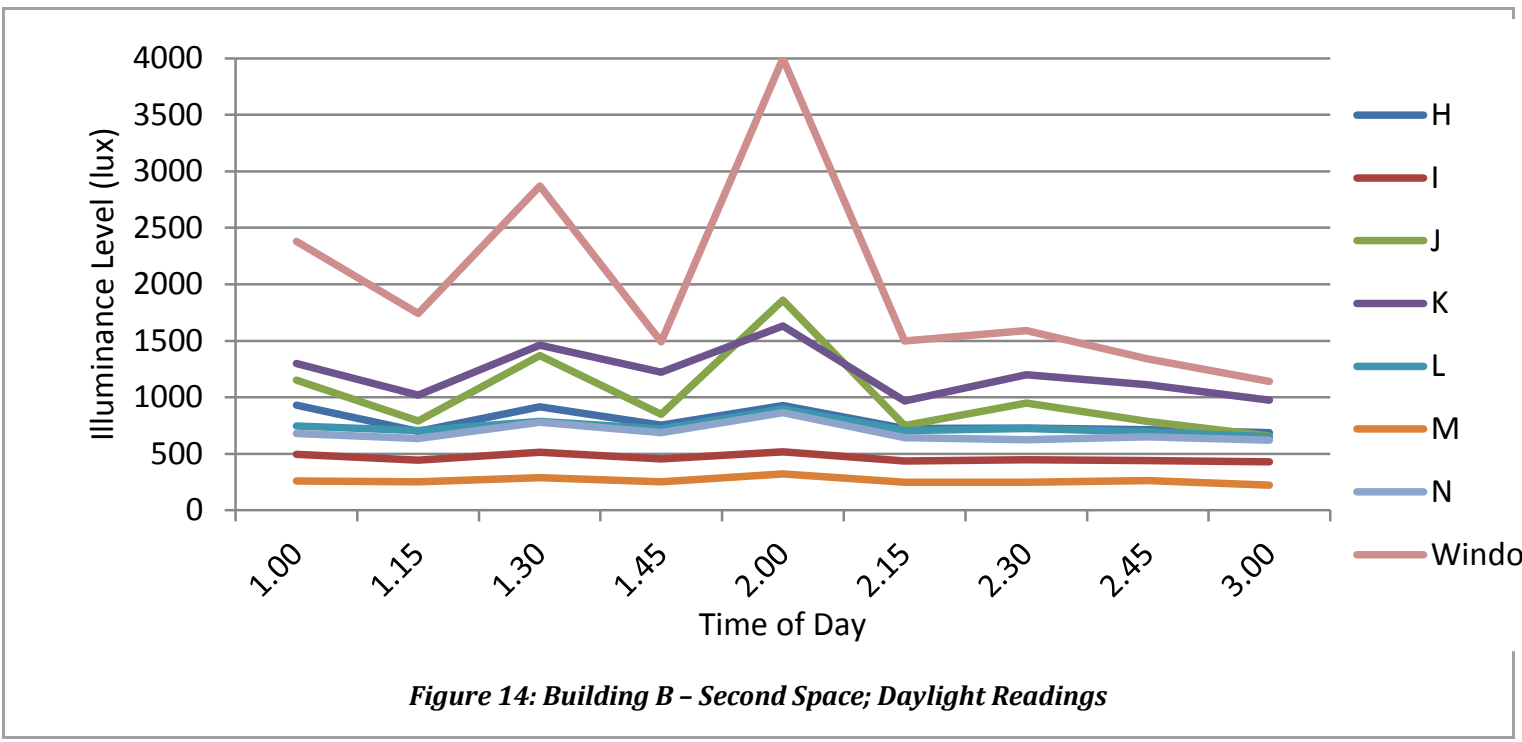

\section{Selected Spaces - Equipment in Each Space}

In Building $B$ there is a low person to area ratio (approximately 1 person per $12 \mathrm{~m}^{2}$ ) which creates a spacious, comfortable environment. There are large floor to ceiling windows and manual blinds which are adjusted by those sitting nearer the perimeter. Due to the height of this level (52.0m from the ground) and the lack of surrounding buildings, occupants may be affected by glare at different times of the day. With the combination of natural light and the ability to regulate the light entering the space using blinds, this level seems to be a comfortable working area.

Building B has recently been refurbished, including the installation of an automated daylight control system. Many of the internal offices and meeting rooms have glass walls, allowing a deep penetration of natural light into the building. As shown in Figure 15, both monitored spaces have desks on the perimeter of the building. At the time of measuring both desks were unoccupied but all the surrounding desks were in use. Figure 16 describes the positions of the illuminance sensors of Spaces 1 and 2 in relation to the window, wall and floor while Figure 17 tabulates the orientation and surroundings. 


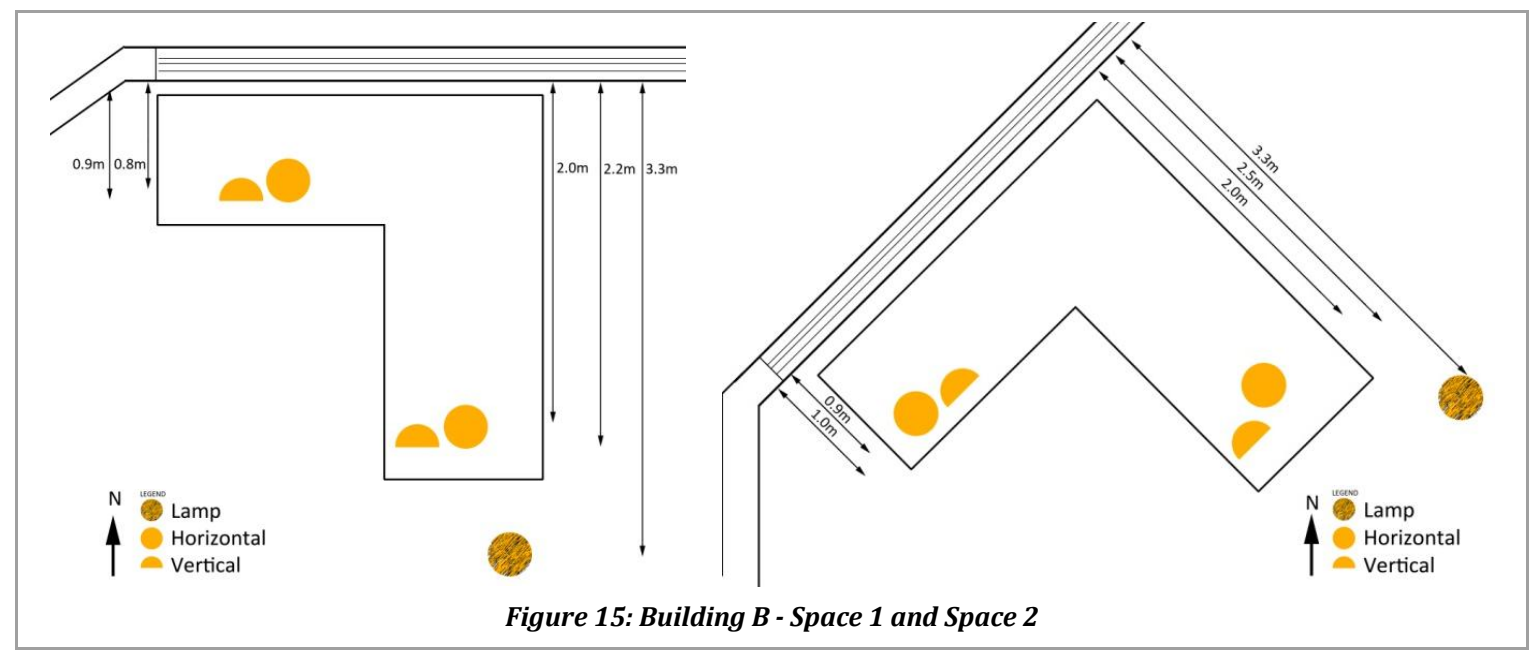

\begin{tabular}{|l|c|c|c|c|c|c|}
\hline & \multicolumn{2}{|c|}{ Distance to Window } & \multicolumn{2}{c|}{ Distance to Wall } & \multicolumn{2}{c|}{ Height from Floor } \\
\hline Illuminance Sensor & Space 1 & Space 2 & Space 1 & Space 2 & Space 1 & Space 2 \\
\hline Lamp & $3.3 \mathrm{~m}$ & $3.3 \mathrm{~m}$ & $7.5 \mathrm{~m}$ & $10.0 \mathrm{~m}$ & $2.6 \mathrm{~m}$ & $2.6 \mathrm{~m}$ \\
\hline Close Horizontal & $0.8 \mathrm{~m}$ & $0.9 \mathrm{~m}$ & $2.0 \mathrm{~m}$ & $8.0 \mathrm{~m}$ & $0.7 \mathrm{~m}$ & $0.7 \mathrm{~m}$ \\
\hline Close Vertical & $0.9 \mathrm{~m}$ & $1.0 \mathrm{~m}$ & $2.0 \mathrm{~m}$ & $8.0 \mathrm{~m}$ & $0.7 \mathrm{~m}$ & $0.7 \mathrm{~m}$ \\
\hline Far Horizontal & $2.0 \mathrm{~m}$ & $2.5 \mathrm{~m}$ & $7.0 \mathrm{~m}$ & $3.5 \mathrm{~m}$ & $0.7 \mathrm{~m}$ & $0.7 \mathrm{~m}$ \\
\hline Far Vertical & $2.2 \mathrm{~m}$ & $2.0 \mathrm{~m}$ & $6.9 \mathrm{~m}$ & $3.5 \mathrm{~m}$ & $0.7 \mathrm{~m}$ & $0.7 \mathrm{~m}$ \\
\hline \multicolumn{7}{|c|}{ Figure 16: Building B - Position of Detailed Monitoring Spaces } \\
\hline
\end{tabular}

\begin{tabular}{|l|c|c|}
\hline & Space 1 & Space 2 \\
\hline Vertical Height & $52.0 \mathrm{~m}$ & $52.0 \mathrm{~m}$ \\
\hline Directional Facing & $0^{\circ}$ Due North & $90^{\circ}$ Due East \\
\hline Surrounding Buildings & Minimal & $\begin{array}{c}\text { There is a building of the same } \\
\text { height directly across street }\end{array}$ \\
\hline \multicolumn{2}{|c|}{ Figure 17: Orientation of Detailed Monitoring Spaces } \\
\hline
\end{tabular}

\section{Daylight Control System Information}

The automated daylight control system that is installed in Building B is a Helvar DigiDim ${ }^{\circledR}$. According to the manufacturer's literature, when using the PIR (Passive Infrared) and Constant Light DigiDim ${ }^{\circledR}$ (which this building has) the system "can achieve maximum energy saving, prolonged lamp life and reduced cost of ownership" (Helvar, 2012). The system provides full control over each individual lamp, making it possible to adjust the lighting levels to suit the occupants in each space. According to the electrical contractor who maintains this system, the system has been set to only dim to a minimum of $50 \%$ of full capacity as there were many complaints from occupants about the lighting quality and the ability to see. This can be expected to reduce the overall energy saving capabilities of this system and is a design issue that needs to be addressed by the building manager.

There are four sensors (combined PIR occupancy and daylight sensors) on each level and they are placed approximately $2.0 \mathrm{~m}$ from the windows. Each orientation $(\mathrm{N}, \mathrm{E}, \mathrm{S}, \mathrm{W})$ has one sensor controlling a bulk set of lamps. 
3.3.3 Building C - Information

\begin{tabular}{|l|l|}
\hline Total Storeys & 15 \\
\hline Type of System & DALI ballasts with a C-Bus ${ }^{\circledR}$ control system \\
\hline Observation Day & $09 / 06 / 11$ \\
\hline Measuring Period & $15 / 11 / 11-28 / 11 / 11$ \\
\hline
\end{tabular}

During the initial inspection the weather was partly cloudy throughout the day but generally it was clear blue sky. While walking around the building, three occupants made their opinions known about their comfort levels and their perception of the lighting within their spaces. On the first floor space, two people reported that during winter one end of the building was affected by low direct sunlight, while in summer the other end of the building became the most uncomfortable due to glare. Although the blinds were pulled to control direct sunlight, the users reported that the blinds did not keep out much light and glare was still an issue.

First Space - On level 1 there was the possibility of closing blinds to counteract glare and reflections from surrounding buildings. There was an individual blind for each window. During the morning observation period (9:30am to 10:45am) five of thirty blinds across the north east window were already closed a third of the way down. This is the only way that the occupants could control their environment; however this is not the case for the second space.

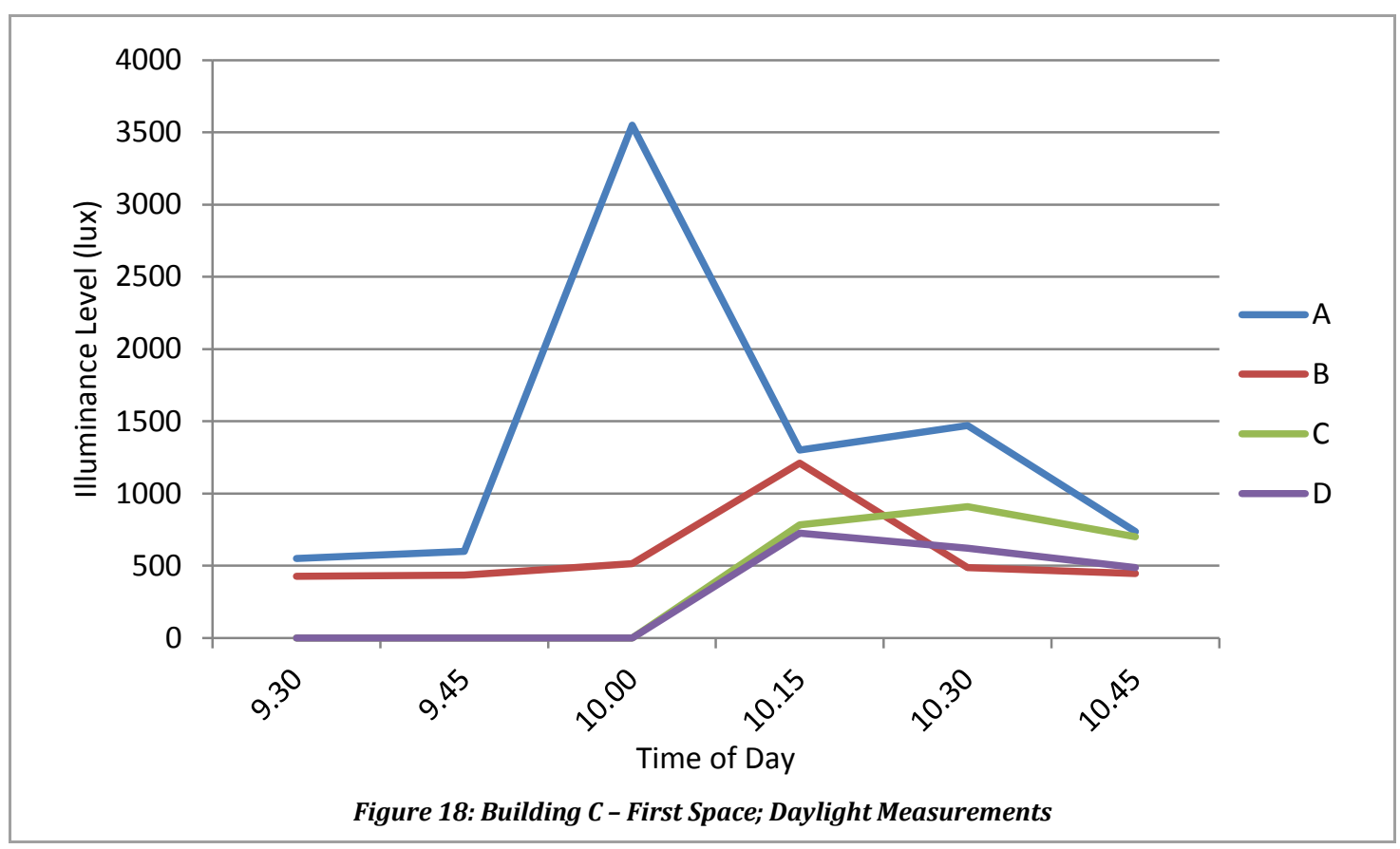


Measurements in this space highlighted the impact of surrounding buildings. While the buildings across the street diminished much of the natural light, the areas between the buildings created a spotlight effect as shown in position $A$ at 10:00, Figure 18.

Second Space - This space is located on the third floor and has an atrium with a large window facing north. There is a neighbouring building that cuts out a lot of the natural light leaving only mid afternoon light able to penetrate into the space. This space is completely different in orientation and height to the first space however the automated lighting control system is the same.

The measurements were taken at an empty desk next to the atrium. Figure 19 shows the illuminance measurements, while Figure 20 shows the measurements without the high values from the window readings. It can be seen that the shape of Figure 20 is similar to Figure 19 however Figure 20 values are $10 \%$ of those recorded at the window.

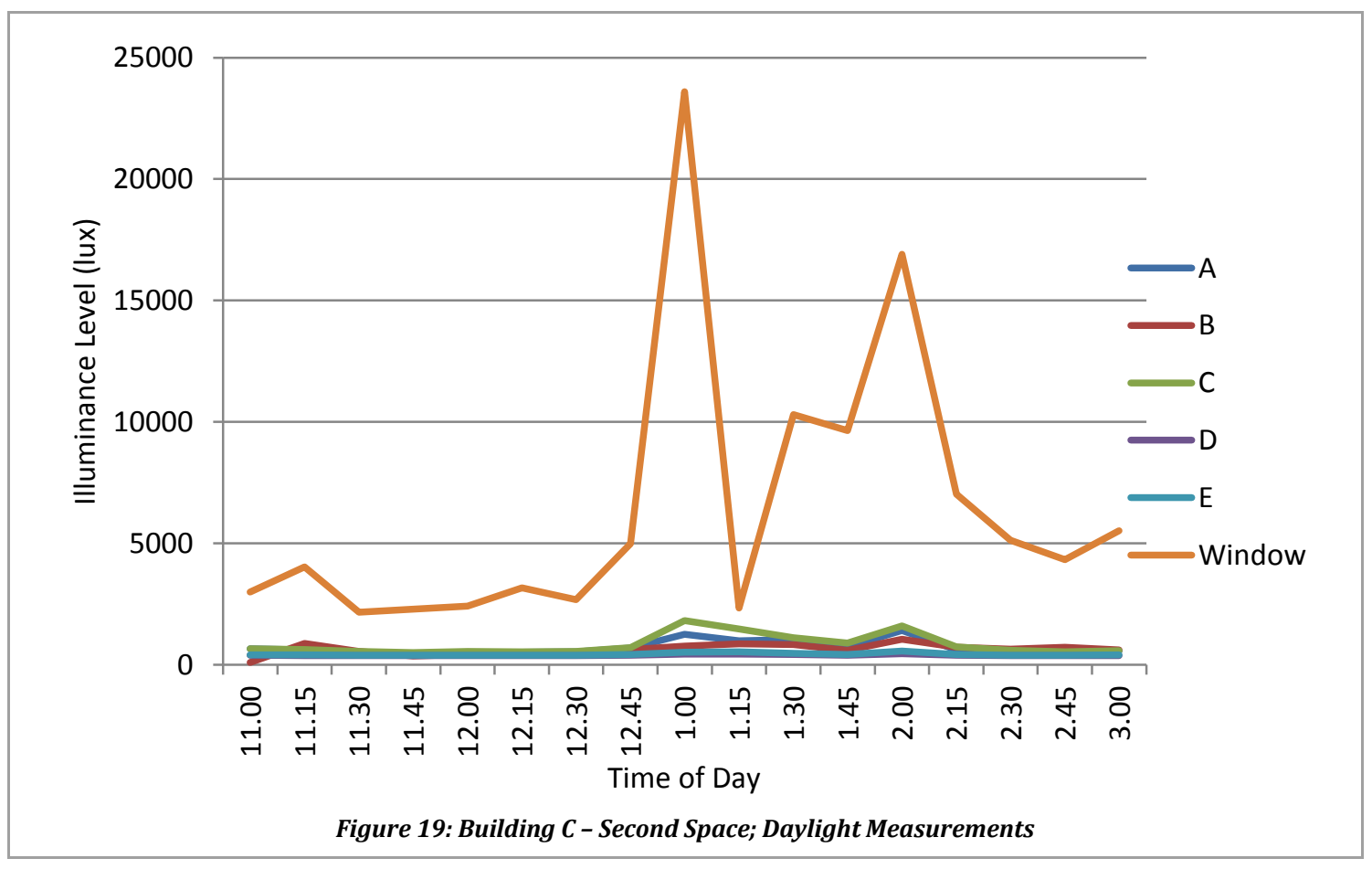




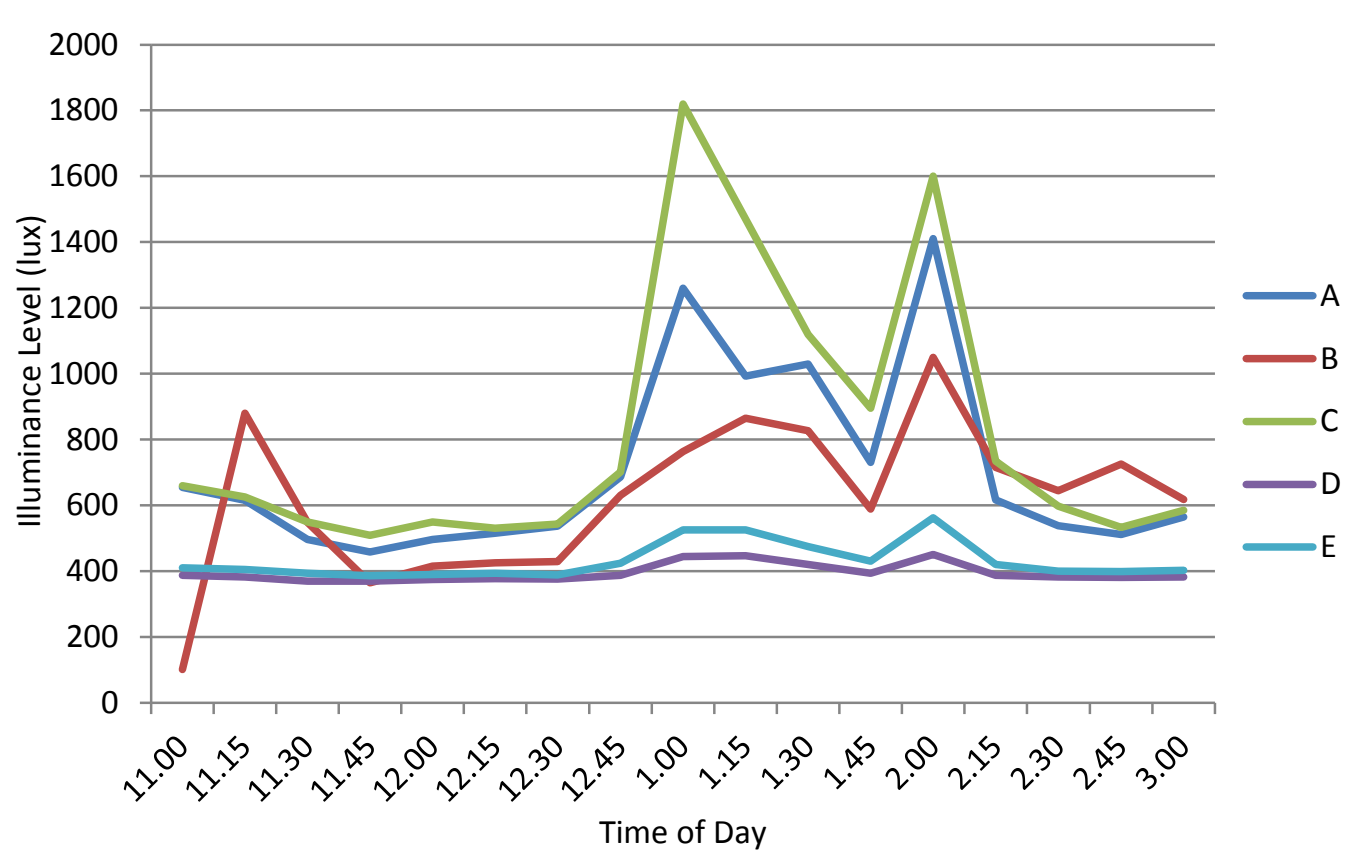

Figure 20: Building C-Second Space; Daylight Measurements with Window Measurements subtracted

Comparing Figure 18 to Figure 20 demonstrates how different the lighting levels will be in both spaces during the detailing measuring. It was during the observations in Building $\mathrm{C}$ that it was decided to place monitoring equipment directly under the lamp in order to record its output to ensure that the amount of light coming from the lamps matched the power use.

\section{Selected Spaces - Equipment in Each Space}

Building $C$ is situated awkwardly on an irregular site between other buildings which gave the opportunity to measure two completely different spaces within the same building. There is a large central atrium and high floor to ceiling windows that provides most of the building occupants with natural light. There is a high occupant to floor area ratio (approximately 1 person per $4 \mathrm{~m}^{2}$ ). The automated daylight control system within this building was installed during a recent retrofitting exercise completed within the last three years. There is a large 10 storey building on the north side of this building which limits the availability of natural light. Spaces in this building are often lacking in natural light, as buildings and trees block out light at different times of the day and of the year. 


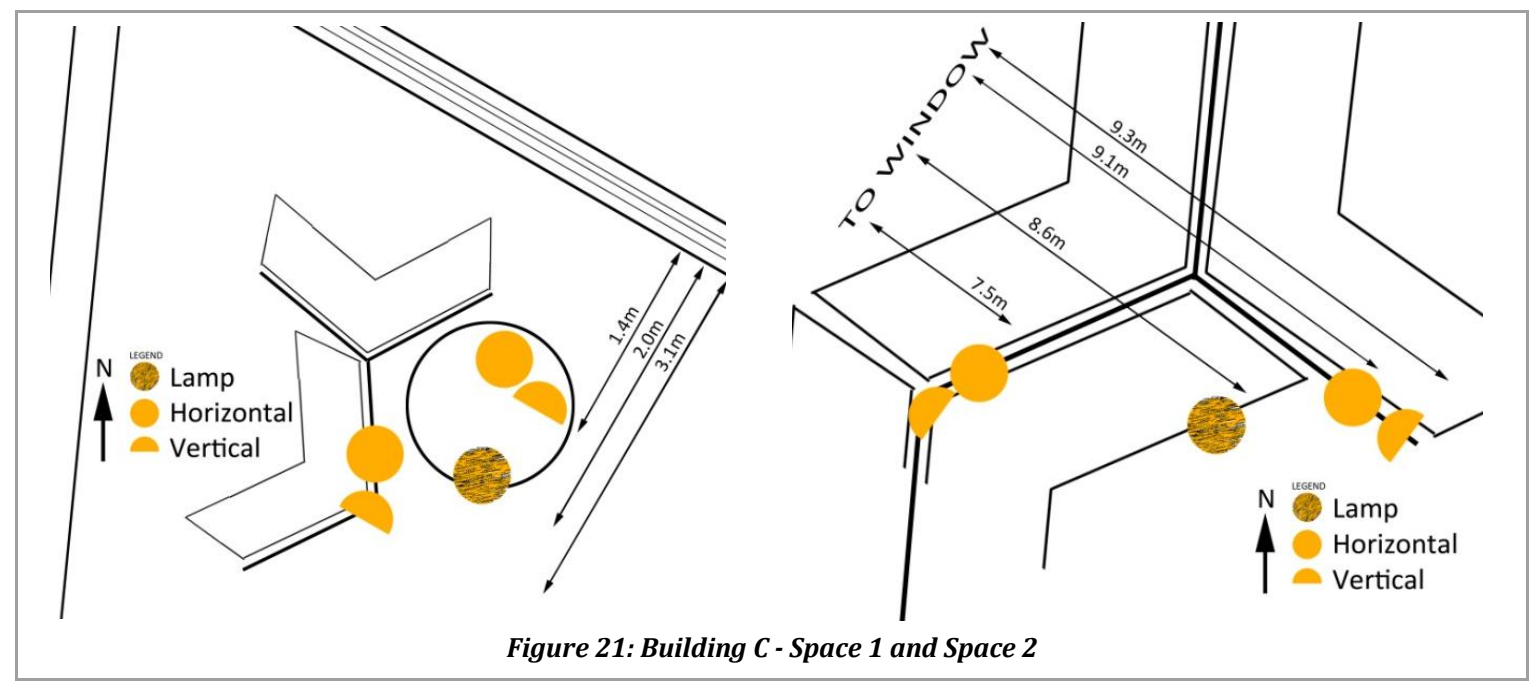

\begin{tabular}{|c|c|c|c|c|c|c|}
\hline & \multicolumn{2}{|c|}{ Distance to Window } & \multicolumn{2}{|c|}{ Distance to Wall } & \multicolumn{2}{|c|}{ Height from Floor } \\
\hline Illuminance Sensor & Space 1 & Space 2 & Space 1 & Space 2 & Space 1 & Space 2 \\
\hline Lamp & $2.0 \mathrm{~m}$ & $8.6 \mathrm{~m}$ & $3.0 \mathrm{~m}$ & - & $2.7 \mathrm{~m}$ & $2.7 \mathrm{~m}$ \\
\hline Close Horizontal & $1.4 \mathrm{~m}$ & $7.5 \mathrm{~m}$ & $3.5 \mathrm{~m}$ & - & $0.6 \mathrm{~m}$ & $1.4 \mathrm{~m}$ \\
\hline Close Vertical & $1.4 \mathrm{~m}$ & $7.5 \mathrm{~m}$ & $3.5 \mathrm{~m}$ & - & $0.6 \mathrm{~m}$ & $1.4 \mathrm{~m}$ \\
\hline Far Horizontal & $3.1 \mathrm{~m}$ & $9.1 \mathrm{~m}$ & $2.0 \mathrm{~m}$ & - & $1.4 \mathrm{~m}$ & $1.4 \mathrm{~m}$ \\
\hline Far Vertical & $3.1 \mathrm{~m}$ & $9.3 \mathrm{~m}$ & $2.0 \mathrm{~m}$ & - & $1.4 \mathrm{~m}$ & $1.4 \mathrm{~m}$ \\
\hline
\end{tabular}

Figure 22 describes the positions of the illuminance sensors of Spaces 1 and 2 in relation to the window, wall and floor while Figure 23 describes the orientation.

\begin{tabular}{|l|c|c|}
\hline & Space 1 & Space 2 \\
\hline Vertical Height & $6.0 \mathrm{~m}$ & $9.0 \mathrm{~m}$ \\
\hline Directional Facing & $45^{\circ}$ North East & $295^{\circ}$ West North West \\
\hline Surrounding Buildings & Low level, city centre & Light confined by alleyway \\
\hline \multicolumn{2}{r}{ Figure 23: Orientation of Detailed Monitoring Spaces } \\
\hline
\end{tabular}

\section{Daylight Control System Information}

The automated daylight control system that is installed has DALI ballasts with a C-Bus ${ }^{\circledR}$ control system which allows it to dim or turn on/off any light. This building has an extensive array of sensors installed. For Space 1, the daylight sensors are placed at $1.0-2.0 \mathrm{~m}$ above the desks and are approximately $2.0 \mathrm{~m}$ from the windows. For Space 2, due to its position next to the atrium, the nearest sensor was $9.0-10.0 \mathrm{~m}$ away from the window. The sensors are both PIR occupancy and daylight sensors. 
3.3.4 Building D - Information

\begin{tabular}{|l|l|}
\hline Total Storeys & 4 \\
\hline Type of System & Thorn Sensa DSI ${ }^{\circledR}$ \\
\hline Observation Day & $04 / 06 / 11$ \\
\hline Measuring Period & $29 / 11 / 11-16 / 12 / 11$ \\
\hline
\end{tabular}

Due to the nature of the daylight control system and the small offices that were chosen for monitoring, it was considered unnecessary to conduct a day long observation study in Building D. Only levels 1 and 2 (of 4 levels in total) were fitted with an automated daylight control system. Level 1 was set out as a large teaching or seminar room, while level 2 around the perimeter was divided into five private offices. It was not possible to leave the measuring equipment for long periods in the larger rooms on level 1 due to the lack of security and the potential of equipment being tampered with. Monitoring was limited to the five offices on level 2 where two of the occupants were able to assist. This four storey building is situated between two adjacent buildings, blocking the north and south facades. This leaves only the east and west facades able to receive natural light.

Space 1 - This space is a corner office with a corner window which gets daylight from the north-east direction. The exterior wall has a window that is half of the wall (vertically) and spreads the whole way across (horizontally). Only one person occupies this space.

Space 2 - Similar to Space 1, this space is positioned directly beside Space 1 but does not have a corner window. It has a similar exterior wall with the window stretching the width of the office. Only one person occupies this space.

\section{Selected Spaces - Equipment in Each Space}

From observation, it appears that both spaces receive more skylight rather than sunlight due to their orientation. In addition because there are no surrounding buildings or trees on the east, both spaces benefit from the morning sun and then have only skylight for the rest of the day. 


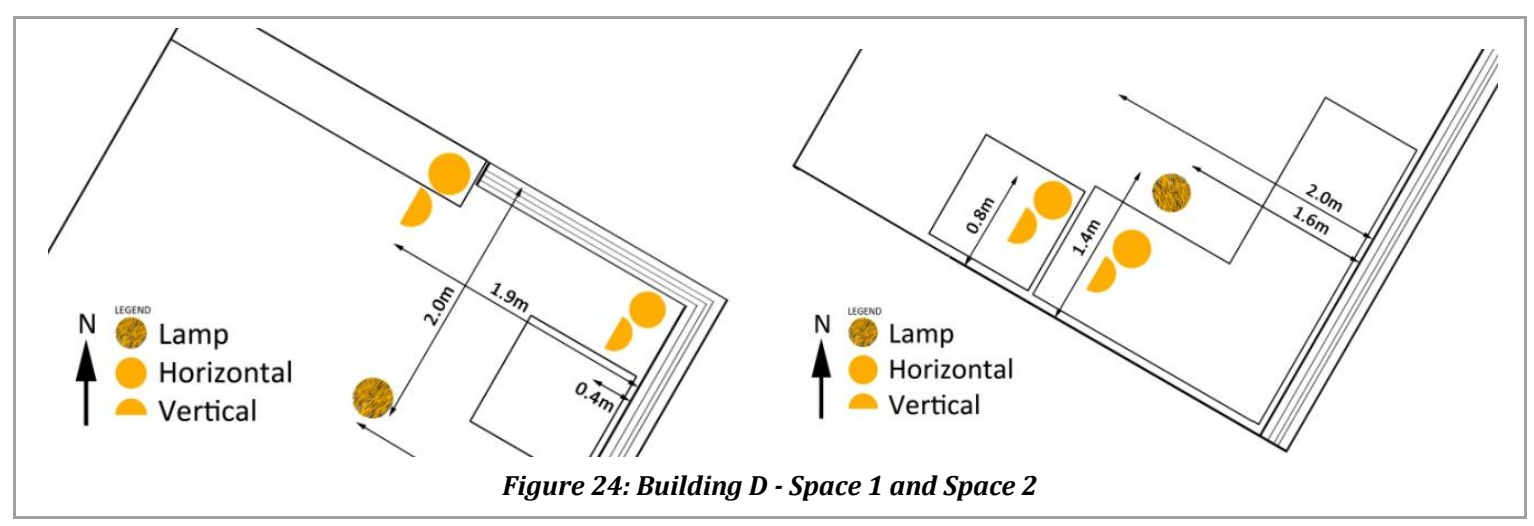

\begin{tabular}{|l|c|c|c|c|c|c|}
\hline & \multicolumn{2}{|c|}{ Distance to Window } & \multicolumn{2}{c|}{ Distance to Wall } & \multicolumn{2}{c|}{ Height from Floor } \\
\hline Illuminance Sensor & Space 1 & Space 2 & Space 1 & Space 2 & Space 1 & Space 2 \\
\hline Lamp & $1.4 \mathrm{~m}$ & $1.6 \mathrm{~m}$ & $2.0 \mathrm{~m}$ & $1.4 \mathrm{~m}$ & $2.6 \mathrm{~m}$ & $2.6 \mathrm{~m}$ \\
\hline Close Horizontal & $0.4 \mathrm{~m}$ & $1.6 \mathrm{~m}$ & $0.4 \mathrm{~m}$ & $0.8 \mathrm{~m}$ & $1.2 \mathrm{~m}$ & $0.7 \mathrm{~m}$ \\
\hline Close Vertical & $0.4 \mathrm{~m}$ & $1.6 \mathrm{~m}$ & $0.4 \mathrm{~m}$ & $0.7 \mathrm{~m}$ & $1.2 \mathrm{~m}$ & $0.7 \mathrm{~m}$ \\
\hline Far Horizontal & $1.9 \mathrm{~m}$ & $2.0 \mathrm{~m}$ & $0.2 \mathrm{~m}$ & $0.8 \mathrm{~m}$ & $0.6 \mathrm{~m}$ & $1.3 \mathrm{~m}$ \\
\hline Far Vertical & $1.9 \mathrm{~m}$ & $2.0 \mathrm{~m}$ & $0.25 \mathrm{~m}$ & $0.7 \mathrm{~m}$ & $0.6 \mathrm{~m}$ & $1.3 \mathrm{~m}$ \\
\hline
\end{tabular}

Figure 25 describes the positions of the illuminance sensors of Spaces 1 and 2 in relation to the window, wall and floor, while Figure 26 describes the orientation.

\begin{tabular}{|l|c|c|}
\hline & Space 1 & Space 2 \\
\hline Vertical Height & $8.0 \mathrm{~m}$ & $8.0 \mathrm{~m}$ \\
\hline Directional Facing & $115^{\circ}$ East South East & $115^{\circ}$ East South East \\
\hline Surrounding Buildings & None in east direction & None in east direction \\
\hline \multicolumn{2}{|r}{ Figure 26: Orientation of Detailed Monitoring Spaces } \\
\hline
\end{tabular}

\section{Daylight Control System Information}

The automated daylight control system is a Thorn Sensa DSI ${ }^{\circledast}$ system with PIR sensor. The sensors for this system were placed approximately $2.0 \mathrm{~m}$ away from the windows.

Unlike the other three buildings which are open plan offices with many people in each of the spaces, these two spaces are personal offices with only one occupant per space. This may result in a higher use of the blinds as each occupant does not have to consider anyone else's comfort.

A complication with the measuring of the lighting circuits in each space was that even though Space 1 and Space 2 were each on separate lighting circuits, each circuit was connected to other offices (as illustrated in Appendix Two). Each of the connected offices in both circuits have occupancy sensors, but only the corner office of Space 1 has daylight control, while all of the offices connected with Space 2 have both occupancy sensors and daylight control. 


\subsection{Summary}

During an observation day in each of the four research buildings, information was gathered on appropriate positions for placement of the measuring equipment. Illuminance measurements were also taken and some aspects of occupant behaviour were understood. These lessons were implemented into a methodology for the detailed measuring period.

Monitoring location - It was decided that the illuminance sensor should be placed next to the window in line with where people sit and in line with the automated daylight control system sensors. Having enough natural light present in the space to activate the sensor is all that is required.

Daylight dimming - It was hard to detect if the lamps were dimming in response to daylight availability by observations alone, except when dimmed very low. In all four buildings during the initial observations, the human eye was used to detect if the lighting controls were working. This was harder than first anticipated, as the daylight control system dims the lamps at such small increments that over a short period the change is undetectable. Only in Building C was it obvious that the lamps were dimmed as this was the only time during all the observation days that there was enough daylight to significantly reduce the power to the lamps. The level of control was obvious with high external illuminance levels, as the reduced output lamps produced a purple tint and were visibly less bright. This suggested that it is important to place an illuminance sensor directly under a lamp to ensure they are dimming at the same time the power is being measured. Researchers have found that when fluorescent tubes are dimmed, their light tends to appear 'more purple' at lower levels (Karlen \& Benya, 2004 , p. 8). From these observations it was concluded that although the human eye is a valuable instrument, illuminance sensors would be required to quantify the automated daylight control system performance and quantify small changes (Lamp position).

Occupant satisfaction - One of the most important aspects realised from the observation days was the importance of occupant satisfaction and comfort. A Post Occupancy Evaluation survey was used to measure self-assessing factors such as comfort, health and productivity that can only be rated by those who occupy the building.

Measurement period - Measurements at 15 minute increments can be achieved with hand held instruments and give an overall view of how much light is within a space. However, the advantage of data loggers is the ability to measure at one minute increments to provide more detailed information that will be used to assess the point of change of each system. 
After the initial pilot study and observation days were completed, calibration of the illuminance sensors and obtaining appropriate data logger software to record sensor outputs was completed (see Section 4.2). 


\subsection{Methodology}

As highlighted in the literature review Chapter 2.0, there are two types of approaches used when investigating automated daylight control systems. The first approach uses surveys while the second investigates the physical properties and energy savings. This research uses a combination of both. This dual approach evaluates the automated daylight control systems through actual savings as well as environmental aspects rated by occupants. This allows the researcher to understand the overall savings as well as the benefits and disadvantages perceived by the occupants.

The following Sections describe the locations of the four buildings selected, list the monitoring equipment used, explains the on-site measuring activities and details how the analysis was carried out. The occupant survey is discussed in Chapter 5.0, and the results in Chapter 6.0.

\subsection{Location}

Four buildings were selected as they met the criteria required for this research. The criteria for selection are listed below;

- Located in Wellington,

- Have a working automated daylight control system in a north facing area of the building,

- Willing to install monitoring equipment for a set period of time,

- Have occupants willing to complete a survey,

- Have information on each building and its system.

As discussed in Chapter 3.0, within each building two spaces were chosen for analysis. Each space was located on the north, east or west facades near windows on available desks. As highlighted in the initial pilot study the southern facade was not appropriate for measuring as the light entering from this direction is constant. This study therefore used the dynamic light from the north as this would prove a better test over a short period of measuring. Each of the chosen spaces were positioned as far away as possible from each other. This allowed for a better understanding of occupant behaviours and needs, whilst measuring the effect of obstructions on the automated daylight control system's performance. 


\subsection{Monitoring Equipment}

To measure the physical aspects of automated daylight control systems, both illuminance and electricity usage had to be monitored and the data recorded. Ten illuminance sensors were obtained and calibrated, as well as two power meters, two data loggers and two laptops. To measure two spaces the equipment was split into two sets. Details of the calibration process can be found in the first part of Appendix Three, while a list of the equipment and its detailed information can be found in the following parts of Appendix Three.

- Introduction: Information on VUW's - School of Architecture's Lighting Lab,

- (a): HIOKI 3423 Calibration Certificate,

- (b): HIOKI 3423 Corrections \& Uncertainties,

- (c): Information on the Hewlett Packard 34401A Multimeter,

- (d): LI-Cor LI-210SA Photometric Calibration Certificates,

- (e): LI-Cor LI-210SA General Information,

- (f): Spectral Response of HIOKI and LI-Cor illuminance sensors,

- (g): HOBO Power meter information.

\subsection{Methodology Test}

Once the illuminance sensors were calibrated and suitable data logging software was purchased, the equipment was set up in a university office on $0.7 \mathrm{~m}$ high desks in a north facing office next to the window and left to run for 10 days. The illuminance sensors were placed in different areas both close to and far from the windows and walls to obtain a range of lighting levels and to understand how the surroundings might affect the sensors. The recordings were checked periodically to ensure both the sensors and data logging computer software were working correctly.

Once the equipment was working correctly the equipment was placed into a selected research building for five days using the proposed methodology. This further tested the methodology and provided an understanding of equipment installation, including the setup and checking time, the disruption to occupants nearby and any other equipment needed to fasten cords and mount sensors. While this equipment arrangement is commonly used for this type of research, this particular array of equipment had not been used together before on site. During this onsite test, only the illuminance sensors were used as the BEES power monitoring meter with built in data logger required installation by a qualified electrician. 


\subsection{0n-site Measurements}

In each building the two selected spaces had empty desks where measuring equipment could be set up with minimal disruption. Both spaces investigated in all of the four buildings were orientated north, east or west (not south) as explained in the first pilot study. The two sets of measuring equipment were placed in different locations to see how obstructions and occupants affect the automated daylight control system. There were some slight position changes from the spaces chosen during the observation day measurements to the actual measuring due to desks being either re-occupied or the original positions were found to be unsuitable for monitoring.

For the on-site measurements, two (of a total of 5 sensors per space) of the illuminance sensors were placed facing upward (horizontal position), and two were placed vertically facing towards the exterior window. The vertical sensors were attached to a small L-shaped holder, illustrated in Figure 27. The fifth illuminance sensor was hung just below a lamp to record when the lamp was dimming to make sure this was consistent with the power meter readings.

The performance of the automated daylight control system sensor can be altered and adjusted during the commissioning process. This is a vital part of the design process as "photosensor signals should represent workplane illuminance in the space, but the location and spatial response of photosensors mounted on the ceiling affect their accuracy. Therefore, the optimal location and spatial response are a very critical point in photosensor system design" (Choi et al., 2005, p. 40). According to the research by Choi et al. (2005, p.48), sensors located at $2.4 \mathrm{~m}$ and $3.4 \mathrm{~m}$ from the window are the best positions to record horizontal illuminance levels. Therefore one pair of illuminance sensors (one horizontal and one vertical) were placed close to the window to react to direct light and the extremes of the day. The other pair were placed further into the room close to the location of the automated daylight control systems sensor. A schematic depiction of this layout is given in Figure 27 below. 


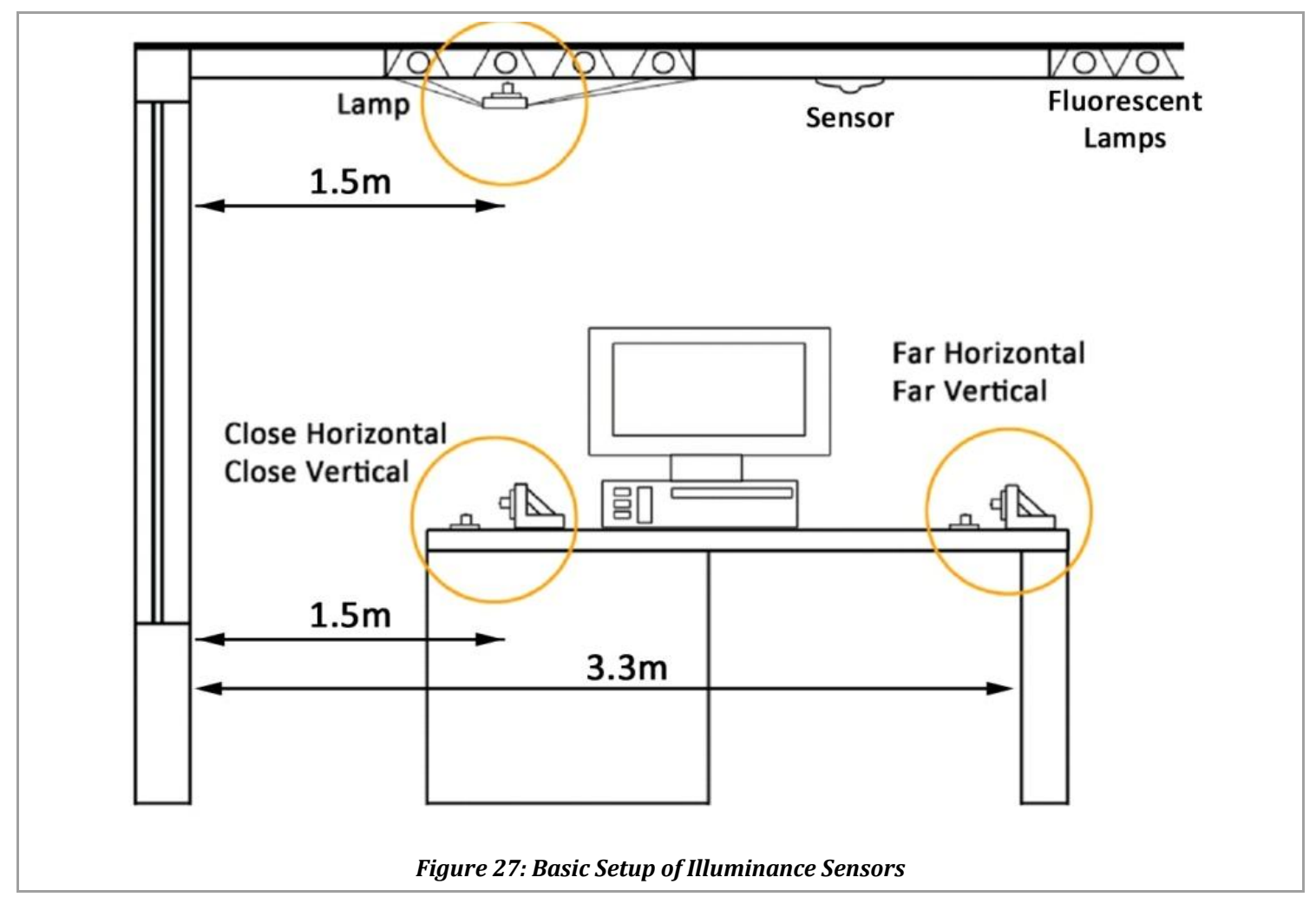

Power meters, with built-in data loggers, were attached to the two lighting circuits (one for each space) by a qualified electrician, employed as part of the overall BEES research. The illuminance meters recorded the electricity use for each monitored circuit once every minute. The data loggers recorded the power use in milli-Volts $(\mathrm{mV})$. For this research only the shape of the power graph was required for comparison with the illuminance meters, so a conversion from $\mathrm{mV}$ was not required.

\subsection{Physical Equipment Data Analysis}

Once the data was downloaded from the data loggers, it was placed into spreadsheets to be organised and analysed. Five graphs were produced for each day for each space (ten graphs in total for two spaces). Each graph showed the power in the circuit and the illuminance level for each sensor. This information was then produced as a visual depiction of how the automated daylight control system operated for each day. The example below in Figure 28 shows a working automatic daylight control system where the power reduces as the illuminance levels increase. 


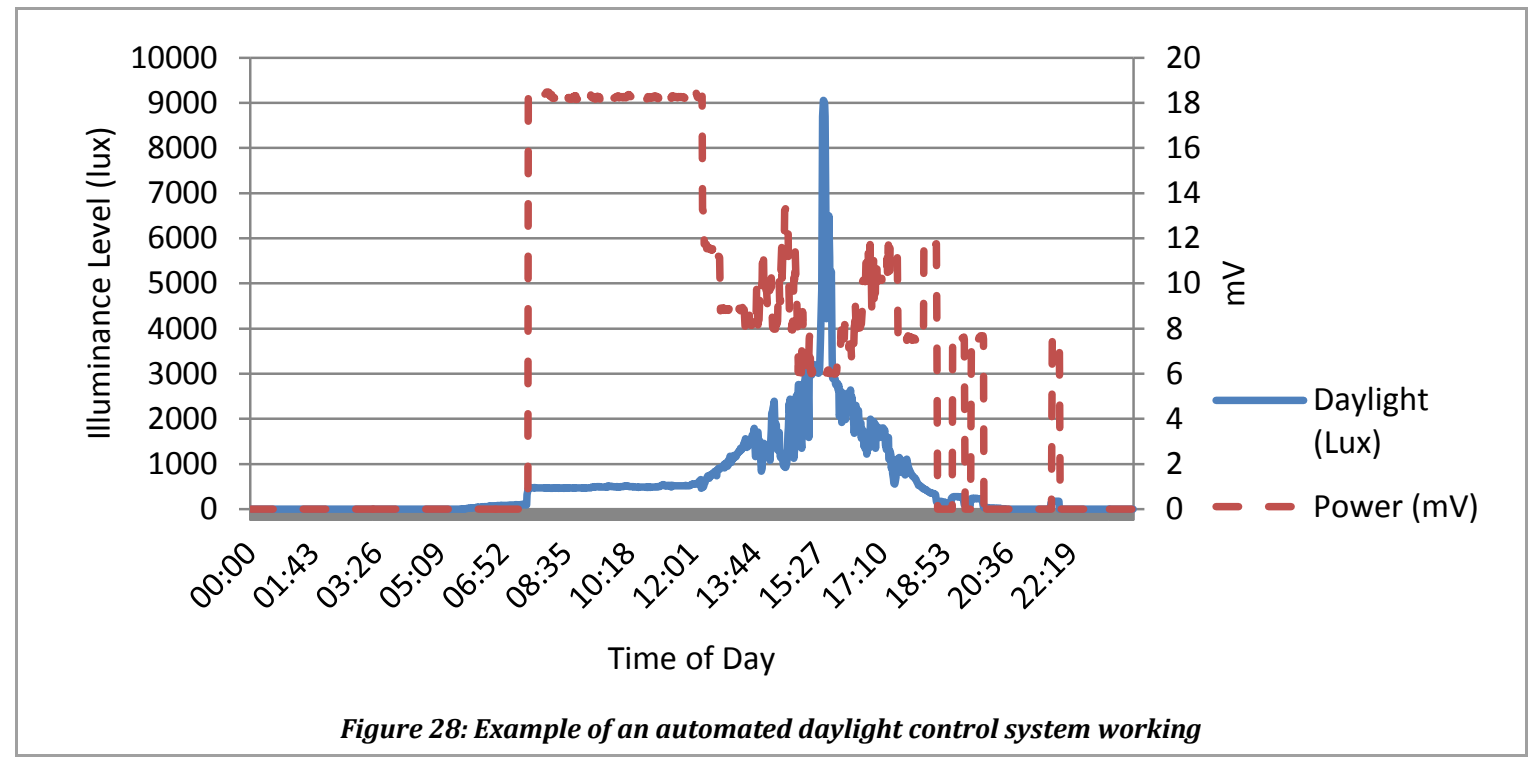

Each illuminance sensor creates a different graph depending on its location and orientation but the power use is the same for each of the sensors as all illuminance sensors were measuring lighting on the same circuit. From these graphs the peak power consumption can be calculated using the equation given in Figure 34. Once the total energy savings for each day were calculated, the information was separated into three time divisions to quantify the influence of the automated daylight control system. This was achieved automatically by formulas placed into each spreadsheet to calculate the savings overall (24/7), for a standard working day (9:00am to 5:00pm) and only when the power was on (Power On). 'Power On' was manually calculated based on the time the power was turned on in the morning until it was turned off at the end of the day. All three categories are depicted schematically in Figure 29 below. 


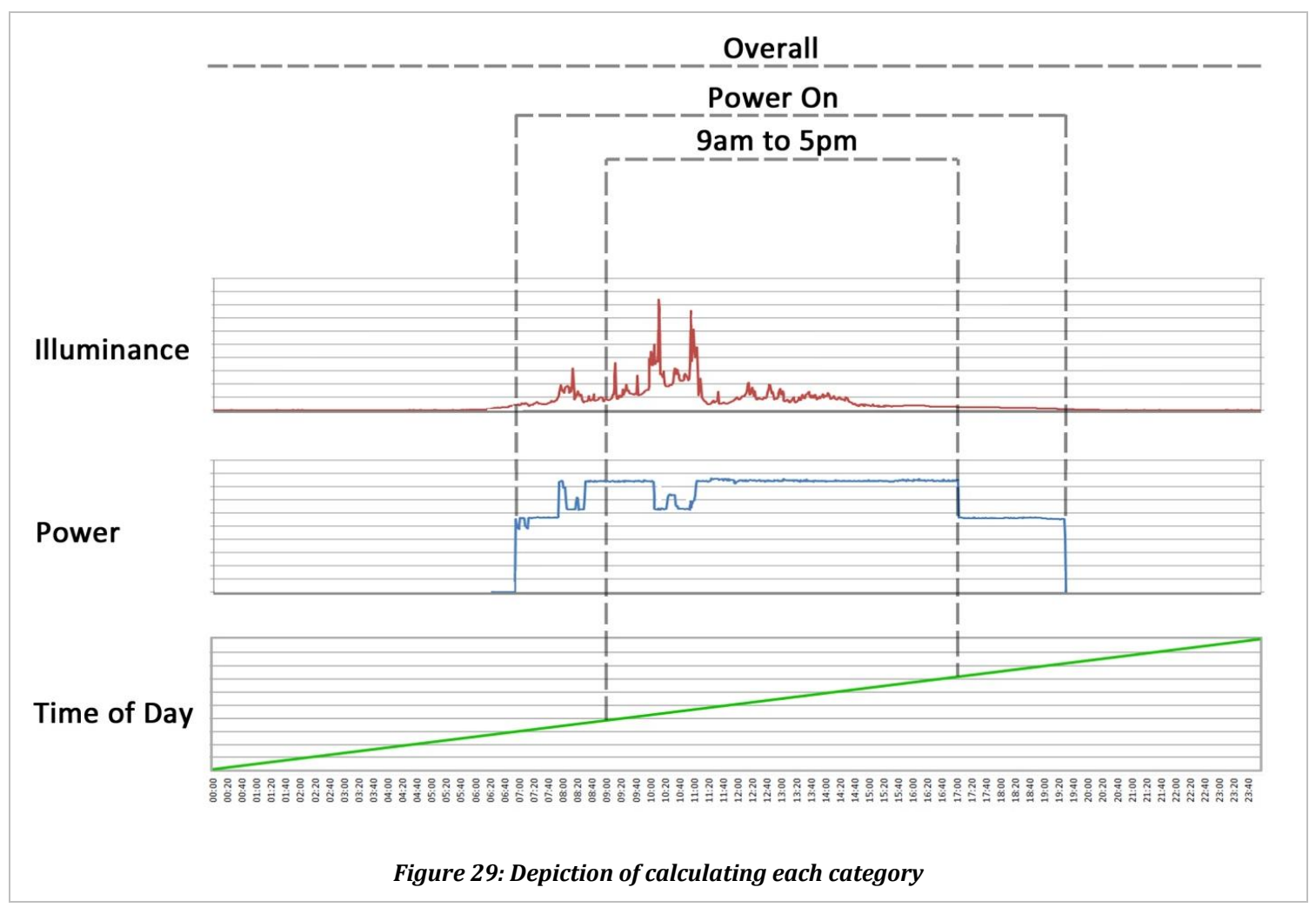

\subsection{Calculating Energy Savings}

In order to quantify the amount of savings each building is achieving, each day of data must be calculated. It was established that three different time periods were to be measured to understand how a building manager may obtain the same information. The below Figure 30 is a visual depiction of how each day was calculated for each space. The black line at the top of the graph indicates the maximum power usage. The diagonal cross hatch represents the amount of energy being saved, while the red area is the amount of power consumed. The entire cross hatch is the overall savings for a 24 hour period while the cross hatch between the solid vertical lines is the amount of savings for a standard working day 19:00am to 5:00pm). The area between the dashed vertical lines is the manually calculated amount of energy for the time the power is on. The power on calculation was used to illustrate times when occupants stayed in the building longer than a standard day therefore increasing the overall energy output. 


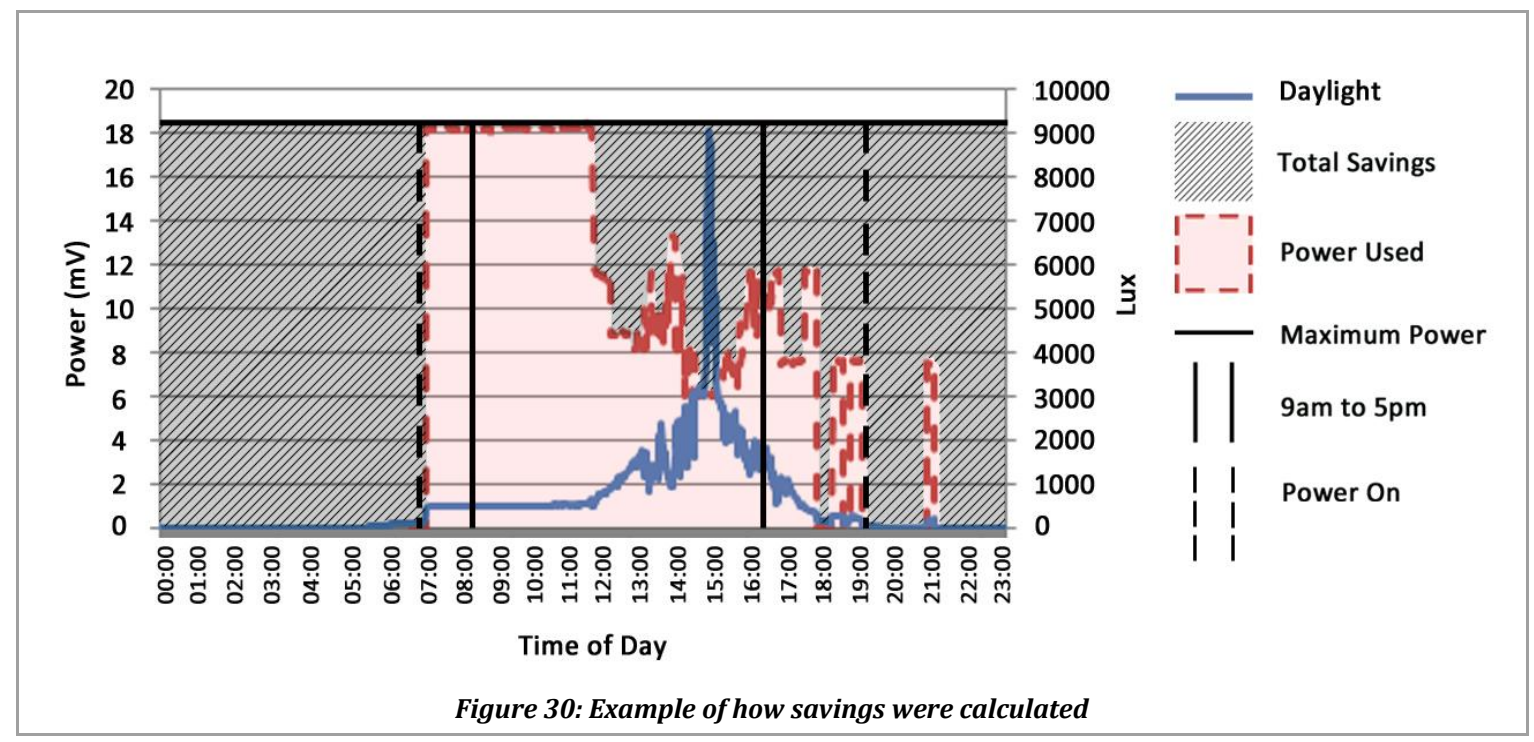

The purpose of automated daylight control systems is to utilise the natural light throughout the day instead of using electricity to power artificial lighting. Examples of different lighting setups, two with automated daylight control systems installed and one without are illustrated below. The images below have been produced as examples to show the difference in savings between having an automated daylight control system and having a standard lighting system. The lux levels for all examples are representative of a mixed sunny/cloudy day.

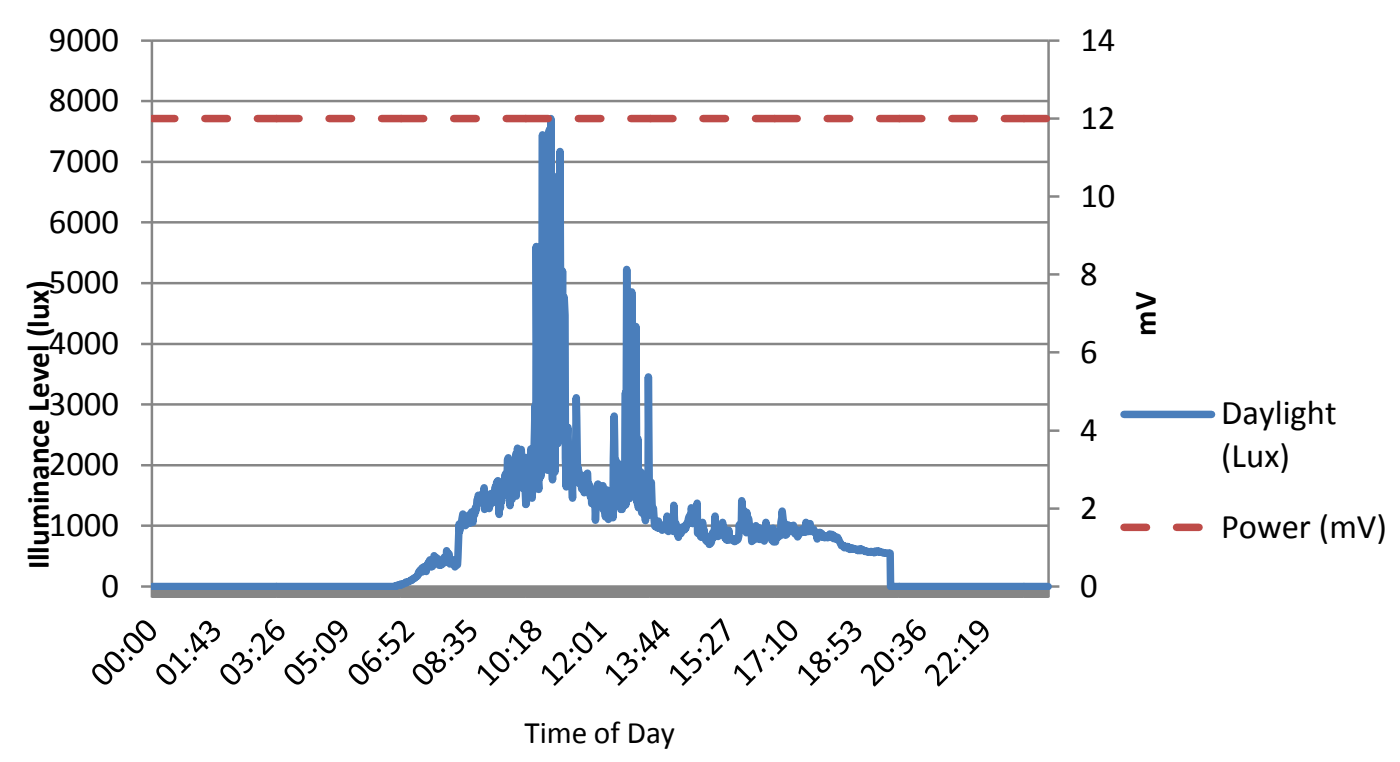

Figure 31: Example 1; Typical Day with lighting on constantly 
Figure 31 (Example 1) shows a lighting circuit that is left on all day and all night (power use shown by dotted red line - note the units are as reported by the data logger, and not converted to actual electricity (kW) use). This is common in buildings that have 24 hour uses, such as emergency services, call centres or buildings with high security. If this building is not used for these purposes and the lights are just left on then there is a large amount of wasted electricity. As tabulated in Figure 35 , as the lights are not controlled by the availability of daylight, there are no savings.

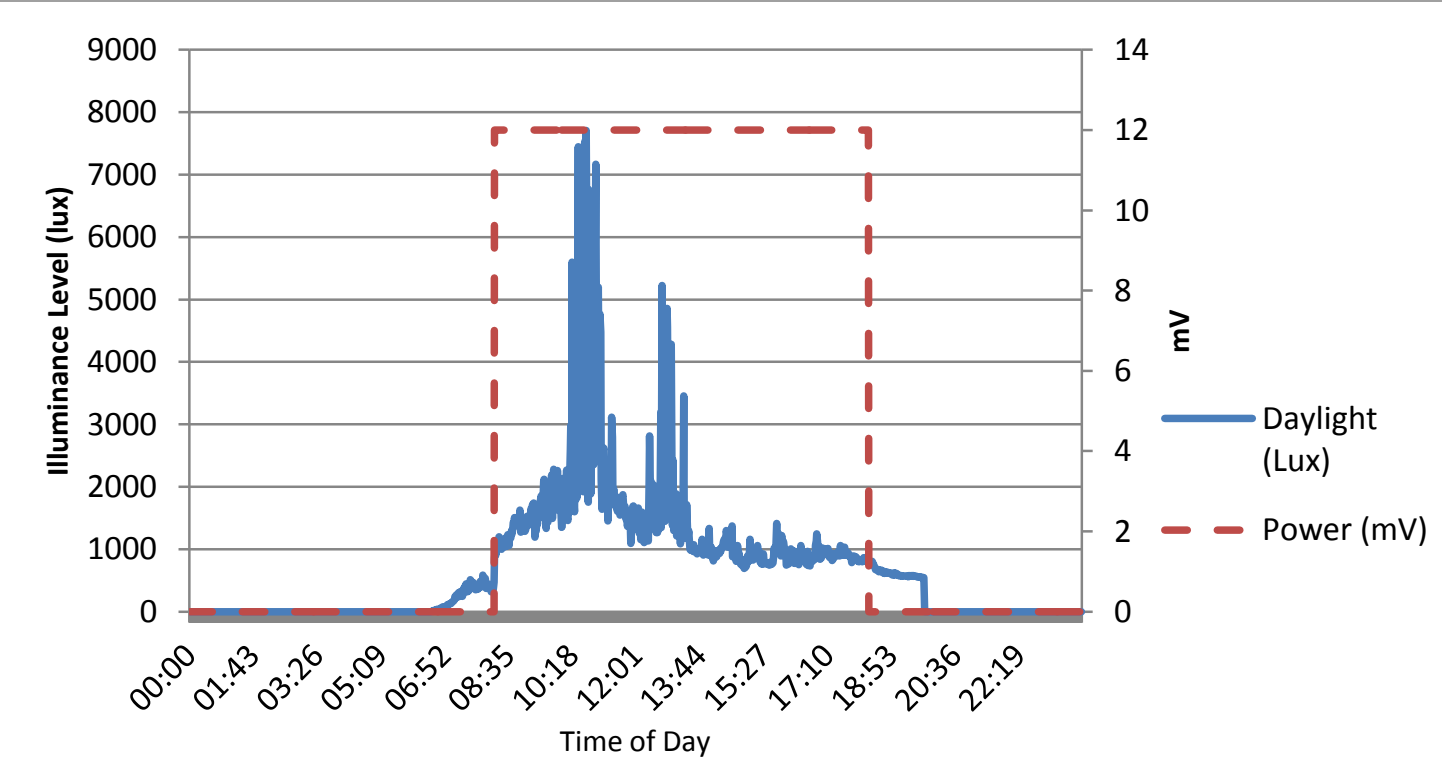

Figure 32: Example 2; Typical Day with manual switching

The example of Figure 32 (Example 2) shows what the energy used by a lighting circuit would more commonly look like, with the lighting circuit switched on at 9.00am and off at $6.00 \mathrm{pm}$. This could be an entire floor that is controlled by a main switch which is manually turned on by whoever comes first into the building and then off by the last person to leave. This is a very common office lighting setup but is still an inefficient practice as further discussed in research conducted by the Energy Research Group; "If a daylighting system is to produce energy savings it is important that artificial lighting is not switched on as long as daylight is providing adequate illumination. For example, it is common practice for large numbers of luminaires in a workspace to be controlled by one or two banks of wall-mounted switches located near the doorways. The first person arriving early on a dark winter morning will switch on all the lights. As the day brightens it is likely that no one will notice that the lights are still on or, if they do, bother to switch them off" (Energy Research Group, 1994, p. 12). 


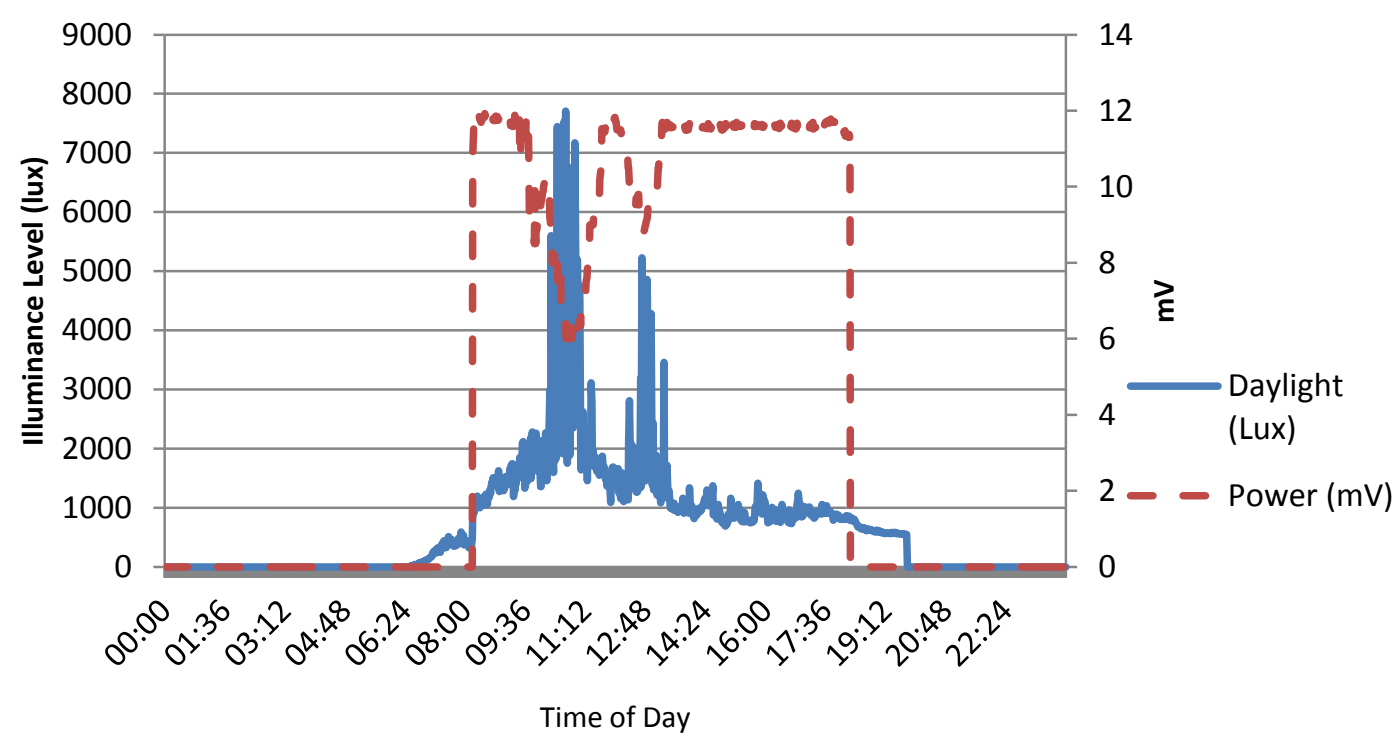

Figure 33: Example 3; Typical Day with an automated daylight control system

Once an automated daylight control system is installed, as shown in the Figure 33 above (Example 3), the power is reduced when daylight is detected by the sensor which reduces the artificial lighting while maintaining a constant set level of illuminance. For this particular example, the point of change is set at 1,000 lux. The percentage of saving will ultimately be determined by this value, as the higher this set point is, the less overall savings there will be.

The energy savings were calculated by taking the highest point of electricity used for the day, and then subtracting anytime the actual value was lower to find the difference. The differences are then totalled and averaged to find the overall saving percentage for each day. These savings were calculated by using the formula in Figure 34 below, where: $A(\max )$ is the highest $\mathrm{mV}$ reading for the 24 hour period, $\mathrm{A}$ is the $\mathrm{mV}$ reading at each minute interval, leaving a difference of $B$. By taking $B$ and dividing it by $A(\max )$, the percentage of total power is given. This formula was completed for every minute of each day that was measured to calculate the daily overall savings. This is visually depicted in Figure 30.

$$
\begin{aligned}
& A(\max )-A=B \\
& B / A(\max )=\%
\end{aligned}
$$

Figure 34: Saving Percentages Formula

Figure 35 shows the savings from each of the three examples above, which clearly illustrates the benefits of having an automated daylight control system. Example 1 uses the most electricity as the lights are always on. Example 2 assumes the lights are on from 9.00am to 
$6.00 \mathrm{pm}$, as would be the case for general office buildings. Compared to Example 1 (24/7), there is a saving of $54 \%$ by having the lights turned off during the night when no one is using the building.

There are further savings opportunities when using an automated daylight control system, as seen in the difference between Example 2 (Figure 32) and Example 3 (Figure 33) which by utilising natural light results in a further $12 \%$ saving and $66 \%$ overall.

\begin{tabular}{|l|c|c|c|}
\hline & Example 1 & Example 2 & Example 3 \\
\hline $\mathbf{2 4 / 7}$ & $0 \%$ & $54 \%$ & $66 \%$ \\
\hline $\mathbf{9 - 6}$ & $0 \%$ & $0 \%$ & $12 \%$ \\
\hline Power 0n & $0 \%$ & $0 \%$ & $9 \%$ \\
\hline \multicolumn{3}{|c|}{ Figure 35: Saving Percentages of Examples } \\
\hline
\end{tabular}

The 'Power On' times are generated manually by investigating each graph individually and assessing the time that the power was on during the day. This does not take into account times during the night when the lighting power is switched on. The 9.00am $-5.00 \mathrm{pm}$ time bracket has been used in this study as a standard working day, and shown in Figure 30 by the dashed vertical lines. This nominal value of an 8-hour working day, as referenced by the Department of Labour (Department of Labour - New Zealand Government, 2013) has been used in this study as a standard working day because a standard full time job as described by the Department of Labour is a 40 hour week.

An automated daylight control system will operate as soon as the daylight sensor reads that the minimum lux level to activate, then the artificial lights will dim accordingly. It does not have to be direct sunlight for this to happen, as shown in Examples 4 and 5, displaying an overcast day and a clear day, where both have the ability to save energy. 


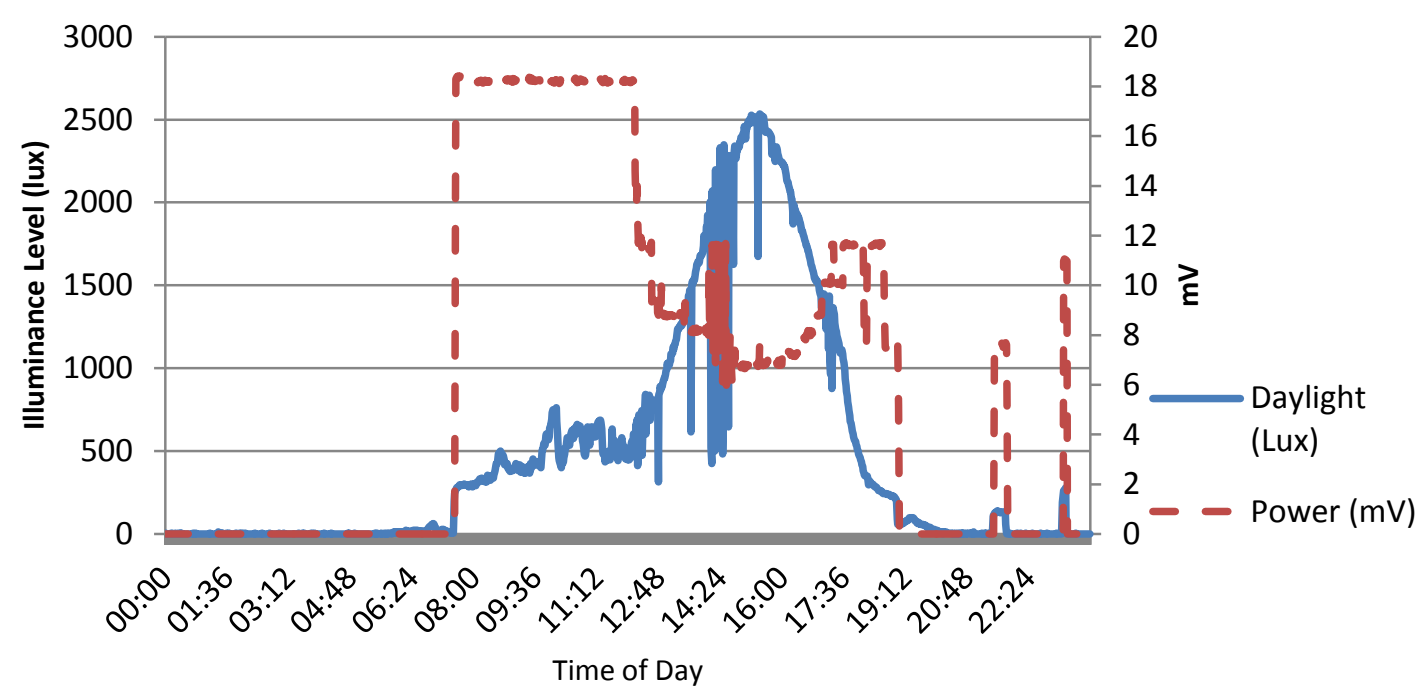

Overall; $66 \%$

9:00am-5:00pm; 34\%

Power On; 32\%

Figure 36: Example 4; Overcast day

For the overcast day example in Figure 36, there was a maximum illuminance level of 2,500 lux. The 'point of change' is set at 1,000 lux. Overall there is a saving of $66 \%$ with a saving throughout the standard working day of $34 \%$ and $32 \%$ savings from when the power was on during the day, in this case from 7:15am to 7:00pm.

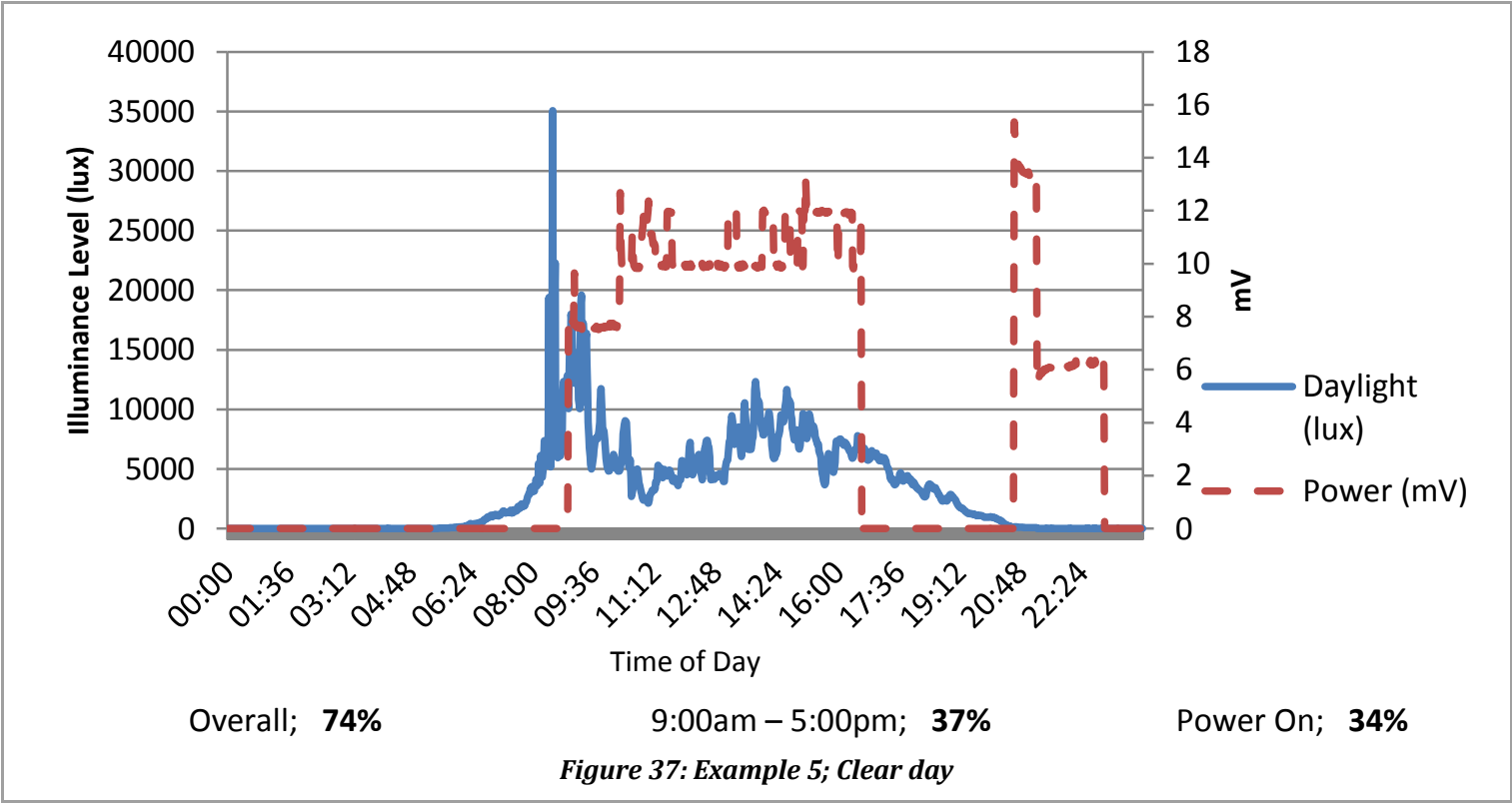

Compared to the overcast day in Figure 36 (Example 4), Figure 37 (Example 5) displays a clear day where direct sunlight is present and similar savings are achieved - 34\% on an overcast day compared to $37 \%$ on a clear day, during a standard working day. This comparison shows that overall cloud cover and a clear blue sky can both produce high enough lighting levels for an automated daylight control system to be effective. 
Depending on the position of the sensor, the orientation of the building and its position with regard to surrounding buildings and obstructions, it is not always possible to obtain full daylight in a building. In the example above (Figure 37), sunlight is only available for the early part of the morning before it is blocked by surrounding buildings, leaving only skylight and reflections off buildings to get natural light into a building. With varying building shapes, sizes and surroundings as well as variations from one system to the next, highlighted by Reinhart and Selkowitz, there are many issues and considerations that must be made to have a system working correctly and at its optimum:

Once the decision to use automated controls has been made, the design team faces a new series of challenges: deciding which system to purchase, and making sure the system is properly commissioned, affordable, and programmed in a manner that will provide occupant satisfaction and save energy. While automated, integrated controls have been commercially available for some time, market penetration is still low, particularly in North America, due to high cost and performance uncertainties. (Reinhart \& Selkowitz, 2006, p.5)

The commissioning stage (after installation where the system is configured to the building and its occupants) of an automated daylight control system is very important, to be able to attain the highest possible savings without compromising occupant satisfaction levels. The importance of this has been recognised as an issue of automated daylight control systems. This, among other reasons explained previously, is the purpose of this research and the reasoning behind the development of the methodology. It is the performance uncertainties and design issues that need to be addressed so that each building is able to maximise its savings potential. 


\subsection{Survey}

The Building Use Studies (BUS Methodology) surveys were developed by Adrian Leaman and Bill Bordass. For this research extra questions specific to automated daylight control systems were added (see Appendix Four to view the full survey). The survey was completed by the occupants in each of the buildings at the beginning of the measuring period and they were given four days to complete them. The survey forms were personally handed out in three out of four of the buildings. In the first building (Building A) due to security restrictions, the survey forms were placed in boxes on each level for occupants to pick up, fill in and drop off.

The survey was given to the occupants on a Tuesday and collected the following Friday. During this time reminders were sent out via each building's intranet requesting occupants complete the surveys and have them ready to be picked up on the Friday. In contrast to using an electronic survey, based on past literature (Baird \& Leaman, 2009), a paper hand-out was expected to obtain a higher response rate and hence a better data set for analysis.

Each survey form was printed on coloured paper (blue, green, pink or yellow) firstly to help ensure that the survey was not lost amongst other work and secondly to allow quality control during processing. Handing the forms out personally allowed the occupants to ask questions and be provided with an appropriate explanation of the survey, its procedure and its future use. During the distribution of the survey, any questions regarding its purpose were answered in a manner that did not identify lighting or automated daylight control systems as the intention; rather a generic answer regarding the entire internal environment was given so as to allow the occupant to view each aspect equally. The analysis of the survey responses resulted in a mean value calculated for each question, for each building. The comments were manually sorted into positive, balanced and negative categories.

\subsection{BUS Survey}

This three-page survey has 70 questions on it with 16 opportunities to write comments about specific questions throughout (including the added questions on automated daylight control systems). To make sure that there was no bias toward lighting or automated daylight control systems specifically, the whole survey was used. This allowed the occupants to analyse their entire internal environment without any bias toward what the researcher was specifically investigating. Appendix 5 provides a summary of the results for each building. 
The original survey had no specific questions about automated daylight control systems so with the help of the survey original author Adrian Leaman, four questions and a space for comments were added to the survey.

The questions (with answers in brackets) that were added to the survey were as follows;

- Does this building have a daylight control system? (Yes, No, Don't know)

- Is there enough light on your work surface during a normal working day? (Too littleToo much)

- Does the automatic control system turn off/dim the lights to a point where it is difficult to view tasks? (Never - Often)

- How do you think the automatic control system is working? (Poorly - Very well)

All questions are rated on a 7-point Likert scale, (except for the question on productivity which is a 9-point scale). Each question has a possible best answer of 1, 4, or 7 depending on what is being asked. An example of the varying best answers is given within the automated daylight control system questions above. A score of 4 , between Too little and Too much, is best for 'Is there enough light on your desk', a score of 1 (Never to Often) is best for, 'does the automatic control system turn off/dim the lights to a point where it is difficult to view tasks' and a score of 7 is best when asked about, 'How do you think the automatic control system is working' from Poorly to Very well.

\subsection{Ethics Approval}

All the information gathered by the surveys had to remain anonymous and the answered survey forms were destroyed after the information was stored electronically. On the survey there is a place for occupants to print their name; however experience with the BUS (Baird \& Thompson, 2012) has found this is rarely completed, as anonymity often influences occupants to answer the survey more critically. The seating arrangements and positions of occupants in each building were also not recorded for the same reasons.

\subsection{Survey Content}

The survey can be grouped into ten main sections: Building Overall, Personal Space, Comfort, Noise, Lighting, Productivity, Health, Automated Daylight Control System, Personal Control and Travel to Work. As discussed above, not all of the questions in the BUS survey are required for the purposes of this research. However, using the whole survey maintains consistency with the BUS database which allows an overall comparison and helps ensure 
there is no bias towards lighting. The questions and survey form can be found in Appendix Four.

\subsubsection{Relevant Questions}

The questions that have been identified as being important to this research are Lighting, Comfort, Health, Productivity and the especially created Automated Daylight Control System questions. These sections of the survey all contribute to the answering the proposed research question, 'Are automated daylight control systems working as they should?' The survey results are provided in Chapter 6.0.

\section{Lighting}

The lighting section has five questions about both natural and artificial lighting. The introduction to this section is; How would you describe the quality of the lighting in your normal working area?

Lighting Overall - This question is rated from Unsatisfactory (1) to Satisfactory (7). This is about the overall lighting situation from natural to artificial and all of the advantages and disadvantages that come with both.

Natural Light - Are the occupants getting Too little (1) or Too much (7) daylight?

Glare from Sun and Sky - Glare may be an issue at one time or another. An answer of None (1) is the best answer with the worst answer being Too much (7).

Artificial Light - This is rated on a scale of Too little (1) to Too much (7) artificial light. With an automated daylight control system installed, this becomes a very important question.

Glare from Lights - The glare from the lights is another issue. The positions of lights, as well as the angle of view, can become an issue for work performance.

\section{Comfort, Health \& Productivity}

Personal comfort, health and productivity are aspects that can be affected by lighting conditions. It is of interest to see how these aspects are perceived and if any lighting related issues arise in the comment sections for each category.

Overall Comfort - This is an important aspect because if an occupant is uncomfortable in their environment then they will not be able to work at their optimum. 
Productivity - Self-reported productivity is the only question measured on a 9-point scale that is scored from $-40 \%$ to $+40 \%$ with a mid-point of $0 \%$ or 'no change'.

Overall Health - Self-reported overall health provides an indication of the respondent's feelings of wellbeing.

\section{Automated Daylight Control System}

This section starts with the main question, Automated Daylight Control System - How would you describe the lighting control system in your normal working area? Although this is a very specific set of questions, it was assumed that the majority of the occupants would be aware of an automated daylight control system being installed in their building, as this new technology was only recently installed.

Enough Light - Although a question has been specifically asked on natural and artificial lighting, this question is asking whether the lighting control system affects the amount of light, Is there enough light on your working surface?

Ability to see - Does the automatic control system turn off/dim the lights to a point where it is difficult to view your work? This question is posed to obtain whether or not the control systems are visibly changing to the naked eye, or hindering the ability to work.

Working Well - This general question asks more of personal perception, How do you think the daylight control system is working? This is followed by a comment box allowing for notes to be made that may not have been covered from the previous questions.

\subsection{Analysis of Survey vs. Physical Measurements?}

The power meter data, the illuminance sensor data and survey data were collected, sorted, placed into spreadsheets and analysed. It was then possible to explore the performance of the automated daylight control systems from the two different research approaches.

The need for the two approaches is supported by Floyd \& Parker's research exploring energy savings, where they found that "energy savings are meaningless if lighting quality is compromised to such a degree that occupant comfort and productivity is affected. While aspects of good lighting design cannot easily be measured, monitoring desktop illumination can provide information on the relative performance of a dimming system" (Floyd \& Parker, 1995, p. 4). 
The following combinations were used to understand the overall system operation.

- The general layout of the system vs. the comments made about the system on the survey.

- The illuminance levels vs. the scores and comments from the questions on lighting in the survey.

- The overall energy saving percentages vs. the aspects of comfort, health, productivity and any stand out comments from the survey overall. 


\subsection{Survey Results}

This Chapter provides the results and analysis of the survey. Firstly the response rate is calculated to understand how many occupants of each building responded to the survey in comparison to the amount of surveys distributed. To understand how natural light affects the occupants, the external environment for each day is analysed. This analysis is also combined with the researcher's observations from time spent in the building during the measuring period. Next are the mean scores of the questions from the sections that are being further examined. Each building's score is placed on a scale to visually depict how they compare to each other and how well they place on the overall scale. This is followed by an analysis of the automated daylight control system question and how the answers were distributed (Yes, No, or Don't know) to understand how many occupants were aware of the system and how this may affect the following questions. Lastly is the analysis of the comments made for each section, with a summary section compiling the comments into common themes.

\subsection{Response Rate}

The number of surveys handed out was compared to the number of surveys completed giving an overall percentage or response rate. The higher the response rate the better the overall data set will be at representing the perceptions and comments of the whole building. It is noted that when collecting the surveys, occupants would often comment that they were too busy and forgot to fill in the survey. It is noted that Building A had security restrictions which made it impossible to hand out the surveys personally. As a result Building $\mathrm{A}$ had the smallest sample size. The response rates for Buildings A, B, C and D, are shown in Figure 38 with a range from $51 \%$ to $68 \%$. The scores for each question from each building have been tabulated and are provided in Appendix Five.

\begin{tabular}{|c|c|c|c|}
\hline Building A & Building B & Building C & Building D \\
\hline 31 of 50 & 108 of 160 & 175 of 320 & 76 of 150 \\
\hline $62 \%$ & $68 \%$ & $55 \%$ & $51 \%$ \\
\hline \multicolumn{4}{|c|}{ Figure 38: Survey Response Rates } \\
\hline
\end{tabular}

\subsection{Exterior Illuminance}

A normal practice in daylight studies is to record the external illuminance levels at the same time as the interior illuminance measurements so a direct comparison can be obtained. This was not undertaken in this research as it was not possible to gain access to the necessary areas within each of the research buildings. This included no access being granted to the roof. In addition the measuring equipment was not designed for outdoor use. 
As discussed in Section 3.1 measurements were taken next to the windows but not outside as the research is concerned with the performance of the automated daylight control system for the occupants. External obstructions, glazing orientation, the use of glazing films (which were found in all four buildings) and occupant behaviour (e.g. closing of blinds) all impact on the performance of an automated daylight control system and a direct comparison would not be sufficient.

However, understanding the levels of light that each of the buildings occupants were experiencing is important when discussing glare and reasons for adjusting their environment. Glare is an important negative feature in buildings where daylight control is implemented. Data from the Met Service's Kelburn weather station has been obtained and is produced in the below figures. The level of illuminance present during the time of the survey and measuring periods is important as it is expected that higher light levels will create glare and increase the occupant awareness of their surroundings. This may prompt occupants to change their environment to suit their needs and thus alter the performance of the automated daylight control system.

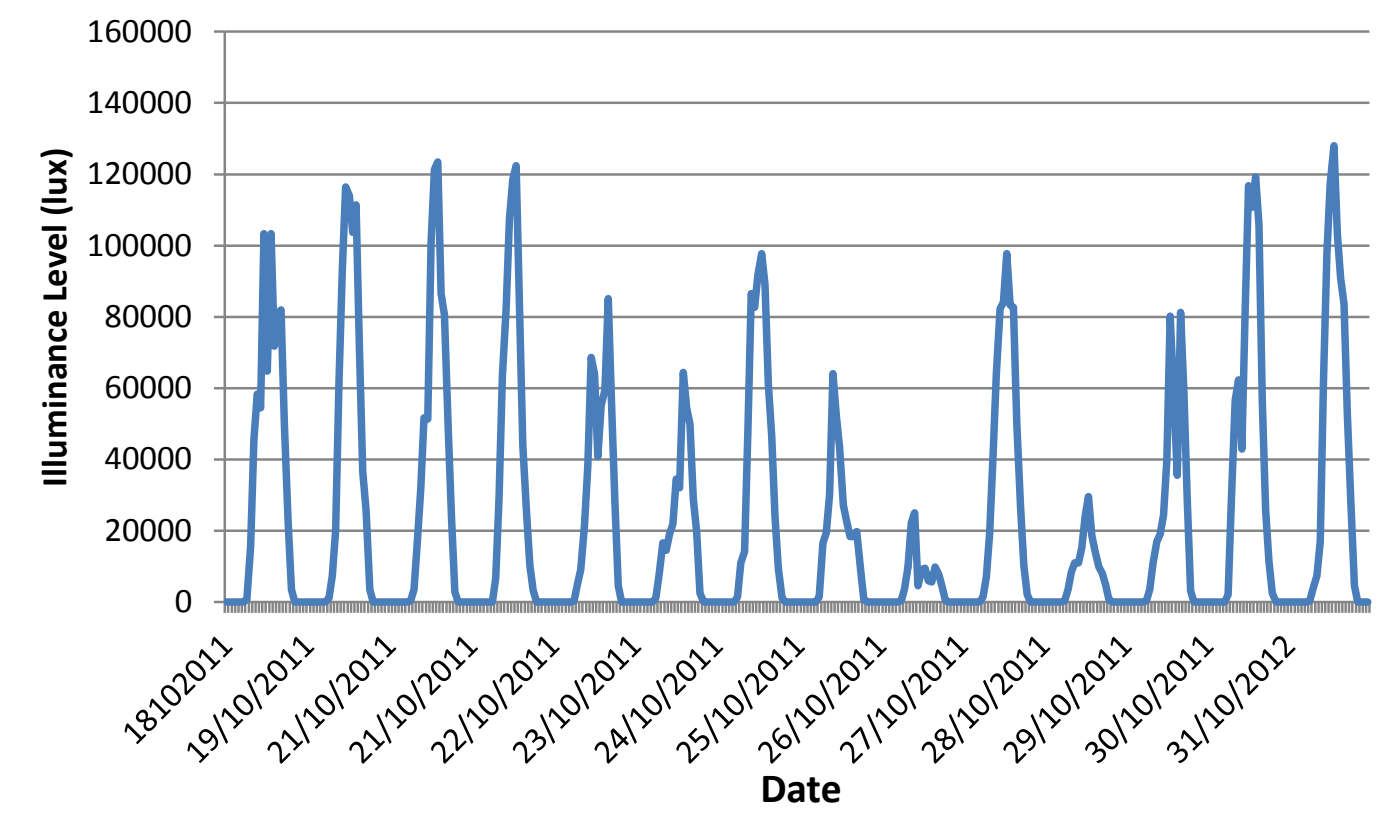

Figure 39: Daily Exterior Illuminance Levels - Building A

Building A had more days with cloud and rain than it did clear sunny days, with the second week of measuring being mostly rain. The first four days of measuring were a mixture of clear days with passing cloud. 


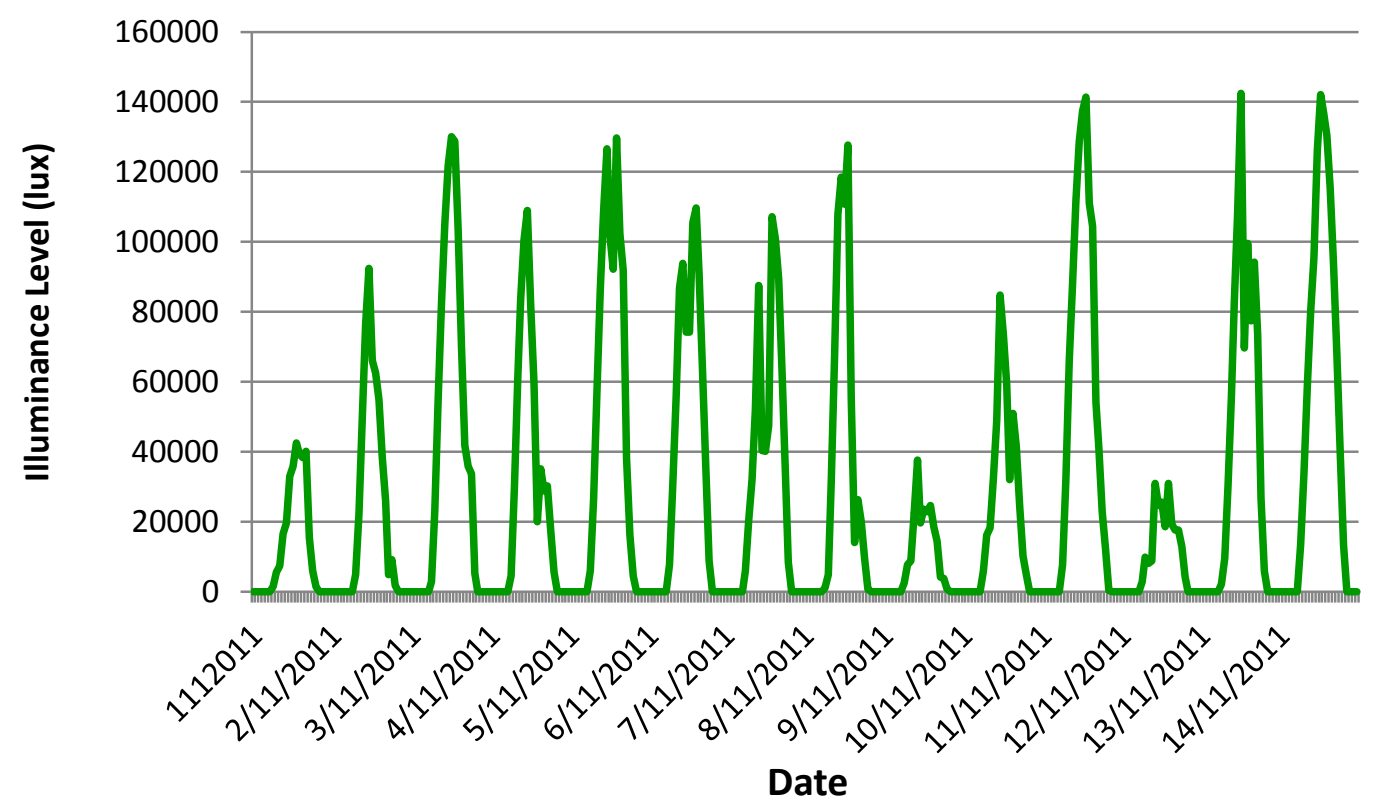

Figure 40: Daily Exterior Illuminance Levels - Building B

Building $B$ is similar to Building $A$, with a mixture of sunny days and days where it rained for most of the second week. There was a day of heavy rain on the first day the survey was handed out which has the potential to influence the final result of the survey assuming most occupants complete it straight away.

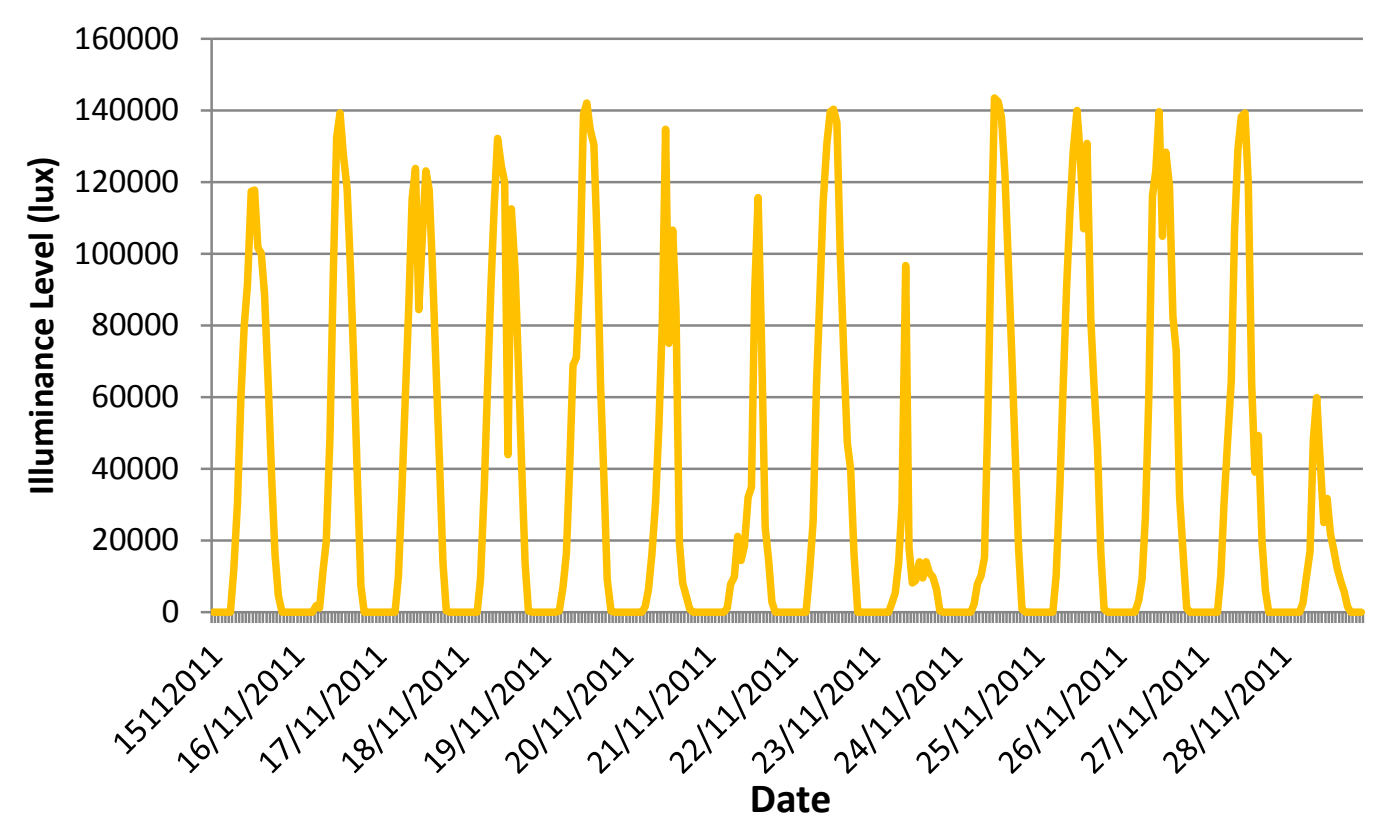

Figure 41:Daily Exterior Illuminance Levels - Building C

Building $\mathrm{C}$ was mainly sunny for the whole measuring period but also had some days where there was a layer of cloud but still recorded high illuminance levels. 


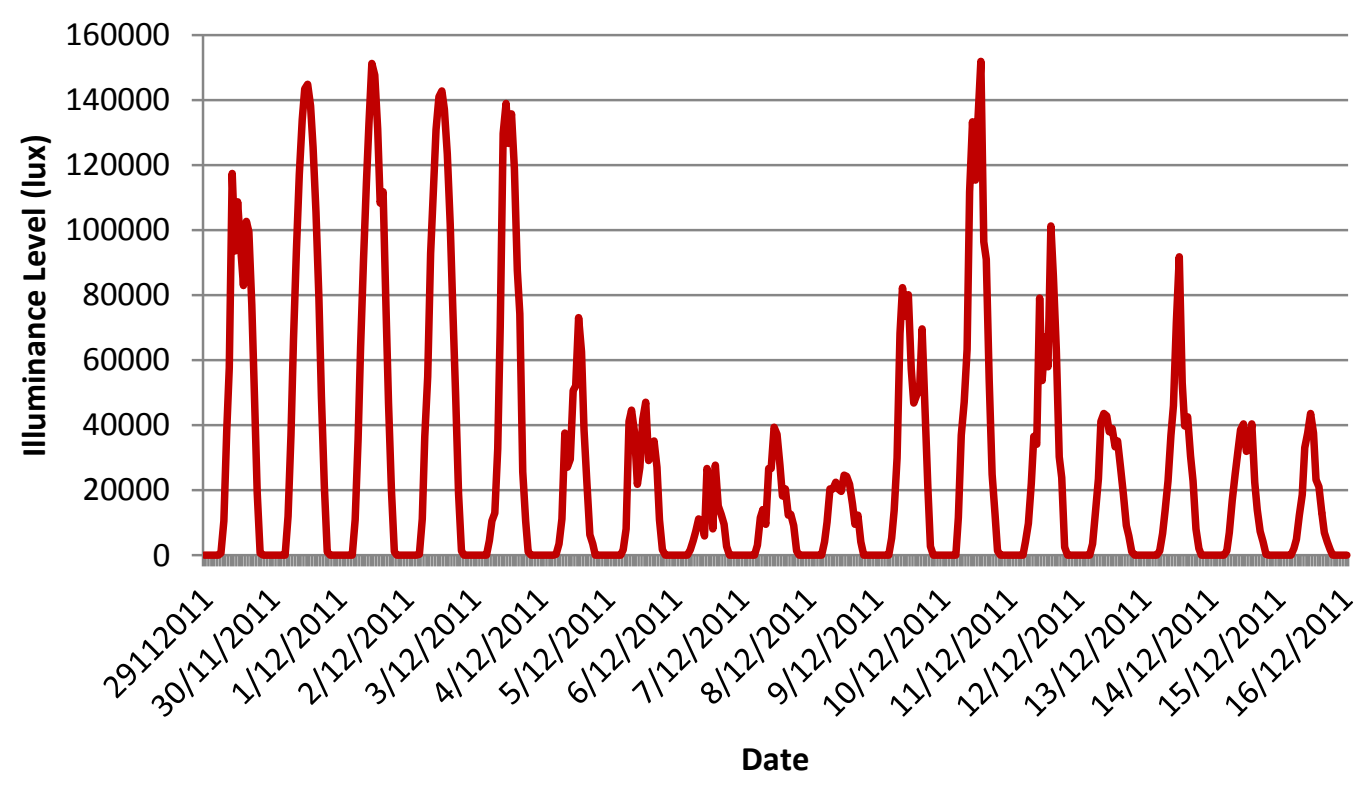

Figure 42: Daily Exterior Illuminance Levels - Building D

Building $D$ had sunny clear days during the period when the survey was being conducted and then the rest of the time was nearly all rain which accounts for the very low illuminance levels.

\subsubsection{External Influences}

As explained in the previous Section, the surveys were distributed by hand at the beginning of each measuring period and the occupants were given four days to complete the forms before they were collected. The weather outside can be influential when a survey is being completed. When an occupant is asked questions that they wouldn't normally consciously think about, they may look around to decide how each aspect is affecting them at that very moment. The illuminance levels noted in the previous Section are a measurement of overall light. This can account for overcast days with nearly uniform skylight which will still have an illuminance value. The information on Figure 43 below shows the amount of sunshine for each day the measuring equipment was in each building. From this information and from observations made by the researcher, a summary of each building will aim to determine if the amount of sunlight during each measuring period was an influential factor when answering questions about lighting and glare. This does not take into account the orientation or obstructions that will reduce the overall illuminance recordings in the individual buildings. 


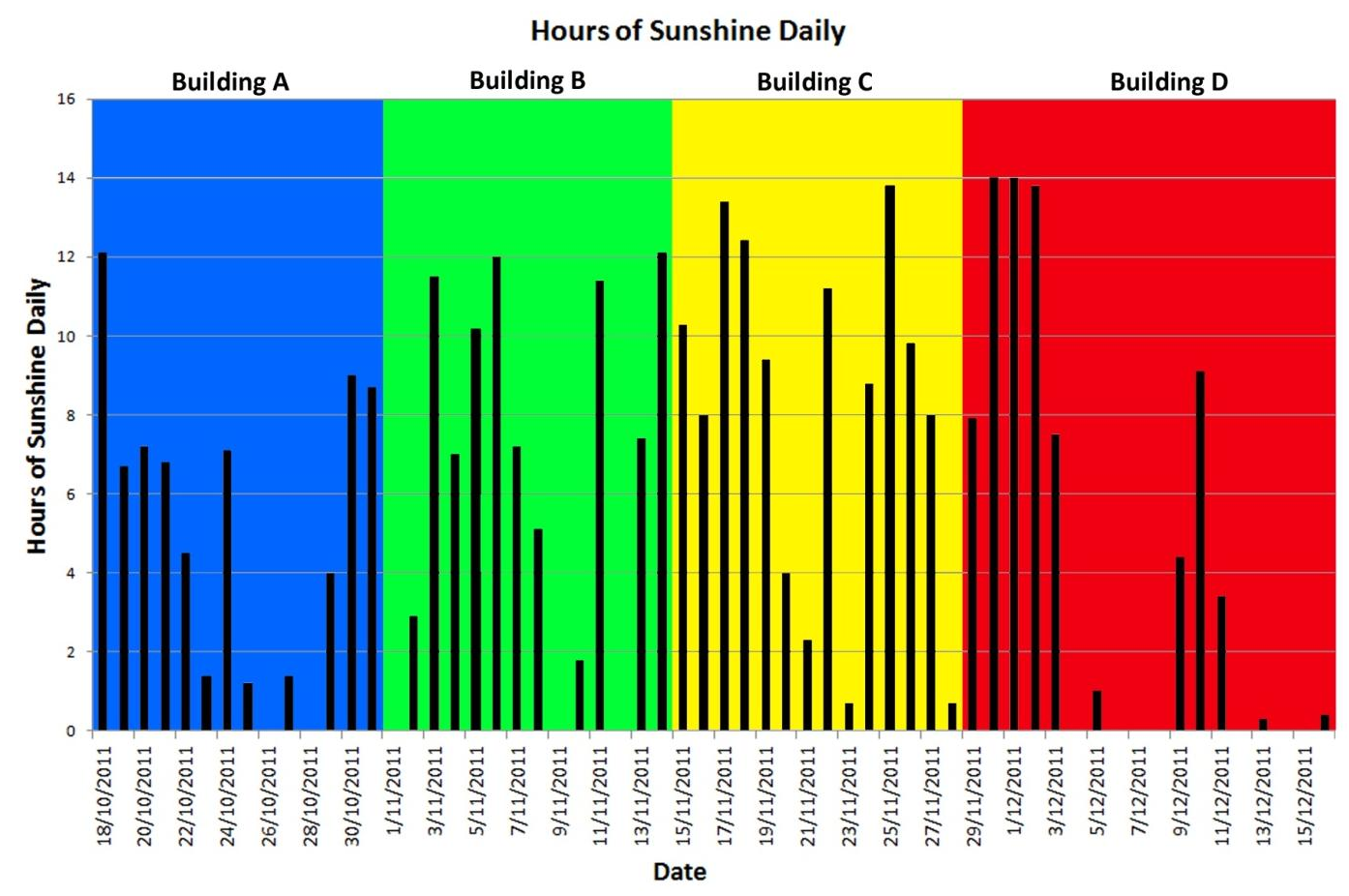

Figure 43: Each Building's Sunshine Hours (Daily)

The information in Figure 43 can be viewed at a larger scale in Appendix Six. This information is combined with the researcher's own observations recorded on the first day of the measuring period which describe the sky type and occupants reactions to the natural light and use of their buildings. The following is a description of each building's first four days with observations from the first day.

\subsubsection{Building A}

On the first day when the surveys were being distributed it was a clear and sunny day with only some passing cloud. It was observed that blinds were required to be pulled during the middle of the day as the sunlight was too harsh for those closest to the windows. The following three days when the survey was being completed were moderately sunny but had patches of cloud that reduced the amount of direct sunlight, however there were still sufficiently high illuminance levels.

\subsubsection{Building B}

The first day of measuring and handing out the surveys was a dark day with torrential rain. As Figure 43 shows, there was no sunlight present at all. This gradually changed over the following three days which became clearer with some sunlight present on the third and forth days. It was observed that some blinds were pulled even on the initial dark day which suggests that there are some issues with glare at certain times during the day and the blinds are left down. 


\subsubsection{Building C}

During the first two days of measuring, Building $C$ had generally sunny skies present with only passing clouds which became clear blue skies for the third and forth days. It was observed that occasional glare in Space 1 was an issue because this space was mostly obstructed with surrounding buildings, so when sunlight was present it appeared to affect the occupants greater than those in Space 2 who had an abundance of light.

\subsubsection{Building D}

On the first day of measuring as the surveys were handed out there was only passing clouds during the middle of the day but was mostly sunny. The following three days had clear sunny skies and it was observed when checking the measuring equipment that the blinds in each of the spaces were pulled. It was observed that glare was an issue for both spaces as each office's workstations were positioned against the window.

\subsection{Detailed Analysis}

The responses to the lighting, comfort, health, productivity and automated daylight control system questions provide an overview of how the occupants perceived their building. In this Section, the individual building scores have been plotted on a colour coded scale, where red indicates the worst scores and green indicates the best scores. The first section is the original survey's lighting questions. These questions analyse Lighting Overall and then specifically Natural Light, Glare from Sun and Sky, Artificial Light and Glare (from artificial lighting). The following questions asking about Comfort, Health and Productivity are important because they provide information on the users' perception of aspects that can't be physically measured and are applicable to the effects of lighting.

\subsubsection{Lighting - Natural \& Artificial}

Responses to the question Lighting Overall, were reasonably high (i.e. towards 'Satisfactory') with all buildings falling between scores of 5 and 6 . However buildings $A, B$ and $D$ are in the top $25 \%$ of the scale whereas Building $C$ is closer to the mid-point of 4 than the other buildings. Overall there is a high satisfaction with the overall lighting (see Figure 44 ) in all four buildings. The lower score for Building $C$ is potentially caused by the irregular shaped footprint of the building which provides some areas with good natural light and other without any natural light. 


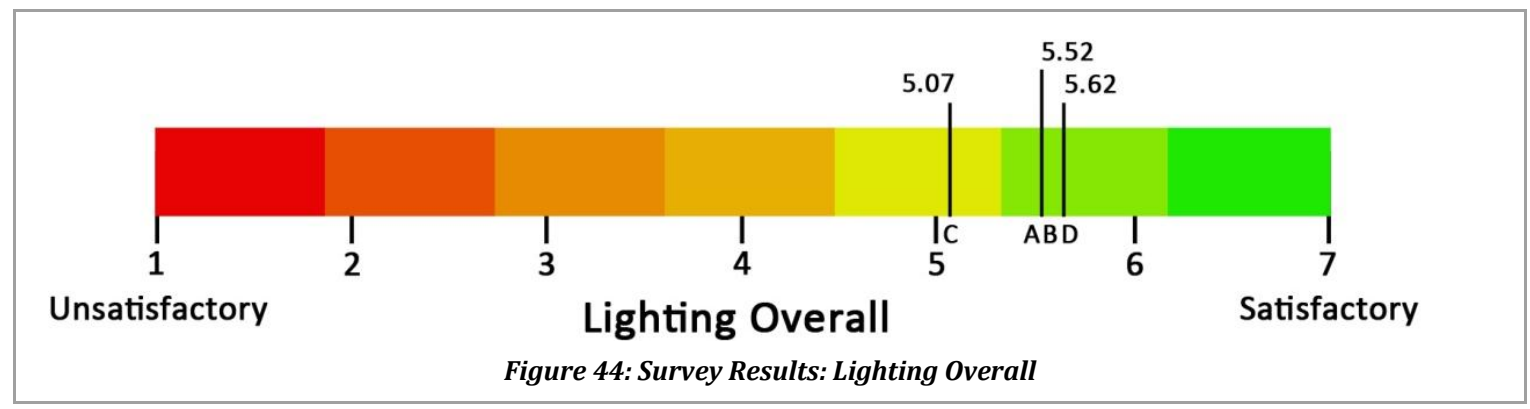

Natural Light, where on the scale Too Little (on the left) and Too Much (on the right) are both unwanted attributes. Figure 45 shows that all of the scores for natural light were very close to the mid-point which is a good result.

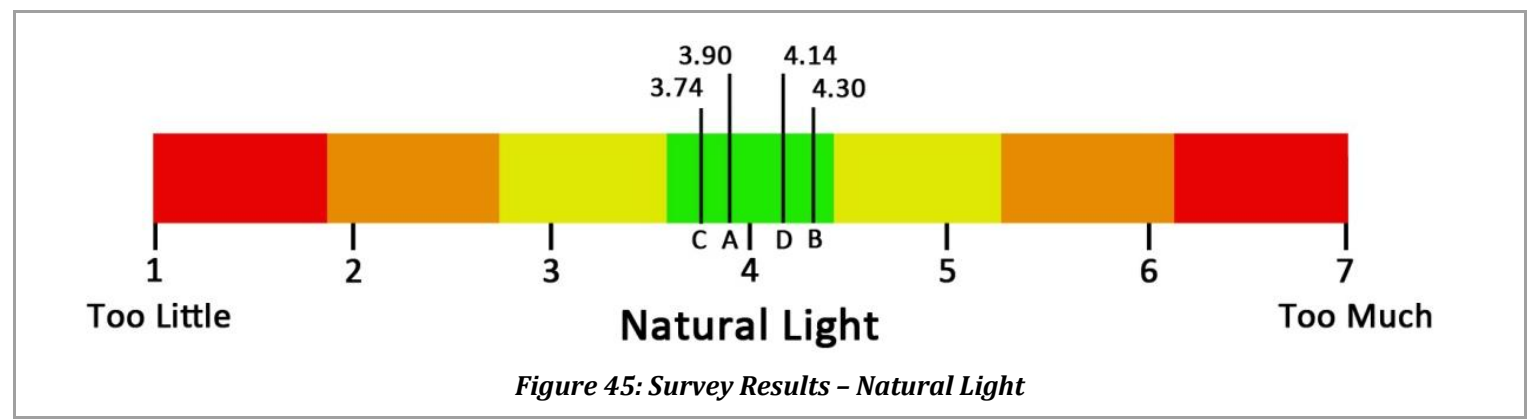

Figure 46 found on average that occupants in all four buildings found only moderate issues with glare from the sun and sky. It is noted that in each of the buildings there are manual blinds that can be used to alter each of the areas by the occupants.

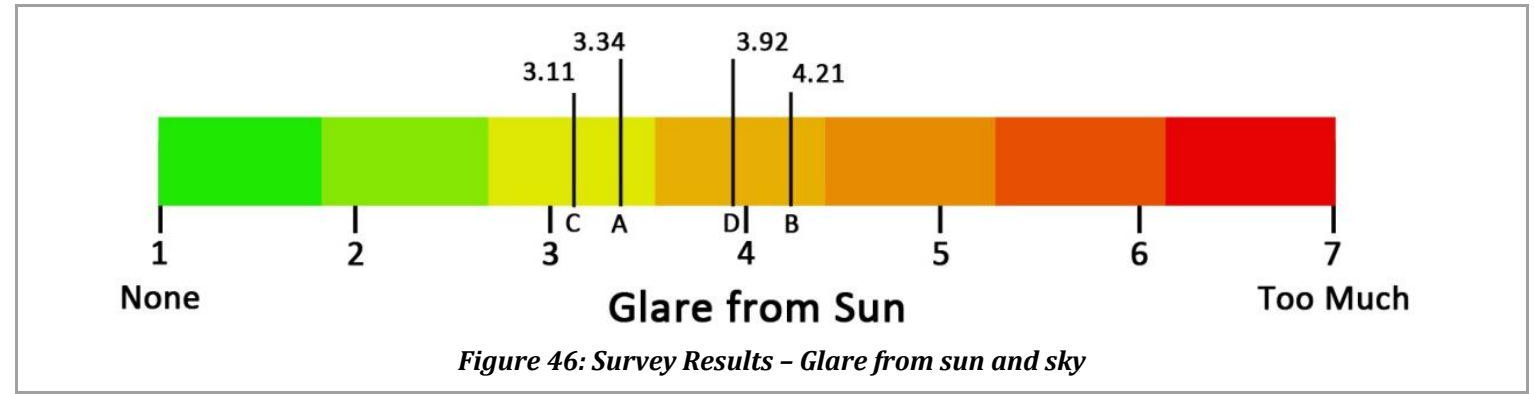

In all of the buildings used for this research, fluorescent lamps were the main source of artificial light. The scores below in Figure 47 show if the artificial light is either Too Little or Too Much. It was observed that all artificial lighting had diffusers on them which help to produce an even distribution of light and the scores were overall good for all buildings. 


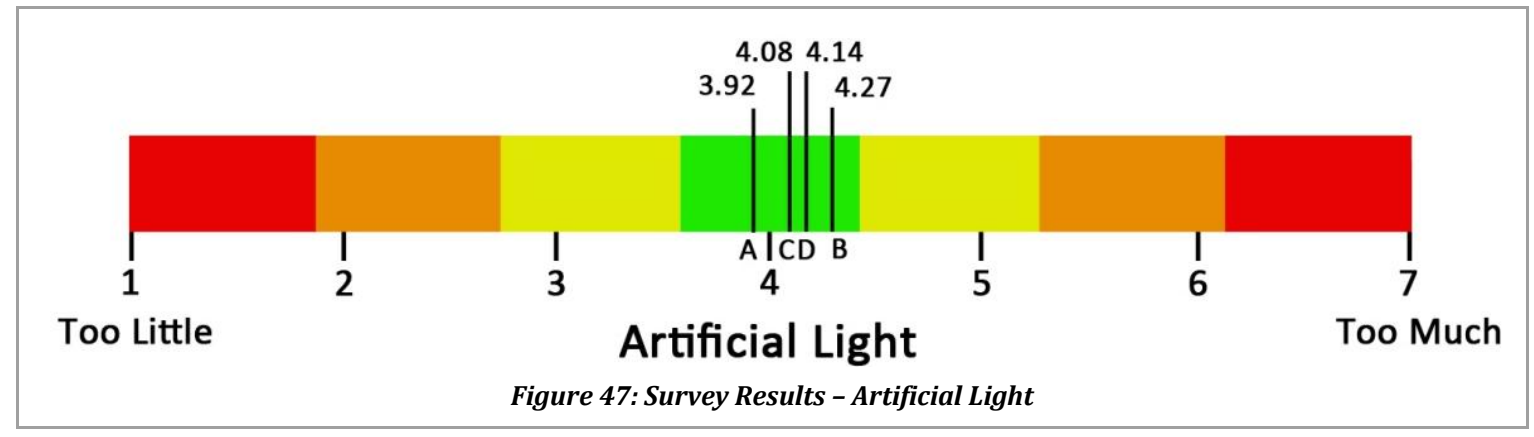

With diffusers on the luminaires in each building, glare from artificial lighting is also reduced. Occupants of each building have perceived the amount of glare from artificial lighting as moderately low. In comparison to natural light, orientation does not affect this question, as the buildings have similar lighting layouts throughout. In Figure 48 below, the overall scores for glare from an artificial source are all below the mid-point not very close to None suggesting there are some issues with glare.

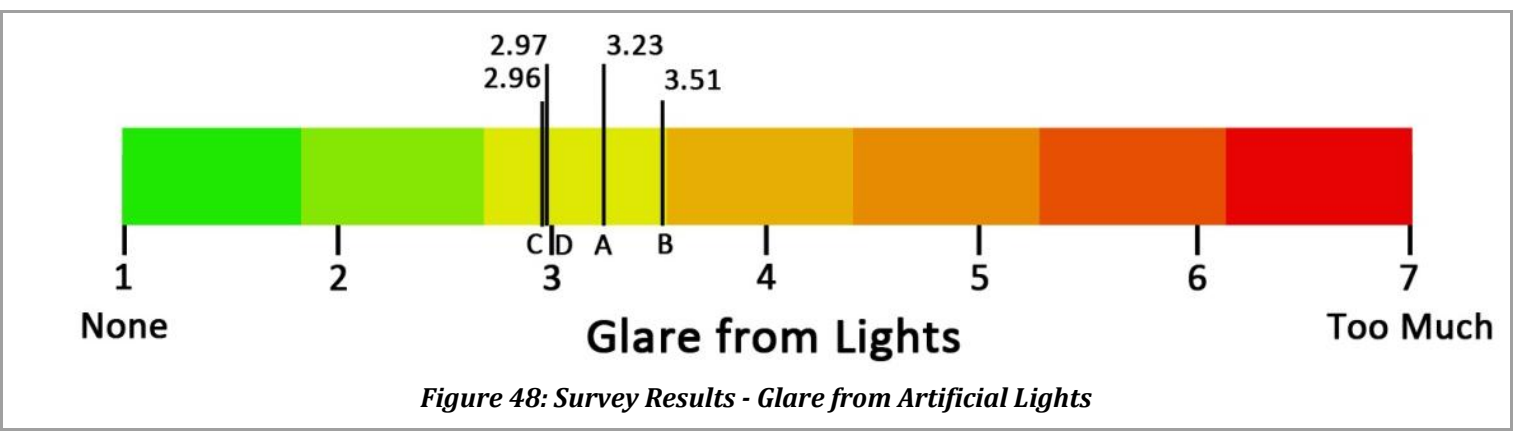

\subsubsection{Comfort, Health \& Productivity}

The Comfort Overall question is very important from both the employers and the occupants' perspective. If the occupants are not comfortable, it is difficult to work at an optimum level which can affect productivity. From an employer's perspective, this results in less productive staff which can ultimately affect their business. From an occupant's point of view, being uncomfortable not only affects their work but can also lead to irritability and deteriorating health issues (refer Section 2.6.2). Figure 49 shows the scores for all four buildings being between 5 and 6 showing that occupants are moderately satisfied with their overall comfort levels. 


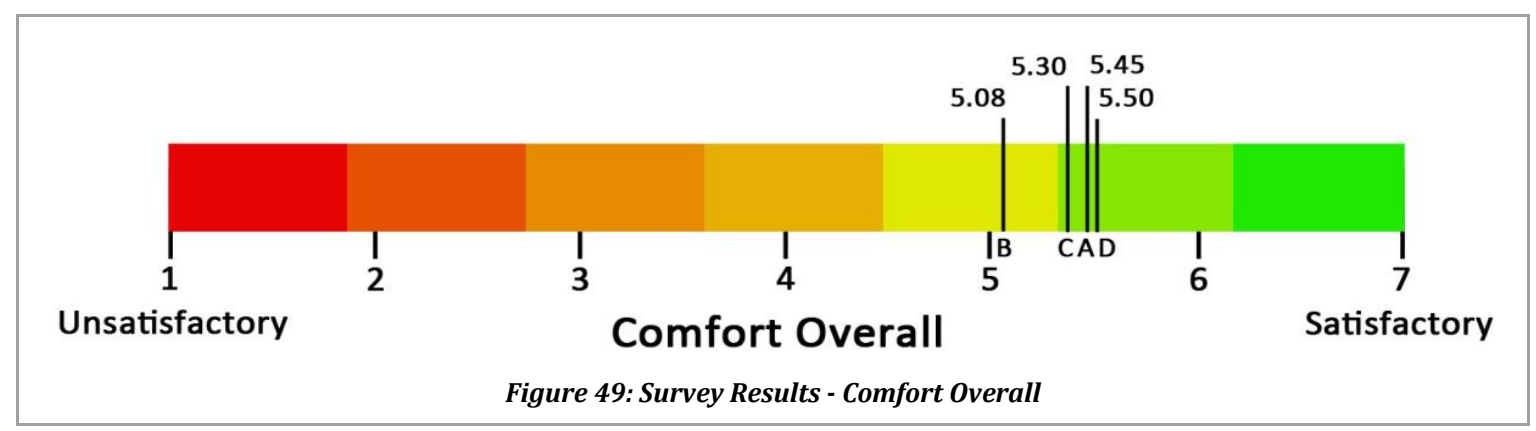

The question on Health asks the respondent to compare their current building to other buildings they have worked in. Figure 50 shows the scores all around the mid-point, suggesting the occupants feel no more or no less healthy (no change) in their current buildings than they have felt in other buildings they have worked in.

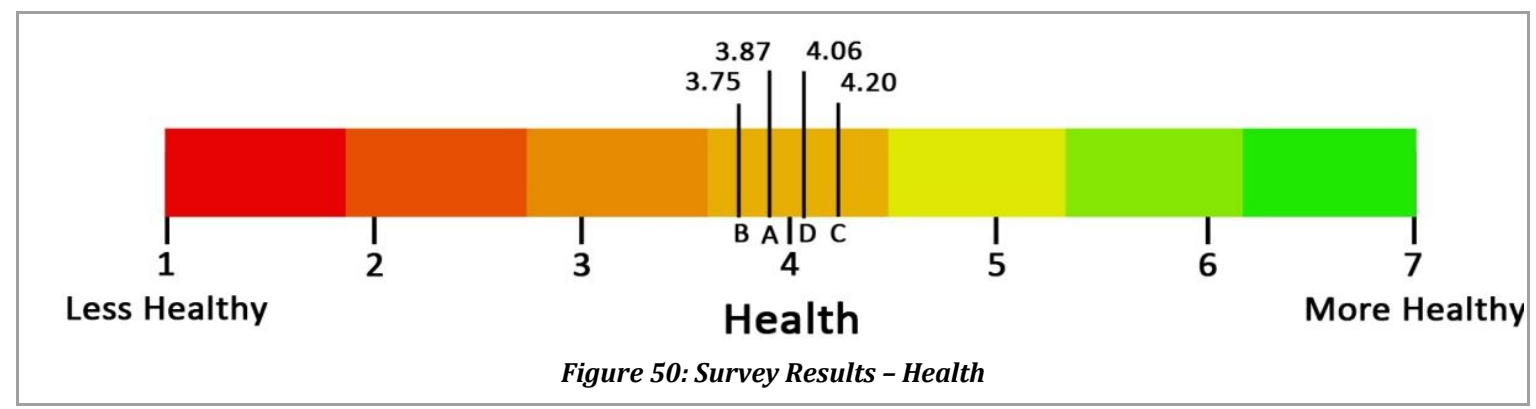

Productivity has long been considered important but it is very difficult to measure and quantify. The ability to calculate 'productivity' is difficult. The question of productivity in the survey is self-assessed and not prompted by any external aspect (such as lighting) but is to be answered on the basis of how the whole internal environment is perceived. At no point are the occupants told that this survey is specifically about lighting, therefore nullifying any possible bias results.

In comparison to the Hawthorne experiment where occupants are aware that they are being externally monitored which in turn increased productivity, the survey is a self assessment of the occupant's surroundings. The survey question allows the occupants to evaluate their building and their working environment and answer how productive they perceive themselves to be. The question was stated as; Please estimate how you think your productivity at work is decreased or increased by the environmental conditions in the building? 


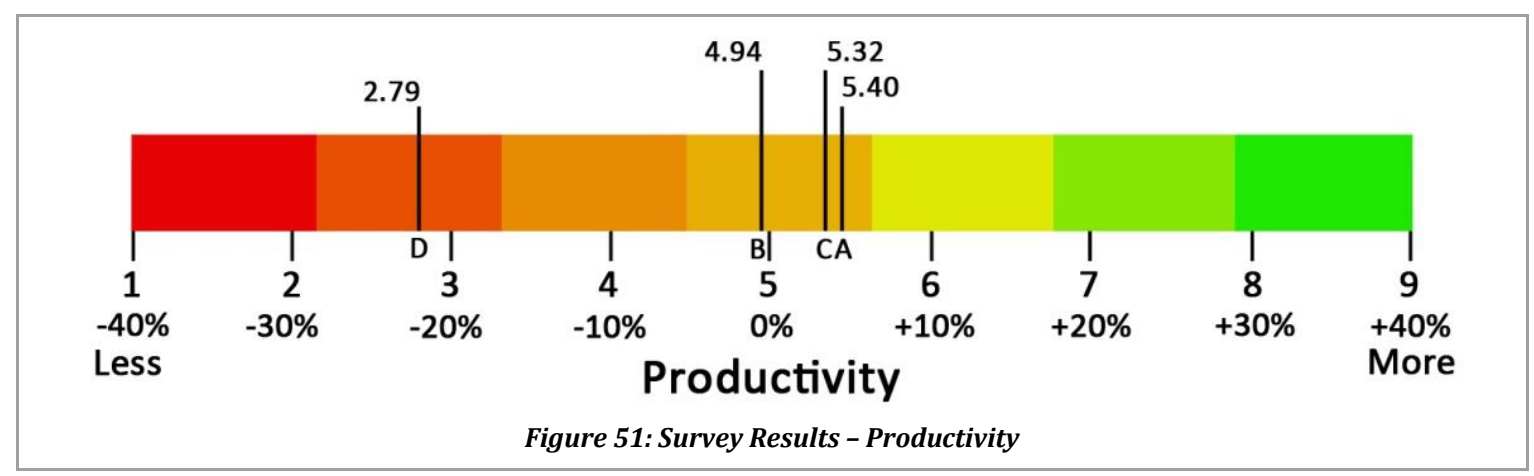

In Figure 51 above, in buildings A, B and C, the occupants perceived their productivity levels to be no better or worse than their current building compared to being in another building they have worked in. However, occupants in Building D felt that on average they were $22 \%$ less productive in their current building, well below the other building scores. Looking at the other responses, on each of the scales for all other aspects investigated, all of the buildings were grouped tightly together. As this is the only question where one building is so far from the other buildings, it is suggested that lighting is not the issue for Building $D$.

\subsubsection{Automated Daylight Control System}

With limited space on the survey form to explain each question, it is difficult to ensure that the participant will have a clear understanding of exactly what each question is asking. Figure 52 shows the automated daylight control system questions as they were placed in the survey (also refer to Appendix Four). It highlights that only a small amount of information was able to be provided to the occupants. As this technology is specific to the construction and engineering industry and the professions of the building occupants surveyed were not in these areas, it was a difficult question to pose. This Section looks at the distribution of how each building answered this question (Yes, No, Don't know) and how this may have affected the occupant comments.

\subsubsection{Does this building have an automated daylight control system?}

It must be made clear that as the survey is distributed throughout the whole building, some questions, such as Does this building have a daylight control system?, may not be apparent to those who may be in a area without any component of an automated daylight control system. As daylight will not be present in every space, neither will the presence of an automated daylight control system. 
When answering the first question of the automated daylight control system section, the majority of respondents were unaware that their building had an automatic daylight control system installed, with an average of $59 \%$ of the occupants responding with Don't know. In the figures below, the green section represents those who are aware of the automated daylight control system. The red represents those who do not have any system in their area or are not aware of any system and the blue represents those who didn't know.

Of those that completed the survey in Building $A$, only two were aware there was an automated daylight control system installed, one said that there wasn't such
Daylight control system

Does this building have a daylight control system?

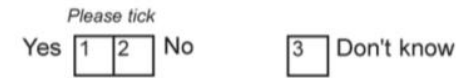

Is there enough light on your work surface during a normal working day?

Too little \begin{tabular}{|l|l|l|l|l|l|l|}
\hline & 2 & 3 & 4 & 5 & 6 & 7 \\
\hline
\end{tabular}

Does the automatic control system turn off/dim the lights to a point where it is diffcult to view tasks? Never \begin{tabular}{|l|l|l|l|l|l|l|}
\hline 1 & 2 & 3 & 4 & 5 & 6 & 7 \\
\hline
\end{tabular}

How do you think the automatic control system is working?

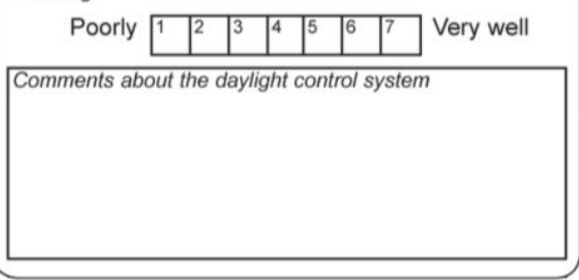

Figure 52: Automated Daylight Control System Questions a system in their area of work and 28 said they didn't know (see Figure 53). This is the highest proportion of occupants of all four buildings that were unaware of any type of automated daylight control system installed in their working environment.

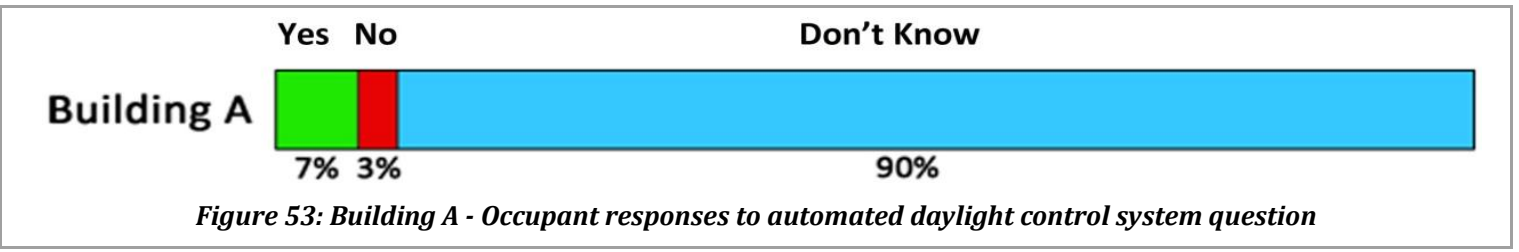

Building B has been retrofitted in the past two years, which as well as a general fit out also included the installation of an automated daylight control system. However, the majority of the occupants (62 people) did not know whether or not there was a system installed in their building, (see Figure 54) while 19\% said that there was no automated daylight control system in their work space.

\begin{tabular}{|c|c|c|c|}
\hline \multirow[b]{2}{*}{ Building B } & Yes & No & Don't Know \\
\hline & & & \\
\hline & $17 \%$ & $19 \%$ & $64 \%$ \\
\hline
\end{tabular}

The only building with a Green Star rating was Building C. From a research perspective, it was expected that most occupants would be more aware of the energy efficient aspects of the building. This was proven correct with nearly half of the occupants (76 of 161) indicating that 
they were aware that there was an installed automated daylight control system - the highest percentage of all four buildings. There were only four people who stated that they did not have an automated daylight control system in their space while $51 \%$ (82 of 161) did not know (see Figure 55).

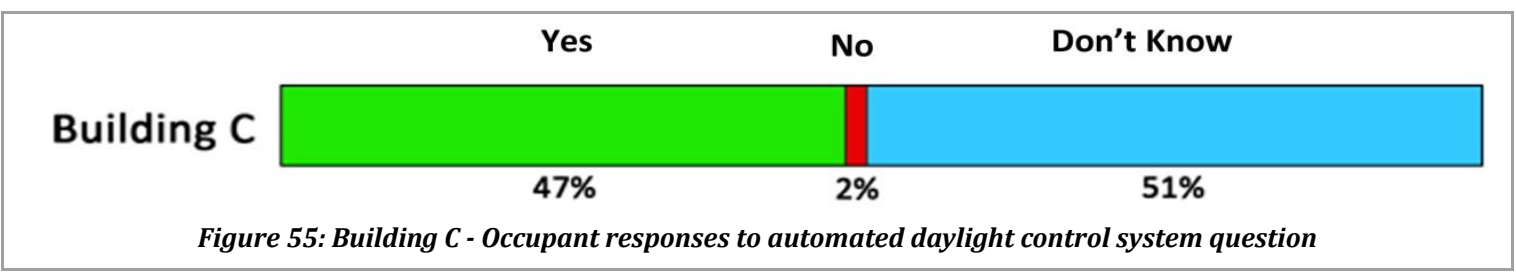

Building $D$ which is a relatively new building also had results that showed occupants were aware of the building's installed energy efficient technologies, with 24 of 65 (37\%) answering yes to the question. Only two people stated that there was no such system installed in their work area, while 46 were unsure (see Figure 56). As this building has teaching specific areas and conference rooms, it should be noted that only permanent offices and laboratories were surveyed.

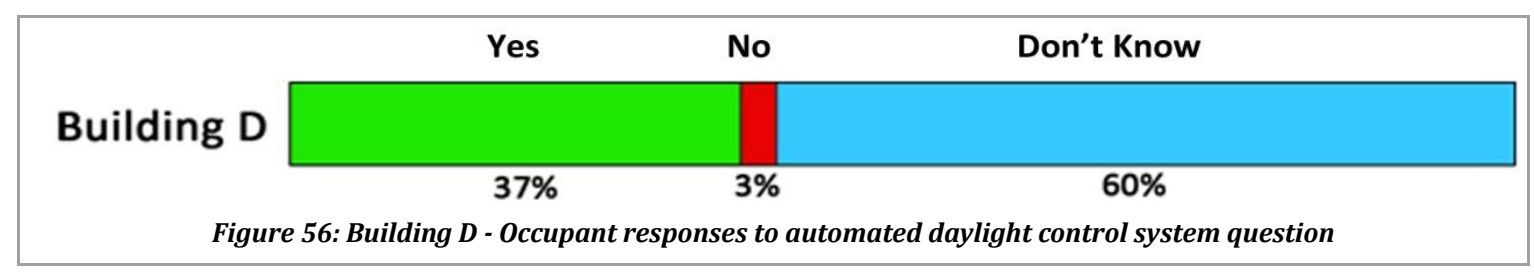

This survey question found that a large portion of occupants were not aware of the implementation of automatic daylight control systems either in their building. This may be due to such systems being a relatively new technology or a lack of interest.

Given the occupants general lack of knowledge about automated daylight control systems and their incorporation into the buildings, it may have been difficult for the occupants to answer this question as only 34\% (211 of 355) on average (for all four buildings) were aware of such an installed system. To gauge how well this question was answered, a table showing the number of occupants who answered each question in comparison to those who were aware of an automated daylight control system is shown in Figure 57 below.

\begin{tabular}{|l|c|c|c|c|}
\hline & Building A & Building B & Building C & Building D \\
\hline Light on Work Surface & $30(100 \%)$ & $96(98 \%)$ & $160(99 \%)$ & $65(100 \%)$ \\
\hline View Tasks at Desk & $22(73 \%)$ & $71(72 \%)$ & $151(94 \%)$ & $62(95 \%)$ \\
\hline Daylight Control System Overall & $16(53 \%)$ & $57(58 \%)$ & $147(91 \%)$ & $58(89 \%)$ \\
\hline Aware of System in building & $7 \%$ & $17 \%$ & $47 \%$ & $37 \%$ \\
\hline \multicolumn{4}{|r|}{ Figure 57: Number of Occupants who answered each question } \\
\hline
\end{tabular}


This table shows that even though a small number of occupants were aware of an automated daylight control system installed in their building the majority of occupants still attempted to answer all questions. Not knowing of an installed automated daylight control system may have altered the results of the following questions.

\subsubsection{Is there enough light on your work surface?}

As discussed in Section 2.3, an automated daylight control system should only dim the artificial lights when there is enough daylight present. However, with the percentages from Figure 57 above, it is possible that the following results are not very reliable. Figure 58 records the responses to this question on whether there is ever Too Little or Too Much light on the work surface. The tight grouping of scores around the centre suggests that the systems are working to suit the occupant's needs with the correct amount of light in each of the buildings either from natural or artificial light sources.

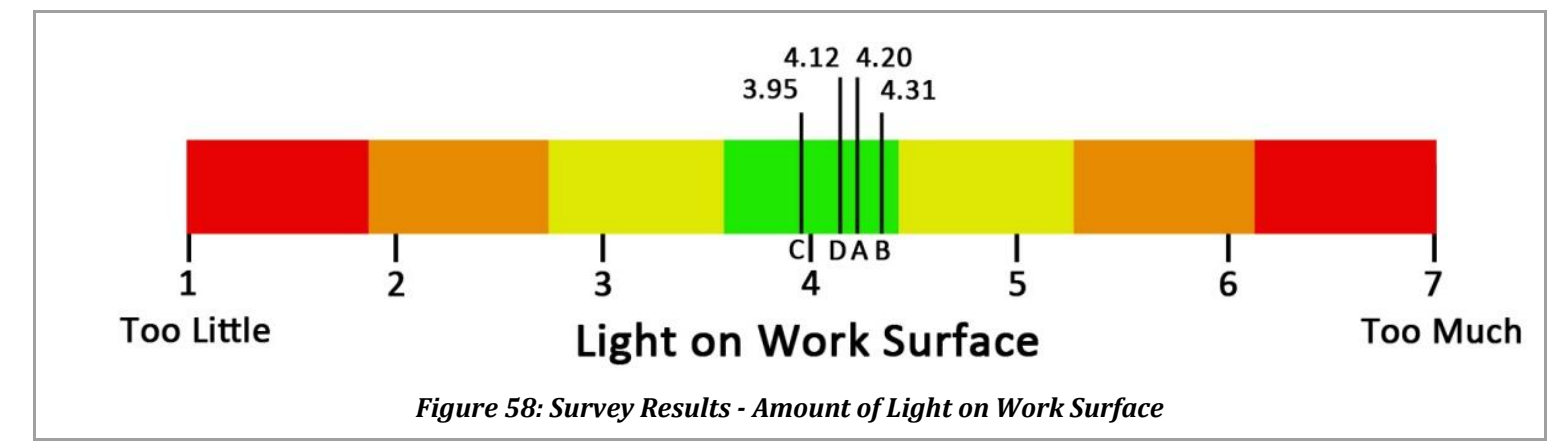

\subsubsection{Lighting System and difficulty in viewing tasks}

Immediately following the above question is; Does the automatic control system turn off/dim the lights to a point where it is difficult to view tasks? (Figure 59). This question relates to 'how often there is enough light on the work surface at any given time' and was proposed to make the occupant think about this in relation to the automated daylight control system. From the system turning off Never to Often, Buildings A and B both had scores close to Never. Whereas Building $C$ and $D$ were close to the mid-point which suggests that their systems would sometimes turn off while people were still at their desks. 


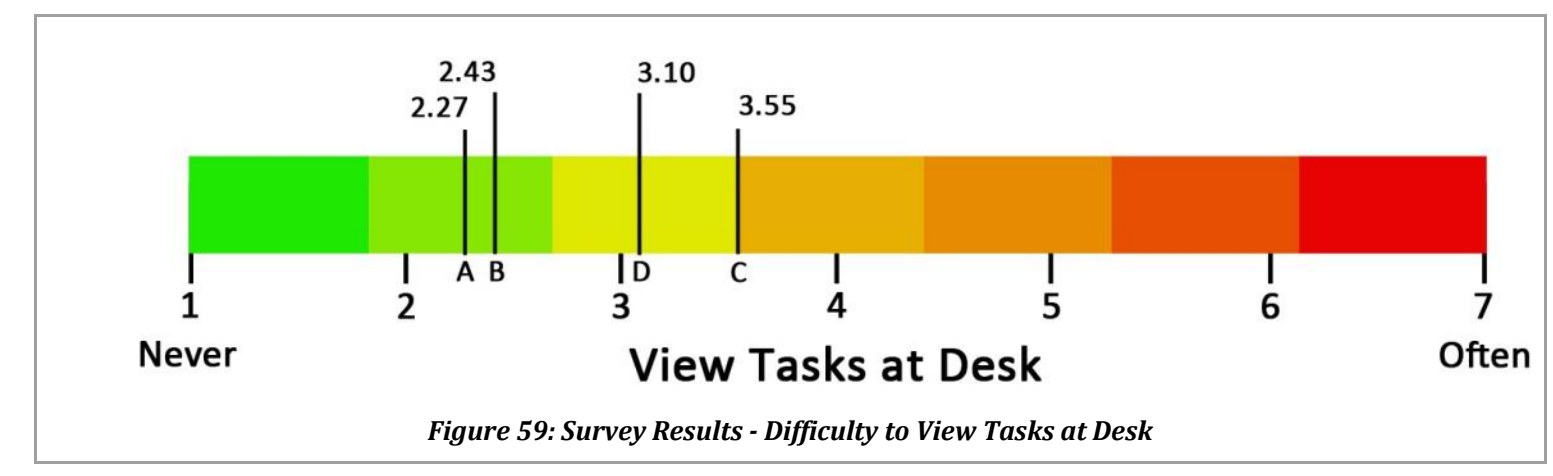

All buildings are better than the mid-point of 4 with buildings $C$ and $D$ in the 3.0 to 3.5 range while buildings $A$ and $B$ are less than 2.5 on the scale.

\subsubsection{How is the system working overall?}

Building B is right on the mid-point between Poorly and Very Well, while buildings A, C and D are closer to the Very Well end but still in the 4 to 5 range (see Figure 60). From this question it appears that the occupants believed that the automated daylight control systems were not working as well as they should. It is however difficult to view the results as true in light of those occupants who were unaware of the systems in the first place.

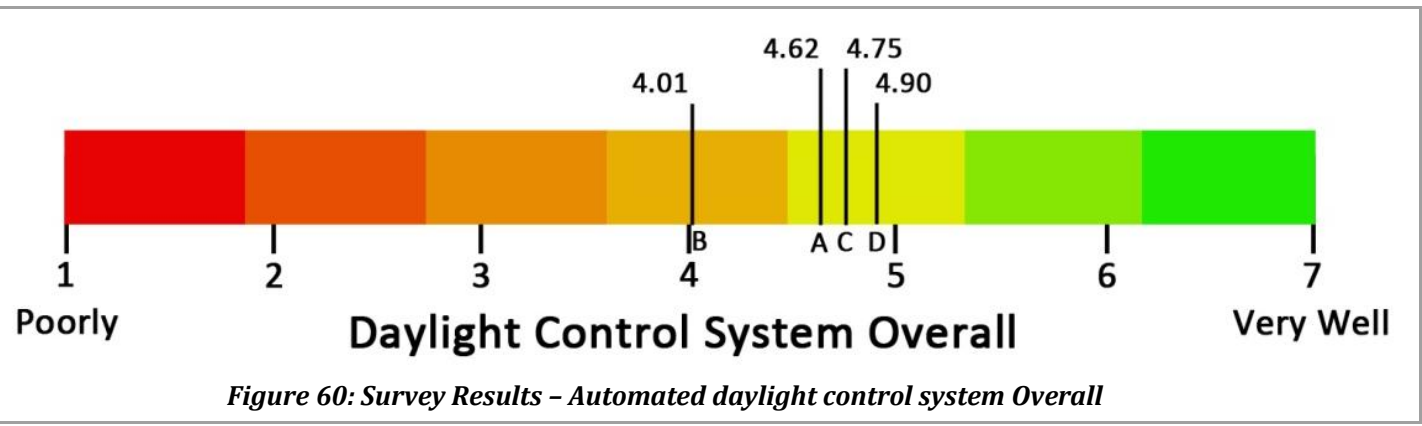

\subsection{Comments}

Throughout the survey there are 16 comment boxes where the occupant was able to write their opinion if the questions did not fully address their concerns. Of these 16 comment boxes, five aspects (Lighting, Automated Daylight Control System, Comfort, Health and Productivity) were further investigated. The comments were analysed and manually placed into Positive, Balanced or Negative categories. Anonymous surveys often bring out negative comments and complaints from occupants that would not normally voice their opinion. In research on 30 sustainable buildings conducted by Prof. George Baird, it was found that on average the ratio of positive comments to negative comments was 1:2.25 (Baird, 2010) for all comments from all aspects. The ratios for this survey are investigated at the end of this Section. 
As Health, Comfort and Productivity are closely related with aspects of lighting, the comments made in each aspect are separated into common themes (Lighting, Air and Temperature, and Noise) to see if any of the occupants mentioned lighting. A full analysis of the comments for each building is provided in Appendix Seven.

\subsubsection{Building A - Comments}

Due to the low number of respondents to the survey in Building $A$, only a small number of comments were received. In total, 20 comments were made over the five aspects. The distribution of the comments did not show any great weighting towards any category. The greatest difference was with Productivity where there was only one positive comment to the three negative comments (see Figure 61).

\begin{tabular}{|l|c|c|c|c|}
\hline Building A & Positive & Balanced & Negative & Total \\
\hline ADCS & - & - & - & $\mathbf{0}$ \\
\hline Lighting & $2(25 \%)$ & $3(38 \%)$ & $3(38 \%)$ & $\mathbf{8}$ \\
\hline Health & $3(50 \%)$ & $2(33 \%)$ & $1(17 \%)$ & $\mathbf{6}$ \\
\hline Comfort & $1(50 \%)$ & - & $1(50 \%)$ & $\mathbf{2}$ \\
\hline Productivity & $1(25 \%)$ & - & $3(75 \%)$ & 4 \\
\hline \multicolumn{5}{|c|}{ Figure 61: Building A - Comment Distribution } \\
\hline
\end{tabular}

Comments made about lighting that appeared in the aspects of Health, Comfort and Productivity were very few. There was one positive comment from Health with one negative comment from Comfort and one from Productivity that related specifically to light. The positive comment complimented the natural light while the negative comments were unhappy with the artificial lighting. In the general lighting section, the comments made indicated that they were pleased with the access to natural light but unhappy with the artificial lighting as they would often dim too much especially closer to the core of the building. Overall, from such a small sample size it is difficult to quantify how well the automated daylighting control system is working. The comments that were made suggested the need for more light deeper into the building and that a general re-commissioning of the system is required.

\subsubsection{Building B - Comments}

In total, 108 comments were made across the five aspects being investigated in this section. Automated Daylight Control System comments were generally balanced, with most indicating that they didn't realise the building had such a system or that they didn't know what such a system was. The three positive comments described the system as working well as they hadn't noticed it, while the negative comments mentioned how the system didn't work as well the closer the system was to the core of the building. 
With the Lighting comments nearly evenly distributed, the positive comments praised the natural light; the balanced comments mostly talked about the blinds around the windows and how they enjoyed the natural light but found the blinds necessary, while the negative comments were either about glare or about how people close to the windows were closing the blinds to suit their own needs making it darker for those seated deeper into the building (see Figure 62).

\begin{tabular}{|l|c|c|c|c|}
\hline Building B & Positive & Balanced & Negative & Total \\
\hline ADCS & $3(12 \%)$ & $17(71 \%)$ & $4(17 \%)$ & $\mathbf{2 4}$ \\
\hline Lighting & $6(29 \%)$ & $6(29 \%)$ & $9(42 \%)$ & $\mathbf{2 1}$ \\
\hline Health & $3(16 \%)$ & - & $16(84 \%)$ & 19 \\
\hline Comfort & $7(39 \%)$ & $1(5 \%)$ & $10(56 \%)$ & $\mathbf{1 8}$ \\
\hline Productivity & $4(15 \%)$ & - & $22(85 \%)$ & $\mathbf{2 6}$ \\
\hline \multicolumn{5}{|r|}{ Figure 62: Building B - Comment Distribution } \\
\hline
\end{tabular}

Analysis of the five aspects found that lighting was not considered a negative aspect with regard to health, comfort or productivity. In fact only three comments were negative about lighting in the Productivity section which related to bright reflections and glare. The main contributor to the negative comments was air and temperature, which totalled 30 comments across the three aspects. Other than the comments made in the Automated Daylight Control System and Lighting aspects, lighting does not seem to benefit or hinder in health, comfort or productivity issues.

\subsubsection{Building C - Comments}

With the highest number of occupants completing this survey out of the four buildings (175 of 320), 159 comments were made throughout the five aspects. Figure 63 is a summary of the comments for Building C. There are a high percentage of negative comments overall, with the highest percentage for the automated daylight control question. The comments from this section were mainly negative toward the system making the artificial lighting too dim, turning off when people are still in the room, being too slow to respond to changes in light and similar general issues in the smaller meeting rooms. The two positive comments had no problem with the system while the balanced comments mentioned aspects that were negative but also gave the solutions to these problems (such as the use of blinds).

On the aspect of Lighting, the comments are nearly evenly distributed between positive and negative (and five for balanced). It appears that seating positions (as noted by the text in the comments) in the building have an impact on whether a positive or negative comment was made in the survey. The positive comments generally appreciate the natural lighting and 
attractiveness of sitting next to a window or atrium, while negative responses were about dark and gloomy spaces where there was often not enough light on desk tops. The main negative concerns were dull areas ( 7 comments), glare (3 comments), artificial lighting (2 comments), lack of natural light ( 3 comments) and difficulty to read ( 2 comments). Two comments made that were deemed balanced discussed how "lights tends to go off when it's bright outside" and "the lights above my desk dim and then randomly go bright, it's pretty annoying" which shows that not everyone in this building is aware of the system and how it operates (see Figure 63) and also demonstrates that the system is not working as well as it should.

\begin{tabular}{|l|c|c|c|c|}
\hline Building C & Positive & Balanced & Negative & Total \\
\hline ADCS & $2(6 \%)$ & $2(6 \%)$ & $27(88 \%)$ & $\mathbf{3 1}$ \\
\hline Lighting & $16(42 \%)$ & $5(13 \%)$ & $17(45 \%)$ & $\mathbf{3 8}$ \\
\hline Health & $8(17 \%)$ & $5(14 \%)$ & $24(69 \%)$ & $\mathbf{3 5}$ \\
\hline Comfort & $10(37 \%)$ & $2(7 \%)$ & $15(56 \%)$ & $\mathbf{2 7}$ \\
\hline Productivity & $10(32 \%)$ & $1(3 \%)$ & $20(65 \%)$ & $\mathbf{3 1}$ \\
\hline \multicolumn{5}{|r|}{ Figure 63: Building C-Comment Distribution } \\
\hline
\end{tabular}

Investigating further into the comments found that the comments concerning health, comfort and productivity did not relate to lighting nor was it a concern in any way with only four comments being made, three of which being positive (two in Health, one in Productivity) and one negative (Comfort) complaining about poor lighting levels. This was from a total of 93 comments in all three aspects.

\subsubsection{Building D - Comments}

There were 121 comments across the five further investigated aspects, a larger number than Building $B$, but from a smaller number of answered surveys. From observations and opinions from staff during the time the survey was distributed, it was clear that the occupants were aware of the automated daylight control system. A large proportion of the comments were negative with only three positive comments about the system and two balanced comments. The negative comments were based around the lighting turning off while people were sitting still in rooms, dimming the lights to levels which made it difficult to see and some respondents preferring manual control over automatic.

In Lighting there were 11 negative comments, but unlike the majority of the comments made of the other four buildings, most were about the inadequacy of the artificial lights (6 comments) with the rest covering glare, manual switching and the lights turning off when the occupants were sitting still. The positive comments appreciated the natural light while the 
balanced comments were focused on small amounts of glare and the need for more blinds (see Figure 64).

\begin{tabular}{|l|c|c|c|c|}
\hline Building D & Positive & Balanced & Negative & Total \\
\hline ADCS & $3(12 \%)$ & $2(8 \%)$ & $20(80 \%)$ & $\mathbf{2 5}$ \\
\hline Lighting & $7(29 \%)$ & $6(25 \%)$ & $11(46 \%)$ & $\mathbf{2 4}$ \\
\hline Health & $5(19 \%)$ & $10(38 \%)$ & $11(42 \%)$ & $\mathbf{2 6}$ \\
\hline Comfort & $7(32 \%)$ & $2(9 \%)$ & $13(59 \%)$ & $\mathbf{2 2}$ \\
\hline Productivity & $6(25 \%)$ & $7(30 \%)$ & $11(45 \%)$ & $\mathbf{2 4}$ \\
\hline \multicolumn{5}{|r|}{ Figure 64: Building D - Comment Distribution } \\
\hline
\end{tabular}

When analysing comments made about lighting in the other aspects, there were very few from health, comfort and productivity that related to lighting. In all three aspects there are only seven comments ( 3 positive, 4 negative) concerning lighting. The main issues that arose were about air, temperature and noise. The comments made about Lighting and the Automated Daylight Control System mostly relate to the operational aspects of the system. The main topics complain about the brightness of the artificial lights, the system turning off while people are still in the room and requesting manual switching.

\subsection{Lighting \& Automated Daylight Control System Comment Summary}

As discussed in the previous Section, surveys can be a place to voice an opinion and are often used to freely complain without repercussions. Overall there were very few negative comments about lighting in the five further investigated sections. Comments on lighting were only mentioned 17 times out of the 250 comments for all four buildings, with seven positive comments and 10 negative. Occupants commented more about temperature, air quality and noise as affecting their health, comfort or productivity but seldom considered the lighting to be relevant to these aspects.

While analysing the comments from the Automated Daylight Control System question, it was found that if the occupants were more aware that their building had a system (i.e. answered Yes - Building A: 7\%, B: 17\%, C: 47\%, D: 37\%), they were more critical of how it did or didn't work. Occupants in buildings A and B were least aware of their lighting system with the two highest percentages answering that they Don't know of any system (A: $90 \%, B: 64 \%)$. For Buildings $C$ and $D$, comments were directed at poor light levels due to dimming, the system turning off when occupants were sitting still for long periods of time, and a lowered amount of light toward the core of the building due to the system dimming the lights from a sensor near the window (Don't know; C: 51\%, D: 60\%). 
The comments overall for lighting were quite evenly balanced, with the four buildings totalling 31 positive comments, 20 balanced comments and 40 negative comments. This indicates that there are nearly as many good things being said about lighting as there are bad. Negative comments specifically relating to natural light were approximately one third (14 of 40), which included issues of glare and lack of natural light in some areas of the building.

The Automated Daylight Control System comments had 8 positive, 21 balanced and 51 negative. It was interesting to find that much of the negative feedback about the automated daylight control system related specifically to the artificial lighting, with comments such as 'not having enough light on the desks when seated closer to the core of the building'.

Overall it can be concluded that natural light is an appreciated light source, but it has the disadvantage of glare. The comments suggest that glare from natural light appears to be less than the issues with the artificial lighting and automated daylight control system itself. Furthermore, with regard to health, comfort and productivity it seems that lighting is not of high concern when compared to issues of air, temperature and noise which have the greatest number of negative comments.

\subsection{Survey Comments Overall}

To further explore the influence that natural and artificial lighting had on the occupants; the survey comments for all four buildings were compiled and analysed as one set. This set of 423 comments from all five aspects was used to understand overall how occupants perceive their environment by looking at common themes. For all four buildings there was an overall uncertainty about whether or not there was an automated daylight control system installed. As described in the previous section, this may alter the data set as most occupants answered all questions in the survey anyway.

It should be noted that if the occupant does not know whether or not the building has an automated daylight control system, it is difficult for occupants to comment, complain or be able to make changes to their environment if they don't understand how it works. However, the researcher was not able to inform the occupant of this fact to maintain an unbiased position. 


\begin{tabular}{|l|c|c|c|c|c|}
\hline & ADCS & Lighting & Health & Comfort & Productivity \\
\hline Positive & $8(10 \%)$ & $31(34 \%)$ & $20(20 \%)$ & $24(35 \%)$ & $21(24 \%)$ \\
\hline Balanced & $21(26 \%)$ & $20(22 \%)$ & $19(19 \%)$ & $5(7 \%)$ & $8(10 \%)$ \\
\hline Negative & $51(64 \%)$ & $40(44 \%)$ & $58(61 \%)$ & $40(58 \%)$ & $57(66 \%)$ \\
\hline Ratio +/- & $1: 6.38$ & $1: 1.29$ & $1: 2.9$ & $1: 1.67$ & $1: 2.71$ \\
\hline \multicolumn{7}{|c|}{ Figure 65: Overall Comment Totals \& Percentages } \\
\hline
\end{tabular}

Tables of the comments separated into common themes for each building and overall, are in Appendix Eight.

The ratios of positive comments to negative comments for the four buildings are: Lighting (1:1.29), Comfort (1:1.67), Health (1:2.9) and Productivity (1:2.71). When comparing the positive to negative comments for the new question of Automated Daylight Control System, there was a very high weighting for negative comments with a ratio of 1:6.38. This ratio of negative to positive comments shows the affect that the automated daylight control system has on the occupants. These results were compared to Baird's positive to negative ratio findings of 1:2.25. With regard to Baird's ratio from his research, the positive to negative ratios for all questions except for the automated daylight control system are similar. The automated daylight control system is far worse suggesting that there are many issues with the system that need to be addressed.

Combining all comments made from all four buildings made it easier to detect common themes. For the automated daylight control system question, the positive comments had no specific themes, nearly half of the balanced comments were of not knowing of the existence of a system and the main (18 of 50 ) negative comments were that the system would turn off too often. The second largest negative comment was about the overall office lighting being too dim which may be caused by the automated daylight control system itself.

The lighting question received nearly as many positive comments as it did negative, with nearly one third (9 of 31) of the positive comments being specifically about natural light and how much it is enjoyed while only two comments praised the artificial lighting. The majority of negative comments were about dark and gloomy spaces in the buildings that didn't get enough natural light (13 of 40) and about glare from the sun and surroundings (15 of 40).

Further investigation into the health question found that lighting accounted for a small number of the negative comments with only two relevant comments ( 2 of 58), one complaining about feeling unhealthy under artificial lighting and the other feeling unhealthy from a lack of sunlight. This is in comparison to the relevant positive comments (5 of 20) about the health benefits of natural light and how it is appreciated in the workplace. 
With a high number of comments made about the dark and gloomy spaces as well as glare in the lighting section, it was surprising to find that only five (5 of 40 ) negative comments related to lighting for the comfort question (visual comfort). Furthermore, of those five comments made, two were about glare from natural light while the rest were about the artificial lights.

Lighting did not seem to affect self-assessed productivity with only four negative comments ( 4 of 57 ) and only two positive comments ( 2 of 21 ) about general or overall good lighting. It is concluded that the lighting levels are adequate for work to be completed, otherwise more comments on the lack of lighting or there being too much would have been made. The main issue for productivity from the comments was about noise from surroundings as well as fluctuating temperatures.

It became clear from the analysis that the benefit of natural light is offset by its disadvantages. There were nearly the same number of comments made praising natural light as there were condemning the glare that comes with it. Overall it seems that occupants are happy to have natural light in their working environments but require blinds to combat glare at certain times of the day and year. As noted in an earlier section, blinds were installed in all four buildings and it was observed that they were being used when required.

It is concluded that lighting is not considered to be as important to health, comfort and productivity when compared to the issues that arose for temperature, air quality, and to a lesser extent noise. The continuous changes in temperature, draughts, dry air and contaminated air as well as open plan designs have become the main complaints in these buildings. However the analysis of these comments has led to the understanding that natural light is preferred to artificial lighting. 


\subsection{Physical Measurement Results}

To understand if the automated daylight control systems are working correctly, the physical attributes of power and lighting were measured. The power meter data was investigated to quantify the savings with energy savings reported as an average percentage saved per day. Any time energy is below the maximum power demand it is considered a saving, which was further separated into three groupings: Overall, (entire 24 hour period); 9:00am to 5:00pm (a standard working day); and Power On (from the time in the morning when the power is turned on until the time it is turned off again at the end of the day). This Chapter begins by analysing the saving percentages for each day for all three categories, using this to explore the operation of the automated daylight control systems.

The lighting was measured with five illuminance meters set up near the window, near to the automated daylight control system sensor and directly under a lamp. This data was graphed alongside the power meter data to determine at what lux level the automated daylight control system changed (point of change) the artificial light illuminance level.

As discussed previously in Section 2.3, the purpose of understanding how much light would be measured was by measuring the horizontal illuminance. This measures the amount of light on the desks while the vertical illuminance sensors measure how much light is reaching the occupant directly. This is measured by the lux levels from 9:00am to 5:00pm for each of the sensors, with both the maximum value and the averages tabulated and discussed.

\subsection{Power Meter - Saving Percentages}

This Section examines the energy savings that result from the operation of the automated daylight control systems in each building. To calculate how much energy is being used from each of the lighting circuits that the power meters are connected to, a simple formula was developed (refer to Section 4.6). It was assumed that the highest point of energy use was when the lighting of each circuit was at its maximum output, so anything less than this value is a saving.

The power meters recorded data at one minute intervals. Each minute of power usage was compared against the highest output, with the difference divided by the original highest output, giving the percentage that is being saved. This was averaged for each day to give overall savings including for the time during the night when the lighting was completely off. It was then further separated into a standard working day from 9:00am to 5:00pm and then a more detailed analysis of only when the power was on. Again it should be noted that while 
the data was collected every minute, averages were used because automated daylight control systems do not rapidly respond to light as this would cause sharp changes in lighting levels and cause discomfort. However, to see the point at which the system begins to change, one minute intervals are important in understanding how well the system is working overall.

\subsubsection{Overall - $24 / 7$}

The percentages shown in Figure 66 are savings for a 24 hour period, which is why they are so high (due to the amount of time the lighting is completely switched off). The overall percentage ultimately dictates the amount of energy saved during the day and accounts for any time that the lights could be on. Please note that these tables are presented with all of the buildings side by side but they were not measured simultaneously. This means each day's illuminance level and sky type (due to the weather patterns and amount of sunshine as described previously) will vary between the buildings. In the case of Building $A$, a public holiday and a day where a fault occurred, meant two days of data were not able to be collected.

To understand the savings percentages, a small recap of the characteristics of each building and the two spaces is provided so a better idea of what may be happening in each space can be made. It is these characteristics that control how much an automated daylight control system will be able to save on energy use, often resulting with less than maximum savings.

One of the two spaces in Building A had generally uninterrupted access to natural light as it was on the $12^{\text {th }}$ floor while the other (Space 2) had a building across the street from it which would block light from the east. Building $B$ is a tall building with no surrounding buildings from level three up, giving both spaces on level 14 uninterrupted natural light. Space 1 faces directly north and Space 2 faces north-west, but is in the corner of the building which means light comes from both the north and west directions. Building C's measurements were taken at lower levels ( $1 \& 3)$. There were many obstructions such as buildings and trees that could minimise the amount of natural light that could penetrate into the building as these office spaces were closer to the ground (in comparison to the other taller buildings). Building D was measured in two offices next to each other. Space 1 is a corner office with a corner window facing north east to east, while Space 2 faced south east. This building was positioned between two other buildings, covering its north and south facades, which meant daylight was unable to enter from these sides. 


\begin{tabular}{|c|c|c|c|c|c|c|c|c|}
\hline \multicolumn{9}{|c|}{ Energy Savings of both spaces - Overall 24/7 } \\
\hline & \multicolumn{2}{|c|}{ Building A } & \multicolumn{2}{|c|}{ Building B } & \multicolumn{2}{|c|}{ Building $\mathrm{C}$} & \multicolumn{2}{|c|}{ Building D } \\
\hline & Space 1 & Space 2 & Space 1 & Space 2 & Space 1 & Space 2 & Space 1 & Space 2 \\
\hline Day One & $32 \%$ & $51 \%$ & $38 \%$ & $35 \%$ & $40 \%$ & $69 \%$ & $66 \%$ & $66 \%$ \\
\hline Day Two & $45 \%$ & $55 \%$ & $58 \%$ & $56 \%$ & $54 \%$ & $66 \%$ & $63 \%$ & $82 \%$ \\
\hline Day Three & $55 \%$ & $54 \%$ & $60 \%$ & $60 \%$ & $52 \%$ & $66 \%$ & $60 \%$ & $72 \%$ \\
\hline Day Four & $55 \%$ & $54 \%$ & $59 \%$ & $59 \%$ & $53 \%$ & $65 \%$ & $74 \%$ & $64 \%$ \\
\hline Day Five & $41 \%$ & $39 \%$ & $55 \%$ & $53 \%$ & $54 \%$ & $63 \%$ & $77 \%$ & $71 \%$ \\
\hline Day Six & $44 \%$ & $41 \%$ & $54 \%$ & $53 \%$ & $52 \%$ & $65 \%$ & $75 \%$ & $76 \%$ \\
\hline Day Seven & $50 \%$ & $52 \%$ & $51 \%$ & $53 \%$ & $51 \%$ & $53 \%$ & $75 \%$ & $73 \%$ \\
\hline Day Eight & & & $56 \%$ & $55 \%$ & $53 \%$ & $66 \%$ & $64 \%$ & $73 \%$ \\
\hline Day Nine & & & $63 \%$ & $62 \%$ & $52 \%$ & $66 \%$ & $75 \%$ & $77 \%$ \\
\hline $\begin{array}{l}\text { Average } \\
\text { Overall }\end{array}$ & $46 \%$ & $49 \%$ & $55 \%$ & $54 \%$ & $51 \%$ & $64 \%$ & $70 \%$ & $73 \%$ \\
\hline
\end{tabular}

From the observations made in each building, it was assumed that Buildings $A$ and $B$ would have the most savings due to a lack of obstructing surroundings and the measuring equipment being positioned at a high level. As detailed in Figure 66 this was not the case, with $46 \%$ and $49 \%$ for Building $A, 55 \%$ and $54 \%$ for Building $B$, while Building $C$ had similar savings in Space 1, 51\% but performed better in Space 2,64\%. The highest overall savings came from Building D (70\% \& 73\%).

Building $D$ was a difficult building to analyse due to the complicated nature of the lighting circuit/power setup. Each of the spaces that were investigated had three other separate offices using the same lighting circuit, making it a complex set of data. For Space 1, the other three offices had only occupancy sensors, no daylight sensors, while Space 2 was a set of four offices, all with both occupancy and daylight sensors. This building was different to the other three buildings as personal offices were being measured instead of open plan offices, as well as having each spaces lighting circuit being connected to three other offices. The issue when calculating the energy savings was, for example; if all four offices were occupied in the morning the power would be at a maximum for all four offices, until the natural light initiates the system into dimming. But as soon as someone leaves their office the lights will automatically turn off. If two people were to leave, then both of their offices would have lights off, which isn't uncharacteristic in this type of building. There is no possible way to distinguish the offices of Space 1 and Space 2 from the rest of the data, which may have led to apparently high energy savings.

Overall 24/7 savings are a good indicator of how much energy is being saved and the number of hours the building is in use, but they don't directly indicate the automated daylight control 
system savings, however for a continuously running system this may be the only way to monitor savings. A better understanding is to analyse the data for a standard working day.

\subsubsection{Standard Working Day}

A standard working day is considered to be from 9:00am to 5:00pm; although this may vary depending on the type of business and main occupation of the building. However for the purpose of this research, it is assumed a standard working day is eight hours. The data from each building has been graphed to show the difference in average savings between each of the spaces and the buildings over the nine days of measuring. The numerical values are given in Figure 68. Again note that these readings were not taken simultaneously which means that each building would have experienced different weather patterns.

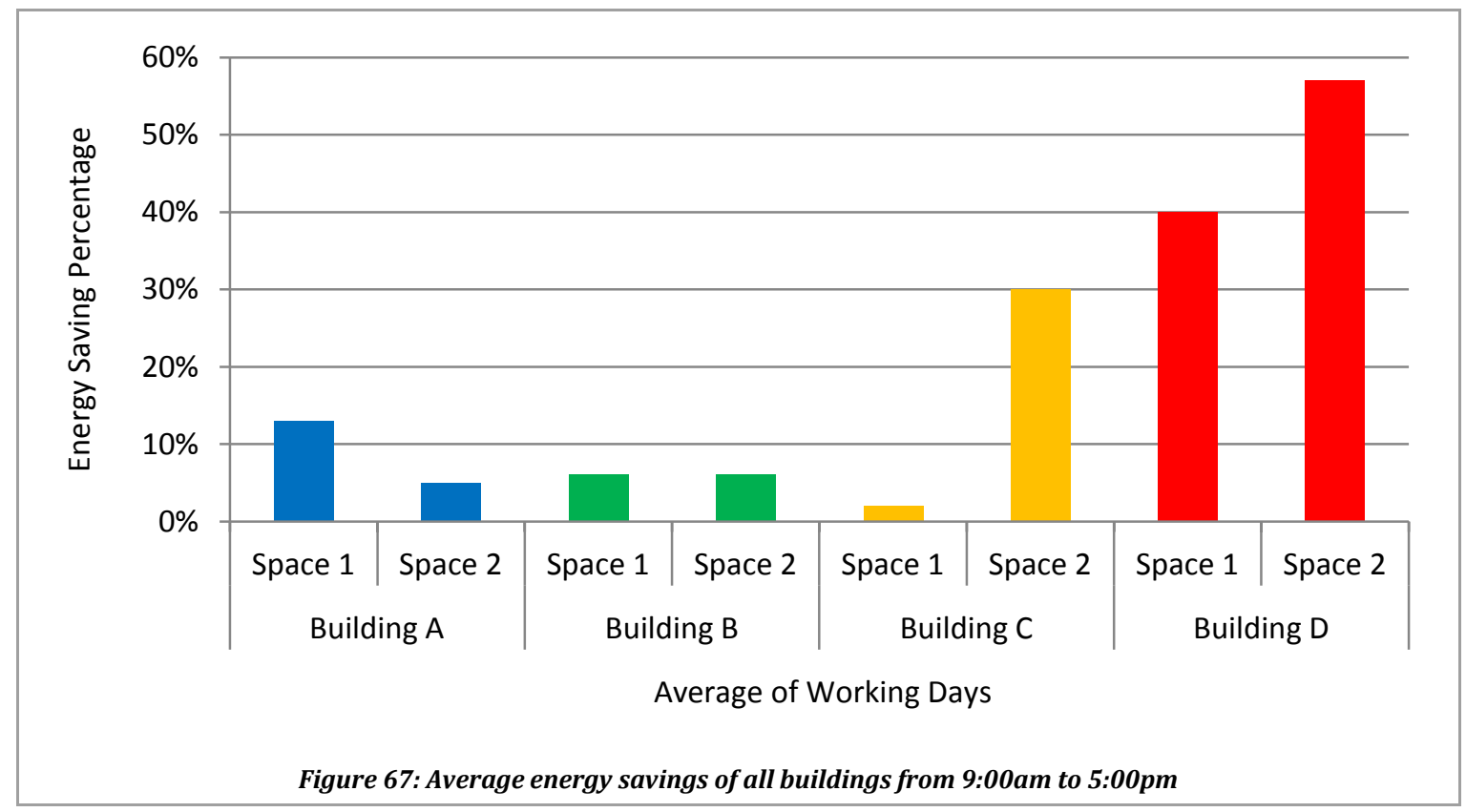

Building $A$ had quite small energy savings for the observed natural light, with $13 \%$ and $5 \%$ respectively. There were higher energy savings in Space 1 as it was facing due north, while Space 2 had significantly lower readings facing east. Overall this building did not achieve the positive savings that were assumed from time spent in the building during the observation days.

Building $B$ had the least savings of all the buildings, reaching a maximum savings of $9 \%$ and averaging $6 \%$ for both spaces. This was a surprising result as both spaces in this building have uninterrupted skylines. As described earlier, this building only has one sensor for each orientation (N, E, S \& W) which is $2.0 \mathrm{~m}$ from the window. With only four sensors controlling each floor, the savings are far less than what would be expected and less than what the 
literature had indicated expected savings to be. These results indicate that the system is not working at its full capability and has possibly drifted from its original settings.

Building $\mathrm{C}$ performed as it was expected to do judging from the initial observations made. Due to the surrounding buildings and trees, Space 1 on the first floor had a low percentage (2\% average) of energy savings. Orientation is important when trying to optimise an automated daylight control system (Space 1 faces NE) but if there are too many obstructions then orientation becomes unimportant. Space 2 however, performed very well with an average savings of $30 \%$. This is a good outcome that was an expected result from time spent in the building on the observation day.

Building $D$, as explained in the previous Section 7.1.1, was a complicated setup which led to very high savings in energy during the hours of 9:00am to 5:00pm as shown in Figure 68, with $40 \%$ and $57 \%$ savings in Space 1 and Space 2 respectively. Regardless of the complicated setup, these spaces were expected to perform well due to their orientation and clear line of sight.

\begin{tabular}{|c|c|c|c|c|c|c|c|c|}
\hline \multicolumn{9}{|c|}{ Energy Savings of both spaces - 9:00am to 5:00pm } \\
\hline & \multicolumn{2}{|c|}{ Building A } & \multicolumn{2}{|c|}{ Building B } & \multicolumn{2}{|c|}{ Building C } & \multicolumn{2}{|c|}{ Building D } \\
\hline & Space 1 & Space 2 & Space 1 & Space 2 & Space 1 & Space 2 & Space 1 & Space 2 \\
\hline Day One & $23 \%$ & $3 \%$ & $1 \%$ & $2 \%$ & $2 \%$ & $50 \%$ & $32 \%$ & $34 \%$ \\
\hline Day Two & $18 \%$ & $5 \%$ & $7 \%$ & $7 \%$ & $2 \%$ & $34 \%$ & $27 \%$ & $70 \%$ \\
\hline Day Three & $22 \%$ & $5 \%$ & $8 \%$ & $8 \%$ & $2 \%$ & $35 \%$ & $28 \%$ & $56 \%$ \\
\hline Day Four & $8 \%$ & $5 \%$ & $9 \%$ & $8 \%$ & $3 \%$ & $30 \%$ & $37 \%$ & $43 \%$ \\
\hline Day Five & $4 \%$ & $5 \%$ & $5 \%$ & $7 \%$ & $2 \%$ & $25 \%$ & $53 \%$ & $58 \%$ \\
\hline Day Six & $17 \%$ & $8 \%$ & $8 \%$ & $8 \%$ & $2 \%$ & $31 \%$ & $46 \%$ & $64 \%$ \\
\hline Day Seven & $2 \%$ & $2 \%$ & $2 \%$ & $2 \%$ & $3 \%$ & $2 \%$ & $52 \%$ & $66 \%$ \\
\hline Day Eight & & & $2 \%$ & $2 \%$ & $1 \%$ & $34 \%$ & $29 \%$ & $56 \%$ \\
\hline Day Nine & & & $9 \%$ & $8 \%$ & $2 \%$ & $32 \%$ & $60 \%$ & $67 \%$ \\
\hline $\begin{array}{l}\text { Average } \\
\text { Overall }\end{array}$ & $13 \%$ & $5 \%$ & $6 \%$ & $6 \%$ & $2 \%$ & $30 \%$ & $40 \%$ & $57 \%$ \\
\hline
\end{tabular}

\subsubsection{Power 0n}

Even though a standard working day is a good benchmark, these times are not adequate for all building types or occupations. As each building has occupancy sensors integrated in with their daylight sensors, it is possible to establish exactly when the first occupant enters the room until the last person leaves by viewing the recorded power meter data. By manually analysing each days worth of data, it was possible to accurately calculate the amount of energy saved during the hours of occupation or the time when the power was on (Power On). From this information it was found that the occupants of these buildings work a very similar 
pattern to a standard working day and on average there is very little change between the two tables for each space. However on closer inspection, there are some differences between the percentages for each day, for example Building B on Day Nine had 9\% savings when calculated from 9:00am to 5:00pm but when looking at the time specifically when power was on, there is a saving of $17 \%$ which is nearly double using the same data for the same day.

\begin{tabular}{|l|c|c|c|c|c|c|c|c|}
\hline \multicolumn{7}{|c|}{ Energy Savings of both spaces - Power On } \\
\hline & \multicolumn{2}{|c|}{ Building A } & \multicolumn{2}{c|}{ Building B } & \multicolumn{2}{c|}{ Building C } & \multicolumn{2}{c|}{ Building D } \\
\hline & Space 1 & Space 2 & Space 1 & Space 2 & Space 1 & Space 2 & Space 1 & Space 2 \\
\hline Day One & $19 \%$ & $3 \%$ & $7 \%$ & $13 \%$ & $5 \%$ & $52 \%$ & $33 \%$ & $36 \%$ \\
\hline Day Two & $14 \%$ & $5 \%$ & $12 \%$ & $9 \%$ & $5 \%$ & $32 \%$ & $32 \%$ & $71 \%$ \\
\hline Day Three & $16 \%$ & $5 \%$ & $12 \%$ & $12 \%$ & $2 \%$ & $31 \%$ & $36 \%$ & $60 \%$ \\
\hline Day Four & $7 \%$ & $8 \%$ & $15 \%$ & $16 \%$ & $3 \%$ & $33 \%$ & $34 \%$ & $48 \%$ \\
\hline Day Five & $8 \%$ & $5 \%$ & $14 \%$ & $11 \%$ & $2 \%$ & $24 \%$ & $49 \%$ & $58 \%$ \\
\hline Day Six & $13 \%$ & $6 \%$ & $14 \%$ & $13 \%$ & $2 \%$ & $28 \%$ & $46 \%$ & $65 \%$ \\
\hline Day Seven & $6 \%$ & $7 \%$ & $10 \%$ & $4 \%$ & $3 \%$ & $2 \%$ & $49 \%$ & $64 \%$ \\
\hline Day Eight & & & $5 \%$ & $4 \%$ & $2 \%$ & $32 \%$ & $33 \%$ & $59 \%$ \\
\hline Day Nine & & & $17 \%$ & $14 \%$ & $3 \%$ & $30 \%$ & $52 \%$ & $63 \%$ \\
\hline $\begin{array}{l}\text { Average } \\
\text { Overall }\end{array}$ & \multirow{2}{*}{$\mathbf{1 2} \%$} & $\mathbf{6} \%$ & $\mathbf{1 2 \%}$ & $\mathbf{1 0 \%}$ & $\mathbf{3} \%$ & $\mathbf{2 9} \%$ & $\mathbf{4 0 \%}$ & $\mathbf{5 8 \%}$ \\
\hline
\end{tabular}

When comparing the standard working day to the Power On average savings, there weren't significant differences. With the two calculations being so close, it is apparent that the formula for a standard working day has preference over the time consuming Power On calculation process. A simple formula is also beneficial to a larger data set or for a longer period of time. This opens an issue of analysis if this type of research was to be completed on a larger scale for a longer period of time. With both averages being very similar but with significant differences between the days it would be of interest to verify which way of calculating would be best suited or if there is a major difference at all. The 9:00am to 5:00pm would be preferred as it is a far more simplistic calculation whereas the 'Power On' calculation requires a lot of manual input and time. Without a larger data set it is difficult to convincingly state that one preference is better than the other.

\begin{tabular}{|l|c|c|c|c|c|c|c|c|}
\hline & Building A & \multicolumn{2}{c|}{ Building B } & \multicolumn{2}{c|}{ Building C } & \multicolumn{2}{c|}{ Building D } \\
\hline & Space 1 & Space 2 & Space 1 & Space 2 & Space 1 & Space 2 & Space 1 & Space 2 \\
\hline $\mathbf{2 4 / 7}$ & $46 \%$ & $49 \%$ & $55 \%$ & $54 \%$ & $51 \%$ & $64 \%$ & $70 \%$ & $73 \%$ \\
\hline 9am - 5pm & $13 \%$ & $5 \%$ & $6 \%$ & $6 \%$ & $2 \%$ & $30 \%$ & $40 \%$ & $57 \%$ \\
\hline Power On & $12 \%$ & $6 \%$ & $12 \%$ & $10 \%$ & $3 \%$ & $29 \%$ & $40 \%$ & $58 \%$ \\
\hline \multicolumn{8}{|c|}{ Figure 70: Average Percentages of all three measurements } \\
\hline
\end{tabular}

Figure 70 shows the average savings for the three calculation methods. The $24 / 7$ (overall) savings are higher, but this takes into account the night values. However measuring in normal 
circumstances would be ongoing and therefore measuring $24 / 7$ was used to understand how this would affect overall saving percentages. From the above information, the difference between the $24 / 7$ values and the others ranges from $33-49 \%$ (excluding Building $D$ ) and an average difference of $38 \%$.

\subsection{Lux Level Readings}

To maximise the savings potential of each automated daylight control system, the point at which the systems' sensor reads that there is enough light to dim the artificial lights is critical. This 'point of change' has been assessed for each building for each day of recording. This has been completed to understand how much light had to enter each space before the system reacted and dimmed accordingly.

According to New Zealand Standards (AS/NZS 1680.1:2006), the amount of light required on the working plane is 400 lux for routine office work of moderately difficult tasks. Therefore to be able to obtain optimal savings results and using this value as a benchmark of minimum lighting requirements, 400 lux was used as the recommended set point for optimal savings potential. This analysis was completed manually by viewing each of the graphs separately and noting the point of change which is when the illuminance levels increase enough for the power meter to dip in power demand. This was using the 'far horizontal' illuminance sensor as this was positioned a similar distance and position from the window as the automated daylight control systems sensor.

The example shown in Figure 71 is how the process was carried out. Point $A$ is where the maximum power starts to decrease and where Point $B$ is measured. On this example Point $B$ is 800 lux which shows that once the sensor read 800 lux the system automatically dimmed and continued to decrease and increase the artificial lighting in intensity to maintain the required illuminance level on the working plane. For this example, the set point is 400 lux above the 400 lux recommended set point. 


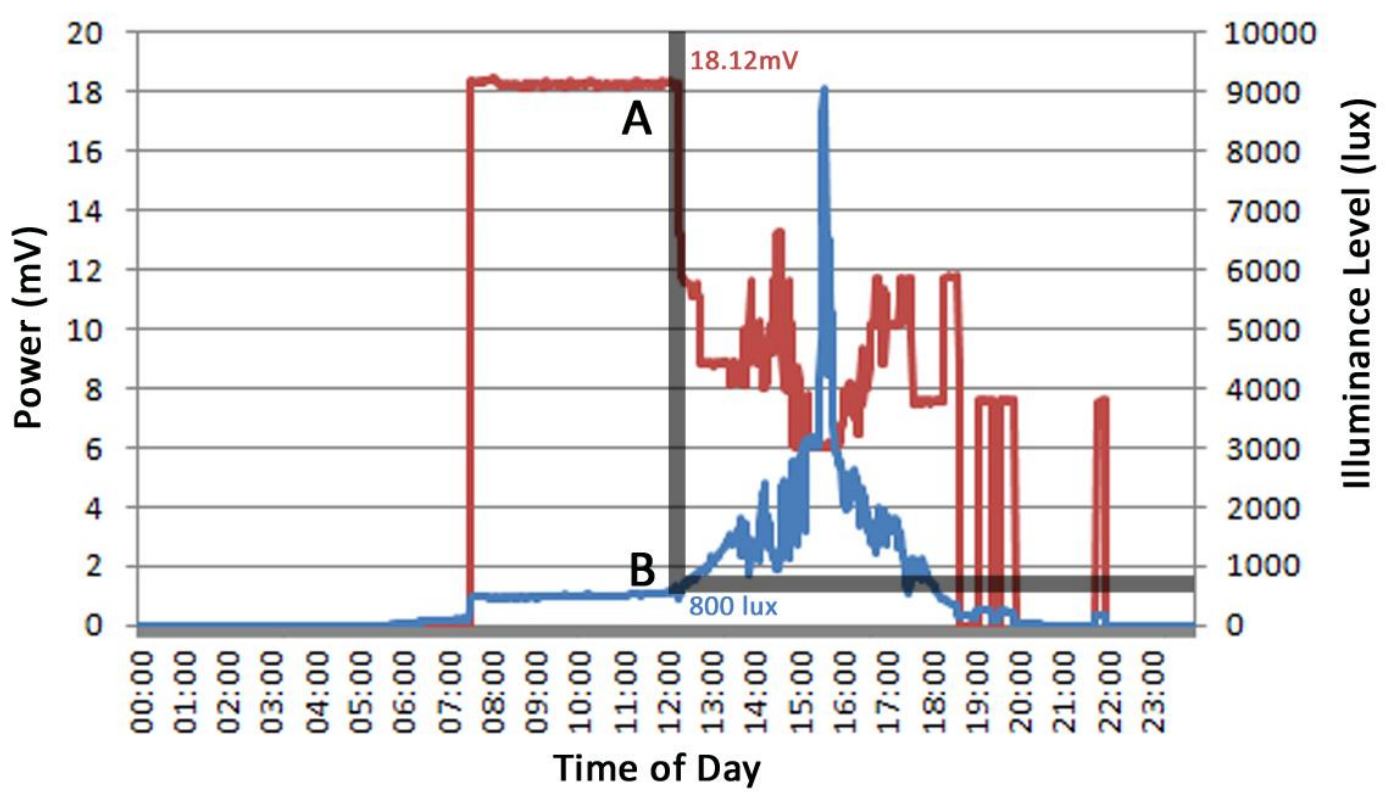

Figure 71: Image showing the automated daylight control system point of change

The results for each building for each day are shown in Figure 72 , which gives a better understanding to why some of the buildings are not achieving the expected energy savings. The values are the minimum lux levels that were recorded for each day at the "point of change' when the power began to reduce. The values that are in bold are the maximum lux level recorded on the far horizontal sensor for the days when the system did not respond to the amount of daylight available and did not decrease the artificial light output at all that day.

\begin{tabular}{|c|c|c|c|c|c|c|c|c|}
\hline & \multicolumn{2}{|c|}{ Building A } & \multicolumn{2}{|c|}{ Building B } & \multicolumn{2}{|c|}{ Building C } & \multicolumn{2}{|c|}{ Building D } \\
\hline & Space 1 & Space 2 & Space 1 & Space 2 & Space 1 & Space 2 & Space 1 & Space 2 \\
\hline Day 1 & 800 & 500 & $1500 *$ & $1200 *$ & 1000 & 1000 & $1300^{*}$ & 1000 \\
\hline Day 2 & 800 & 650 & 1800 & $1400 *$ & 1000 & 1000 & $1800^{*}$ & 1200 \\
\hline Day 3 & 750 & 650 & $1400^{*}$ & 900* & $750 *$ & 1000 & $1500^{*}$ & $2000 *$ \\
\hline Day 4 & - & - & $1800 *$ & 1100* & 650* & 1000 & $1800^{*}$ & 1200 \\
\hline Day 5 & 800 & 700 & 1800 & $1200^{*}$ & $600 *$ & 1000 & 1600 & 2000 \\
\hline Day 6 & 700* & $600 *$ & $1800 *$ & $1000 *$ & $600 *$ & 500 & $1600^{*}$ & 800 \\
\hline Day 7 & 800 & 700 & 1600* & 1400* & $400 *$ & $1000 *$ & $1600^{*}$ & 800 \\
\hline Day 8 & $600^{*}$ & 700 & $3000 *$ & 1500* & 700* & 1000 & $1000^{*}$ & 800 \\
\hline Day 9 & - & - & $1300 *$ & $1000 *$ & $600 *$ & 1000 & $1000^{*}$ & 5000* \\
\hline
\end{tabular}

*Note that for all measurements that are in bold there was no change at this lux level

If the automated daylight control systems are dimming when there is less than 400 lux present, they can be considered to be not working correctly as there would be high occupant dissatisfaction due to not enough light. Conversely, with the system not dimming at some of the higher levels of illuminance (more than 400 lux) which were recorded to be from 1,000 
lux up to 5,000 lux, means that the system could be adjusted to produce higher savings percentages while still maintaining a comfortable illuminance level for the occupants.

One of the issues stated earlier was that it wasn't possible to set up the monitoring equipment directly under the control sensors for a variety of reasons. This meant that the dimming of the lamps and the amount of the light in each space could be slightly off due activities happening directly around either the sensor or the equipment. In some instances it was noted that the blinds were pulled near the automated daylight control system sensor but not near the equipment (or vice versa) which could drastically affect the measured light levels. This may be the case where 3,000 and 5,000 lux were recorded in the space but no dimming occurred. Looking at each building individually helps to understand why energy savings were either poor in the cases of Buildings A and B, or relatively good for Buildings $C$ and D.

\subsubsection{Building A - Point of Change}

Building $A$ had higher savings in Space 1 than Space 2, but still was not achieving high percentages overall. The system in Space 1 was reacting to the daylight levels of 800 lux, which is 400 lux above the recommended lighting level, but given the different sensor placements this may not be significant. There is the possibility of further savings within this point of change difference, but there is the possibility that the dimming level has been altered in response to complaints about the light levels in this space. Space 2, which is facing east responded to less daylight but didn't achieve savings as high as Space 1 due to its orientation. However, if the sensor was calibrated to an illuminance level close to the recommended working plane level, this would deliver higher saving percentages.

\subsubsection{Building B - Point of Change}

Building $B$ overall seemed to not be working very well with only two instances where the system dimmed at illuminance levels of 1,800 lux. With only four sensors per floor and with so many lights being controlled per sensor for each orientation, the savings depend on how well those sensors work. Both spaces had large quantities of natural light present but the automated daylight control system sensor did not reduce the artificial lighting. With 1,3003,000 lux in Space 1 and $900-1,500$ lux in Space 2 being recorded, the system seemed to be barely dimming. This could have been altered to suit the occupants of the building who may require more light but the system may also require recalibrating to achieve improved energy savings. A re-commissioning process in this building is required as it was observed that there were significant amounts of natural light with a high potential for energy savings. 


\subsubsection{Building C - Point of Change}

Space 1 was a very dull space that lacked natural light for the majority of the day due to the congested surroundings and being on the first floor in the building. On two occasions the system dimmed the lights when the illuminance level reached 1,000 lux, but for everything under that there was no change. With only 400 lux required on the working plane, more savings could be achieved but due to the dull surroundings (observed as the building across the street blocking out most of the light) more light may have been required or requested from the occupants of that area. Space 2 had sufficient amounts of natural light but the system dimmed the lights at 1,000 lux nearly every day. There is potential for more savings in Space 2.

\subsubsection{Building D - Point of Change}

As explained earlier, Building $D$ has a complicated system that is difficult to decipher. Furthermore, due to the personal use of the offices there is more control over the blinds and less consistent occupancy levels. As the illuminance sensors were not able to be placed directly under the sensors it is concluded that the system is working correctly but it was found that closing one blind near the sensor directly affects the dimming capability. This is shown with changes at 800 lux but then no change at 2,000 lux. From the minimum illuminance values that the system changed at, it is concluded that this system's point of change is 800 lux for both spaces.

\subsubsection{Summary}

Overall, all four buildings have point of change illuminance levels that are much higher than the recommended minimum illuminance level of 400 lux (see Figure 73). The lighting may have been adjusted to these higher lux settings to make sure there is always a high amount of light on each desk which may have been in response to occupant complaints. Therein lies an issue that this thesis is investigating; are buildings sacrificing occupant satisfaction and comfort for higher energy savings? The points of change values are higher than the recommended lighting level, which if they were adjusted, could potentially save more energy but may create an uncomfortable lighting environment. 


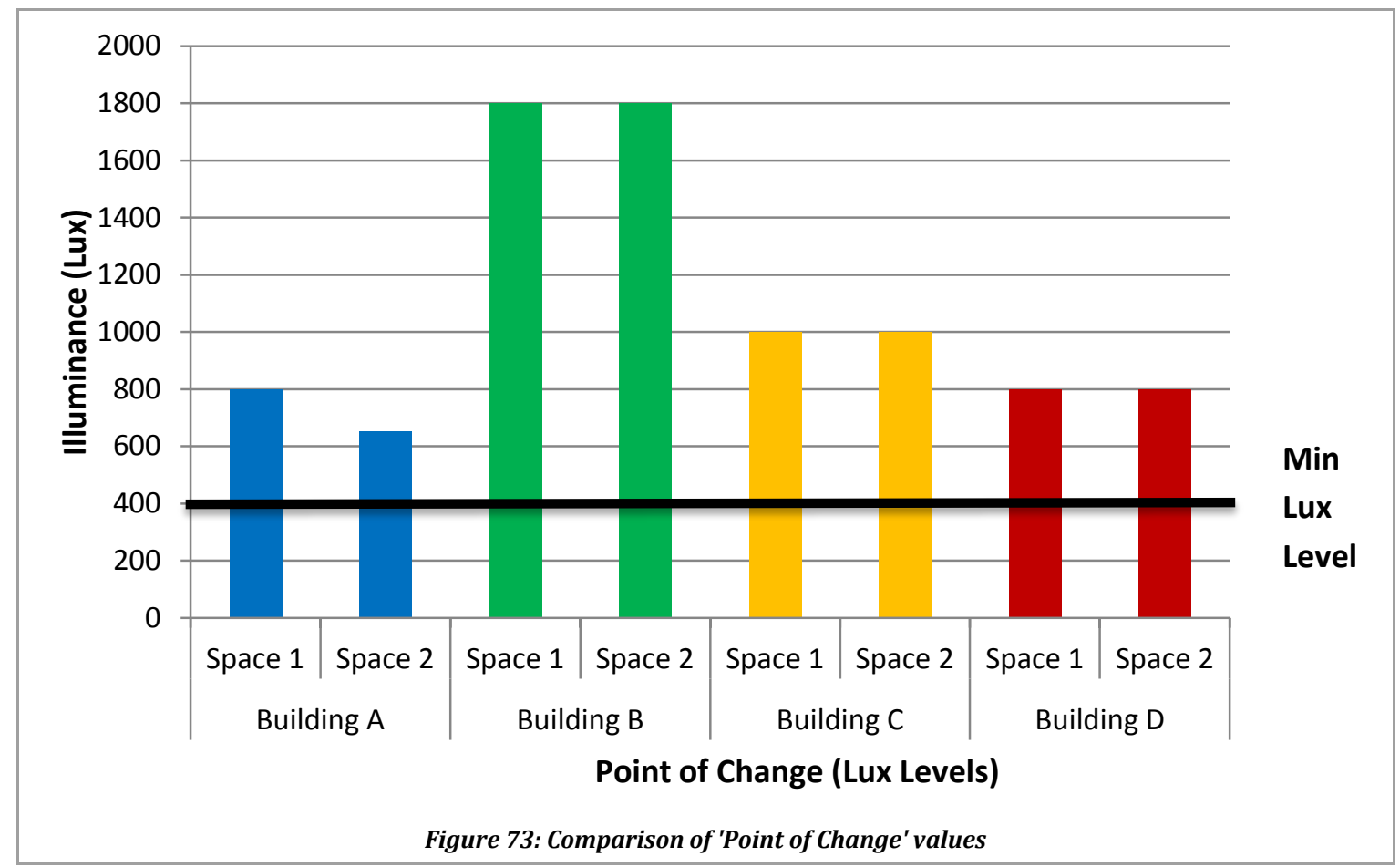

\subsection{Horizontal vs. Vertical Illuminance}

From the literature discussed in 2.3 , it was found that there are two potential ways to measure the amount of light in a building. The horizontal plane is used as a standard measurement to attain the amount of light on a desk, while the vertical plane is used to understand occupant comfort and glare by measuring the amount of light reaching the eye. As this research is investigating how automated daylight control systems work as well as occupant comfort, both planes were measured.

\subsubsection{Comparison of Light Availability by Plane}

As this research was only able to measure for a short period of time, a limited comparison was made between the readings from horizontal and vertical sensors to see if there were any obvious differences. The analysis found that there is a relationship between the horizontal and vertical readings, with the vertical reading being slightly higher than the horizontal in nearly three quarters of the cases ( 23 out of 32 or $72 \%$ ). The average maximum and average values for each space and building for the entire nine days are shown in Figure 74 (for complete tables see Appendix Nine). The values can be seen to be mostly above the midpoint of the $y=x$ line which suggests that there is more light present on the vertical plane, but overall both planes are very similar. 


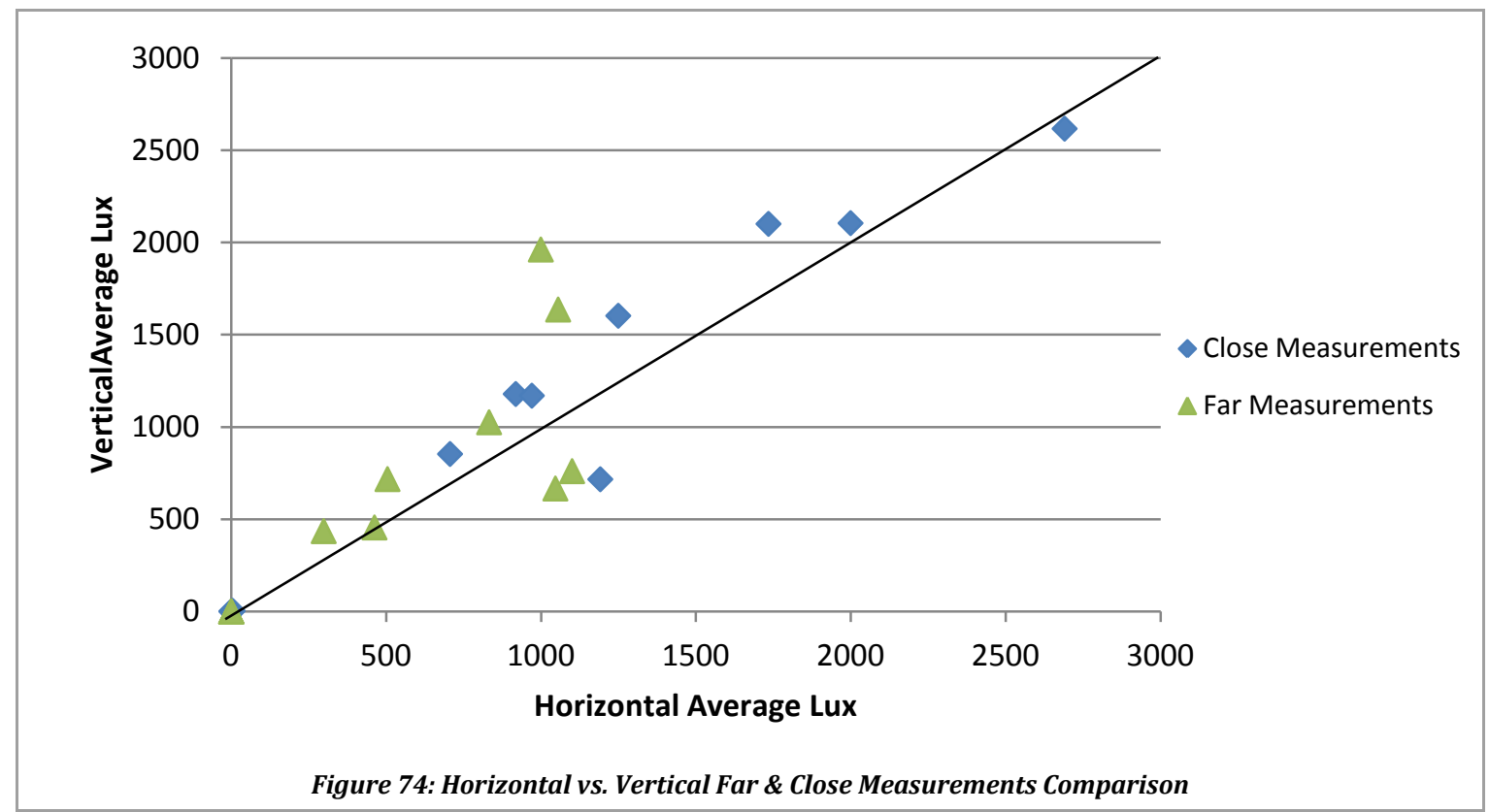

While the New Zealand Standard measures illuminance on the horizontal plane, researchers such as Cuttle, Cantin \& Dubois, have the opinion that measuring the vertical plane is also important. When comparing the illuminance values on the horizontal plane to the vertical plane on average for these test buildings, there is only a small difference (see Figure 74).

\subsubsection{Close vs. Far}

When comparing the close horizontal and close vertical illuminance sensors to their respective far illuminance sensors (see Section 2.3.1), the results could be expected to show that the close illuminance sensors are recording higher lux levels than the far illuminance sensors. This is due to the natural light at the window being far higher than further into the building as all measurements were taken on the northern, north eastern or north western sides of the buildings. Having one sensor hard up against the window (close) and another under where the automated daylight control systems sensor is (far), there should be a large difference between the two readings.

To demonstrate how much of a difference there is between the close and far illuminance sensor readings, Figure 75 below shows the average for each building over a standard working day. This is a comparison of the values measured at the different distances from the window and shows that predominantly the measurement next to the window is higher. 


\begin{tabular}{|c|c|c|c|c|}
\hline \multicolumn{5}{|c|}{ Average Difference between Close \& Far (9 - 5 values) } \\
\hline & & Close Horizontal & Far Horizontal & $\begin{array}{c}\text { \% Difference } \\
\text { (Far/Close) }\end{array}$ \\
\hline \multirow[t]{2}{*}{ Building A } & Space 1 & 2691 & 504 & $19 \%$ \\
\hline & Space 2 & 705 & 460 & $65 \%$ \\
\hline \multirow[t]{2}{*}{ Building B } & Space 1 & 5932 & 1054 & $18 \%$ \\
\hline & Space 2 & 1192 & 1101 & $92 \%$ \\
\hline \multirow[t]{2}{*}{ Building C } & Space 1 & 921 & 298 & $32 \%$ \\
\hline & Space 2 & 973 & 1049 & $108 \%$ \\
\hline \multirow[t]{2}{*}{ Building D } & Space 1 & 5931 & 834 & $14 \%$ \\
\hline & Space 2 & 1717 & 984 & $57 \%$ \\
\hline & & Close Vertical & Far Vertical & $\begin{array}{c}\text { \% Difference } \\
\text { (Far/Close) }\end{array}$ \\
\hline \multirow[t]{2}{*}{ Building A } & Space 1 & 2617 & 717 & $27 \%$ \\
\hline & Space 2 & 852 & 452 & $53 \%$ \\
\hline \multirow[t]{2}{*}{ Building B } & Space 1 & 6109 & 1635 & $27 \%$ \\
\hline & Space 2 & 716 & 759 & $106 \%$ \\
\hline \multirow[t]{2}{*}{ Building C } & Space 1 & 1182 & 435 & $37 \%$ \\
\hline & Space 2 & 1172 & 668 & $57 \%$ \\
\hline \multirow[t]{2}{*}{ Building D } & Space 1 & 7319 & 1026 & $14 \%$ \\
\hline & Space 2 & 2083 & 1926 & $92 \%$ \\
\hline \multicolumn{5}{|c|}{ Figure 75: Overall Differences between Close and Far Illuminance Sensors } \\
\hline
\end{tabular}

As the 'far' sensors are approximately $2.0-3.5 \mathrm{~m}$ from the 'close' sensors, this data shows the high reduction in illuminance levels over a short distance for half of the cases. It appears that in Space 1 of each building there are large differences between the two sensors. While in Space 2 there is not a great change in lux levels between the two sensor readings. By using this information or this setup of illuminance sensors for testing, a far more accurate automated daylight control system could be installed. This would show that more sensors are required in an area that has a large increase in illuminance levels towards the window while somewhere with a relatively even distribution would be able to have less sensors installed.

This information can only be viewed as indicative but has proven to be very useful in the overall understanding of how much potential savings available in a building. Undertaking an investigation prior to installing a system (a retrofit or daylight study), would benefit the systems design by understanding the amount of light entering the space. By knowing how far natural light is penetrating into the building, the design of the automated daylight control system can be created to more specifically suit the surroundings. The system can also be commissioned to an optimum level, while limiting the cost, number of sensors required and associated equipment required to dim and adjust the lights. For references to the positions 
of the close and far illuminance sensors in relation to the windows, see Figure 10, Figure 15, Figure 21 and Figure 24.

\subsection{Summary}

This Chapter on physical measuring has taken the data from the power meters and the illuminance sensors and analysed the overall energy and daily savings in energy. The setpoint of the automated daylight control system sensor, the differences between the horizontal and vertical planes, and how much of a difference in illuminance levels there is between the close and far illuminance sensors have also been analysed. Analysis has shown that the overall energy savings were poor in comparison to those found in the literature review. This may be partly due to the high point of change settings, with all but one of the spaces being double the base measurement of 400 lux.

When comparing the two measured planes (horizontal and vertical) it was found that they were very similar for this set of buildings with vertical readings only slightly more than horizontal, giving an almost equal amount of light on both planes. The close vs. far illuminance sensor results showed that daylight is reduced significantly between the two sensors (separated by $3-4.5 \mathrm{~m}$ ) which demonstrates the need for careful placement and programming of sensors to maintain a constant lighting level and achieve maximum levels of savings.

The final task is to combine the physical measurements and the psychological survey to understand overall how the automated daylight control systems in these buildings are really working. 


\subsection{Results \& Analysis}

In this Chapter the physical and the psychological approaches are combined to attain an overall rating of how well each automated daylight control system is working. The physical environment was tested using illuminance sensors and power meters to understand how the automated daylight control system is reacting to natural light, while the survey tested the psychological environment by obtaining the perceptions of the occupants.

The combination of the physical measuring and the psychological survey was difficult as there were no precedents to follow. It must be made clear that the physical data can only be generalised when comparing it to the survey data, as the illuminance and power meter values are measured in specific positions, while the survey is self-assessments based on experiences.

The comparison was undertaken by firstly understanding how the automated daylight control system itself is setup and the point of change lux values, then comparing these to the survey scores and comments of the automated daylight control system question on the survey. This also compared the lighting layout and the position of the automated daylight control system sensors to the automated daylight control system questions and the survey comments on how well the system was working. Next was the analysis of the illuminance levels using the maximum and average values for a standard working day (from 9:00am to 5:00pm) against the scores and comments made in the lighting section of the survey. The vertical illuminance levels at the close and far positions are compared to see if any high illuminance values (glare) were an issue and compared to the mean scores and comments made and the average illuminance levels throughout the day. The illuminance levels are then compared to the scores of lighting overall and the comments made by the occupants.

Finally an analysis is provided on the average energy savings, comparing the results to what other studies have found, and whether or not each system is working. This is analysed by identifying if occupant satisfaction such as health, comfort and productivity if being sacrificed compared to the overall energy savings.

\subsection{Layout vs. Automated Daylight Control System}

The first part of this analysis directly investigates how the system is configured in each building and how it is operating in comparison to occupant perception. The comments made by the occupants about the automated daylight control system have been grouped into positive, balanced and negative categories. The overall mean scores (see Figure 76 and 
Figure 77) and the point-of-change values that were established in Section 7.2 are discussed in the following sections.

\begin{tabular}{|l|c|c|c|c|c|}
\hline $\begin{array}{c}\text { Automated Daylight Control } \\
\text { System Comments }\end{array}$ & A & B & C & D & Overall \\
\hline Positive & - & 3 & 2 & 3 & 8 \\
\hline Balanced & - & 17 & 2 & 2 & 21 \\
\hline Negative & - & 4 & 27 & 20 & 51 \\
\hline \multicolumn{4}{|l}{ Figure 76: Survey Results for automated daylight control system Questions - Comments } \\
\hline
\end{tabular}

\begin{tabular}{|l|c|c|c|c|c|}
\hline \multicolumn{1}{|c|}{ Building } & A & B & C & D & Best Score \\
\hline Light on Work Surface & 4.20 & 4.31 & 3.95 & 4.12 & 4 \\
\hline View Tasks at Desk & 2.27 & 2.43 & 3.55 & 3.10 & 1 \\
\hline Daylight Control System Overall & 4.62 & 4.01 & 4.75 & 4.90 & 7 \\
\hline \multicolumn{2}{r}{ Figure 77: Survey Results for automated daylight control system Questions } \\
\hline
\end{tabular}

\subsubsection{Building A}

The system layout for Building $A$ is very basic, with seven sensors spread around each floor level approximately $2.0 \mathrm{~m}$ from the window. These sensors control large banks of lights around the perimeter and deeper towards the core but do not control the lights directly around the centre core of the building. The results suggest that there was enough light on the working plane with the system very rarely going below lux levels that would make it difficult to see. Overall the system was deemed to be average and of the 31 respondents no occupant made either a positive or negative comment about it. There aren't many obstructions surrounding the buildings at this high level which allows plenty of natural light to penetrate deep into the building. The layout of this system and how it is working has been given the best scores overall from the occupants. This was a good result with the point of change illuminance levels at 800 lux (the lowest of all four buildings) the occupants are still comfortable and there is the potential to save more energy if calibrated correctly.

\subsubsection{Building B}

Building B has a very basic layout with only four sensors per floor level controlling large banks of lights. The sensors are $2.0 \mathrm{~m}$ from the windows and control the lights to the core of the building (approximately 8.0m deep). From the occupant's comments in the survey, it was noted that there is normally enough light on their desks to work and the system doesn't turn off very often. This may be because the artificial lighting does not begin to dim until the sensor records 1,800 lux (refer to Figure 72). Overall, the occupants did not find their system to be either working poorly or very well, with a score right in the middle of the scale. The majority of comments that were made were deemed balanced as they mostly did not know (64\% or 12 of 17 ) that the building had a system at all. 


\subsubsection{Building C}

Building $C$ has an elaborate system with a multitude of sensors placed close to each other controlling only small sets of lights. This is also the only Green Star building in this study which meant the occupants should be more aware of this type of technology. This is reflected in the scores and comments made. There is the right amount of light on the occupants' desks but it appears that the system turns off quite often making it difficult to complete work. This was shown during the analysis of the data as they had the worst mean score (3.55 refer to Figure 77), which is nearing the mid-point of the scale. This would be described as being moderately difficult to view tasks. Overall the system is perceived to be working slightly above average but there are an overwhelming number of negative comments. These are mainly about the lights turning off while people are still in the room and when the lighting dims too much it creates a dull and gloomy environment. The layout of the system may not be adjusted correctly for those seated further from the windows which may be generating the negative comments. Also the point of change is set at 1,000 lux ensuring a substantial amount of natural light is required to penetrate to activate the sensor.

\subsubsection{Building D}

In Building $\mathrm{D}$ personal offices were measured as only the perimeter rooms have sensors installed and as a result only one person would be in an office most of the time. It was not surprising that of the four buildings it had the second worst score (3.10 refer to Figure 77) for the system turning off too often. With individual offices there is less movement by the occupants which leads to the system turning off more frequently, which is also the top negative comment. Overall the system was rated the highest with a score of 4.90 which is better than the other three buildings which suggests that when the system does dim, it is to a level that the occupants are still happy with. Also, with such individual control of their environments, the use of the blinds may be affecting the system and its effectiveness, which is apparent from the point of change values. The individual control of the room and blinds often made the illuminance sensor read 2,000 lux and the system still did not change the lighting levels (the illuminance sensor and daylight sensor were not aligned which meant some blinds were closed while others weren't).

\subsubsection{Overall}

For all four buildings the layout of each system is similar with most sensors set $2.0 \mathrm{~m}$ from the windows and disbursed around the perimeter of the building, operating lights deep into the central cores ensuring comparability between measurements. The occupants appear to be comfortable, with enough light provided onto their working surfaces, but in buildings $C$ and $D$ 
the occupants were getting frustrated with the lights noticeably turning off at times. Overall occupant satisfaction with the automated daylight control system appears to be good, with the exception of those that sit further away from the window near the middle of the building. This issue is highlighted in Section 7.3.2, which highlighted a large decrease in lux levels between the two illuminance sensors for half of the Spaces measured. This, combined with the number of artificial lights each automated daylight control system operates, can lead to an uncomfortable environment with less light near the middle of the buildings. The majority of negative comments were about the automated daylight control systems turning off too much which is an issue with occupants sitting still and the sensors not recognising any movement and consequently turning off.

\subsection{Illuminance Levels vs. Lighting}

To understand how the amount of light entering the space affects the occupants, the mean scores for all five of the lighting questions (see Figure 78) were compared to the measured illuminance levels. This was completed for both the maximum and averages for the day (refer to 7.3 Horizontal vs. Vertical Illuminance) to see if this was affecting how the occupants perceive their environment. These two aspects were compared because for automated daylight control systems to work efficiently, they need to be designed around utilising natural light which in some instances can be beneficial, but can also be a disadvantage. The five questions on lighting from the survey deal with the benefits and disadvantages, as well as the comments made on lighting. In each building the illuminance sensors were placed near the window and from $2.0-3.0 \mathrm{~m}$ from the window. No light level (on average) from 9:00am to 5:00pm ever fell below the recommended value of 400 lux (AS/NZS 1680.1:2006). The vertical illuminance comparison of the close illuminance readings to the far illuminance readings differs greatly between the maximum values but on average it is suggested that it will not affect the occupants.

\begin{tabular}{|l|c|c|c|c|c|}
\hline \multicolumn{1}{|c|}{ Building } & A & B & C & D & Best Score \\
\hline Lighting Overall & 5.52 & 5.52 & 5.07 & 5.62 & 7 \\
\hline Natural Light & 3.90 & 4.30 & 3.74 & 4.14 & 4 \\
\hline Glare from Sun & 3.34 & 4.21 & 3.11 & 3.92 & 1 \\
\hline Artificial Light & 3.92 & 4.27 & 4.08 & 4.14 & 4 \\
\hline Glare from Lights & 3.23 & 3.51 & 2.96 & 2.97 & 1 \\
\hline
\end{tabular}




\begin{tabular}{|l|c|c|c|c|c|}
\hline \multicolumn{1}{|c|}{ Lighting } & A & B & C & D & Overall \\
\hline Positive & 2 & 6 & 16 & 7 & 31 \\
\hline Balanced & 3 & 6 & 5 & 6 & 20 \\
\hline Negative & 3 & 9 & 17 & 11 & 40 \\
\hline \multicolumn{5}{l}{ Figure 79: Survey Results for Lighting Questions - Comments } \\
\end{tabular}

Comparing these aspects from both the survey and the measured results is problematic as the physical results are representative of only two spaces in each building, while the survey is a representation of the whole building. Therefore specific values can only be considered indicative and will not represent the whole building but give an insight into what levels of illuminance those nearer the windows are experiencing.

\subsubsection{Building A}

As Space 1 was facing directly north, it had higher average lux levels at the window than Space 2 which faces east. The lighting levels for both Spaces deeper into the building however were similar (456 to 718 lux). The vertical illuminance level comparisons show the close measurements are at least double the amount of the far measurements. The glare scores from the survey are close to the mid-point score, suggesting that there is a slight problem with the uncomfortably high amount of light. However, the overall scores for lighting overall, natural light and artificial light, were all good results where all were higher than the mid-points of each scale.

\subsubsection{Building B}

Building B had the worst scores for glare which is supported by the survey comments about the harsh lighting and overall uncomfortable glare. The vertical illuminance levels at the close sensors were at maximum 20,000 lux, while $2.2 \mathrm{~m}$ further into the building the measurements were 3,354 lux (Space 1) and 1,262 lux close with 8,113 lux far in Space 2. These results show that Space 1 would have issues with glare as the surroundings are brighter, whereas Space 2 would not. The scores from the survey for glare from both natural and artificial light sources were highest in Building B compared to the other buildings. The average illuminance values do not vary much and are all above 400 lux which suggests there is enough light to work under.

\subsubsection{Building C}

The illuminance measurements for Building $C$ did not vary greatly between the close and far measurements. The main concern made in the negative comments was of the lack of natural light and the dull or gloomy spaces created from the lighting turning off or dimming too much. This is confirmed by the measurements recorded on average by the window compared 
to those recorded further in. While the close illuminance values were above the recommended level of 400 lux, Space 1 had lighting levels of 299 lux on the horizontal and 436 for vertical (with the lights on during the day) which is lower than maintained illuminance level that is required for moderate office work to be carried out under. Building $C$ had the best glare scores of all four buildings ( 3.11 for sun $\& 2.96$ for artificial). Although the natural and artificial lighting scores were very close to the best score of 4 , it had the lowest score for lighting overall which has not been captured in the survey by occupant comments and is not easily identifiable through physical measurements alone.

\subsubsection{Building D}

There are only two (of 11) negative comments about glare both related to the sun and sky. This is matched by the mean score for glare being close to the mid-point. Building D had the highest score for lighting overall with 5.62, which is closer to the Satisfactory end than the Acceptable mid-point. Most of the positive comments appreciated the natural light which according to the illuminance sensors both close and far lux levels are very high making both spaces generally well lit. The amount of natural light in this building is perceived by the occupants as a good thing and enters the building in such a way that it is non-offensive and reduces glare.

\subsubsection{Overall}

As these buildings have daylight in the working environment, the choice to have natural light is reinforced by the positive comments made in the survey about having natural light in the working environment. Conversely the issue of glare was found by both the survey scores and comments to be less from the artificial lighting than the natural light. The amount of light from both natural and artificial sources is perceived to be the correct amount. This is shown on the survey scale with all scores near the midpoint between Too little and Too much. For buildings $A, B$ and $D$ there are large differences between the amounts of light measured at the window compared to the amount of light measured deeper into the building. This may be the reason there are so many negative comments from the occupants on glare as well as on dull areas with minimal light. However it is difficult to quantify too much light and too little light firstly as each occupant will have a different tolerance level and secondly detailed measurements were not undertaken at all locations into the buildings. 


\subsection{Physical vs. Psychological}

This Section analyses whether or not the automated daylight control systems are sacrificing other environmental aspects, such as comfort and productivity, in order to attain high energy savings. It also analyses how these savings compare to other energy saving percentages found in other field research studies.

The average savings for a standard working day are compared to how occupants perceive their comfort, health and productivity levels and the comments made about each aspect. Figure 80 , gives the energy saving percentages for each of the tested times for all buildings while Figure 81 gives the mean survey scores for Comfort, Health and Productivity. The scores for the Automated Daylight Control System Overall question and their comments were also taken into account in assessing these two approaches. The '9:00am to 5:00pm' savings percentages will be the only savings used for the purpose of this Section.

\begin{tabular}{|l|c|c|c|c|c|c|c|c|}
\hline \multicolumn{10}{|c|}{ Overall Saving Percentages } \\
\hline & \multicolumn{2}{|c|}{ Building A } & \multicolumn{2}{c|}{ Building B } & \multicolumn{2}{c|}{ Building C } & \multicolumn{2}{c|}{ Building D } \\
\hline & Space 1 & Space 2 & Space 1 & Space 2 & Space 1 & Space 2 & Space 1 & Space 2 \\
\hline Overall & $46 \%$ & $49 \%$ & $55 \%$ & $54 \%$ & $51 \%$ & $64 \%$ & $70 \%$ & $73 \%$ \\
\hline 9am to 5pm & $13 \%$ & $5 \%$ & $6 \%$ & $6 \%$ & $2 \%$ & $30 \%$ & $40 \%$ & $57 \%$ \\
\hline Power On & $12 \%$ & $6 \%$ & $12 \%$ & $10 \%$ & $3 \%$ & $29 \%$ & $40 \%$ & $58 \%$ \\
\hline \multicolumn{8}{|c|}{ Figure 80: Overall Saving Percentages for all Buildings } \\
\hline
\end{tabular}

\begin{tabular}{|l|c|c|c|c|c|}
\hline \multicolumn{1}{|c|}{ Building } & A & B & C & D & Best Score \\
\hline Comfort & 5.45 & 5.08 & 5.30 & 5.50 & 7 \\
\hline Health & 3.87 & 3.75 & 4.20 & 4.06 & 7 \\
\hline Productivity & 5.40 & 4.94 & 5.32 & 2.79 & 9 \\
\hline \multicolumn{5}{|l}{} \\
\hline
\end{tabular}

\subsubsection{Building A}

With average savings of $13 \%$ and $5 \%$ for Spaces 1 and 2 for Building $A$, these were very small savings compared to what was found in the literature average saving of $39 \%$ (see Section 2.4). With these small savings it is assumed the artificial lighting does not dim very often (otherwise there would be greater savings). The comments suggest that this system does not impact on occupant behaviour as lighting is not reported as playing a major part with regard to health, comfort or productivity in this building, but more likely because the controls are not working very well. 


\subsubsection{Building B}

Building $B$ had the lowest of savings (on average) for a standard working day with only $6 \%$ savings for both spaces, compared to the literature review average of 39\% (see Section 2.4). This may be why the occupants were mostly unaware of the building having an automated daylight control system as it would be difficult to tell if the lights were ever dimming at all. This may be why there is such a high percentage of occupants unaware of the system as the scores of the automated daylight control system question (refer to Section 6.2.3) was answered mostly as 'don't know (64\%). Given this information, it is difficult to comment on the other psychological factors as there is a general complacency with the building with no negative comments about the system from the point of view of self-reported health, comfort or productivity. However, comments addressed the issues that the automated daylight control system turns off too often when people are still at their desks which leads to an overall dissatisfaction with the current system. The data collected suggests that the occupants are content with their environment, but the system is working poorly with small savings being recorded due to a high point of change lux level (1,800 lux). There isn't any obvious change of occupant behaviour due to the automated daylight control system.

\subsubsection{Building C}

Of all the buildings, Building $C$ had two spaces that showed the greatest difference in savings which was a direct result of the type of spaces that were measured. Space 1 ( $2 \%$ savings) was closed off with close surrounding buildings, while Space 2 (30\% savings) was next to an atrium. Only Space 2 comes close to the literature review average of 39\%. The occupants in this building were more aware of the automated daylight control system than the other buildings and therefore produced far more negative comments. Only one negative comment was found in Comfort while Health received two positive comments and Productivity one positive comment about lighting. The difference in the spaces is reflected in the range of comments made overall, with contrasting comments about glare and too much light compared to dull, gloomy spaces that don't receive enough natural light at all. From the negative comments made on the automated daylight control system question, it shows that there are some issues with lights becoming too dim at times, but mostly occupants are annoyed with the lights turning off which was commented on 18 times (of 51 comments).

\subsubsection{Building D}

Building D had significant savings for both spaces (40\% \& 58\%) which are comparable to the average literature review savings of $39 \%$. From the comments and scores it was found that self-reported comfort, health and productivity did not affect behaviour with regard to the 
automated daylight control system. With regard to comments made on lighting specifically, only three negative comments were made in the Comfort question and one in Productivity while there was one positive comment in Health and two positive comments in Productivity (refer to Appendix Seven). These high savings as explained previously (see Section 7.1.1) are due to the complicated layout of the system in this building. Even so, with such high savings being calculated the system must be working well enough to carry out its main task of saving energy which is noted by the comments made. There are very few complaints also suggesting that the occupants are comfortable within their environment. However it is presumed that high savings can be achieved in these spaces as there is individual control in each individual office that has led occupants to a happy medium between savings and comfort.

\subsubsection{Overall}

From the energy saving percentages (for a standard working day) of all the buildings with a range of savings from $2 \%$ to $57 \%$, there was an average energy savings of $20 \%$. The average of buildings A, B and C (taking away the uncertainty of Building D) is $10 \%$ with a range of $2 \%$ to $30 \%$, which is half of the energy savings when Building $D$ is included and one quarter of what was found in the literature for Field Measurements. It would appear that the three buildings were able to achieve only small savings while maintaining high occupant satisfaction, while the fourth had high savings but there was uncertainty around the data.

The savings from other studies such as from the Field Measurements (average of 39\%), and Manufacturers (average of 60\%) are far higher than the energy savings produced in each of these four research buildings individually. With the data suggesting that occupants are content and comfortable in their current buildings, it would be possible to change the way the automated daylight control system is operating to optimise and increase energy savings. This could be achieved by lowering the point of change lux level and testing how much energy can be saved before the environment is compromised. 


\subsection{Conclusions \& Discussions}

\subsection{Discussion and Recommendations for Individual Buildings}

In Building A more sensors are required further into the building away from the windows to enable the automated daylight control system to be improved. There are currently seven sensors around the perimeter of the building that control large banks of lights, but occupant comments were made about there being less light further from the windows. This is confirmed by the large difference recorded between the close and far meters in Space 1. There is a difference also in the results from orientation alone, with nearly twice the energy savings on the north side compared to the east side.

Similar to Building A, Building B requires more sensors deeper into the building at varying increments to control the deeper lights so that an evenly distributed light level is taken all the way to the core of the building. This building had only four sensors controlling four large banks of lights, which resulted in poor lighting near the core of the building and a lack of sensitivity to different areas the further away from the window.

Building $\mathrm{C}$ has a well performing system in place but could have been able to increase the savings and reduce their payback period by initially not having daylight sensors in areas such as Space 1, as the energy savings are small and a small test period would have been beneficial. This space did not achieve high energy savings, with unresponsive sensors creating dull lighting the further into the building. This was further highlighted by the occupants being frustrated at the lights turning off often due to a lack of movement. This was in comparison to Space 2 near the atrium that received ample natural light and the system resulted in high energy savings.

Building $D$, with its personal offices, does not need to change the automated daylight control system that has been installed. Only the perimeter offices have daylight sensors (other offices have occupancy sensors only) and they are working as well as the occupants of those offices allow them to, because adjusting blinds to suit their needs reduces the savings. From observations and time spent in the building, the only improvement that could be suggested is that more sensors be put in place in other areas of the building where there currently aren't any, in order to potentially achieve higher overall energy savings for the building, as it was observed that many areas had potential to save energy. 


\section{Overall Discussion}

Occupants will always change their environment to suit their needs, if change is permitted or possible. One thing that is easily and rapidly changeable is the amount of natural light coming into a building. As each of the selected building had blinds, they provide a quick and easy solution to issues of glare and/or overheating. The issue with using blinds is that they will dramatically reduce the energy saving potential of the automated daylight control system. If the automated daylight control system isn't able to work, then the overall savings will be lessened and the overall payback period will be increased. However, in many cases blinds are necessary to maintain comfort and reduce the amount of glare, as this was one of the most often commented issues in the survey and noted by the measurements between close and far illuminance meters.

From the survey it was found that nearly half of the balanced comments made about the automated daylight control system were about being unsure that there was a system at all. When the question was posed, Is there an automated daylight control system in this building, the majority of people did not know; furthermore on average, $7 \%$ said there wasn't such a system in their building, $66 \%$ said they did not know if there was such a system or not, leaving only $27 \%$ that were aware. If there was better knowledge about the systems installed, how they are supposed to work and their purpose, occupants would have a better understanding of what is required of the automated daylight control system and would be able to give better feedback to the building managers with regard to the amount of light on their desks and the issues faced from natural light. This could even lead to a greater tolerance for light level variations if they were aware of the energy savings potential.

Selected psychological aspects of the survey were compared with one of the physical aspects from the monitoring to understand how they related to the performance of the automated daylight control system. This was completed by analysing the layout of the automated daylight control system, the illuminance levels, the point of change values and how this may affect the scores and comments made about it by the occupants on the survey.

Overall the automated daylight control question produced more positive comments than negative comments, at a ratio of 1:6.4, complaining mostly about how the lights would often turn off while people are still in the room and occasionally not having enough light to work. This is regarded as quite high when comparing this to Baird's works which had a 1:2.25 positive to negative ratio. 
The overall average illuminance values were compared to the scores and comments from the lighting question in the survey, and compared to the close and far vertical illuminance levels to see if there were any issues of glare and of so how these related to the comments made about glare. This was a difficult comparison as the survey covered the whole building while the physical measurements were only for two spaces in each building. It was concluded that on average the occupants of each of the buildings were content with their lighting (natural and artificial) but had slight issues with glare from both light sources. The comments made about the lighting section were reflective of the main advantage (appreciate natural light) and disadvantage (glare) of natural light with 31 positive comments and 40 negative comments. The illuminance measurements confirmed that there was sufficient natural light near the windows. Overall it can be summarised that occupants of all four buildings were happy with their environments, the automated daylight control system and from observations it appears that the presence of natural light did not affect their behaviour.

Lastly a comparison was made of energy savings of this research with other studies investigated in the literature review (refer to Section 2.4) and whether or not the selected systems achieve maximum savings by sacrificing comfort or whether the occupants are comfortable with their environments. It was found that three of the buildings in this research ( $A, B$, and $C$ ) were only achieving small energy savings, far less than found in other studies. From the results of the survey the occupants appear to be comfortable within their buildings, but the automated daylight control systems are not achieving high enough energy savings.

\subsection{Conclusions}

The aim of this study was to find out whether automated daylight control systems in a selected number of Wellington office buildings are working as they should. This technology is becoming a popular choice in new buildings as well as retrofits as an energy efficient tool. The two main operations of these systems are to reduce the artificial lighting levels when sufficient natural light is detected, and to maintain the light levels to ensure the comfort of the occupants. These two aspects were investigated using two different methods; physical measurements using illuminance sensors and power meters, and a psychological selfassessment using a post-occupancy survey of the building occupants.

These two approaches were chosen because both the electrical and sensory equipment needs to be working correctly to ensure that the occupants are comfortable in their working environment. It was proposed that this combination would lead to a better conclusion than 
measuring each aspect separately, ascertaining whether the automated daylight control systems were working as they should.

Based on the literature review, it was also decided to explore the difference in light levels between the horizontal and vertical planes as there were conflicting ideologies behind the reasoning of each plane. It was found that there wasn't a great difference between the two planes in all four buildings. This result suggests that both planes are equally important to measure and perhaps in further research both should be undertaken.

The greatest difference was between the close and far illuminance meters, which led to the conclusion that more sensors are required at varying increments between the window and the core of a building. The use of more sensors will also require smaller banks of lighting to be connected to them, so that each system can be better suited to the needs of the occupants throughout the building.

It was found that other research in to the performance of automatic daylight control systems had average energy savings of $49 \%$, with field measurements finding average savings of $39 \%$. Both of these are far greater than the results found in these four test buildings which average $20 \%$.

A high proportion of the survey respondents did not know whether or not there was an automated daylight control system in their building. All four buildings had high percentages of occupants who did not know, Building A had $90 \%$, Building B had $64 \%$, Building $C$ had $51 \%$ and Building $\mathrm{D}$ had $60 \%$. On reflection, by posing the question, Does this building have a daylight control system? (Yes, No, Don't Know) suggested the possibility that there wasn't a system when all buildings had at least one automated daylight control system installed. In retrospect it would be more appropriate to state that there was a system, provide a brief explanation of what such a system is and then ask if there is such an automatic daylight control system in their area of work. This would clarify the question and allow the respondent to further examine their working environment. It is expected that this would produce more informed answers and lead to more helpful comments on how each system is working.

Occupants (staff) are described as the most important aspect of a building/business as they are the biggest cost. In all four of the research buildings, the scores and comments from the survey indicate that the occupants are satisfied with their working environment. Furthermore, comfort, health and productivity (three aspects used in this study to assess 
satisfaction levels) had 7 of 40 positive comments mentioning the provision of lighting, while only 11 of 165 negative comments mentioned lighting.

The responses showed that lighting is the least of occupants' worries, with glare being the main concern in the lighting section. Overall the scores from the questions on Lighting Overall, Natural Light and Artificial Light were placed very close to the 'Satisfactory' end of their scales.

The question relating to the performance of the automated daylight control system overall scored very well. These questions concerned artificial lights dimming or not and having enough light on occupants desks so they are able to work. The main negative comment concerned lights turning off completely, leaving the occupants in the dark. These comments accounted for 18 of 51 negative comments made. Each of the buildings have Passive Infrared (PIR) sensors that double as occupancy sensors. These sensors react to light and movement which is why when occupants are sitting still, the lights turn off. These types of sensors (PIR) are best placed in offices with a lot of occupant movement, but in instances where there isn't much movement, this becomes a nuisance. This could possibly be managed by lengthening the time delay before the lights turn off when there is no movement, or by changing the sensor to a combined PIR and acoustic sensor that responds to both movement and sound. It is interesting to find that one of the biggest negative comments about automated daylight control systems has to do with occupant movement, rather than inadequate lighting or system configuration.

To conclude on the psychological aspects of automated daylight control systems, in each of these four buildings the occupants are comfortable and find their automated daylight control systems to be working at a satisfactory level. The physical measurements however have found that the automated daylight control systems are not achieving the maximum possible savings, with three of the four buildings saving from $2-30 \%$ with an average of $10 \%$ savings. The fourth building, Building D, was the exception with $40 \%$ and $57 \%$ savings but due to the complex lighting circuits it is possible these are over-estimates of the actual savings. These poor savings in the three buildings were not due to the surroundings as there were ample amounts of natural light in each building (except Building C, Space 1) and had little to do with the occupant behaviour as blinds appeared to be only pulled when absolutely necessary to reduce glare. 
Measurements from the illuminance sensors found that the 'point of change' levels were set too high with Building $A$ at 800 lux, Building $B$ at 1,800 lux, Building $C$ at 1,000 lux and Building $D$ at 800 lux. This is compared to the recommended working plane minimum illuminance level of 400 lux (AS/NZS 1680.1:2006) leaving the potential for additional savings. It is recommended that the automated daylight control systems in all four buildings be reconfigured so that the point of change provides the recommended minimum illuminance level of 400 lux. It will then be necessary to ensure the building occupants are still happy with the lighting levels provided in their spaces. If necessary a further adjustment may then be required.

As each buildings layout, surroundings and systems are different, it is often difficult to produce standard rules of installing automated daylight control systems, let alone account for the variety of occupant behaviours and personal requirements. Overall the lessons learnt from this research are that daylight designed buildings must take precautions to minimise glare and create automated daylight control systems that gradually dim the lighting. As there is generally only one sensor per space controlling a large group of lights, when the automated daylight control system detects daylight, the lights near the window dim to the same level as those further into the building. With there being less daylight further into the building (past the position of the sensor), there are dull and gloomy spaces being created as described by the occupants in the comment sections of the survey. This needs to be counteracted with more sensors to create a more sensitive and intuitive lighting system.

From the information gathered from the physical environment and the scores and comments from the occupants in the survey, this research concludes that in these buildings automated daylight control systems are not working as they should. It was previously stated that in order to be working correctly an automated daylight control system must be saving energy while creating a comfortable environment. While each of the systems in the test buildings are technically saving energy, the overall savings percentages are too low for the automated daylight control system to be considered as functioning correctly. However, the occupants are comfortable and satisfied with the lighting in their work environment. Therefore, by combining the two research approaches in order to establish a better overall evaluation, it is concluded that all four automated daylight control systems are not working as they should. 


\subsection{Future Work}

A main issue that this research has highlighted is the lack of 'real' data from other research studies into the field performance of automatic daylight control systems. There is a lot of monitoring where the optimum or best results are published. It has been found there are large differences between the energy savings established in this research (20\%), when compared to the literature on Field Measurement studies (39\%), and manufacturers' average data for energy savings (60\%). Regular testing and publishing of how automated daylight control systems are working would lead to a better knowledge base for manufacturers, building owners and building managers alike. This would give those interested in implementing such a system a more realistic view of the savings their building might be able to obtain by comparing themselves to similar buildings with similar surroundings and circumstances.

Overall there needs to be more sharing of information to understand how to make automated daylight control systems more efficient and reap the potential savings that are lost by poor design and commissioning. Issues of this have already been pointed out within this research, such as single sensors controlling large groups of lights and having high 'point of change' values, reducing the potential to save as much energy as possible.

Undertaking this research over a longer period of time would see a better set of data collected. This would also give a better idea of how the system is working and why. In this research, the energy savings were calculated during a standard working day. By using a standard working day a simple formula could be used, in comparison to the manual 'power on' calculation which with a larger set of data would be time consuming.

So what is the next step in lighting control and building automation? The research results suggest that a fully integrated automated lighting system is required. Such a system would take into account glare and over-lighting across the whole year while making the internal environment comfortable (not only with regard to the lighting aspect). Such a system would combine the control of both the artificial light and natural light.

An automated louver system would seem to be the most appropriate technology for these four buildings as it would be able to control the amount of light entering the space, allowing in the low winter sun and moderating the high summer sun. In such a changing climate as New Zealand, and the rapid weather changes of a coastal city such as Wellington, this type of 
system could be able to generate high energy savings (which could possibly offset the energy use of the system itself on top of the normal daylight harvesting capabilities). 


\section{Bibliography}

Standards New Zealand. (2006). AS/NZS 1680.1 Interior \& Workplace Lighting. Wellington: Standards New Zealand.

ABB i-bus. (2011). KNX DALI Light Controller. Retrieved December 19, 2011, from http://www.knx-

gebaeudesysteme.de/sto_g/English/SALES_INFORMATION/DLRS_XX_FL_EN_V1-

0_2CDC507097D0202.PDF

Akashi, Y., \& Boyce, P. R. (2006). A field study of illuminance reduction. Energy and Buildings, 38, 588-599.

Ander, G. D. (2003). Daylighting Performance and Design 2nd ed. New Jersey: John Wiley \& Sons.

Apollo Lighting. (n.d.). DALI Control System. Retrieved January 10, 2012, from Apollo Lighting: http://www.apollolighting.co.uk/products/Lighting\%20Control/DALI\%20Control\%20System/

Atif, M. R., Love, J. A., \& Littlefair, P. (1997). Daylight Monitoring Protocols and Procedures for Buildings. International Energy Agency Task 21/Annex 29: Daylight in Buildings.

Baird, G. (2010). Sustainable Buildings in Practice - What the Users Think. Abingdon, United Kingdom: Routledge.

Baird, G., \& Thompson, J. (2012). Lighting conditions in sustainable buildings - results of a survey of users' perceptions. Architectural Science .

Baird, G., Leaman, A., \& Thompson, J. (2012). An examination of the distribution of user perception scores in a world-wide set of sustainable buildings. Architectural Science .

Begemann, S. H., Beld, G. J., \& Van den, T. A. (1997). Daylight, artificial light and people in an office environment, overview and biological responses. International Journal of Industrial Ergonomics , 20, 231-239.

Bodart, M., \& De Herde, A. (2002). Global energy savings in offices buildings by the use of daylighting. Energy and Buildings , 34, 421-429.

Bordass, W., Cohen, R., Standeven, M., \& Leaman, A. (2001). Assessing building performance in use 3: energy performance of the Probe buildings. Building Research and Information , 2 (29).

Building Use Studies (BUS). (2010). Retrieved September 15, 2011, from Usable Building: http://www.usablebuildings.co.uk/

Cantin, F., \& Dubois, M.-C. (2011). Daylighting metrics based on illuminance, distribution, glare and directivity. Lighting Research \& Technology .

Chauvel, P., Collins, J. B., Dogniaux, R., \& Longmore, J. (1982). Glare from windows: current views of the problem. Lighting Research and Technology, 14 (1), 31-46. 
Choi, A. S., \& Mistrick, R. G. (1999). Analysis of daylight responsive dimming system performance. Building and Environment, 34, 231-243.

Choi, A. S., \& Sung, M. K. (2000). Development of a daylight responsive dimming system and preliminary evaluation of system performance. Building and Environment , 35, 663-676.

Choi, A. S., Song, K. D., \& Kim, Y. S. (2005). The characteristics of photosensors and electronic dimming ballasts in daylight responsive dimming systems. Building and Environment , 40, 3950.

Corbusier, L. (1989). Towards a new architecture. Oxford: Butterworth Architecture.

Cunill, E., Serra, R., \& Wilson, M. (2007). Using Daylight Control in Offices? Post Occupancy Study about their integration with the Electric Lighting. The 24th Conference on Passive and Low Energy Architecture. Singapore.

Cuttle, C. (2010). Towards the third stage of the lighting profession. Lighting Research \& Technology , 73-93.

DALI by Design. (n.d.). Q\&A About DALI. Retrieved January 10, 2012, from DALI by Design: http://www.dalibydesign.us/faq.html

Department of Defense. (2006). Design: Interior and Exterior Lighting and Controls. USA: Unified Facilities Criteria.

Department of Labour - New Zealand Government. (2013, January 15). Kinds of Employment. Retrieved January 15, 2013, from Department of Labour: http://www.dol.govt.nz/infozone/myfirstjob/employees/prior/kinds-of-employment.asp

Doulos, L., Tsangrassoulis, A., \& Topalis, F. (2008). Quantifying energy savings in daylight responsive systems: The role of dimming electronic ballasts. Energy and Buildings , 40, 36-50.

Embrechts, R., \& Van Bellegen, C. (1997). Increased energy savings by individual light control. Right Light 4, (pp. 179-182). Copenhagen.

Energy Research Group - University of Dublin. (1994). Daylighting in Buildings. Dublin: University of Dublin.

Floyd, D., \& Parker, D. (1995). Field Commissioning of a Daylight-Dimming Lighting System. Right Light Tree, 3rd European Conference on Energy Efficient Lighting, (pp. 18-21). Newcastle.

Glamox - Luxo. (n.d.). Lighting Control. Retrieved December 19, 2011, from Glamox - Luxo: http://glamox.com/uk/light-control

Hartkopf, V., \& Loftness, V. (1999). Global relevance of total building performance. Automation in Construction , 8, 377-393.

Helvar. (2011). Retrieved November 15, 2011, from http://www.helvar.com/ 
HEP - Hightech Electronic Products. (2011). Daylight Control. Retrieved December 19, 2011, from HEP - Hightech Electronic Products: http://www.hepgroup.net/download/DM/DL2E_DM

Hoffman, G., Gufler, V., Griesmacher, A., Bartenbach, C., Canazei, M., Staggl, S., et al. (2008). Effects of variable lighting intensities and colour temperatures on sulphatoxymelatonin and subjective mood in an experimental office workplace. Applied Ergonomics , 39, 719-728.

Hopkinson, R. G., Petherbridge, P., \& Longmore, J. (1966). Daylighting. London: Heinemann.

Hua, Y., Oswald, A., \& Yang, X. (2011). Effectiveness of daylighting design and occupant visual satisfaction in a LEED Gold laboratory building. Building and Environment , 46, 54-64.

IEA. Daylight in Buildings. Energy Conservation in Buildings and Community Systems and Solar Heating and Cooling Programmes (ECBCS). IEA - International Energy Agency - Task 21.

IEA. Daylight in Buildings: A Source Book on Daylighting Systems and Components. IEA International Energy Agency - Task 21.

IEA. (2006). Light's Labour's Lost: Policies for Energy-efficient Lighting. Paris: IEA International Energy Agency OCED/IEA.

IPENZ, E. N. (2010). Electricity Generation: Achieving New Zealand's Objectives. Wellington: IPENZ.

Jackson, D. C. (1928). Quantity of Illumination to Efficiency in Industry. Journal of The Franklin Institute - Devoted to Science and the Mechanic Arts , 205 (3), 285-303.

Jennings, J. D., Rubinstein, F. M., DiBartolomeo, D., \& Blanc, S. (2000). Comparison of control options in private offices in an advanced lighting control testbed. Illuminating Engineering Society, 29 (2), 39-60.

Johnsen, K. (1998). Daylight in Buildings, Collaborative Research in International Energy Agency (IEA Task 21). Renewable Energy, 15, 142-150.

Karlen, M., \& Benya, J. (2004). Lighting Design Basics.

Ko, D. H., Elnimeiri, M., \& Clark, R. J. (2008). Assessment and prediction of daylight performance in high-rise office buildings. The Structural Design of Tall and Special Buildings , 17, 953-976.

Kroelinger, M. D. (2005). Informed Design Newsletter. Retrieved June 06, 2011, from Informed Design: http://www.informedesign.org/_news/mar_v03-p.pdf

Lamp Color. (n.d.). Retrieved December 09, 2011, from http://www.venturelighting.com/techcenter/lamps/color_of_light.htm

Lee, E. S., \& Selkowitz, S. E. (2006). The New York Times Headquarters daylighting mockup: monitored performance of the daylighting control system. Energy and Buildings, 38, 914929. 
Leslie, R. P. (2003). Capturing the daylight dividend in buildings: why and how? Building and Environment, 38, 381-385.

Li, D. H. (2010). A review of daylight illuminance determinations and energy implications. Applied Energy , 87, 2109-2118.

Li, D. H., \& Lam, J. C. (2001). Evaluation of lighting performance in office buildings with daylighting controls. Energy and Buildings , 33, 793-803.

Li, D. H., \& Lam, J. C. (2000). Measurements of solar radiation and illuminance on vertical surfaces and daylighting implications. Renewable Energy , 20, 389-404.

Li, D. H., Cheung, G. H., Cheung, K. L., \& Lam, T. N. (2010). Determination of vertical daylight illuminance under non-overcast sky conditions. Building and Environment , 45, 498-508.

Li, D. W., Lam, T. N., \& Wong, S. L. (2006). Lighting and energy performance for an office using high frequency dimming controls. Energy Consersion and Management , 47, 1133-1145.

Linhart, F., \& Scartezzini, J.-L. (2010). Minimizing lighting Power density in office rooms equipped with Anidolic Daylighting Systems. Solar Journal , 84, 587-595.

Loe, D. L. (2009). Energy efficiency in lighting - considerations and possibilities. Lighting and Technology , 41, 209-218.

Loftness, V., Aziz, A., Choi, J., Kampschroer, K., Powell, K., Atkinson, M., et al. (2011). The value of post-occupancy evaluation for building occupants and facility managers. Intelligent Buildings International , 249-268.

Manav, B. (2007) ). An experimental study on the appraisal of the visual environment at offices in relation to color temperature and illuminance. Building and Environment, 979-983.

McDonagh, J. (2010). Electricity Use Trends in New Zealand Office Buildings, $1990-2008$. 17th ERES Conference. Milan.

MicroDAQ.com. (n.d.). HOBO Energy Logger. Retrieved January 13, 2012, from http://www.microdaq.com/occ/h22/energy-logger.php

Moezzi, M., Iyer, M., Lutzenhiser, L., \& Woods, J. (2009). Behavioural Assumptions in Energy Efficiency Potential Studies. Oakland: California Institute of Energy and Environment.

NBN Elektronik. (n.d.). HOBO Energy Logger Pro. Retrieved January 13, 2012, from http://www.nbn.at/cms_data/Downloads/ONSET/ENERGIE/HOBO_EnergyLoggerPro_nbn.pd $f$

Onaygil, S., \& Guler, O. (2003). Determination of the energy saving by daylight responsive lighting control systems with an example from Istanbul. Building and Environment, 38, 973977.

Opdal, K., \& Brekke, B. (1995). Energy saving in lighting by utilisation of daylight. Right Light 3, (pp. 67-74). Newcastle. 
OSRAM. (2011). MULTleco. Retrieved December 19, 2011, from http://www.olafsson.is/resources/Files/Olafsson_is/baeklingar-

pdf/OEM_Customer_Information_March_2011.pdf

Osterhaus, W. K. (2001). Discomfort glare from daylight in computer offices: how much do we really know? LUX Europa 2001, 9th European Lighting Conference, (pp. 448-456). Iceland.

Oxford Dictionary. (n.d.). Oxford Dictionary. Retrieved November 15, 2011, from http://oxforddictionaries.com/definition/productive

Park, B.-C., Choi, A.-S., Jeong, J.-W., \& Eleanor, L. S. (2011). Performance of integrated systems of automated roller shade systems and daylight responsive dimming systems. Building and Environment , 747-757.

Phelan, J. (2002). Commissioning Lighting Control Systems for Daylighting Applications. National Conference of Building Commissioning.

Philips Lighting. (2011). OccuSwitch Occupancy Detector Family . Retrieved December 19, 2011, from OccuSwitch DALI: http://www.lighting.philips.com/pwc_li/main/products/controls/assets/OSD_brochure_Int.p df

Reinhart, C. F., \& Selkowitz. (2006). Guest Editorial: Daylighting - light, form, and people. Energy and Buildings , 38 (7), 715-717.

Roberts, D. (2011, October 03). Artificial Lighting and the Blue Light Hazard. Retrieved December 09, 2011, from The Facts About Lighting and Vision: http://www.mdsupport.org/library/hazard.html

Salkind, N. (2005). Statistics for People Who (Think They) Hate Statistics: 2nd Edition. USA: Sage Publications.

Sinclair Knight Merz. (2006). Renewable Energy Assessment: Greater Wellington Region. Wellington: EECA.

Site Analysis. (n.d.). Retrieved January 9, 2012, from Level: http://www.level.org.nz/siteanalysis/sun/

Stewart, T., \& Ward, B. (2009). Electricity Efficiency in New Zealand: Review of the Commercial Sector Strategy. Wellington: Electricity Commission.

Szerman, M. (1993). Superlink, a computer tool to evaluate the impact of daylight controlled lighting system onto the overall energetic behaviour of buildings. Right Light 2, (pp. 673-685). Arnhem.

Ternoey, S. (2000). Daylight Every Buildings. Wisconsin: Daylighting Collaborative/Energy Center of Wisconsin. 
Tridonic. (2011). PCA EXCEL one4all. Retrieved December 19, 2011, from http://www.slsnw.com/SLS/PCA_EXCEL_one4all.pdf

Tsikaloudaki, K. (2010). A study on the formation of indoor daylight conditions with respect to the urban landscape. Aristotle University. Greece: Laboratory of Building Constructions and Physics.

Vaidya, P., McDougall, T., Douglas, J., \& Eijadi, D. (2005). Making daylighting work: Learning from failures to improve the design and implementation process. ECEEE.

Velds, M. (2002). User acceptance studies to evaluate discomfort glare in daylit rooms. Solar Energy, 73, 95-103.

Verderber, R. R., \& Rubinstein, F. M. (1984). Mutual impacts of lighting controls and daylight applications. Energy and Buildings , 6, 133-140.

Webb, A. R. (2006). Considerations for lighting in the built environment: Non-visual effects of light. Energy and Buildings , 721-727.

Wienold, J., \& Christoffersen, J. (2005). Towards a New Daylight Glare Rating. LuxEuropa, (pp. 157-161). Berlin. 


\section{Appendices}

Appendix One: Recommended Lux levels according to AS/NZ 1680.2006

- Recommended maintained illuminances for various types of tasks, activities or interiors

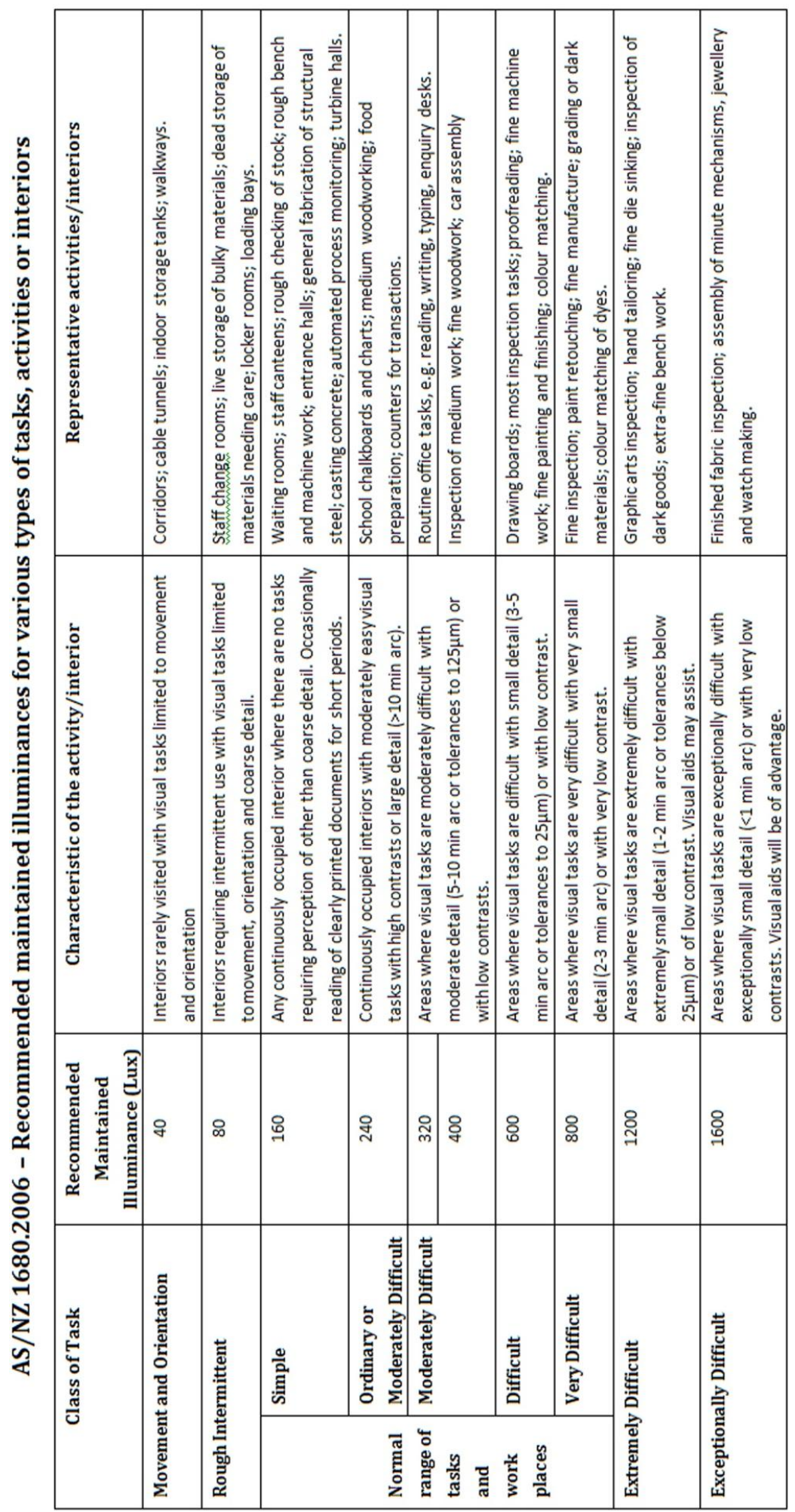


Appendix Two: Layout of Building D System

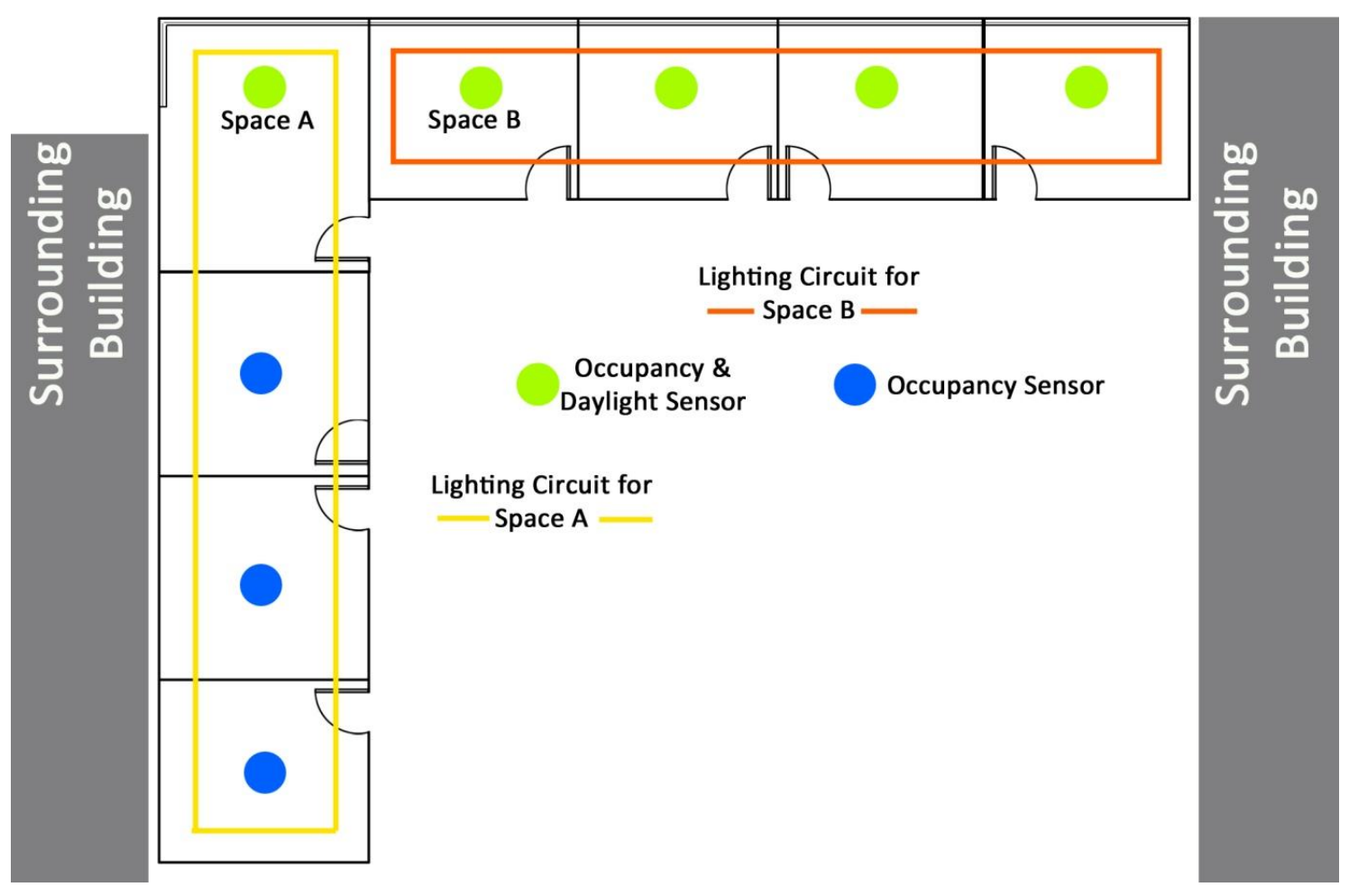




\section{Appendix Three: Calibration Process}

The calibration process was required to ensure the equipment that was being used was accurate. The complete process and list of the equipment used are listed in order below;

Appendix Three: Information on School of Architecture's Lighting Lab

Appendix Three (a): HIOKI 3423 Calibration Certificate

Appendix Three (b): HIOKI 3423 Corrections \& Uncertainties

Appendix Three (c): Information on the Hewlett Packard 34401A Multimeter

Appendix Three (d): LI-Cor LI-210SA Photometric Calibration Certificates

Appendix Three (e): LI-Cor LI-210SA General Information

Appendix Three (f): Spectral Response of HIOKI and LI-Cor illuminance sensors

Appendix Three (g): HOBO Power meter information

To calibrate the LI-Cor LI-210SA Photometric Illuminance sensors, a calibrated HIOKI 3423 illuminance meter was hired. The lighting laboratory in the School of Architecture provided a uniform light for the calibration process. The combinations of white, red, green, blue and yellow fluorescent lamps were used to produce a realistic bright daylight illuminance. This was produced in a $3.5 \mathrm{~m}$ by $3.5 \mathrm{~m}$ room with a $2.33 \mathrm{~m}$ ceiling height where the walls were painted a glossy white to evenly distribute the light within the space. The illuminance sensors were placed on a table $0.75 \mathrm{~m}$ from the floor. The illuminance sensors were positioned right beside each other and directly beside the calibrated HIOKI meter as shown in the image below.

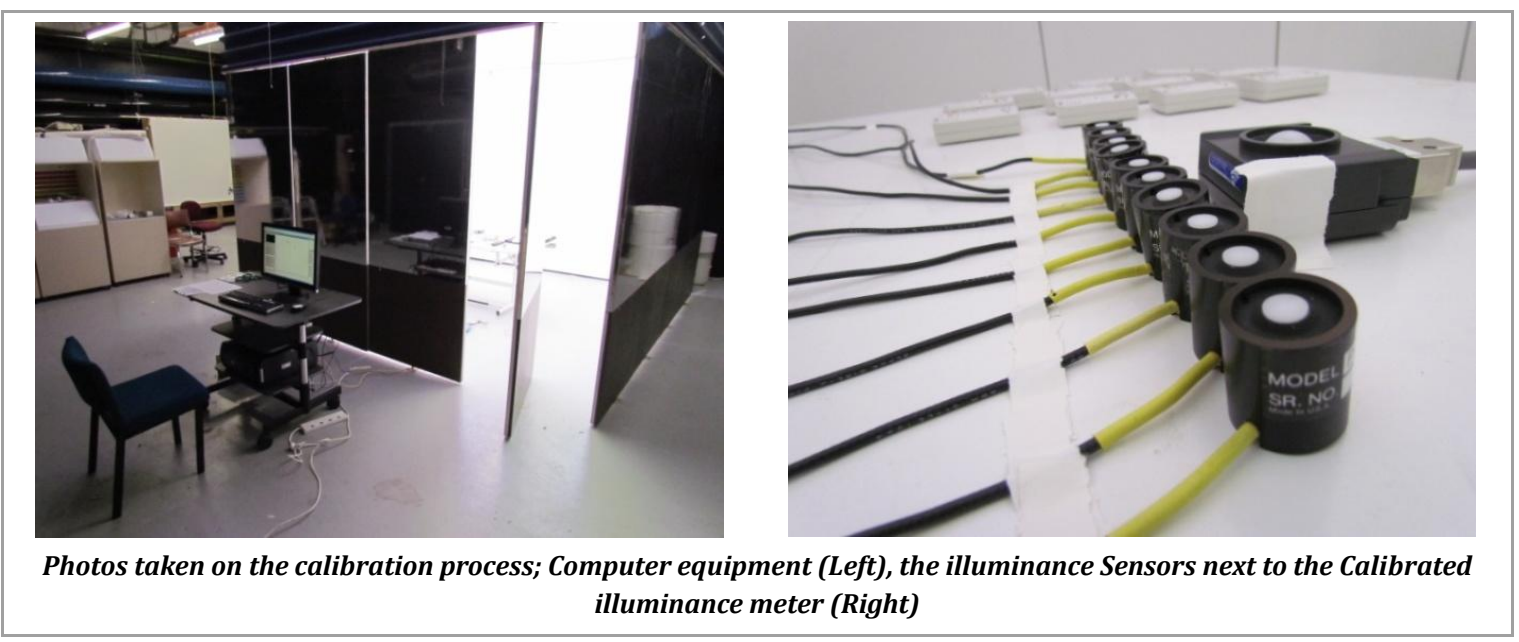

At the same time 11 BRANZ HOBO meters were placed on the table so they could also be calibrated. Ten of these HOBO meters will be placed alongside the LI-Cor illuminance meters during the measuring periods for further analysis of non-residential buildings with the information going to the BEES study. They will also act as another reference point for light 
recordings if needed. From the LI-Cor LI-210SA Photometric Calibration Certificates, these are the multipliers for input range which vary according to each sensor.

\begin{tabular}{|l|c|c|c|c|c|}
\hline S/N & Klux/mV & Reading with correction factor & Difference & Difference & $\mathbf{\pm}$ \\
\hline PH 6085 & 5.44 & 5.42 & 0.02 & $0.4 \%$ & $0.8 \%$ \\
\hline PH 6086 & 5.82 & 5.92 & 0.1 & $1.7 \%$ & $3.4 \%$ \\
\hline PH 6087 & 5.41 & 5.39 & 0.02 & $0.4 \%$ & $0.8 \%$ \\
\hline PH 6088 & 5.81 & 5.84 & 0.03 & $0.5 \%$ & $1.0 \%$ \\
\hline PH 6089 & 5.72 & 5.63 & 0.09 & $1.6 \%$ & $3.2 \%$ \\
\hline PH 6090 & 6.39 & 6.36 & 0.03 & $0.5 \%$ & $1.0 \%$ \\
\hline PH 6091 & 5.81 & 5.83 & 0.02 & $0.3 \%$ & $0.6 \%$ \\
\hline PH 6092 & 5.79 & 5.74 & 0.05 & $0.9 \%$ & $1.8 \%$ \\
\hline PH 6434 & 5.47 & 5.44 & 0.03 & $0.5 \%$ & $1.0 \%$ \\
\hline PH 6435 & 5.09 & 5.16 & 0.07 & $1.4 \%$ & $2.8 \%$ \\
\hline Average & & & $\mathbf{0 . 0 4 6}$ & $\mathbf{0 . 8 \%}$ & $\mathbf{1 . 6 \%}$ \\
\hline
\end{tabular}

The calibration process for the LI-Cor LI-210SA illuminance sensors was a relatively simple procedure. On the original calibration certificates for each illuminance sensor there was a $\mathrm{klux} / \mathrm{mV}$ (kilo lux per milli-Volt) conversion variable which gave a reference point for the calibration. Connecting each illuminance sensor to the multimeter individually, the light levels were increased until the illuminance sensor was recording one milli-Volt. Once one milli-Volt was reached, the lux reading according to the HIOKI meter was noted. Due to the limitations of the lighting lab there was a maximum amount of light that could be produced. In the instances where it wasn't possible to attain the amount of light required to reach one milli-Volt, the highest lux level was measured proportionally against the voltmeter reading. This information is shown in the table above. The correction factor was applied to each lux reading as stated by the MSL calibration on the HIOKI meter, and then it was then compared back to the original calibration setting. The comparisons between the original and newly calibrated results with their differences are listed. All measurement differences were positive, with the highest difference of $1.6 \%$ and the lowest $0.3 \%$, averaging $0.8 \%$

The results were calculated to be so close to the original calibration settings, and taking into account of the uncertainty of the HIOKI meter, as well as the slight uncertainty of the voltmeter, that the original klux/mV calibration figures would be used. Therefore when setting the range for each of the illuminance sensors, the original calibration values were used. 


\section{Correction Factor \& BRANZ Meters}

The LI-Cor illuminance sensor calibration process of uncertainty was carried out in the same way. The Measurement Standards Laboratory New Zealand (MSL) calibrated the HIOKI 3423 illuminance meter. This was completed at room temperature $\left(19^{\circ} \mathrm{C}-23^{\circ} \mathrm{C}\right)$ and a wide range of lighting levels were included so that a full scale was used. This is due to the non-linear nature of the illuminance sensors and the way they are able to record lighting information. To evaluate how closely the illuminance sensors were working compared to the calibrated HIOKO meter on varying lighting intensities, six different lighting levels were chosen to test the illuminance sensors with $(150,300,500,1000,1800,3000$ Lux). This was completed by setting up the data logger to record every 10 seconds once the lighting lab is set to a specific level. Due to a limitation of the lighting lab, it wasn't able to be set at a specific lux value. Therefore manual readings were taken throughout the duration of the measuring. This was completed at three points throughout each minute and then averaged with a total of ten minutes at each lighting level. This gave a better understanding of how accurate the illuminance sensors would be at different ranges. This information can be seen in below where the average manual readings are compared to the data logged information for each lighting level. This was given as averages from all ten illuminance sensors averaged over the ten minute measuring period.

\begin{tabular}{|l|c|}
\hline \multicolumn{2}{|c|}{ Uncertainties of Illuminance Sensors at different Lux levels } \\
\hline Light Level & Uncertainty \\
\hline 150 Lux & $4.70 \%$ \\
\hline 300 Lux & $2.10 \%$ \\
\hline 500 Lux & $0.30 \%$ \\
\hline 1000 Lux & $1.00 \%$ \\
\hline 1800 Lux & $1.40 \%$ \\
\hline 3000 Lux & $1.50 \%$ \\
\hline
\end{tabular}

At the same time that the correction factors were being assessed, BRANZ HOBO meters were placed into the lighting lab. 11 HOBO meters were also being calibrated during this time, using the exact process as described above. Manual readings were taken at three times a minute for ten minutes at each lighting level. This information was then tabulated and sent to BRANZ so that they could calibrated against it as the HOBO meters have built in loggers which require the data to be downloaded. 
Lighting Lab dimensions
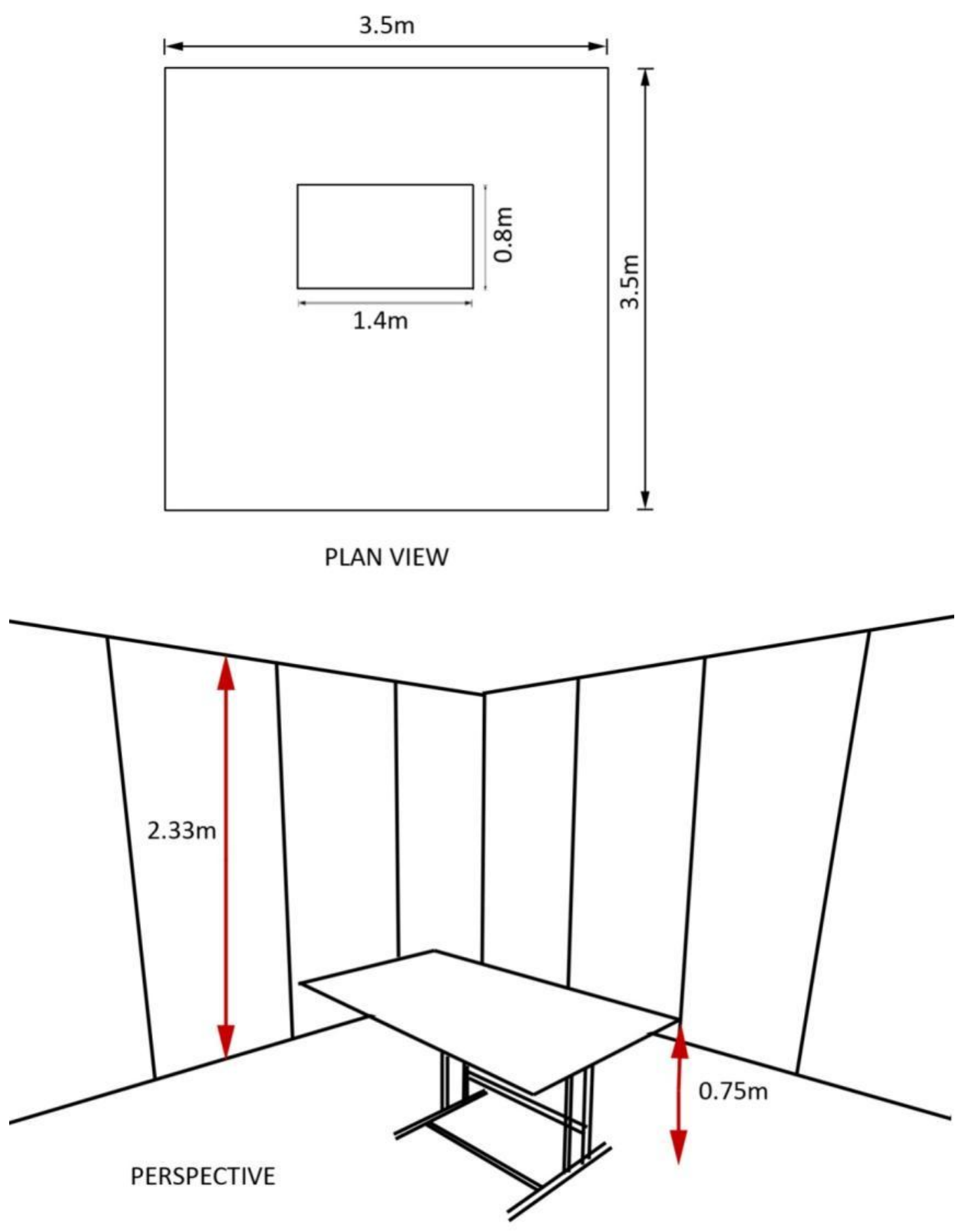


\section{Images of the lighting lab}

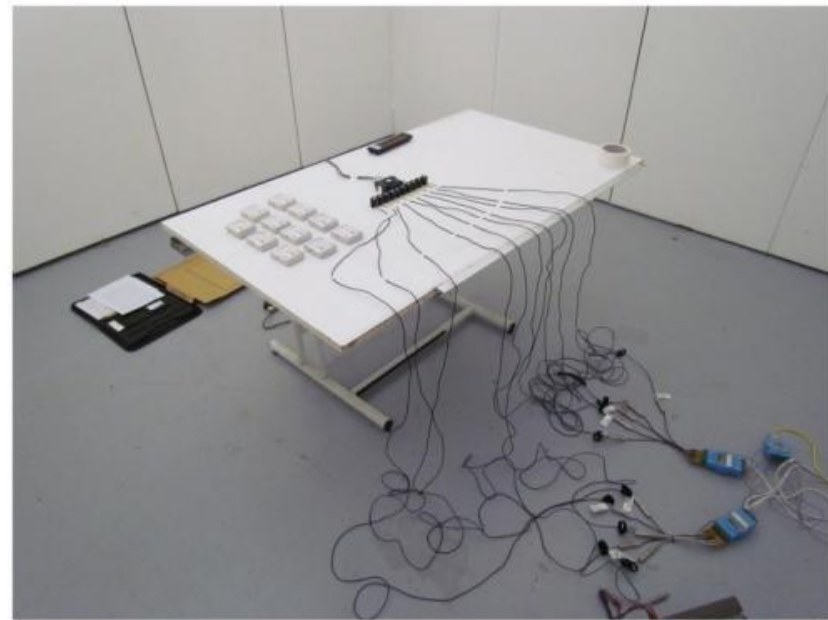

Photo of equipment set-up ready for calibration

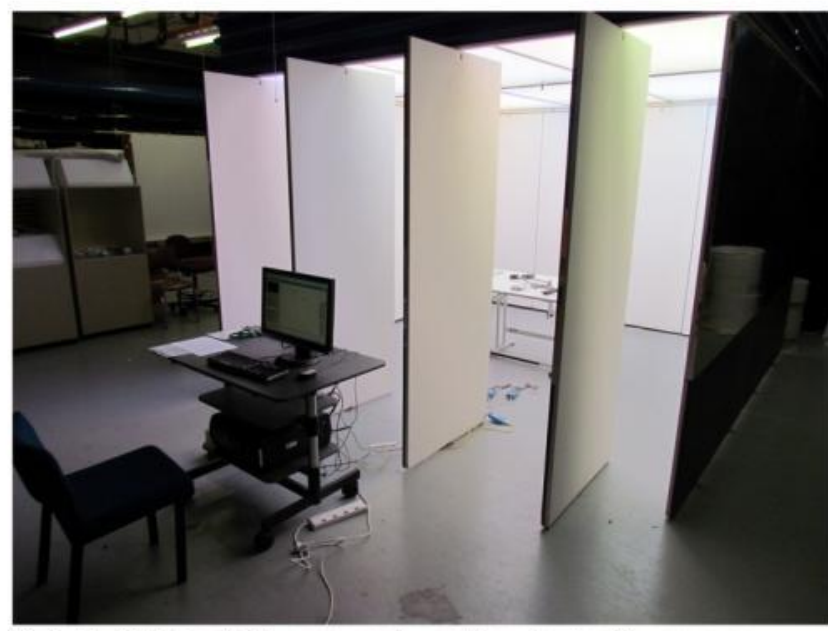

Only the lighting lab lamps are turned on during the process

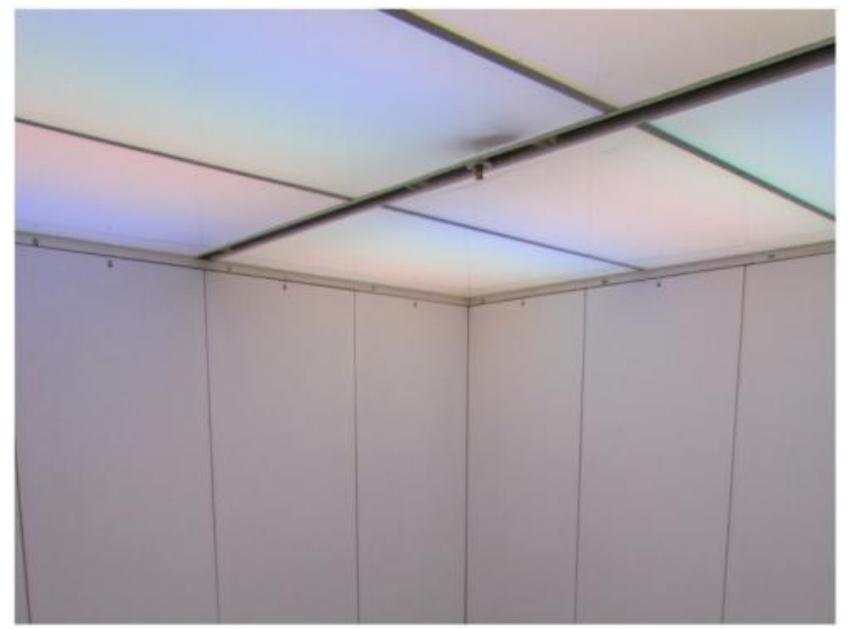

Lamps turned down low, colours of the spectrum seen.

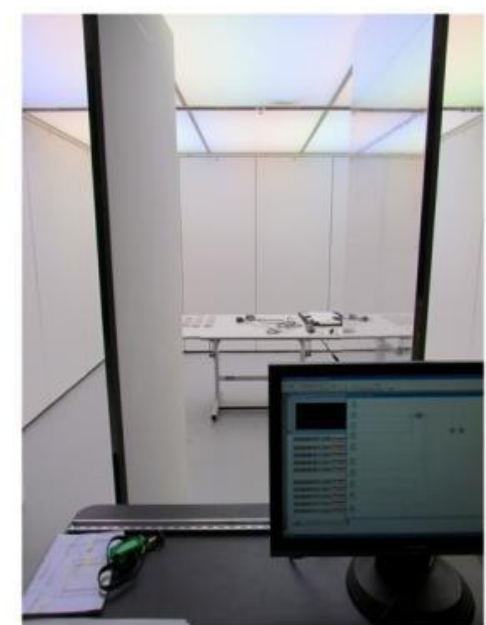

Computer logging at 10 second intervals to measure uncertainty values.

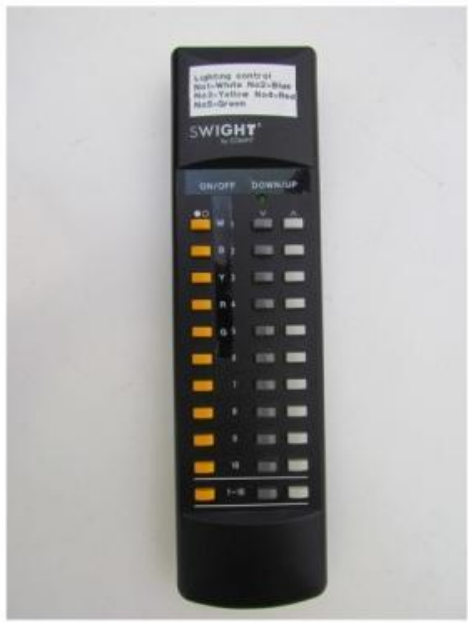

Remote control for all lamps

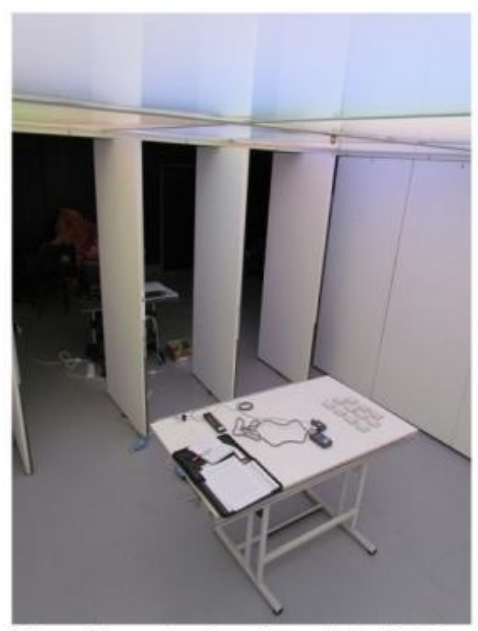

Photo from the interior of the lighting lab 
Appendix Three (a): Uncertainties and Correction Factors for the HIOKI 3423 illuminance meter
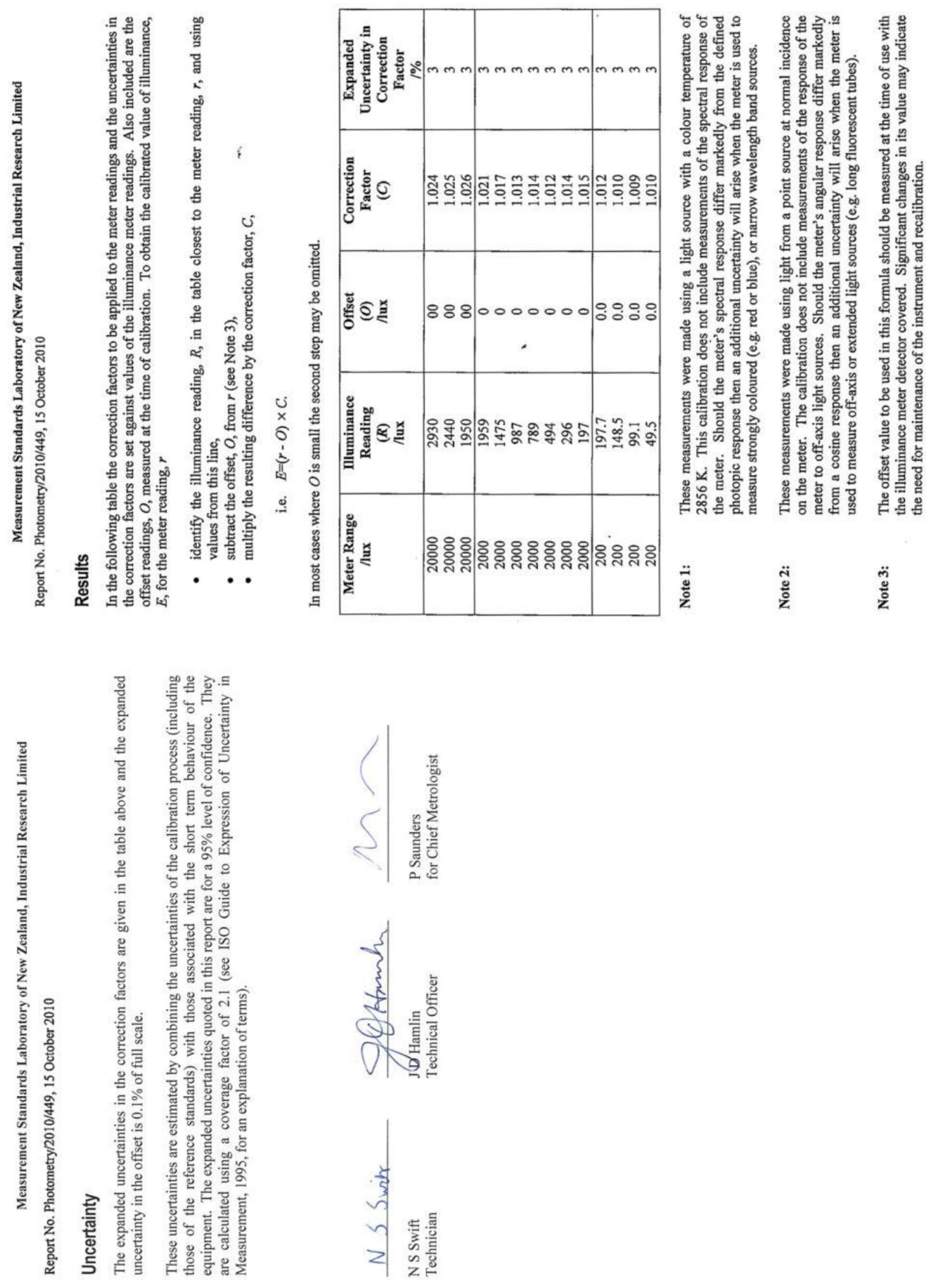
Appendix Three (b): Measurements Standards Laboratory of New Zealand calibration certificate for HIOKI 3423 illuminance meter
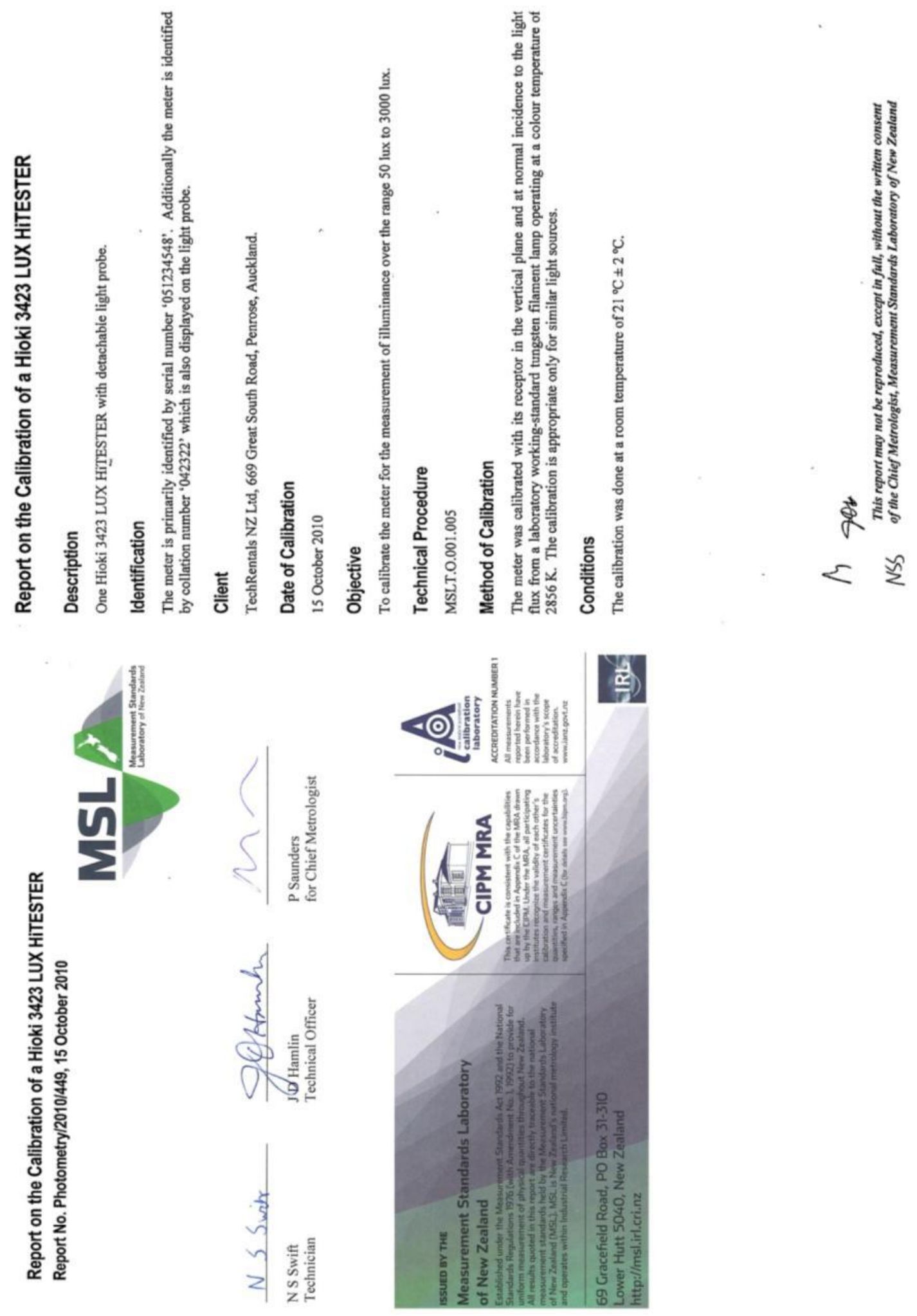


\section{Appendix Three (c): Information on the multimeter used for the calibration process}
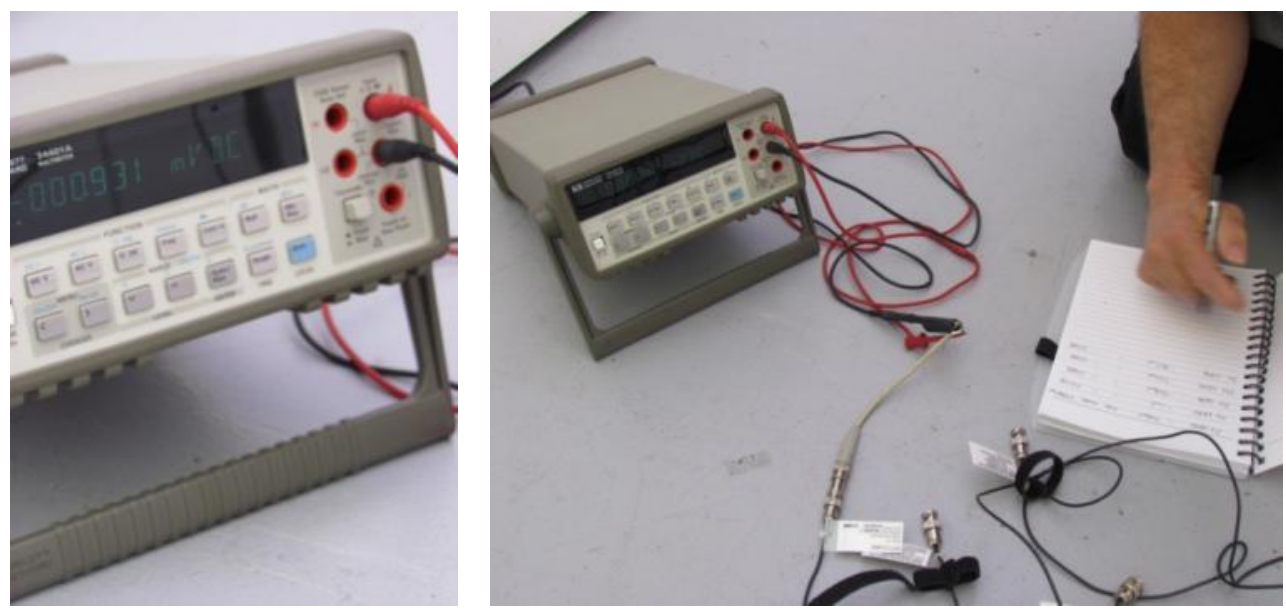

This Hewlett Packard 34401A Multimeter is approximately 12 years old.

- $\quad$ Serial Number 3146A04082

- $\quad$ Made in U.S.A.

The multimeter accuracy is provided in this extract is from the manual.

\section{HP 34401A Multimeter}

Uncompromising performance for benchtop and system testing
- Measure up to 1000 volts with $61 / 2$ digits resolution - dc accuracy of $0.0015 \%$ - ac accuracy of $0.06 \%$

- $3 \mathrm{~Hz}$ to $300 \mathrm{kHz}$ ac bandwidth -1000 readings/sec. direct to
HP-IB
Superior performance

The HP 34401A multimeter gives you the performance you need for fast, accurate bench and systems testing. The HP $34401 \mathrm{~A}$ provides a combination of resolution, accuracy and speed that rivals A $61 / 2$ digit display $0.0015 \%$. 24-hr dcV accuracy and 1,000 readings/sec direct to HP-IB assure you of results that are accurate, fast, and repeatable.

Use it on your benchtop

The HP 34401A was designed with your bench needs in mind. Functions commonly associated with pure bench operation, like continuity and diode test, are buil in. A Null feat remove lead resistan fixed offsets in your measurements. Other capabilities like min/max/av readouts and direct $\mathrm{dB}$ and $\mathrm{dBm}$ measurements make checkout with your DMM faster and easier.

When you want to store readings for future reference, the HP 34T0IA gives you the ability to store up to 512 readings in internal memory. For troubleshooting, a reading ho feature lets you concentrate on placing your test leads without having to constantly glance at the display.

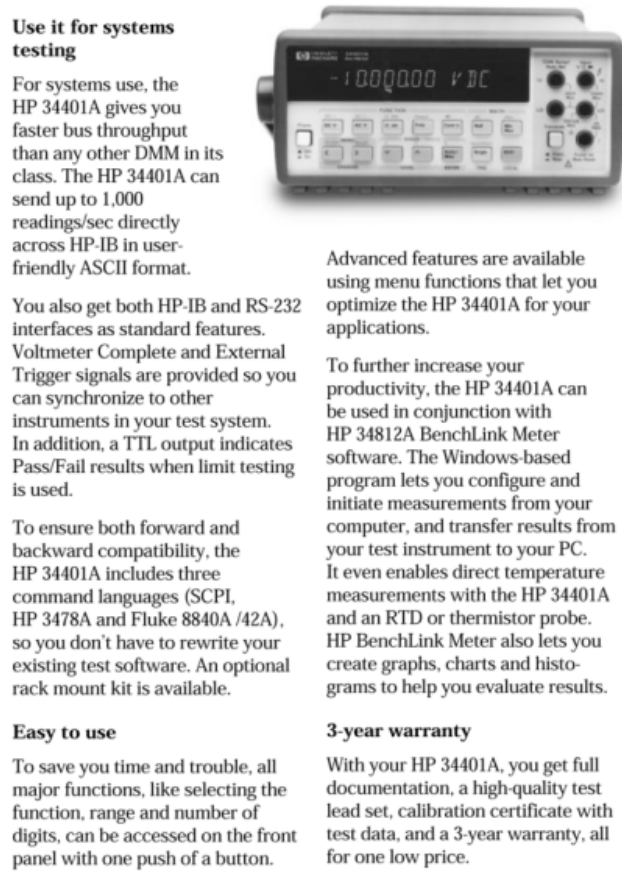




\title{
Appendix Three (d): All ten calibration certificates
}

Combined onto one page showing the klux/mV figure used for the calibration process as well as the original calibration and date of manufacture

\section{CERTIFICATE of CALIBRATION for LI-COR SENSOR}

\author{
Photometric Sensor
}

Model Number: LI-210

PH 6085 For use with LI-COR 2290 (604 ohm) Millivolt Adapter:

Multiplier: $\quad-\mathbf{5 . 4 4}$ klux per millivolt

PH 6086 For use with LI-COR $2290(604 \mathrm{ohm})$ Millivolt Adapter:

Multiplier: $\quad-5.82$ klux per millivolt

PH 6087 For use with LI-COR 2290 (604 ohm) Millivolt Adapter:

Multiplier: $\quad-\mathbf{5 . 4 1}$ klux per millivolt

PH 6088 For use with LI-COR 2290 (604 ohm) Millivolt Adapter:

Multiplier: $\quad-5.81$ klux per millivolt

PH 6089 For use with LI-COR 2290 (604 ohm) Millivolt Adapter:

Multiplier: $\quad-5.72$ klux per millivolt

PH 6090 For use with LI-COR 2290 (604 ohm) Millivolt Adapter:

Multiplier: $\quad-6.39$ klux per millivolt

PH 6091 For use with LI-COR $2290(604 \mathrm{ohm})$ Millivolt Adapter:

Multiplier: $\quad-5.81$ klux per millivolt

PH 6092 For use with LI-COR $2290(604 \mathrm{ohm})$ Millivolt Adapter:

Multiplier: $\quad-5.79$ klux per millivolt

PH 6434 For use with LI-COR 2290 (604 ohm) Millivolt Adapter:

Multiplier: $\quad-5.47$ klux per millivolt

PH 6435 For use with LI-COR 2290 (604 ohm) Millivolt Adapter:

Multiplier: $\quad-5.09$ klux per millivolt

Calibration standard used: Working standard lamp $674 \mathrm{~F}$

Calibration traceable to the National Institute of Standards and Technologies (NIST) through NIST-calibration lamp number F-226. (NBS Test No. 534/237689-86) 


\section{Appendix Three (e): General information on the LI-Cor LI-210SA illuminance sensors}

\section{LJ-210SA PHOTOMETRIC SENSOR}

LI-COR, Inc. Toll Free: 1-800-447-3576 (U.S. \& Canada) • Phone: 402-467-3576 • FAX: 402-467-2819 • E-mail: envsales@env.licor.com • Internet: http.//www licor.com

\section{MEAsures IlLUMinance AS RELATED TO THE CIE Standard OBserver CURVe}

The LI-210SA Photometric Sensor utilizes a filtered silicon photodiode to provide a spectral response that matches the CIE curve within $\pm 5 \%$ with most light sources. This photodiode and filter combination is placed within a fully cosinecorrected sensor head to provide the proper response to radiation at various angles of incidence.

Some of the applications for the LI-210SA Photometric Sensor include interior and industrial lighting, outdoor illuminance, passive solar energy, architecture and lighting models, illumination engineering, and biological sciences that require illuminance measurements. The $\mathrm{LI}-210 \mathrm{SA}$ is a research grade photometric sensor that is very reasonably priced.

\section{LI-210SA SPECIFICATIONS}

Absolute Calibration: $\pm 5 \%$ traceable to NBS.

Sensitivity: Typically $30 \mu \mathrm{A}$ per 100 klux. Linearity: Maximum deviation of $1 \%$ up to 100 klux.

Stability: $< \pm 2 \%$ change over a 1 year period.

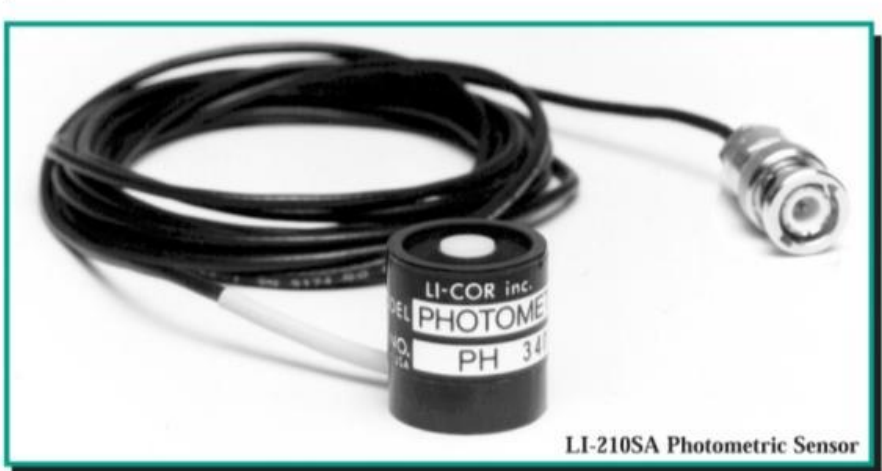

Response Time: $10 \mu \mathrm{S}$.

Temperature Dependence: $\pm 0.15 \%$ per ${ }^{\circ} \mathrm{C}$ maximum.

Cosine Correction: Cosine corrected up to $80^{\circ}$ angle of incidence.

Azimuth: $< \pm 1 \%$ error over $360^{\circ}$ at $45^{\circ}$ elevation.

Tilt: No error induced from orientation.

Operating Temperature: -20 to $65^{\circ} \mathrm{C}$.

Relative Humidity: 0 to $100 \%$.

Detector: High stability silicon photovoltaic detector (blue enhanced).

Sensor Housing: Weatherproof anodized aluminum case with acrylic diffuser and stainles steel hardware.

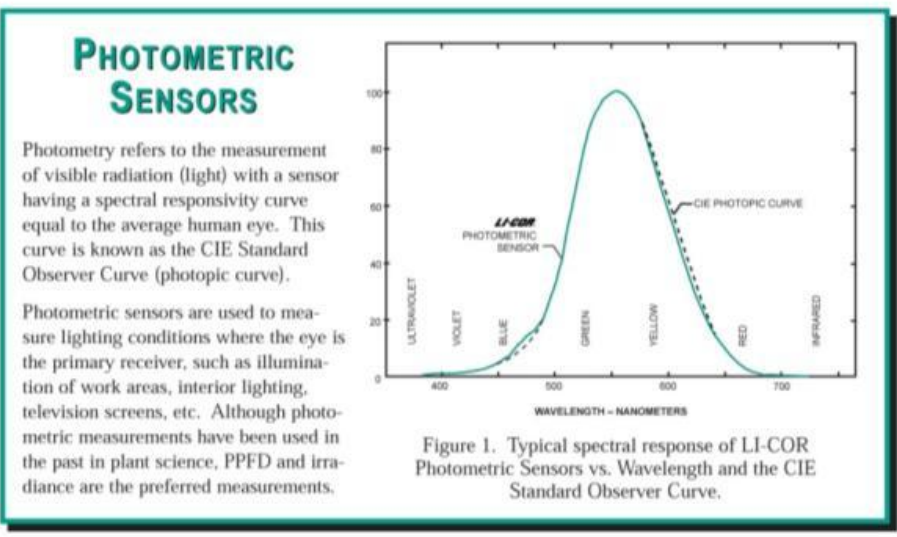

Size: $2.38 \mathrm{Dia} \times 2.54 \mathrm{~cm} \mathrm{H}$

$(0.94 \times 1.07)$

Weight: $28 \mathrm{~g}(1 \mathrm{oz}$.).

Cable Length: $10 \mathrm{ft}$. standard.

\section{ORDERING INFORMATION}

The LI-210SA Photometric Sensor cable terminates with a BNC connector that connects directly to the LI-250 Light Meter or LI-1400 DataLogger. The 2290 Millivolt Adapter should be ordered if the LI-210SA will be used with a strip chart recorder or datalogger that measures millivolts. The 2290 uses a $604 \mathrm{Ohm}$ precision resistor to convert the LI-210SA output from microamps to millivolts. The Photometric Sensor can also be ordered with bare leads (without the connector) and is designated LI-210SZ. The 2003S Mounting and Leveling Fixture is recommended for each sensor unless other provisions for mounting are made. Other accessories are described on the Accessory Sheet.

LI-210SA Photometric Sensor (with BNC connector)

LI-210SZ Quantum Sensor (with bare leads) 2003S Mounting and Leveling Fixture 2222SB-50 Extension Cable (50 ft.) 2222SB-100 Extension Cable (100 ft.) 2290 Millivolt Adapter 


\section{Appendix Three (f): Spectral response for HIOKI 3423 and LI-Cor LI- 210SA illuminance meters}

HIOKI 3423

\section{Relative Spectral Response Characteristics in the Visible Spectrum}

Human perception of brightness ranges from $360 \mathrm{~nm}$ to $830 \mathrm{~nm}$ in the wavelength and is the maximum at $555 \mathrm{~nm}$. The International Commission on Illumination (CIE) has established comparative standards for luminosity, setting the maximum perception for 1 and indication the amount of perception of each wavelength by the relative value, and calculating the average of many people. In the HIOKI 3423 , the relative spectral response characteristics are close to the comparative standards for luminosity.

The deviation from the comparative standards for luminosity is determined by the fs value of JIS standard C 1609-1993

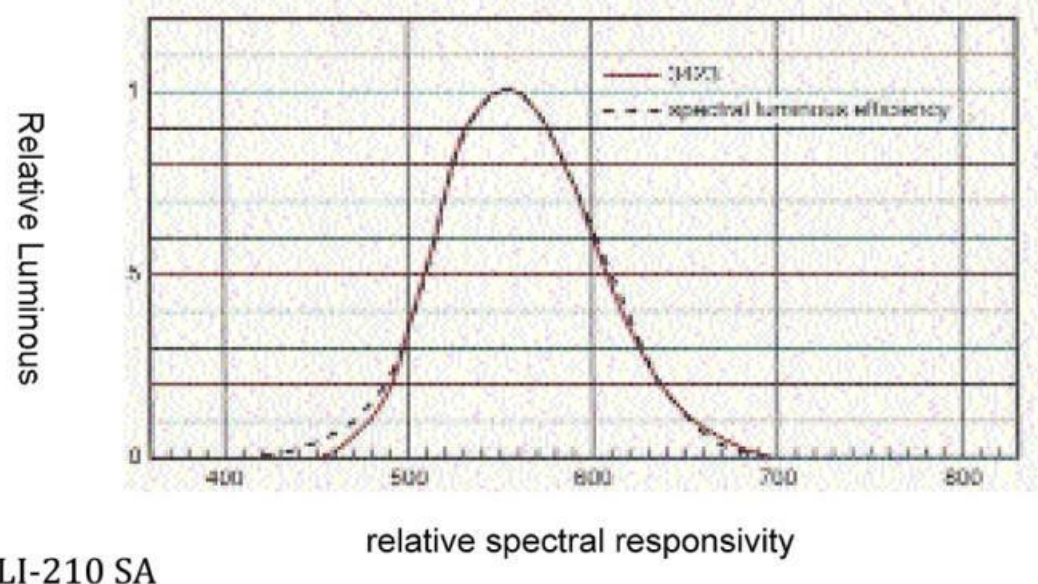

LI-Cor LI-210 SA

Photometric Sensors

Photometry refers to the measurement of visible radiation (light) with a sensor having a spectral responsivity curve equal to the average human eye. This curve in known as the CIE Standard Observer Curve (photopic curve).

Photometric sensors are used to measure lighting conditions where the eye is the primary receiver, such as illumination of work areas, interior lighting, television screens, etc. Although photometric measurements have been used in the past in plant science, PPFD and irradiance are the preferred measurements.

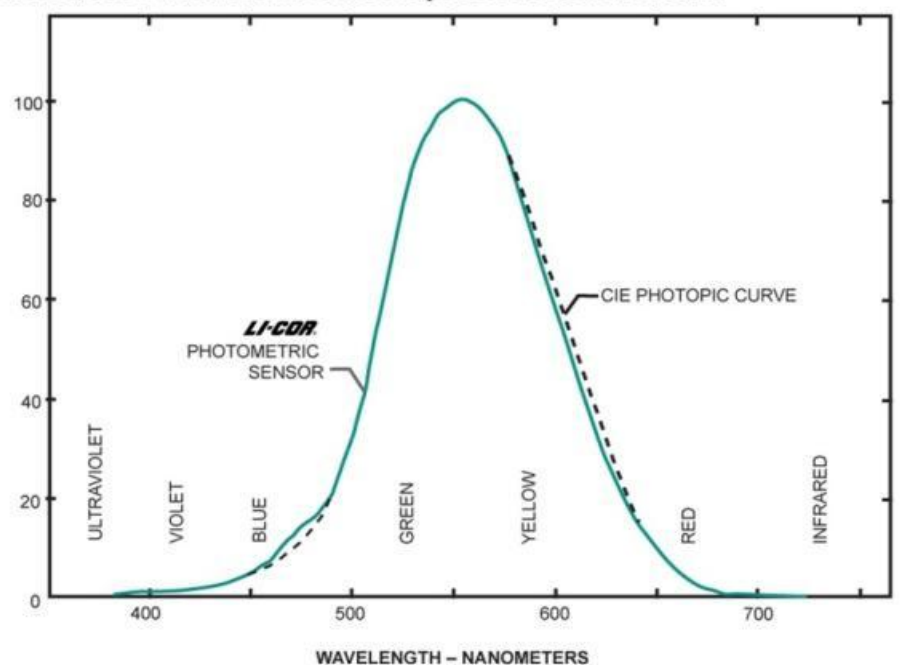

Figure 1. Typical spectral response of LI-COR Photometric Sensors vs. Wavelength and the CIE Standard Observer Curve. 


\section{Appendix Three (g): HOBO Power meter information}

\section{HOBO Energy Logger Specifications}

\begin{tabular}{|c|c|}
\hline $\begin{array}{l}\text { Data Storage } \\
\text { Capacity }\end{array}$ & $\begin{array}{l}\text { 512K Maximum Storage - Number of Samples Dependant on External Sensors and } \\
\text { FlexSmart Modules }\end{array}$ \\
\hline Sampling Rate & $\begin{array}{l}1 \text { Second to } 18 \text { Hours } \\
\text { (2-Second Minimum for \#S-FS-TRMSA operation) }\end{array}$ \\
\hline Sensor Excitation & $\begin{array}{c}12 \text { Volts DC at } 200 \mathrm{~mA} \text { total, with User-Programmable Warmup Time on a per- } \\
\text { Channel Basis }\end{array}$ \\
\hline Logging Modes & Immediate, Timed Delay, or Push-Button Start Options \\
\hline Memory Modes & Stop When Full; Wrap When Full \\
\hline LED Indicators & $\begin{array}{l}\text { Green: Logging or Standby } \\
\text { Red: Low Battery, Storage or Sensor Fail }\end{array}$ \\
\hline Sensor Inputs & 3 FlexSmart multi-Channel Modules and up to 6 Smart Sensors \\
\hline Sensor Connectors & 6 RJ-12 Smart Sensor Jacks and 3 FlexSmart Module Slots \\
\hline $\begin{array}{l}\text { Communications } \\
\text { Type }\end{array}$ & RS-232 Serial via 3.5mm Serial Port or/and 9-pin D-Sub Connector \\
\hline $\begin{array}{l}\text { Communications } \\
\text { Mode }\end{array}$ & Current Readings while Logging; Read Out While Logging; Read Out When Stopped \\
\hline Operating Range & $\begin{array}{l}\text { Alkaline Battery: }-20 \mathrm{C} \text { to } 50 \mathrm{C}(-4 \mathrm{~F} \text { to } 122 \mathrm{~F}) \\
\text { Lithium Battery: }-40 \mathrm{C} \text { to } 60 \mathrm{C}(-40 \mathrm{~F} \text { to } 140 \mathrm{~F})\end{array}$ \\
\hline Battery Life & $\begin{array}{l}1 \text { Year Typical Use ( up to } 75 \text { mA excitation with 10-minute or longer logging } \\
\text { interval and } 1 \text {-second warmup-time) }\end{array}$ \\
\hline Battery & AA Alkaline Batteries (Included) \\
\hline External Power & $\begin{array}{l}\text { 13.6 VDC Regulated AC Wall Adapter Connector } \\
\text { 9-12 VDC Regulated Wall Adapter (Remove Batteries) }\end{array}$ \\
\hline Time Accuracy & 0 to 2 Seconds for first data point and \pm 5 Seconds per Week at $25^{\circ} \mathrm{C}\left(77^{\circ} \mathrm{F}\right)$ \\
\hline $\begin{array}{l}\text { Standards } \\
\text { Compliance }\end{array}$ & CE \\
\hline Weight & $435 \mathrm{~g}(15.23 \mathrm{oz})$ with Batteries \\
\hline Dimensions & $15.6 \mathrm{~cm} \times 8.4 \mathrm{~cm} \times 4.6 \mathrm{~cm}\left(6.13^{\prime \prime} \times 3.31^{\prime \prime} \times 1.81^{\prime \prime}\right)$ \\
\hline
\end{tabular}




\section{Modules}

The FlexSmart Modules are snap-in signal conditioning units that convert signals from nearly any type of sensor. FlexSmart Analog (CVIA) Module (\#S-FS-CVIA); Flexible DC SignalConditioning Module; Accepts 2 Channels, Input Protection and Signal Filtering; Excitation Power to wide range of sensors

\begin{tabular}{|c|c|}
\hline Input Channels & 2, Single-Ended \\
\hline Field Wiring & 2 or 3 Wire Screw terminals on Detachable Terminal Block, 16 to 24 Gauge \\
(AWG)
\end{tabular}

TRMS (TRMSA) Module (\#S-FS-TRMSA) 2 Channel Input Measurement Module; Compatible with Industry-standard Current and Potential Transformers; Input Range of $512 \mathrm{mV}$ RMS Full Scale; Output Range of $333 \mathrm{mV}$ RMS Full Scale

\begin{tabular}{|c|c|}
\hline Input Channels & 2 \\
\hline Field Wiring & 2 Wire Screw Terminals \\
\hline Range & $\begin{array}{c}5 \mathrm{mV} \text { to } 512 \mathrm{mV} \\
\text { (Compatible with } 333 \mathrm{mV} \text { FS Output Sensors) }\end{array}$ \\
\hline Maximum Input & $\pm 1 \mathrm{~V}$ \\
\hline Minimum Input & $5 \mathrm{mV}$ \\
\hline Accuracy & $\pm 0.3 \%$ of Reading; $\pm 0.5 \%$ FSR \\
\hline Resolution & 15 Bits \\
\hline Standards Compliance & CE \\
\hline
\end{tabular}


Appendix Four: Post Occupancy Evaluation Survey
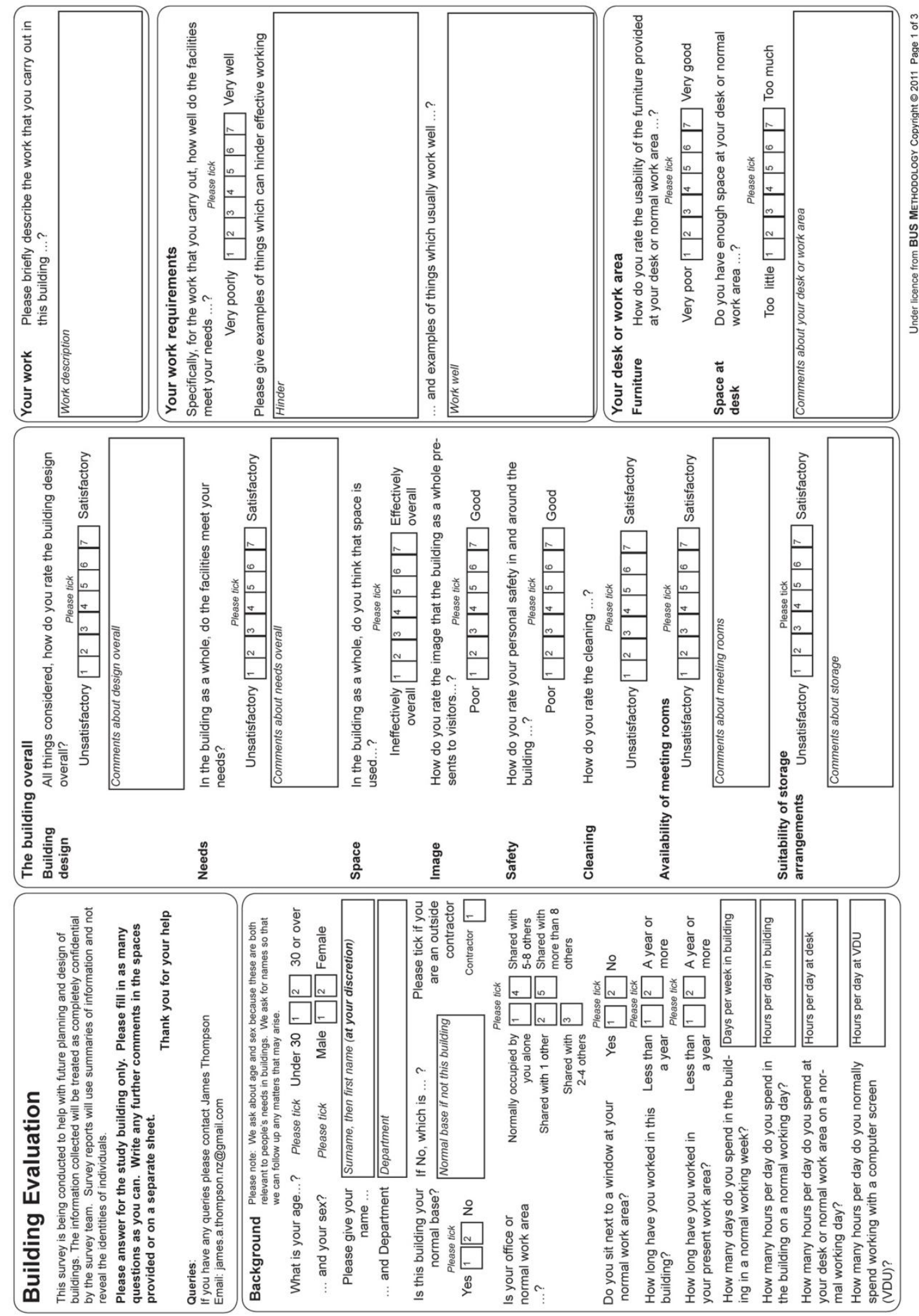

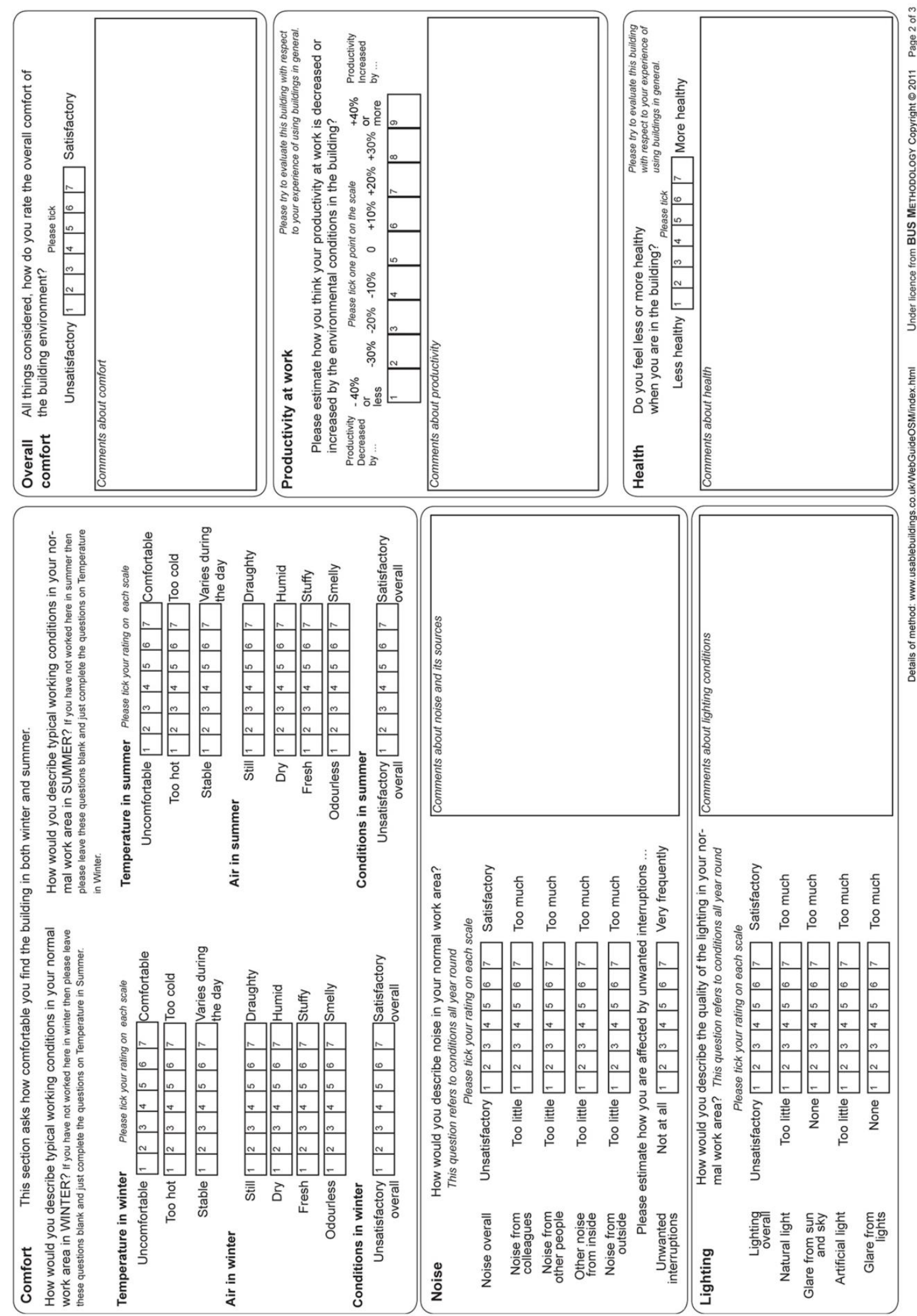


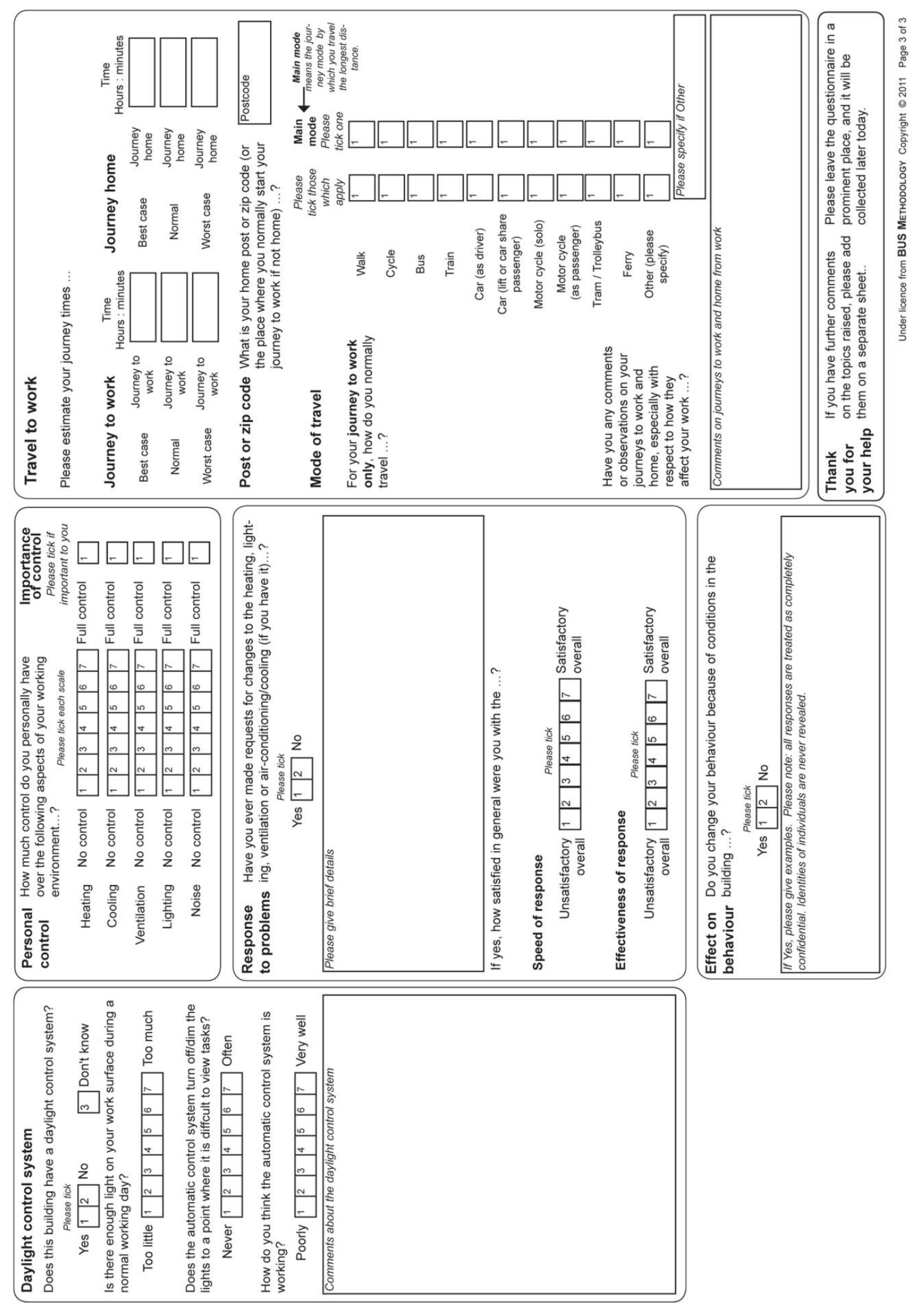




\section{Appendix Five: All Survey Scores}

The best possible score is written beside each question as a superscript. As each question has a numerical value, the average (mean) can be easily calculated. The closer the mean value is to the superscripted value, the better that aspect is perceived by the occupants. As an example for the 'Lighting Overall' question the best score received was 7, so a score of 5.56 is better than a score of 4.59. Whereas the Natural Light question has a best score of 4 , between Too little and Too much, so scores of 3.92 and 4.08 are considered to be the same and scores of 3.46 and 4.98 are respectively worse. 
All Survey Scores - Building A

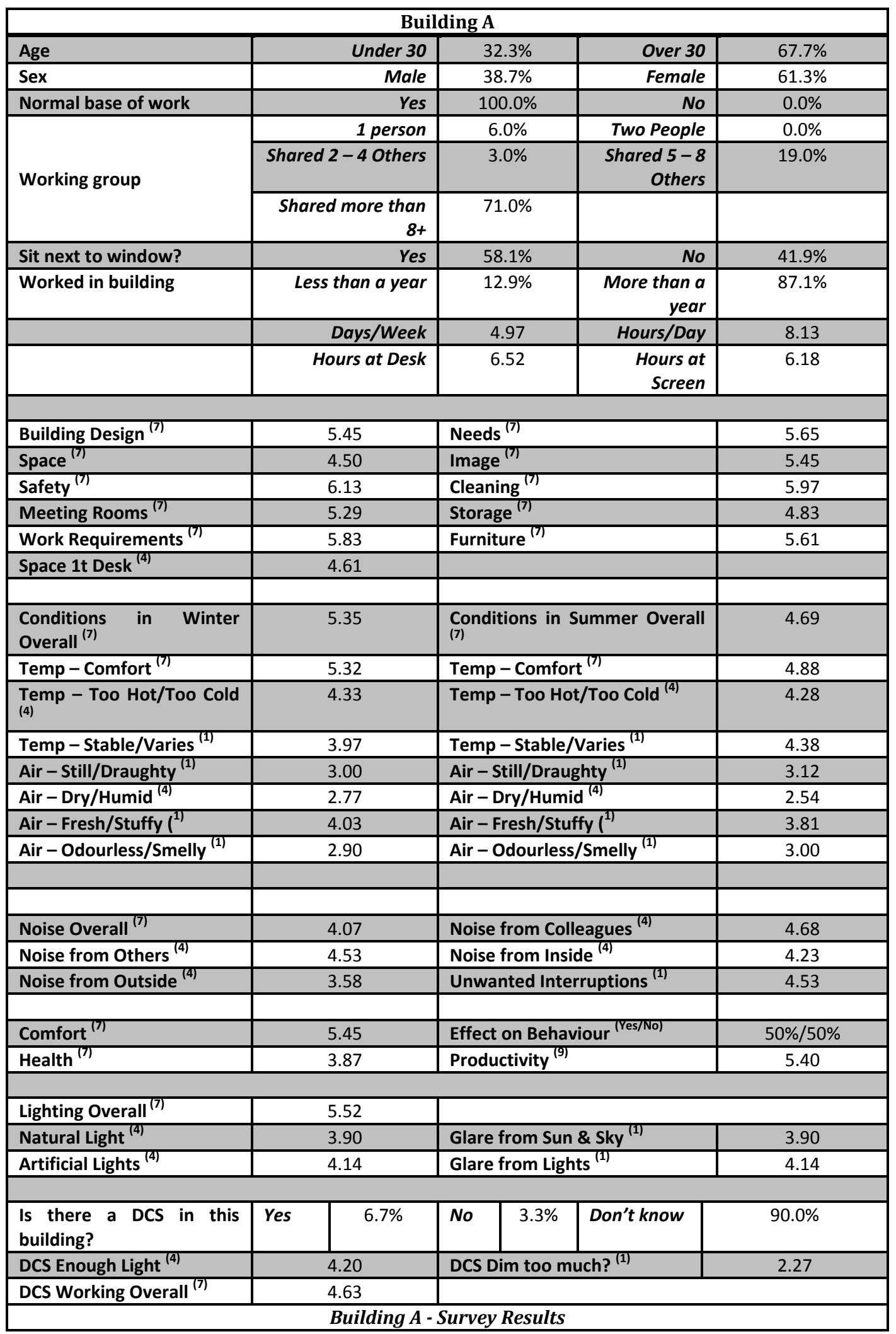




\section{All Survey Scores - Building B}

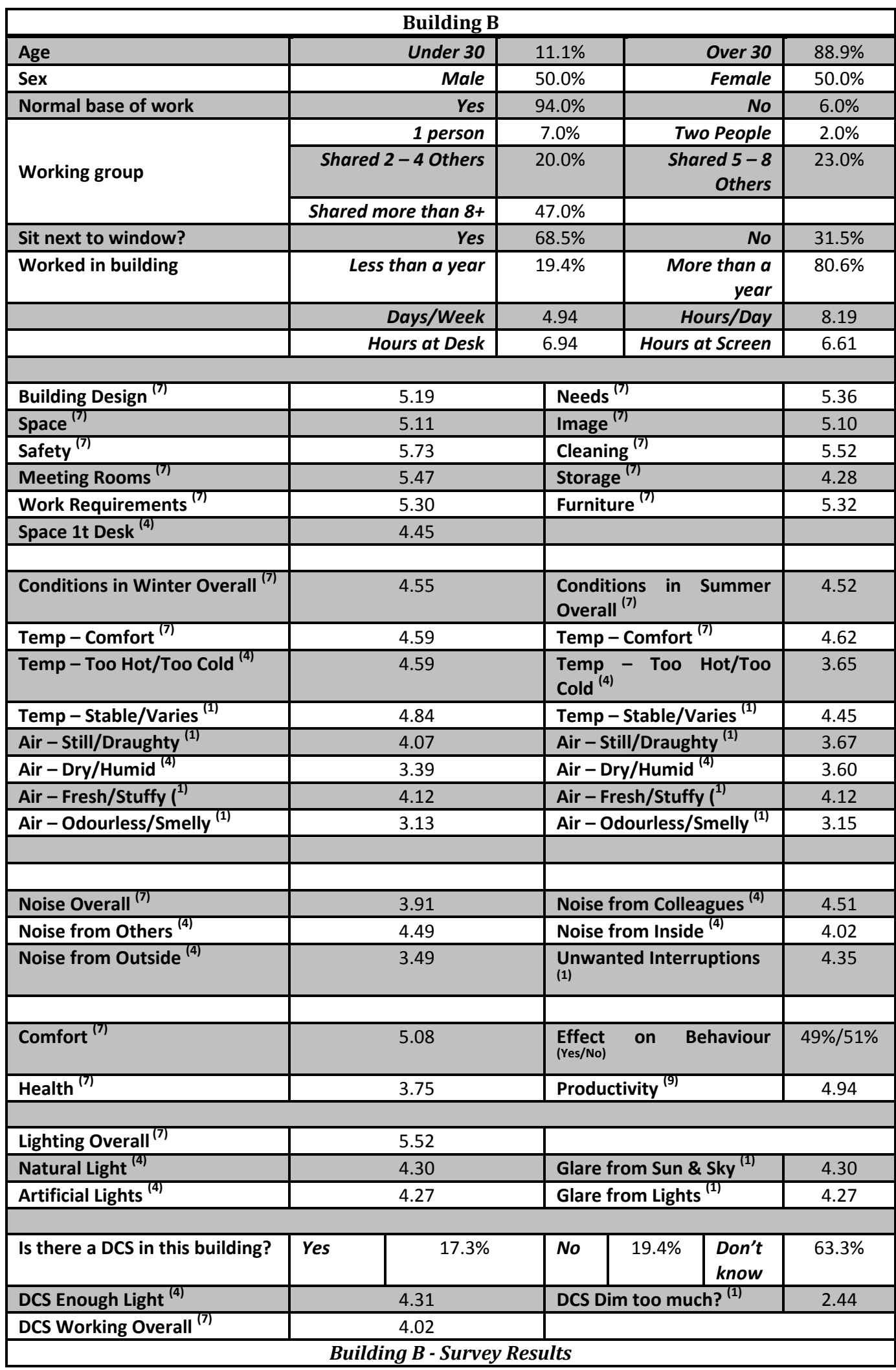




\section{All Survey Scores - Building C}

\begin{tabular}{|c|c|c|c|c|}
\hline \multicolumn{5}{|c|}{ Building C } \\
\hline Age & Under 30 & $15.5 \%$ & Over 30 & $84.5 \%$ \\
\hline Sex & Male & $40.8 \%$ & Female & $59.2 \%$ \\
\hline Normal base of work & Yes & $99.0 \%$ & No & $1.0 \%$ \\
\hline \multirow{3}{*}{ Working group } & 1 person & $19.0 \%$ & Two People & $2.0 \%$ \\
\hline & Shared 2-4 Others & $13.0 \%$ & $\begin{array}{r}\text { Shared 5-8 } \\
\text { Others }\end{array}$ & $14.0 \%$ \\
\hline & Shared more than $8+$ & $52.0 \%$ & & \\
\hline Sit next to window? & Yes & $28.0 \%$ & No & $72.0 \%$ \\
\hline \multirow[t]{3}{*}{ Worked in building } & Less than a year & $21.1 \%$ & $\begin{array}{r}\text { More than a } \\
\text { year }\end{array}$ & $78.9 \%$ \\
\hline & Days/Week & 4.80 & Hours/Day & 8.01 \\
\hline & Hours at Desk & 6.83 & Hours at Screen & 6.47 \\
\hline Building Design $^{(7)}$ & 5.85 & \multicolumn{2}{|l|}{ Needs ${ }^{(7)}$} & 5.67 \\
\hline Space ${ }^{(7)}$ & 5.28 & \multicolumn{2}{|l|}{ Image ${ }^{(7)}$} & 6.36 \\
\hline Safety ${ }^{(7)}$ & 5.87 & \multicolumn{2}{|l|}{ Cleaning ${ }^{(7)}$} & 4.80 \\
\hline Meeting Rooms ${ }^{(7)}$ & 4.85 & \multicolumn{2}{|l|}{ Storage ${ }^{(7)}$} & 4.46 \\
\hline Work Requirements ${ }^{(7)}$ & 5.49 & \multicolumn{2}{|l|}{ Furniture ${ }^{(7)}$} & 5.27 \\
\hline Space 1t Desk ${ }^{(4)}$ & 4.13 & & \\
\hline $\begin{array}{l}\text { Conditions in Winter Overall } \\
\text { (7) }\end{array}$ & 4.65 & \multicolumn{2}{|c|}{ Conditions in Summer Overall $^{(7)}$} & 5.01 \\
\hline Temp - Comfort ${ }^{(7)}$ & 4.58 & \multicolumn{2}{|c|}{ Temp - Comfort ${ }^{(7)}$} & 4.97 \\
\hline Temp - Too Hot/Too Cold ${ }^{(4)}$ & 4.94 & \multicolumn{2}{|c|}{ Temp - Too Hot/Too Cold ${ }^{(4)}$} & 4.15 \\
\hline Temp - Stable/Varies ${ }^{(1)}$ & 5.11 & \multicolumn{2}{|c|}{ Temp - Stable/Varies ${ }^{(1)}$} & 4.47 \\
\hline Air - Still/Draughty ${ }^{(1)}$ & 4.52 & \multicolumn{2}{|c|}{ Air - Still/Draughty ${ }^{(1)}$} & 3.87 \\
\hline Air - Dry/Humid ${ }^{(4)}$ & 3.35 & \multicolumn{2}{|c|}{ Air - Dry/Humid ${ }^{(4)}$} & 3.30 \\
\hline Air - Fresh/Stuffy $\left(^{1)}\right.$ & 3.46 & \multicolumn{2}{|c|}{ Air - Fresh/Stuffy $\left(^{1)}\right.$} & 3.51 \\
\hline Air-Odourless/Smelly ${ }^{(1)}$ & 2.97 & \multicolumn{2}{|c|}{ Air-Odourless/Smelly ${ }^{(1)}$} & 2.91 \\
\hline & & \multirow{2}{*}{\multicolumn{2}{|c|}{ Noise from Colleagues ${ }^{(4)}$}} & \\
\hline Noise Overall ${ }^{(7)}$ & 4.53 & & & 4.44 \\
\hline Noise from Others ${ }^{(4)}$ & 4.44 & \multicolumn{2}{|c|}{ Noise from Inside ${ }^{(4)}$} & 4.51 \\
\hline Noise from Outside ${ }^{(4)}$ & 3.71 & \multicolumn{2}{|c|}{ Unwanted Interruptions ${ }^{(1)}$} & 4.11 \\
\hline Comfort $^{(7)}$ & 5.30 & \multicolumn{2}{|c|}{ Effect on Behaviour (Yes/No) } & $57 \% / 43 \%$ \\
\hline Health $^{(7)}$ & 4.20 & \multicolumn{2}{|c|}{ Productivity ${ }^{(9)}$} & 5.32 \\
\hline Lighting Overall $^{(7)}$ & 5.07 & & \\
\hline Natural Light ${ }^{(4)}$ & 3.74 & \multicolumn{2}{|c|}{ Glare from Sun \& Sky ${ }^{(1)}$} & 3.11 \\
\hline Artificial Lights $^{(4)}$ & 4.08 & \multicolumn{2}{|c|}{ Glare from Lights ${ }^{(1)}$} & 2.96 \\
\hline $\begin{array}{l}\text { Is there a DCS in this } \\
\text { building? }\end{array}$ & $47.0 \%$ & \multicolumn{2}{|c|}{\begin{tabular}{|l|l|l|} 
No & $2.0 \%$ & Don't know \\
\end{tabular}} & $51.0 \%$ \\
\hline DCS Enough Light ${ }^{(4)}$ & 3.95 & DCS Dim toc & ich? ${ }^{(1)}$ & 3.56 \\
\hline DCS Working Overall $^{(7)}$ & 4.76 & & & \\
\hline & Building $C-S u$ & ey Results & & \\
\hline
\end{tabular}


All Survey Scores - Building D

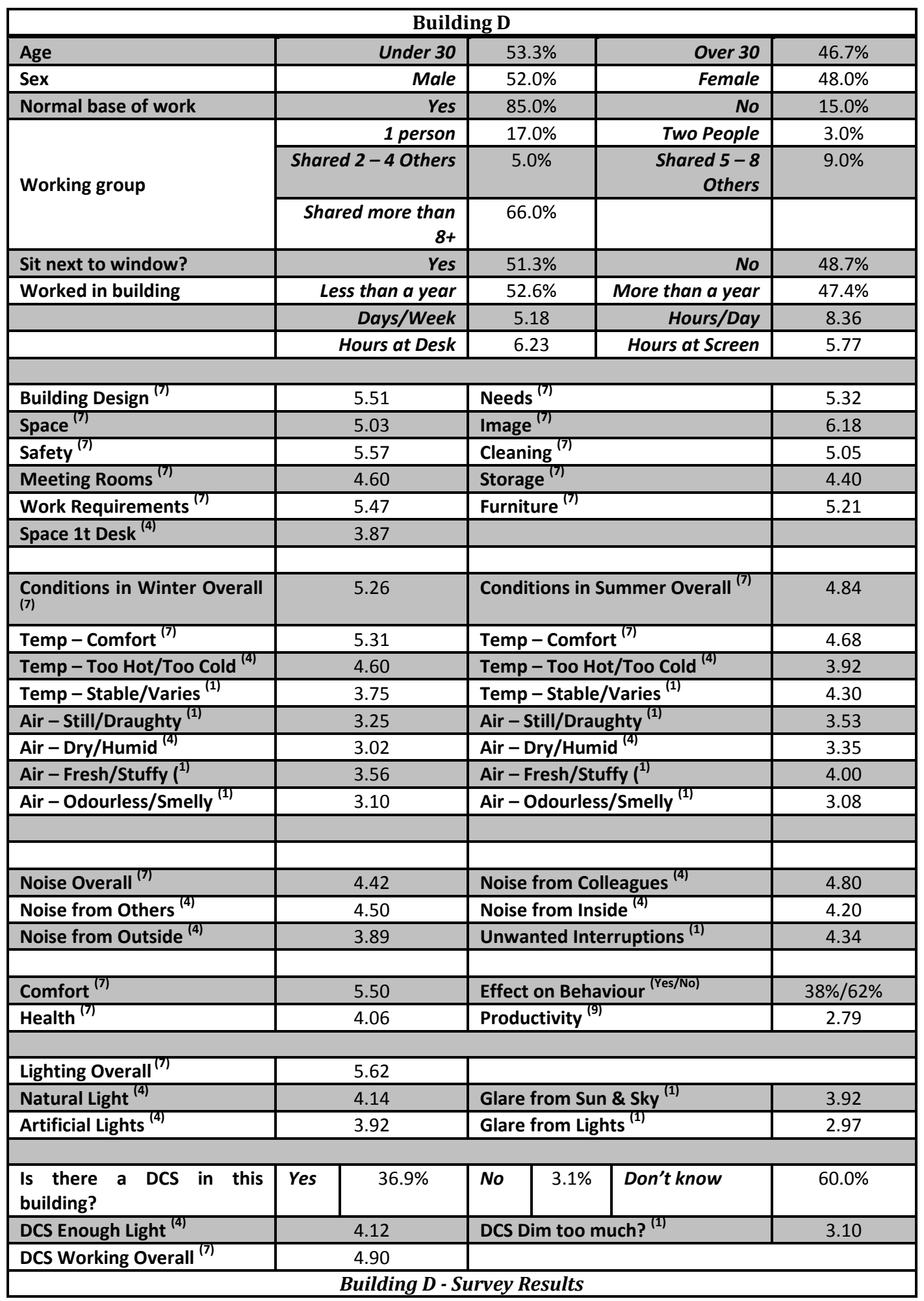



Appendix Six: External Influences - Daily Sunshine Data

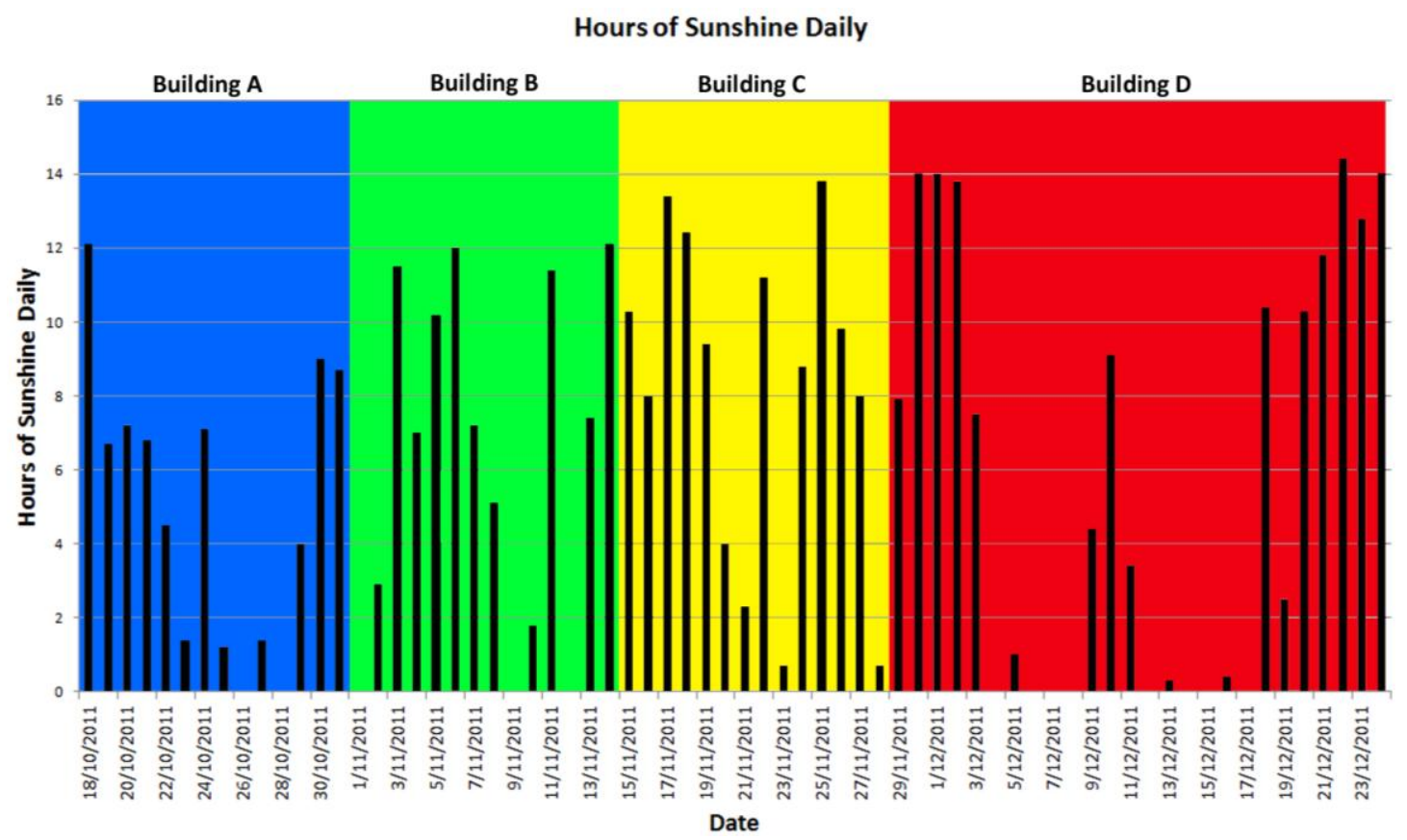




\section{Appendix Seven: Building A - Comment Analysis}

Below each of the comments were placed into Positive, Balanced or Negative categories. The automated daylight control system and lighting questions were analysed first and grouped into the categories. The health, comfort and productivity questions were then analysed and when any of these three categories mentioned lighting, they were placed on the table below. This was used to show if any effect from lighting, if any, were apparent in other aspects of the building environment.

\begin{tabular}{|l|c|c|c|c|c|c|c|c|c|c|}
\hline \multirow{2}{*}{ Building A } & \multirow{2}{*}{ Positive } & \multirow{2}{*}{ Balanced } & \multirow{2}{*}{ Negative } & \multicolumn{2}{|c|}{ Lighting } & \multicolumn{2}{|c|}{ Air \& Temp } & \multicolumn{2}{|c|}{ Noise } \\
\cline { 6 - 11 } & & & & & & & \multirow{2}{*}{ Total } \\
\hline ADCS & - & - & - & & & & & & & \\
\hline Lighting & $2(25 \%)$ & $3(37 \%)$ & $3(37 \%)$ & & & & & & \\
\hline Health & $2(33 \%)$ & $2(33 \%)$ & - & $1(17 \%)$ & - & - & $1(17 \%)$ & - & - & $\mathbf{6}$ \\
\hline Comfort & - & - & - & - & $1(50 \%)$ & - & $1(50 \%)$ & - & - & $\mathbf{2}$ \\
\hline Productivity & $1(25 \%)$ & - & - & - & $1(25 \%)$ & - & $1(25 \%)$ & - & $1(25 \%)$ & $\mathbf{4}$ \\
\hline
\end{tabular}

\begin{tabular}{|l|c|c|c|c|}
\hline \multicolumn{1}{|c|}{ Building A } & Positive & Balanced & Negative & Total \\
\hline ADCS & - & - & - & $\mathbf{0}$ \\
\hline Lighting & $2(25 \%)$ & $3(38 \%)$ & $3(38 \%)$ & $\mathbf{8}$ \\
\hline Health & $3(50 \%)$ & $2(33 \%)$ & $1(17 \%)$ & $\mathbf{6}$ \\
\hline Comfort & $1(50 \%)$ & - & $1(50 \%)$ & $\mathbf{2}$ \\
\hline Productivity & $1(25 \%)$ & - & $3(75 \%)$ & $\mathbf{4}$ \\
\hline
\end{tabular}




\section{Building B - Comment Analysis}

Below each of the comments were placed into Positive, Balanced or Negative categories. The automated daylight control system and lighting questions were analysed first and grouped into the categories. The health, comfort and productivity questions were then analysed and when any of these three categories mentioned lighting, they were placed on the table below. This was used to show if any effect from lighting, if any, were apparent in other aspects of the building environment.

\begin{tabular}{|c|c|c|c|c|c|c|c|c|c|c|}
\hline \multirow{2}{*}{ Building B } & \multirow{2}{*}{ Positive } & \multirow{2}{*}{ Balanced } & \multirow{2}{*}{ Negative } & \multicolumn{2}{|c|}{ Lighting } & \multicolumn{2}{|c|}{ Air \& Temp } & \multicolumn{2}{|c|}{ Noise } & \multirow{2}{*}{ Total } \\
\hline & & & & Positive & Negative & Positive & Negative & Positive & Negative & \\
\hline ADCS & $3(12 \%)$ & $17(71 \%)$ & $4(17 \%)$ & & & & & & & 24 \\
\hline Lighting & $6(29 \%)$ & $6(29 \%)$ & $9(42 \%)$ & & & & & & & 21 \\
\hline Health & $3(16 \%)$ & $2(10 \%)$ & - & - & - & - & $14(74 \%)$ & - & - & 19 \\
\hline Comfort & 7 (39\%) & $1(5 \%)$ & - & - & - & - & $9(50 \%)$ & - & $1(5 \%)$ & 18 \\
\hline Productivity & $3(11 \%)$ & - & - & - & $3(11 \%)$ & - & $7(27 \%)$ & $1(4 \%)$ & $12(46 \%)$ & 26 \\
\hline
\end{tabular}

\begin{tabular}{|l|c|c|c|c|}
\hline \multicolumn{1}{|c|}{ Building B } & Positive & Balanced & Negative & Total \\
\hline ADCS & $3(12 \%)$ & $17(71 \%)$ & $4(17 \%)$ & $\mathbf{2 4}$ \\
\hline Lighting & $6(29 \%)$ & $6(29 \%)$ & $9(42 \%)$ & $\mathbf{2 1}$ \\
\hline Health & $3(16 \%)$ & - & $16(84 \%)$ & $\mathbf{1 9}$ \\
\hline Comfort & $7(39 \%)$ & $1(5 \%)$ & $10(56 \%)$ & $\mathbf{1 8}$ \\
\hline Productivity & $4(15 \%)$ & - & $22(85 \%)$ & $\mathbf{2 6}$ \\
\hline
\end{tabular}




\section{Building C-Comment Analysis}

Below each of the comments were placed into Positive, Balanced or Negative categories. The automated daylight control system and lighting questions were analysed first and grouped into the categories. The health, comfort and productivity questions were then analysed and when any of these three categories mentioned lighting, they were placed on the table below. This was used to show if any effect from lighting, if any, were apparent in other aspects of the building environment.

\begin{tabular}{|c|c|c|c|c|c|c|c|c|c|c|}
\hline \multirow{2}{*}{ Building C } & \multirow{2}{*}{ Positive } & \multirow{2}{*}{ Balanced } & \multirow{2}{*}{ Negative } & \multicolumn{2}{|c|}{ Lighting } & \multicolumn{2}{|c|}{ Air \& Temp } & \multicolumn{2}{|c|}{ Noise } & \multirow{2}{*}{ Total } \\
\hline & & & & Positive & Negative & Positive & Negative & Positive & Negative & \\
\hline ADCS & $2(6 \%)$ & $2(6 \%)$ & $27(88 \%)$ & & & & & & & 31 \\
\hline Lighting & $16(46 \%)$ & $2(6 \%)$ & $17(48 \%)$ & & & & & & & 35 \\
\hline Health & $6(17 \%)$ & $5(14 \%)$ & - & $2(6 \%)$ & - & - & $22(63 \%)$ & - & - & 35 \\
\hline Comfort & $10(37 \%)$ & $2(7 \%)$ & - & - & $1(4 \%)$ & - & $14(52 \%)$ & - & - & 27 \\
\hline Productivity & $9(29 \%)$ & $1(3 \%)$ & - & $1(3 \%)$ & - & - & $8(26 \%)$ & - & $12(39 \%)$ & 31 \\
\hline
\end{tabular}

\begin{tabular}{|l|c|c|c|c|}
\hline \multicolumn{1}{|c|}{ Building C } & Positive & Balanced & Negative & Total \\
\hline ADCS & $2(6 \%)$ & $2(6 \%)$ & $27(88 \%)$ & $\mathbf{3 1}$ \\
\hline Lighting & $16(42 \%)$ & $5(13 \%)$ & $17(45 \%)$ & $\mathbf{3 8}$ \\
\hline Health & $8(17 \%)$ & $5(14 \%)$ & $24(69 \%)$ & $\mathbf{3 5}$ \\
\hline Comfort & $10(37 \%)$ & $2(7 \%)$ & $15(56 \%)$ & $\mathbf{2 7}$ \\
\hline Productivity & $10(32 \%)$ & $1(3 \%)$ & $20(65 \%)$ & $\mathbf{3 1}$ \\
\hline
\end{tabular}




\section{Building D - Comment Analysis}

Below each of the comments were placed into Positive, Balanced or Negative categories. The automated daylight control system and lighting questions were analysed first and grouped into the categories. The health, comfort and productivity questions were then analysed and when any of these three categories mentioned lighting, they were placed on the table below. This was used to show if any effect from lighting, if any, were apparent in other aspects of the building environment.

\begin{tabular}{|c|c|c|c|c|c|c|c|c|c|c|}
\hline \multirow{2}{*}{ Building D } & \multirow{2}{*}{ Positive } & \multirow{2}{*}{ Balanced } & \multirow{2}{*}{ Negative } & \multicolumn{2}{|c|}{ Lighting } & \multicolumn{2}{|c|}{ Air \& Temp } & \multicolumn{2}{|c|}{ Noise } & \multirow{2}{*}{ Total } \\
\hline & & & & Positive & Negative & Positive & Negative & Positive & Negative & \\
\hline ADCS & $3(12 \%)$ & $2(10 \%)$ & $20(78 \%)$ & & & & & & & 25 \\
\hline Lighting & 7 (29\%) & $6(25 \%)$ & $11(46 \%)$ & & & & & & & 24 \\
\hline Health & $4(16 \%)$ & $10(38 \%)$ & - & $1(4 \%)$ & - & - & $10(38 \%)$ & - & $1(4 \%)$ & 26 \\
\hline Comfort & $6(27 \%)$ & $2(9 \%)$ & - & - & $3(14 \%)$ & - & $8(36 \%)$ & $1(5 \%)$ & $2(9 \%)$ & 22 \\
\hline Productivity & $4(16 \%)$ & $7(30 \%)$ & - & $2(8 \%)$ & $1(4 \%)$ & - & $2(8 \%)$ & - & $8(34 \%)$ & 24 \\
\hline
\end{tabular}

\begin{tabular}{|l|c|c|c|c|}
\hline \multicolumn{1}{|c|}{ Building D } & Positive & Balanced & Negative & Total \\
\hline ADCS & $3(12 \%)$ & $2(10 \%)$ & $20(78 \%)$ & $\mathbf{2 5}$ \\
\hline Lighting & $7(29 \%)$ & $6(25 \%)$ & $11(46 \%)$ & $\mathbf{2 4}$ \\
\hline Health & $5(19 \%)$ & $10(38 \%)$ & $11(42 \%)$ & $\mathbf{2 6}$ \\
\hline Comfort & $7(32 \%)$ & $2(9 \%)$ & $13(59 \%)$ & $\mathbf{2 2}$ \\
\hline Productivity & $6(25 \%)$ & $7(30 \%)$ & $11(45 \%)$ & $\mathbf{2 4}$ \\
\hline
\end{tabular}




\section{Appendix Eight: Combined Buildings Overall Comment Analysis}

\begin{tabular}{|c|c|c|c|c|c|c|c|}
\hline \multicolumn{8}{|c|}{ Automated Daylight Control System } \\
\hline Positive & \multicolumn{2}{|c|}{ Balanced } & \multicolumn{5}{|c|}{ Negative } \\
\hline General & General & $\begin{array}{c}\text { Unaware of } \\
\text { System }\end{array}$ & General & $\begin{array}{c}\text { System } \\
\text { Turns Off }\end{array}$ & Too Dim & Glare & $\begin{array}{l}\text { Manual } \\
\text { Control }\end{array}$ \\
\hline 8 & 10 & 11 & 20 & 18 & 7 & 3 & 3 \\
\hline $10 \%$ & $13 \%$ & $14 \%$ & $25 \%$ & $23 \%$ & $13 \%$ & $4 \%$ & $4 \%$ \\
\hline
\end{tabular}

\begin{tabular}{|c|c|c|c|c|c|c|c|c|c|c|}
\hline \multicolumn{11}{|c|}{ Lighting } \\
\hline \multicolumn{3}{|c|}{ Positive } & \multicolumn{4}{|c|}{ Balanced } & \multicolumn{4}{|c|}{ Negative } \\
\hline General & $\begin{array}{l}\text { Natural } \\
\text { Lighting }\end{array}$ & $\begin{array}{l}\text { Artificial } \\
\text { Lighting }\end{array}$ & General & $\begin{array}{c}\text { Sometimes } \\
\text { Dark }\end{array}$ & $\begin{array}{c}\text { ADCS } \\
\text { No } \\
\text { Idea }\end{array}$ & Blinds & General & $\begin{array}{c}\text { Dark/Minimal } \\
\text { Light }\end{array}$ & Glare & $\begin{array}{c}\text { ADCS } \\
\text { Complaints }\end{array}$ \\
\hline 20 & 9 & 2 & 8 & 3 & 3 & 6 & 8 & 13 & 15 & 4 \\
\hline $22 \%$ & $10 \%$ & $2 \%$ & $9 \%$ & $3 \%$ & $3 \%$ & $7 \%$ & $9 \%$ & $14 \%$ & $16 \%$ & $4 \%$ \\
\hline
\end{tabular}

\begin{tabular}{|c|c|c|c|c|c|c|c|c|c|c|}
\hline \multicolumn{11}{|c|}{ Health } \\
\hline \multicolumn{3}{|c|}{ Positive } & \multicolumn{3}{|c|}{ Balanced } & \multicolumn{5}{|c|}{ Negative } \\
\hline General & Lighting & Air/Ventilation & General & Air & $\begin{array}{c}\text { Being } \\
\text { Seated }\end{array}$ & Lighting & Air & Temperature & Sickness & Noise \\
\hline 13 & 5 & 2 & 10 & 3 & 6 & 2 & 23 & 6 & 23 & 1 \\
\hline $14 \%$ & $5 \%$ & $2 \%$ & $11 \%$ & $3 \%$ & $7 \%$ & $2 \%$ & $24 \%$ & $7 \%$ & $24 \%$ & $1 \%$ \\
\hline
\end{tabular}

\begin{tabular}{|c|c|c|c|c|c|}
\hline \multicolumn{5}{|c|}{ Comfort } \\
\hline Positive & Balanced & \multicolumn{4}{c|}{ Negative } \\
\hline General & General & Lighting & Temperature & Noise & Air \\
\hline 24 & 5 & 5 & 22 & 5 & 8 \\
\hline $35 \%$ & $7 \%$ & $7 \%$ & $32 \%$ & $7 \%$ & $12 \%$ \\
\hline
\end{tabular}

\begin{tabular}{|c|c|c|c|c|c|c|c|c|c|}
\hline \multicolumn{4}{|c|}{ Productivity } & Balanced & \multicolumn{5}{c|}{ Negative } \\
\hline Pesitive & Lighting & $\begin{array}{c}\text { Open } \\
\text { Plan }\end{array}$ & General & General & Lighting & Temperature & Sickness & $\begin{array}{c}\text { Open } \\
\text { Plan/Noise }\end{array}$ & Air \\
\hline 15 & 2 & 4 & 8 & 3 & 4 & 15 & 2 & 31 & 2 \\
\hline $17 \%$ & $2 \%$ & $5 \%$ & $9 \%$ & $3 \%$ & $5 \%$ & $17 \%$ & $2 \%$ & $36 \%$ & $2 \%$ \\
\hline
\end{tabular}


Appendix Nine: Building A - Maximum \& Average Lux Levels

\begin{tabular}{|l|c|c|c|c|c|c|c|c|}
\hline Space 1 & \multicolumn{2}{|c|}{ Close Horizontal } & \multicolumn{2}{|c|}{ Close Vertical } & \multicolumn{2}{c|}{ Far Horizontal } & \multicolumn{2}{c|}{ Far Vertical } \\
\hline & Max & Average & Max & Average & Max & Average & Max & Average \\
\hline Day 1 & 10493 & 2336 & 9779 & 2146 & 941 & 539 & 1303 & 558 \\
\hline Day 2 & 10470 & 1600 & 9501 & 1393 & 853 & 320 & 1196 & 356 \\
\hline Day 3 & 9935 & 1277 & 9571 & 1159 & 957 & 359 & 1400 & 396 \\
\hline Day 4 & 9372 & 1610 & 8610 & 1444 & 837 & 310 & 1176 & 357 \\
\hline Day 5 & 9854 & 498 & 9750 & 666 & 853 & 99 & 1593 & 225 \\
\hline Day 6 & 1871 & 305 & 2385 & 471 & 438 & 79 & 926 & 191 \\
\hline Day 7 & 10621 & 1154 & 10410 & 1184 & 1373 & 142 & 1420 & 294 \\
\hline Day 8 & 7710 & 700 & 7550 & 641 & 963 & 299 & 1517 & 330 \\
\hline Day 9 & 2748 & 473 & 1859 & 282 & 717 & 298 & 779 & 229 \\
\hline Day 10 & 10284 & 1067 & 9299 & 1063 & 974 & 395 & 1496 & 472 \\
\hline Day 11 & 1545 & 439 & 1523 & 324 & 689 & 259 & 789 & 223 \\
\hline Day 12 & 8099 & 388 & 7301 & 555 & 640 & 89 & 1303 & 210 \\
\hline Day 13 & 10057 & 1335 & 9009 & 1318 & 1636 & 150 & 1079 & 293 \\
\hline Day 14 & 9918 & 2171 & 8708 & 1840 & 1012 & 264 & 1496 & 355 \\
\hline Average & 8070 & 1097 & 7518 & 1035 & 920 & 257 & 1248 & 321 \\
\hline
\end{tabular}

\begin{tabular}{|l|c|c|c|c|c|c|c|c|}
\hline Space 2 & \multicolumn{2}{|c|}{ Close Horizontal } & \multicolumn{2}{|c|}{ Close Vertical } & \multicolumn{2}{c|}{ Far Horizontal } & \multicolumn{2}{c|}{ Far Vertical } \\
\hline & Max & Average & Max & Average & Max & Average & Max & Average \\
\hline Day 1 & 1315 & 508 & 1511 & 567 & 665 & 449 & 561 & 311 \\
\hline Day 2 & 1333 & 346 & 1638 & 362 & 563 & 257 & 578 & 199 \\
\hline Day 3 & 1531 & 351 & 1975 & 406 & 709 & 285 & 715 & 222 \\
\hline Day 4 & 2683 & 360 & 5578 & 396 & 801 & 305 & 4742 & 301 \\
\hline Day 5 & 1257 & 232 & 1673 & 361 & 384 & 94 & 721 & 170 \\
\hline Day 6 & 1048 & 224 & 1336 & 316 & 325 & 86 & 623 & 149 \\
\hline Day 7 & 1670 & 267 & 6670 & 424 & 427 & 109 & 2849 & 199 \\
\hline Day 8 & 2607 & 452 & 4480 & 504 & 1104 & 322 & 4113 & 317 \\
\hline Day 9 & 1234 & 324 & 1296 & 239 & 752 & 342 & 686 & 195 \\
\hline Day 10 & 1554 & 509 & 1801 & 519 & 839 & 393 & 881 & 311 \\
\hline Day 11 & 1170 & 320 & 1220 & 266 & 714 & 301 & 635 & 194 \\
\hline Day 12 & 1205 & 231 & 1563 & 351 & 390 & 95 & 698 & 173 \\
\hline Day 13 & 3899 & 357 & 7721 & 667 & 4452 & 170 & 6303 & 493 \\
\hline Day 14 & 1583 & 322 & 1888 & 369 & 752 & 247 & 921 & 221 \\
\hline Average & 1721 & 343 & 2882 & 410 & 920 & 247 & 1788 & 247 \\
\hline
\end{tabular}


Building B - Maximum \& Average Lux Levels

\begin{tabular}{|l|c|c|c|c|c|c|c|c|}
\hline Space 1 & \multicolumn{2}{|c|}{ Close Horizontal } & \multicolumn{2}{c|}{ Close Vertical } & \multicolumn{2}{c|}{ Far Horizontal } & \multicolumn{2}{c|}{ Far Vertical } \\
\hline & Max & Average & Max & Average & Max & Average & Max & Average \\
\hline Day 1 & 3294 & 1003 & 5150 & 1560 & 1621 & 514 & 2894 & 842 \\
\hline Day 2 & 32528 & 2589 & 31594 & 2762 & 2789 & 526 & 4616 & 829 \\
\hline Day 3 & 29007 & 3646 & 24735 & 3488 & 1429 & 486 & 2099 & 625 \\
\hline Day 4 & 31387 & 3458 & 26022 & 3483 & 2440 & 515 & 3810 & 750 \\
\hline Day 5 & 30223 & 3565 & 23977 & 3260 & 1755 & 431 & 2580 & 639 \\
\hline Day 6 & 33570 & 2611 & 27245 & 2994 & 2899 & 519 & 4931 & 887 \\
\hline Day 7 & 21074 & 1199 & 21067 & 1588 & 2603 & 482 & 4193 & 748 \\
\hline Day 8 & 28850 & 2729 & 23414 & 2654 & 2121 & 519 & 3283 & 774 \\
\hline Day 9 & 5622 & 615 & 7206 & 842 & 1749 & 315 & 3117 & 445 \\
\hline Day 10 & 28762 & 1145 & 18675 & 1385 & 2911 & 452 & 4582 & 691 \\
\hline Day 11 & 29880 & 3113 & 22311 & 2844 & 1470 & 503 & 2162 & 659 \\
\hline Day 12 & 2991 & 446 & 3982 & 618 & 1110 & 191 & 2048 & 332 \\
\hline Day 13 & 32022 & 1389 & 23149 & 1666 & 2510 & 446 & 4176 & 782 \\
\hline Day 14 & 22395 & 2244 & 21478 & 2335 & 1702 & 350 & 2471 & 518 \\
\hline Average & 23686 & 2125 & 20000 & 2249 & 2079 & 446 & 3354 & 680 \\
\hline
\end{tabular}

\begin{tabular}{|l|c|c|c|c|c|c|c|c|}
\hline Space 2 & \multicolumn{2}{|c|}{ Close Horizontal } & \multicolumn{2}{c|}{ Close Vertical } & \multicolumn{2}{c|}{ Far Horizontal } & \multicolumn{2}{c|}{ Far Vertical } \\
\hline & Max & Average & Max & Average & Max & Average & Max & Average \\
\hline Day 1 & 2359 & 925 & 1225 & 551 & 2304 & 814 & 1395 & 522 \\
\hline Day 2 & 2661 & 572 & 1417 & 395 & 2704 & 475 & 1670 & 371 \\
\hline Day 3 & 1685 & 463 & 1242 & 368 & 1366 & 350 & 8108 & 420 \\
\hline Day 4 & 2429 & 563 & 1220 & 379 & 2449 & 460 & 16034 & 493 \\
\hline Day 5 & 1760 & 405 & 897 & 250 & 2038 & 430 & 18014 & 527 \\
\hline Day 6 & 2266 & 492 & 1439 & 317 & 2565 & 552 & 18925 & 651 \\
\hline Day 7 & 2434 & 620 & 1335 & 439 & 2385 & 505 & 12404 & 527 \\
\hline Day 8 & 2196 & 560 & 1532 & 396 & 2218 & 432 & 1909 & 364 \\
\hline Day 9 & 3039 & 663 & 1395 & 394 & 3364 & 588 & 1848 & 383 \\
\hline Day 10 & 3230 & 794 & 1701 & 440 & 3028 & 755 & 3960 & 489 \\
\hline Day 11 & 1760 & 503 & 996 & 346 & 1592 & 407 & 14125 & 401 \\
\hline Day 12 & 1697 & 360 & 520 & 120 & 2079 & 447 & 1598 & 202 \\
\hline Day 13 & 2591 & 466 & 1564 & 196 & 2530 & 545 & 2621 & 325 \\
\hline Day 14 & 1999 & 331 & 1182 & 235 & 2171 & 294 & 10969 & 295 \\
\hline Average & 2293 & 551 & 1262 & 345 & 2342 & 504 & 8113 & 426 \\
\hline
\end{tabular}


Building C - Maximum \& Average Lux Levels

\begin{tabular}{|l|c|c|c|c|c|c|c|c|}
\hline Space 1 & \multicolumn{2}{|c|}{ Close Horizontal } & \multicolumn{2}{|c|}{ Close Vertical } & \multicolumn{1}{|c|}{ Far Horizontal } & \multicolumn{2}{|c|}{ Far Vertical } \\
\hline & Max & Average & Max & Average & Max & Average & Max & Average \\
\hline Day 1 & 2677 & 614 & 3933 & 742 & 1412 & 432 & 1379 & 316 \\
\hline Day 2 & 2636 & 400 & 3700 & 461 & 1232 & 313 & 1133 & 206 \\
\hline Day 3 & 2782 & 428 & 3966 & 487 & 779 & 126 & 1270 & 216 \\
\hline Day 4 & 1787 & 369 & 2413 & 401 & 627 & 114 & 1093 & 189 \\
\hline Day 5 & 2666 & 406 & 4041 & 620 & 808 & 128 & 1110 & 158 \\
\hline Day 6 & 1851 & 326 & 2943 & 514 & 639 & 95 & 852 & 119 \\
\hline Day 7 & 2409 & 332 & 3538 & 381 & 657 & 90 & 927 & 139 \\
\hline Day 8 & 1560 & 377 & 1872 & 428 & 645 & 137 & 1058 & 211 \\
\hline Day 9 & 1845 & 263 & 2662 & 274 & 378 & 57 & 572 & 99 \\
\hline Day 10 & 2369 & 398 & 3051 & 454 & 755 & 143 & 1150 & 209 \\
\hline Day 11 & 1711 & 398 & 2202 & 460 & 651 & 110 & 1024 & 207 \\
\hline Day 12 & 2153 & 412 & 3214 & 579 & 186 & 20 & 875 & 158 \\
\hline Day 13 & 1612 & 364 & 2256 & 538 & 134 & 18 & 881 & 151 \\
\hline Day 14 & 1577 & 174 & 2137 & 190 & 145 & 31 & 395 & 59 \\
\hline Average & 2117 & 376 & 2995 & 466 & 646 & 130 & 980 & 174 \\
\hline
\end{tabular}

\begin{tabular}{|l|c|c|c|c|c|c|c|c|}
\hline Space 2 & \multicolumn{2}{|c|}{ Close Horizontal } & \multicolumn{2}{|c|}{ Close Vertical } & \multicolumn{2}{|c|}{ Far Horizontal } & \multicolumn{2}{|c|}{ Far Vertical } \\
\hline & Max & Average & Max & Average & Max & Average & Max & Average \\
\hline Day 1 & 3114 & 620 & 8730 & 767 & 3989 & 708 & 2530 & 480 \\
\hline Day 2 & 2533 & 485 & 13604 & 603 & 3231 & 541 & 2301 & 372 \\
\hline Day 3 & 2458 & 420 & 6542 & 506 & 3208 & 453 & 2016 & 319 \\
\hline Day 4 & 2789 & 414 & 10880 & 508 & 3532 & 430 & 2270 & 303 \\
\hline Day 5 & 2922 & 394 & 12647 & 490 & 3735 & 463 & 2362 & 321 \\
\hline Day 6 & 2835 & 261 & 3599 & 327 & 3572 & 303 & 2270 & 207 \\
\hline Day 7 & 6449 & 384 & 8599 & 469 & 3891 & 368 & 2453 & 246 \\
\hline Day 8 & 4555 & 432 & 5968 & 508 & 3202 & 456 & 1710 & 275 \\
\hline Day 9 & 906 & 212 & 1171 & 278 & 834 & 159 & 529 & 101 \\
\hline Day 10 & 8802 & 527 & 9994 & 601 & 5749 & 519 & 1975 & 302 \\
\hline Day 11 & 7350 & 486 & 9058 & 572 & 4910 & 492 & 2026 & 294 \\
\hline Day 12 & 7472 & 455 & 8533 & 517 & 3399 & 495 & 1837 & 294 \\
\hline Day 13 & 2673 & 310 & 3140 & 371 & 3387 & 365 & 1787 & 213 \\
\hline Day 14 & 854 & 143 & 1072 & 187 & 776 & 112 & 484 & 70 \\
\hline Average & 3979 & 396 & 7396 & 479 & 3387 & 419 & 1896 & 271 \\
\hline
\end{tabular}


Building D - Maximum \& Average Lux Levels

\begin{tabular}{|l|c|c|c|c|c|c|c|c|}
\hline Space 1 & \multicolumn{1}{|c|}{ Close Horizontal } & \multicolumn{2}{|c|}{ Close Vertical } & \multicolumn{2}{|c|}{ Far Horizontal } & \multicolumn{2}{|c|}{ Far Vertical } \\
\hline & Max & Average & Max & Average & Max & Average & Max & Average \\
\hline Day 1 & 39215 & 3332 & 14445 & 3773 & 1534 & 452 & 2019 & 494 \\
\hline Day 2 & 45862 & 5001 & 53402 & 8652 & 14165 & 669 & 36768 & 1310 \\
\hline Day 3 & 45472 & 5268 & 52515 & 9106 & 14107 & 713 & 35704 & 1334 \\
\hline Day 4 & 45175 & 4606 & 58677 & 7939 & 13200 & 612 & 32718 & 1116 \\
\hline Day 5 & 47695 & 2630 & 20141 & 2585 & 2655 & 386 & 3066 & 479 \\
\hline Day 6 & 8445 & 2034 & 10669 & 2734 & 1557 & 413 & 2065 & 534 \\
\hline Day 7 & 19963 & 2230 & 35051 & 3137 & 2888 & 499 & 3684 & 616 \\
\hline Day 8 & 10278 & 1060 & 11886 & 1428 & 1708 & 244 & 2259 & 296 \\
\hline Day 9 & 6518 & 1586 & 8591 & 2096 & 1441 & 346 & 1910 & 430 \\
\hline Day 10 & 4516 & 1329 & 6162 & 1797 & 982 & 297 & 1304 & 366 \\
\hline Day 11 & 34222 & 3237 & 48582 & 4465 & 1964 & 443 & 2471 & 548 \\
\hline Day 12 & 40304 & 3875 & 65180 & 6654 & 8732 & 656 & 38484 & 1301 \\
\hline Day 13 & 16407 & 2271 & 18551 & 3035 & 2045 & 423 & 2694 & 556 \\
\hline Day 14 & 8328 & 2222 & 11826 & 3034 & 1557 & 438 & 2013 & 563 \\
\hline Day 15 & 9894 & 2271 & 13087 & 3136 & 1906 & 335 & 2179 & 397 \\
\hline Average & 25486 & 2863 & 28584 & 4238 & 4696 & 462 & 11289 & 689 \\
\hline
\end{tabular}

\begin{tabular}{|l|c|c|c|c|c|c|c|c|}
\hline Space 2 & \multicolumn{2}{|c|}{ Close Horizontal } & \multicolumn{2}{|c|}{ Close Vertical } & Far Horizontal & \multicolumn{2}{|c|}{ Far Vertical } \\
\hline & Max & Average & Max & Average & Max & Average & Max & Average \\
\hline Day 1 & 4206 & 1011 & 5136 & 1150 & 2965 & 825 & 5436 & 1578 \\
\hline Day 2 & 34302 & 2099 & 45214 & 2545 & 25430 & 1701 & 45108 & 3807 \\
\hline Day 3 & 33570 & 2156 & 44780 & 2625 & 25217 & 1730 & 44115 & 3910 \\
\hline Day 4 & 32408 & 1842 & 43494 & 2276 & 24905 & 1543 & 47322 & 3511 \\
\hline Day 5 & 4177 & 478 & 5153 & 554 & 2483 & 423 & 4749 & 878 \\
\hline Day 6 & 1952 & 478 & 2351 & 560 & 1482 & 378 & 3135 & 771 \\
\hline Day 7 & 7809 & 591 & 8801 & 676 & 4633 & 482 & 10440 & 938 \\
\hline Day 8 & 2225 & 304 & 2519 & 297 & 1619 & 273 & 3324 & 425 \\
\hline Day 9 & 1662 & 387 & 1916 & 402 & 1291 & 335 & 2611 & 591 \\
\hline Day 10 & 1272 & 355 & 1337 & 371 & 1039 & 298 & 1837 & 523 \\
\hline Day 11 & 27586 & 976 & 34010 & 1170 & 3692 & 632 & 7508 & 1304 \\
\hline Day 12 & 26325 & 1038 & 37948 & 1416 & 26097 & 1272 & 51195 & 3049 \\
\hline Day 13 & 3991 & 536 & 4175 & 618 & 2708 & 436 & 5848 & 901 \\
\hline Day 14 & 3288 & 573 & 4134 & 633 & 1439 & 450 & 2855 & 854 \\
\hline Day 15 & 3172 & 593 & 3706 & 656 & 2013 & 490 & 3848 & 969 \\
\hline Average & 12530 & 894 & 16312 & 1063 & 8468 & 751 & 15955 & 1601 \\
\hline
\end{tabular}




\section{All Buildings - Overall Maximum \& Average Values}

\begin{tabular}{|c|c|c|c|c|c|c|c|c|c|}
\hline \multicolumn{10}{|c|}{ Overall Averages - Maximum Lux and Average Lux (9:00am to 5:00pm) } \\
\hline & & \multicolumn{2}{|c|}{ Close Horizontal } & \multicolumn{2}{|c|}{ Close Vertical } & \multicolumn{2}{|c|}{ Far Horizontal } & \multicolumn{2}{|c|}{ Far Vertical } \\
\hline & & Max & Average & Max & Average & $\operatorname{Max}$ & Average & Max & Average \\
\hline \multirow[t]{2}{*}{ Building A } & Space 1 & 8070 & 2691 & 7518 & 2617 & 920 & 505 & 1248 & 718 \\
\hline & Space 2 & 1721 & 707 & 2882 & 854 & 920 & 463 & 1788 & 456 \\
\hline \multirow[t]{2}{*}{ Building B } & Space 1 & 23686 & 5954 & 20000 & 6115 & 2079 & 1056 & 3354 & 1637 \\
\hline & Space 2 & 2293 & 1192 & 1262 & 717 & 2342 & 1101 & 8113 & 761 \\
\hline \multirow[t]{2}{*}{ Building C } & Space 1 & 2117 & 919 & 2995 & 1179 & 646 & 299 & 980 & 436 \\
\hline & Space 2 & 3979 & 971 & 7396 & 1170 & 3387 & 1047 & 1896 & 667 \\
\hline \multirow[t]{2}{*}{ Building D } & Space 1 & 25486 & 5945 & 28584 & 7403 & 4696 & 833 & 11289 & 1026 \\
\hline & Space 2 & 12530 & 1735 & 16312 & 2101 & 8468 & 1000 & 15955 & 1962 \\
\hline
\end{tabular}

